Aus der Klinik für Kardiologie und Pneumologie

(Prof. Dr. med. G. Hasenfuß)

im Zentrum Innere Medizin

der Medizinischen Fakultät der Universität Göttingen

\title{
Angiotensin II induziert Nox 2 - abhängig Arrhythmien in ventrikulären Kardiomyozyten der Maus
}

\author{
INAUGURAL - DISSERTATION \\ zur Erlangung des Doktorgrades \\ der Medizinischen Fakultät der \\ Georg-August-Universität zu Göttingen
}

vorgelegt von

Azadeh Azizian

aus

Karaj / Iran

Göttingen 2015 
I. Berichterstatter: Prof. Dr. med. L. S. Maier

II. Berichterstatter/in: Prof. Dr. Susanne Lutz

III. Berichterstatter/in: Prof. Dr. Margarete Schön

Tag der mündlichen Prüfung: $\quad$ 28.10.2015 


\section{Inhaltsverzeichnis}

Abbildungsverzeichnis.

IV-V

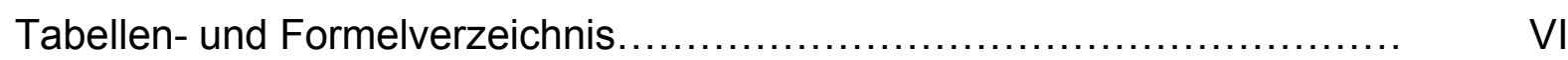

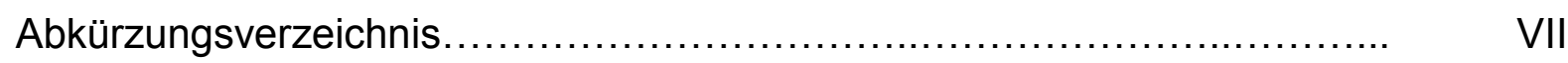

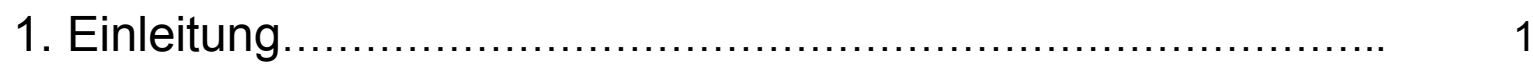

1.1 Die chronische Herzinsuffizienz................................. 1

1.2 Die Herzmuskelzelle ......................................... 3

1.2.1 Die Ultrastruktur der Herzmuskelzelle....................... 3

1.2.2 Der kontraktile Apparat ................................ 5

1.2.3 Das Aktionspotential .................................... 6

1.2.4 Die Elektromechanische Koppelung ........................ 10

1.2.5 Veränderungen im insuffizienten Myokard .................... 15

1.3 Die $\mathrm{Ca}^{2+}$-Calmodulin-abhängige Proteinkinase II (CaMKII)........... 17

1.3.1 Die Struktur der CaMKII.................................. 18

1.3.2 Die Aktivierung der CaMKII................................ 19

1.3.3 Die Funktion der CaMKII................................... 20

1.3.4 Die Hemmung der CaMKII.............................. 21

1.3.5 CaMKII, Herzinsuffizienz und Arrhythmien.................... 22

1.4 Kardiale Arrhythmien............................................ 24

1.4.1 Die Erregungsbildung und -leitung......................... 25

1.4.2 Störungen der Erregungsbildung ........................... 25

1.4.3 Störungen der Erregungsleitung ........................... 27

1.5 Der spannungsabhängige Natriumkanal......................... 27

1.5.1 Aufbau und Funktion des Natriumkanals..................... 28

1.5.2 Regulationsmechanismen des Natriumkanals................. 30

1.5.3 Mutationen des Natriumkanals............................ 31

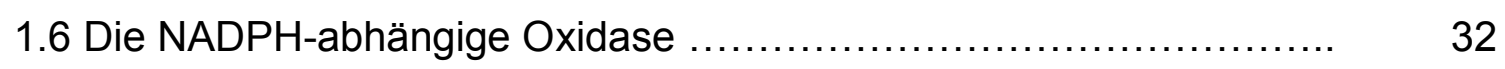

1.6.1 Klassifikation und Struktur der NADPH-abhängigen Oxidase... 33

1.6.2 Aktivierung und Funktion der NADPH-abhängigen Oxidase 2.. 35

1.6.3 Die Wirkung der ROS auf die Herzmuskelzelle................ 36

1.6.4 Hemmung der NADPH-abhängigen Oxidase................. 37

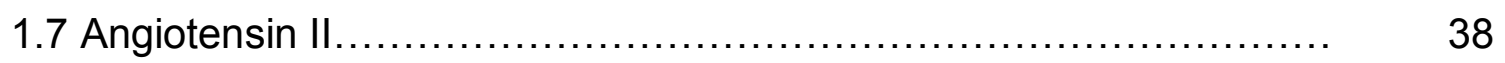


1.7.1 Die akuten Effekte des Angiotensin II am Herzen................ $\quad 40$

1.7.2 Die Bedeutung des Angiotensin II für das kardiale Remodeling 41

1.8 Hypothesen und Fragestellungen..................................... 43

2. Material und Methoden.................................... 44

2.1 Die genetisch veränderte Maus......................................... 44

2.1.1 Das Prinzip der Knockout-Maus............................... 44

2.1.2 Herstellung der CaMKII-Knockout- und der gp91 ${ }^{\text {phox_Knockout- }}$ Maus............................................................... 45

2.2 Isolation ventrikulärer Mäusemyozyten................................ 49

2.3 Die Patch-Clamp-Technik .............................................. 52

2.3.1 Das Patch-Clamp-Setup ....................................... 53

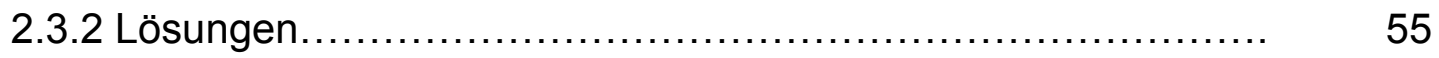

2.3.3 Pipetten und Elektroden......................................... 56

2.3.4 Versuchsdurchführung........................................... 5

2.4 Pharmakologische Intervention.................................. $\quad 59$

2.4.1 Angiotensin II (human)........................................ 59

2.4.2 Diphenyliodoniumchlorid (DPI) ................................ 59

2.5 Datenerfassung und Auswertung................................... 60

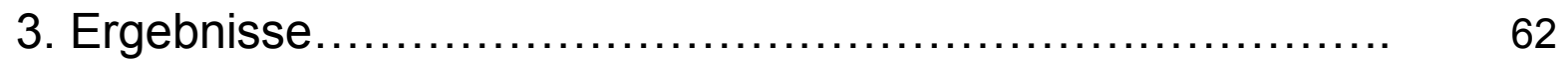

3.1 Auswertung der Herz-Körpergewichtverhältnisse von CaMKIIסc-

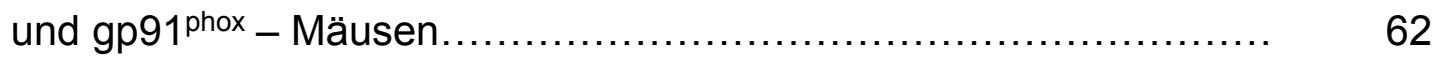

3.2 Angiotensin II beschleunigt die maximale Aufstrichgeschwindigkeit $\left(V_{\max }\right)$ des Aktionspotentials............................................ 63

3.3 Angiotensin II hat keinen Einfluss auf die Aktionspotentialdauer...... $\quad 69$

3.4 Synopsis aller AP-Parameter und zugehörigen Messvariablen........ $\quad 75$

3.5 Angiotensin II steigert signifikant die Häufigkeit von späten

Nachdepolarisationen................................................ 76

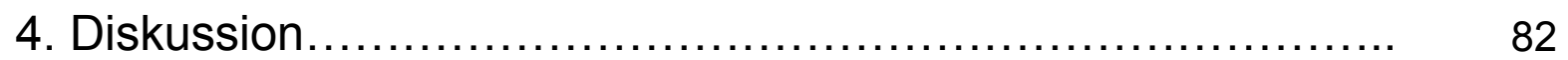

4.1 Angiotensin II beschleunigt die maximale Aufstrichgeschwindigkeit des Aktionspotentials, verändert aber nicht die Aktionspotentialdauer....... 
4.2 Die Bedeutung der Nox2 und der Serin-/Threonin-Proteinkinasen für die Ang II - Wirkung auf Aktionspotential und Natriumkanalfunktion......

4.3 Die Bedeutung der Nox2 und der CaMKII für die Aktionspotentialdauer

4.4 Es kommt unter Stimulation durch Ang II zu vermehrter getriggerter Aktivität in Form von DADs

5. Zusammenfassung.

6. Literaturverzeichnis. 


\section{Abbildungsverzeichnis}

Abb. 1.1: Schematischer Aufbau der Biomembran .................. 4

Abb. 1.2: Die Diade.............................................. 5

Abb. 1.3: Schematische Darstellung der Sarkomere in einer

Herzmuskelzelle....................................... 6

Abb. 1.4: Kurvenverlauf eines Aktionspotentials in einer Herzmuskelzelle $\quad 8$

Abb. 1.5: Vergleichende Darstellung des Aktionspotentials und der jeweiligen lonenstöme in humanen bzw. Maus-Kardiomyozyten (mit freundlicher Erlaubnis, aus Nerbonne 2004, S. 84)

Abb. 1.6: Die elektromechanische Koppelung.

(mit freundlicher Erlaubnis, aus Bers 2002 b, S. 198)

Abb. 1.7: Die $\beta$-adrenerge Stimulation

(mit freundlicher Erlaubnis, aus Bers 2002 b, S. 203)

Abb. 1.8: Aktin und Myosin.

(mit freundlicher Erlaubnis, aus Bers 2001, S. 25)

Abb. 1.9: CaMKII

(mit freundlicher Erlaubnis, aus Maier und Bers 2002, S.924)

Abb. 1.10: Übersicht über die verschiedenen Wege der CaMKII-

Aktivierung.

(mit freundlicher Erlaubnis, aus Pellicena und Schulman 2014)

Abb. 1.11: Nachdepolarisationen.

Abb. 1.12: $\alpha$-Untereinheit des Natriumkanals.

Abb. 1.13: Schematische Darstellung der Nox2.

Abb. 1.14: Schematische Darstellung der Membrantranslokation der regulatorischen Untereinheiten.

Abb. 1.15: Das klassische und das neue Renin-Angiotensin-System..

Abb. 1.16: Angiotensin II.

Abb. 2.1: Herstellung der Knockout-Maus schmetisch dargestellt......

Abb. 2.2: Gene Targeting der CaMKIIס-Knockout-Maus.

Abb. 2.3: Western Blot - Analysen.

Abb. 2.4: Gene Targeting der gp91 ${ }^{\text {phox }}$-Knockout-Maus.

Abb. 2.5: Immunblotanalyse

Abb. 2.6: Schematische Darstellung der Perfusionsanalge nach 
Langendorff.

Abb. 2.7: Die vier Konfigurationsformen................................. 53

Abb. 2.8: Schmatische Darstellung des Patch-Clamp-Setups.......... 54

Abb. 2.9: Das Prinzip des Pipettenziehgeräts.......................... 57

Abb. 2.10: Darstellung der Pipette am Pipettenhalter.................... 58

Abb. 2.11: Schematische Darstellung von Pipette und Zelle nach dem rupturing ............................................. 58

Abb. 3.1: Beispiel für die Originalregistrierung eines Aktionspotentials und die vergrößerte Darstellung des Aktionspotentialaufstrichs

Abb. 3.2: Vergleich der $V_{\max }$ anhand von vergrößerten Originalregistrierungen

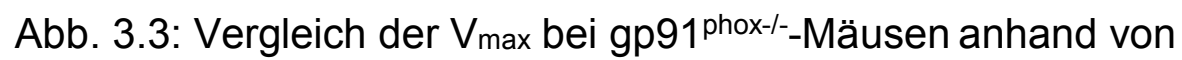

Originalregistrierungen ohne und mit der Hinzugabe von Ang II 65

Abb. 3.4: $V_{\max }$ bei unterschiedlichen Stimulationsfrequenzen.

Abb. 3.5: Vergleich der $V_{\max }$ anhand von vergrößerten Original-

Registrierungen (CaMKII-Wildtyp)

Abb. 3.6: Vergleich der $V_{\max }$ anhand von vergrößerten Original-

Registrierungen (CaMKII-Knockout).

Abb. 3.7: $V_{\max }$ bei unterschiedlichen Stimulationsfrequenzen.

Abb. 3.8: Säulendiagramm zur Übersicht über die $V_{\max }$-Mittelwerte

Abb. 3.9: APD 80 (gp91 phox_Mäuse).....................................

Abb. 3.10: APD 80 (CaMKIIIc-Mäuse)................................

Abb. 3.11: Säulendiagramm zum Vergleich der APD 80 der WildtypMäuse mit den CaMKIIס $\mathrm{c}^{-1}$-Mäusen.

Abb. 3.12: Säulendiagramm zur Übersicht über die Mittelwerte für APD 80

Abb. 3.13: Originalregistrierungen von jeweils drei stimulierten Aktionspotentialen

Abb. 3.14: Anzahl der EADs und DADs pro Minute (gp91 ${ }^{\text {phox-Mäuse) }}$

Abb. 3.15: Originalregistrierungen von jeweils drei stimulierten Aktionspotentialen

Abb. 3.16: Anzahl der EADs und DADs pro Minute (CaMKIIIc-Mäuse)

Abb. 3.17: Säulendiagramm zur Veranschaulichung des Anteils arrhythmischer Zellen pro Gruppe 


\section{Tabellen- und Formelverzeichnis}

\section{Tabellen}

Tabelle 2-1: Lösungen für die Isolation von ventrikulären Mäusemyozyten

Tabelle 2-2: Bad- und Pipettenlösung für die Messung von Aktionspotialen mit der Patch-Clamp-Technik................................ $\quad 56$

Tabelle 3-1: Basale Charakteristika der untersuchten Mäuse.................. 63

Tabelle 3-2: Übersichtstabelle über alle AP-Parameter........................ 75

Tabelle 3-3: Übersichtstabelle über alle Messvariablen......................... 76

\section{Formeln}

Formel 1.2: Kalium-Gleichgewichtspotential nach der Nernst-Gleichung...... 


\section{Abkürzungsverzeichnis}

\begin{tabular}{|c|c|}
\hline Abb. & Abbildung \\
\hline $\mathrm{AHA}$ & American Heart Association \\
\hline Ang II & Angiotensin II \\
\hline AP & Aktionspotential \\
\hline APD & Aktionspotentialdauer \\
\hline APD 30 & Dauer bis zur $30 \%$ igen Repolarisation des Aktionspotentials \\
\hline APD 50 & Dauer bis zur $50 \%$ igen Repolarisation des Aktionspotentials \\
\hline APD 80 & Dauer bis zur $80 \%$ igen Repolarisation des Aktionspotentials \\
\hline APD 90 & Dauer bis zur $90 \%$ igen Repolarisation des Aktionspotentials \\
\hline $\mathrm{AT}_{1}$ & Angiotensin II - Rezeptor I \\
\hline ATP & Adenosin-Triphosphat \\
\hline $\mathrm{Ca}^{2+},\left[\mathrm{Ca}^{2+}\right] \mathrm{i}$ & Kalzium, intrazelluläre Kalziumkonzentration \\
\hline CaMKII & $\mathrm{Ca}^{2+}-$ Calmodulin-abhängige Proteinkinase II \\
\hline CaMKII $\delta_{c}$ & $\begin{array}{l}\text { Splicevariante c der } \delta \text {-Isoform der } \mathrm{Ca}^{2+} \text {-Calmodulin-abhängigen } \\
\text { Proteinkinase II }\end{array}$ \\
\hline DAD & delayed afterdepolarization (späte Nachdepolarisation) \\
\hline EAD & early afterdepolarization (frühe Nachdepolarisation) \\
\hline FAD & Flavin-Adenin-Dinukleotid \\
\hline $\mathrm{ICa}$ & sarkolemmaler L-Typ-Kalziumkanalvermittelter Kalziumstrom \\
\hline $\mathrm{IKr}, \mathrm{Ks}$ & sarkolemmaler auswärtsgerichteter Kaliumstrom \\
\hline $\mathrm{I}_{\mathrm{Na}}$ & sarkolemmaler Natriumstrom \\
\hline $\mathrm{K}^{+}$ & Kalium \\
\hline $\mathrm{Na}^{+},\left[\mathrm{Na}^{+}\right]_{\mathrm{i}}$ & Natrium, intrazelluläre Natriumkonzentration \\
\hline NADPH & Nicotinamidadenindinukleotidphosphat, reduzierte Form \\
\hline NCX & sarkolemmaler $\mathrm{Na}+/ \mathrm{Ca}^{2+}$-Austauscher \\
\hline Nox & NAPDH - abhängige Oxidase \\
\hline Nox1-5 & Isoform 1-5 der NAPDH - abhängigen Oxidase \\
\hline PLB & Phospholamban \\
\hline RyR & Ryanodin-Rezeptor \\
\hline SERCA & $\mathrm{Ca}^{2+}$-ATPase des sarkoplasmatischen Retikulums \\
\hline SR & sarkoplasmatisches Retikulum \\
\hline T-Tubuli & transversale Tubuli \\
\hline$V_{\max }$ & maximale Aufstrichgeschwindigkeit \\
\hline WT & Wildtyp \\
\hline
\end{tabular}




\section{Einleitung}

Angiotensin II (Ang II) ist ein Hormon, das eine bedeutende Rolle bei der Entwicklung von Herzhypertrophie, Herzinsuffizienz und Arrhythmien spielt. Die Mechanismen der Ang II - Wirkung auf die Herzmuskelzelle sind dabei bislang jedoch nur unzureichend erforscht. Die vorliegende Arbeit untersucht die Ang II - Wirkung auf die Herzmuskelzelle im Hinblick auf Aktionspotential und Arrhythmien.

Dabei wird vor allem der Bezug der Ang II Wirkung zu den beiden Enzymen $\mathrm{Ca}^{2+}$ Calmodulin-abhängige Proteinkinase $\| \delta_{c}\left(C a M K I I \delta_{c}\right)$ und NADPH-abhängige Oxidase 2 (Nox2) untersucht, wofür vergleichende Versuche an Wildtyp- und Knockout-Mäusen der CaMKIII $\delta_{c}$ sowie der gp91 ${ }^{\text {phox }}$ durchgeführt wurden.

Es konnte gezeigt werden, dass Ang II Nox2-abhängig steigernde Effekte auf die maximale Aufstrichgeschwindigkeit des Aktionspotentials und eine arrhythmogene Wirkung hat. Dies könnte von großer Relevanz für die Therapie von Patienten mit Herzhypertrophie und -insuffizienz sein.

\subsection{Die chronische Herzinsuffizienz}

Die chronische Herzinsuffizienz ist definiert als eine progressive krankhafte Unfähigkeit des Herzens, die peripheren Organe bedarfsgerecht mit Blut zu versorgen. Je nach klinischem Schweregrad, welcher anhand der Kriterien der New York Heart Association in NYHA Grad I bis IV eingeteilt wird, tritt dieses Missverhältnis zwischen Bedarf des Organismus an Blut und Pumpleistung des Herzens entweder subjektiv nicht wahrnehmbar (Grad I), erst bei schwerer Belastung (Grad II), bei mittelschwerer bis leichter Belastung (Grad III) oder bereits in Ruhe (Grad IV) auf (NYHA 1964).

Die Ursachen einer Herzinsuffizienz können vielfältig sein: koronare Herzerkrankungen, arterielle Hypertonie, verschiedene Kardiomyopathien und Herzklappenfehler sind einige Beispiele hierfür (Hoppe et al. 2005).

Die Herzinsuffizienz zählt in den Industriestaaten zu den Volkskrankheiten: Weltweit wird die Anzahl der Betroffenen derzeit auf etwa 20 Millionen Menschen geschätzt (Liquori et al. 2014), wobei vor allem ältere Menschen daran erkranken. Aufgrund der demographischen Entwicklung ist somit in den nächsten Jahrzehnten mit einer deutlich steigenden Prävalenz zu rechnen. Das Lebenszeitrisiko, an einer Herzinsuffizienz zu 
erkranken, beträgt laut der Framingham-Studie für 40-jährige Männer 21\%, für Frauen 20,3\% (Lloyd-Jones et al. 2002).

Nicht nur ist die hohe Prävalenz der Herzinsuffizienz markant, sondern auch die Tatsache, dass in den letzten Jahrzehnten trotz der verbesserten medikamentösen Therapie mit ACE-Hemmern, Angiotensin-II-Rezeptor-I-Blockern, AldosteronAntagonisten und $\beta$-Blockern die Mortalität der Herzinsuffizienz immer noch enorm hoch ist (Braunwald und Bristow 2000). Laut der Framingham-Herz-Studie beträgt die mittlere Überlebenszeit nach der Erstdiagnose der Herzinsuffizienz für Männer 1,7 Jahre, für Frauen 3,2 Jahre (Lloyd-Jones et al. 2002). Laut dem Statistischen Bundesamt Deutschland rangierte die Herzinsuffizienz im Jahre 2011 mit 48.306 Fällen auf Platz drei der häufigsten Todesursachen (Statistisches Bundesamt 2011; https://www.destatis.de/DE/ZahlenFakten/GesellschaftStaat/Gesundheit/Todesursac hen/Tabellen/Sterbefaellelnsgesamt.html). Bei den Todesursachen muss man das Pumpversagen mit der Entwicklung eines kardiogenen Schocks durch Minderperfusion der Organe von dem plötzlichen Herztod durch ventrikuläre Herzrhythmusstörungen abgrenzen. Die bislang einzige kurative Therapie ist nach wie vor die Herztransplantation. Deshalb ist die Suche nach neuartigen Therapiemöglichkeiten von immenser Bedeutung.

Im insuffizienten Myokard kommt es zu einer Reihe von elektrophysiologischen Veränderungen, die zu elektrischer Instabilität und damit zu Herzrhythmusstörungen führen können (Tomaselli und Zipes 2004). Auch ist das Risiko für einen plötzlichen Herztod im Vergleich zur Normalbevölkerung um bis das 9-Fache erhöht (Thom et al. 2006).

Um diesen Komplikationen und generell auch einem weiteren Fortschreiten der Herzinsuffizienz vorbeugen zu können, müssen zuvor die Mechanismen in der Zelle erfasst werden, die diesen Prozess begünstigen bzw. hervorrufen.

Im Folgenden werde ich zunächst auf die physiologischen Verhältnisse in der Zelle eingehen und anschließend die Abweichungen dazu im insuffizienten Myokard aufzeigen. Ein besonderes Augenmerk soll dabei auf die NADPH-abhängige Oxidase 2 (Nox2) und die Kalzium-Calmodulin-abhängige Proteinkinase II $\delta_{c}\left(\right.$ CaMKII $\left._{c}\right)$ gelegt werden. 


\subsection{Die Herzmuskelzelle}

Das Myokard besteht aus parallel zueinander ausgerichteten quergestreiften Muskelzellen, die miteinander durch Disci intercalares (Glanzstreifen) verbunden sind (Sjöstrand et al. 1958). Zum einen ermöglichen die dort liegenden Desmosomen eine mechanische Verankerung der Myozyten untereinander, zum anderen befinden sich im Bereich der Glanzstreifen auch die sogenannten Gap Junctions (Nexus), die eine schnelle Erregungsübertragung zwischen den Zellen durch lonenströme ermöglichen (Makowski et al. 1977, Unwin und Zampighi 1980, Maeda und Tsukihara 2011). So sind eine elektrische Kontinuität und damit eine synchronisierte Kontraktion gewährleistet.

Man unterscheidet im Myokard grundsätzlich zwischen den Zellen des ventrikulären Arbeitsmyokards, des atrialen Arbeitsmyokards, den Schrittmacher-Zellen und den Zellen der Erregungsleitungssystems.

\subsubsection{Die Ultrastruktur der Herzmuskelzelle}

Jede einzelne Herzmuskelzelle wird von einer Biomembran umschlossen (Abbildung 1.1), die das Zellinnere von der Umgebung abgrenzt. Diese Membran, auch Sarkolemm genannt, besteht aus einer Phospholipid-Doppelschicht mit asymmetrisch eingelagerten Proteinen und erfüllt zwei gegensätzliche Aufgaben: Zum einen trennt sie den Extrazellulär- vom Intrazellulärraum, zwei wässrige Lösungen unterschiedlicher lonenzusammensetzung, zum anderen ermöglicht sie die Kommunikation zwischen den Kompartimenten. Ein Kompartiment ist die Summe aller gleichartigen zellulären Räume in einer Zelle, wie zum Beispiel das mitochondriale Kompartiment, der Zellkern oder das Zytoplasma.

Die Biomembran ist für lipophile Substanzen passierbar, während hydrophile Substanzen nur mit Hilfe von Transportern und Kanälen in die Zelle hinein oder aus der Zelle heraus gelangen können. So kann das Ausmaß der Kommunikation über das Öffnen und Schließen bestimmter Kanäle reguliert werden. 


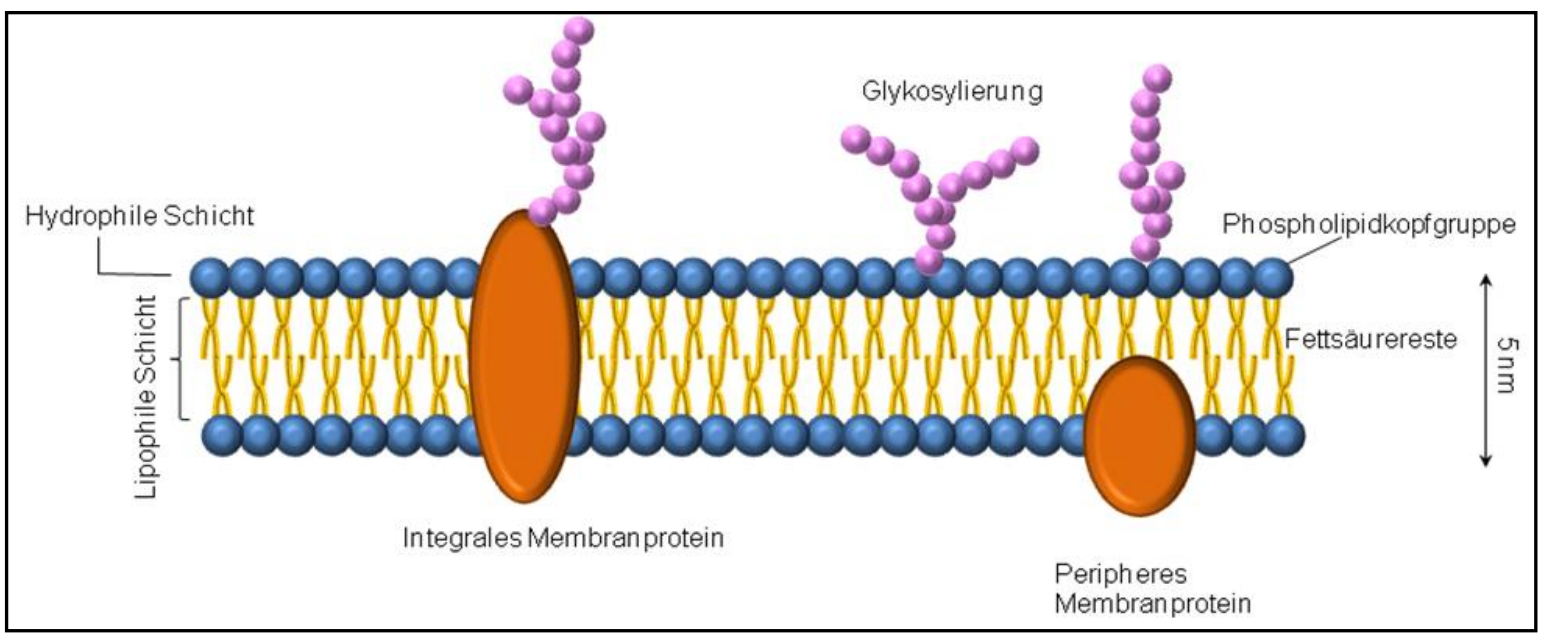

Abb. 1.1: Schematischer Aufbau der Biomembran. Die Phospholipid-Doppelschicht ist so orientiert, dass sich die lipophilen Fettsäurereste gegenüberstehen, während die hydrophilen Kopfgruppen auf der einen Seite am Zytoplasma angrenzen und auf der anderen Seite die Zelle zum Extrazellulärraum hin abschließen.

Im Zytoplasma befindet sich das Zytoskelett, welches v.a. für intrazelluläre Transportprozesse, Bewegung der gesamten Zelle und die Stabilisierung der Zellgestalt verantwortlich ist. Andere Zellorganellen - wie der Zellkern, das endoplasmatische Retikulum, der Golgi-Apparat oder die Mitochondrien - sind durch eine Doppelmembran vom Zytoplasma abgetrennt. Im Zellkern wird die genetische Information gespeichert, verarbeitet und repliziert. Die inn umgebende Membran wird auch Kernhülle genannt. Die Kommunikation mit dem Zytoplasma erfolgt über die Aussparungen der Kernhülle, die Kernporen. Die Kernhülle geht in das endoplasmatische Retikulum über, in welchem die Synthese vieler Lipide und Proteine stattfindet. Man unterscheidet das rauhe von dem glatten endoplasmatischen Retikulum, ersteres weist einen Besatz mit Ribosomen auf. In Mitochondrien finden die für die ATP-Gewinnung wichtigen chemischen Prozesse - wie der Zitratzyklus und die Atmungskette - statt (Korbmacher et al. 2005).

Eine Besonderheit der Herzmuskelzelle sind die fingerförmigen Einstülpungen des Sarkolemms, die sogenannten T-Tubuli (= transversale Tubuli), die mit dem sarkoplasmatischen Retikulum (SR) in der Zelle in enger funktioneller und anatomischer Verbindung stehen. Ein Großteil der L-Typ-Kalziumkanäle befindet sich auf der Membran der T-Tubuli. In der Membran des SR wiederum befinden sich bestimmte Kalziumkanäle, die in Abhängigkeit von der Kalziumkonzentration ihre Öffnungswahrscheinlichkeit ändern. Dieser spezielle Kalziumkanal wird Ryanodin- 
Rezeptor (RyR) genannt. Der Komplex aus T-Tubuli, SR und Zytosol wird als Diade bezeichnet, der zytosolische Raum dazwischen als Diadischer Spalt (Abb. 1.2)

Diese enge Verbindung ist für die elektromechanische Koppelung von großer Bedeutung (siehe Kapitel 1.2.4.).

T-Tubulus

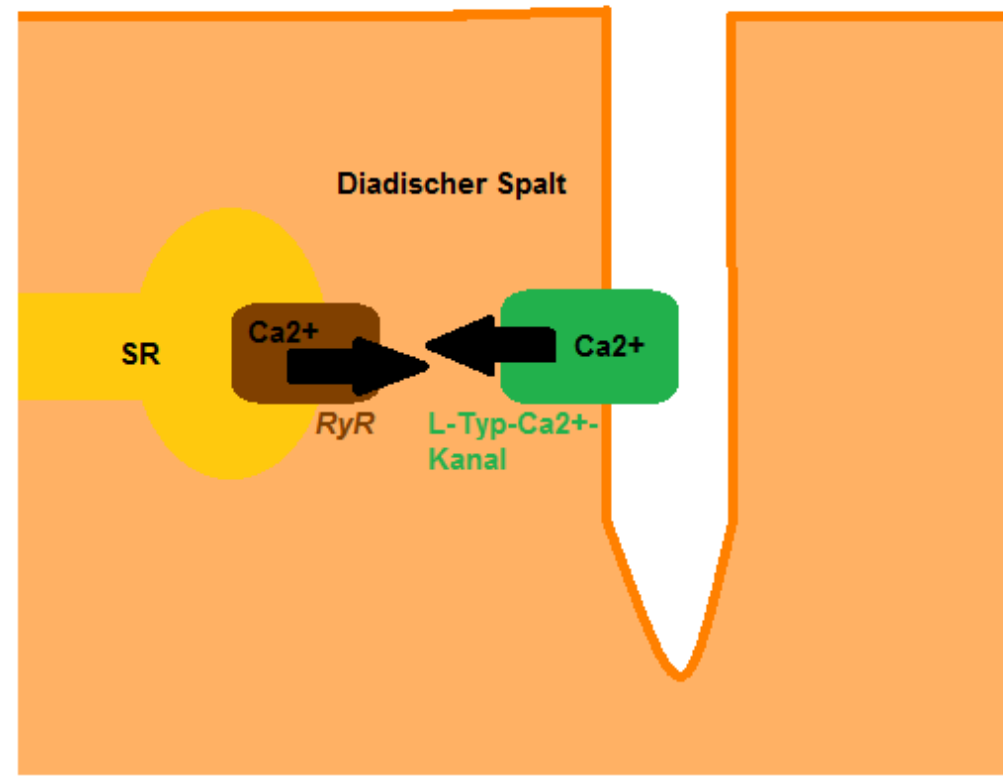

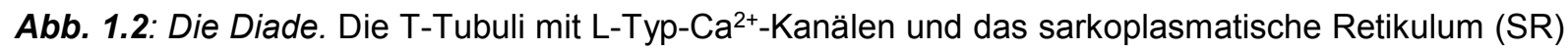
mit den Ryanodin-Rezeptoren (RyR) befinden sich in direkter örtlicher Nachbarschaft und stehen in enger funktioneller Verbindung (siehe Kapitel 1.2.4).

\subsubsection{Der kontraktile Apparat}

Durch die regelmäßige Anordnung von kontraktilen Myofibrillen im Zytoplasma der Zelle kommt es lichtmikroskopisch zu deutlich erkennbarer Querstreifung der Muskelfasern (Hanson und Huxley 1953). Diese Myofibrillen bestehen aus dicken Myosin- und dünnen Aktin-Filamenten, die zusammen die Kontraktion bzw. die Erschlaffung des Muskels ermöglichen (Abb. 1.3). 


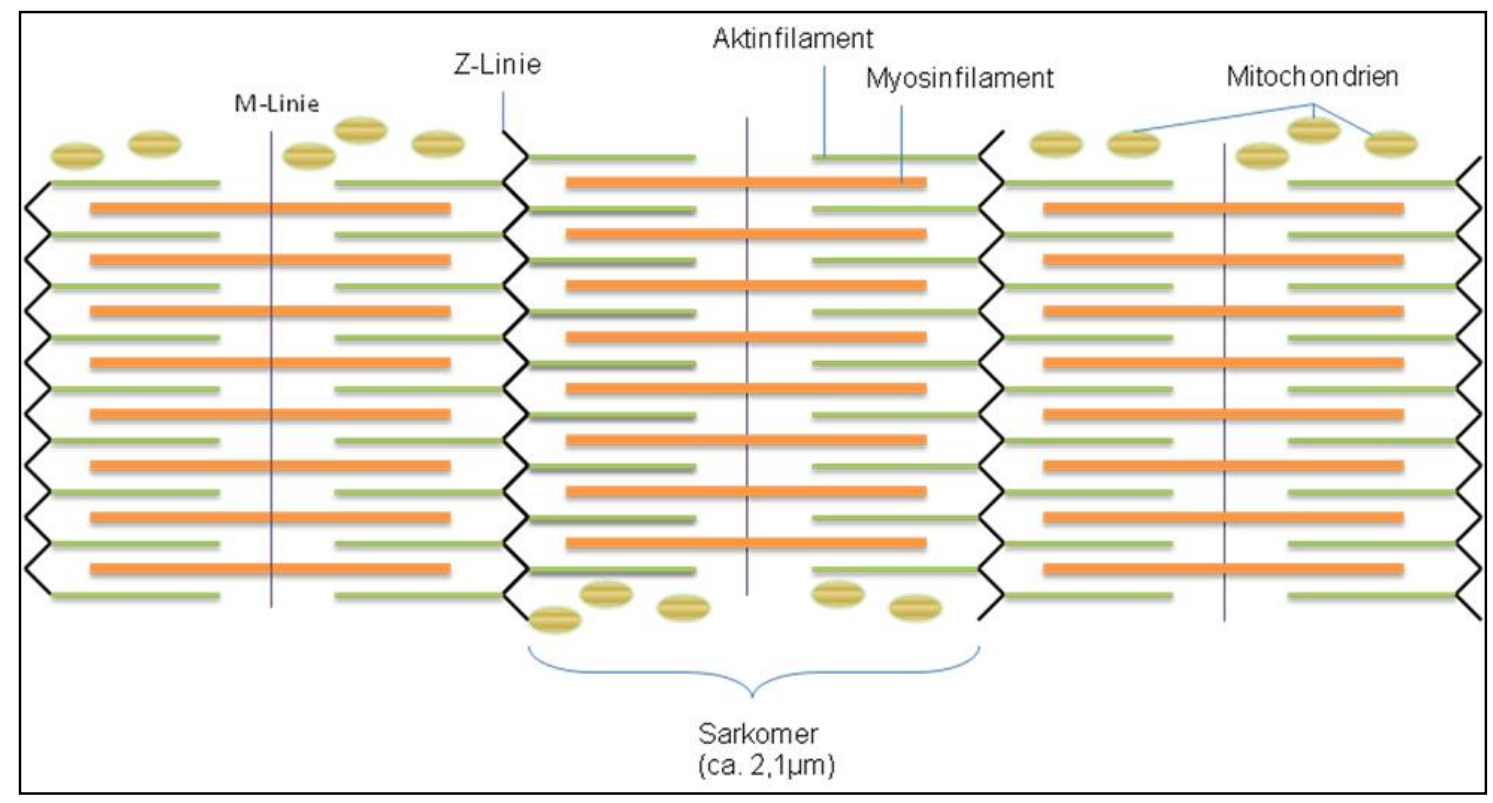

Abb. 1.3: Schematische Darstellung der Sarkomere in einer Herzmuskelzelle. Bei Kontraktion schieben die Myosinfilamente die Aktinfilamente an sich vorbei, so dass der Abstand zwischen den Z-Linien sich verkleinert. Dadurch, dass alle Sarkomere einer Zelle dieses gleichzeitig tun, verkürzt sich die gesamte Zelle. Das Resultat des Zusammenziehens aller Zellen im Zellverband ist die Kontraktion.

\subsubsection{Das Aktionspotential}

In Ruhe ist die Zellmembran des Arbeitsmyokards weitestgehend nur für Kaliumionen permeabel, weshalb das Ruhemembranpotential annährend dem KaliumGleichgewichtspotential entspricht (Korbmacher et al. 2005), welches wiederum bestimmt wird durch die intrazelluläre und die extrazelluläre Konzentration für Kalium. Das Kalium-Gleichgewichtspotential wird mit der Nernst-Gleichung wie folgt berechnet:

$\mathrm{EK}^{+}=\mathrm{RT} / \mathrm{F} \times \ln \left(\left[\mathrm{K}^{+}\right]_{\mathrm{o}} /\left[\mathrm{K}^{+}\right]_{\mathrm{i}}\right)$

Formel 1.2: Kalium-Gleichgewichtspotential nach der Nernst-Gleichung.

Dabei steht $\mathrm{R}$ für die allgemeine Gaskonstante, $\mathrm{T}(\mathrm{K})$ für die absolute Temperatur, $\mathrm{F}$ für die Faraday-Konstante, $\left[\mathrm{K}^{+}\right]$i steht für die intrazelluläre und $\left[\mathrm{K}^{+}\right]_{\circ}$ für die extrazelluläre Konzentration von Kalium in $\mathrm{mmol} / \mathrm{L}$.

Unter physiologischen Bedingungen liegt das Ruhemembranpotential nahe des Kalium-Gleichgewichtspotentials $\left(\left[\mathrm{K}^{+}\right]_{\mathrm{o}}=120 \mathrm{mmol} / \mathrm{l},\left[\mathrm{K}^{+}\right]_{\mathrm{i}}=4 \mathrm{mmol} / \mathrm{l}\right)$ bei ca. $-85 \mathrm{mV}$ (Korbmacher et al. 2005). 
Die Bewegung der lonen in Ruhe oder während des Aktionspotentials wird durch den elektrochemischen Gradienten bestimmt. Dieser ist eine Kombination aus dem chemischen Gradienten (Konzentrationsgefälle) und dem elektrischen Gradienten (elektrische Spannung).

Die Zellen des Arbeitsmyokards reagieren auf einen Reiz (meist aus dem Sinusknoten stammend), der die Membran depolarisiert, mit einem Aktionspotential, welches im humanen Myokard eine Dauer von ca. 300 ms hat (in den untersuchten Mäusemyokardzellen ist das Aktionspotential deutlich kürzer, siehe Abbildung 1.5).

Das Aktionspotential lässt sich in fünf Phasen einteilen (Birkeland et al. 2005):

In der Phase 0 (Phase der schnellen Depolarisation) öffnen sich auf einen depolarisierenden Reiz hin die spannungsabhängigen einwärtsgerichteten Natriumkanäle in der Zellmembran und bewirken eine Depolarisation des Membranpotenzials von $-85 \mathrm{mV}$ weit in den positiven Bereich hinein (etwa bis zu +40 $\mathrm{mV}$ ) in Richtung des Gleichgewichtpotentials für Natriumionen, das allerdings nicht erreicht wird. Dabei folgen die Natriumionen ihrem elektrochemischen Gradienten und strömen in die Zellen hinein, bis sich die Natriumkanäle zeitabhängig wieder schließen. Der Zeitraum, in dem die Natriumkanäle geöffnet sind, beträgt nur wenige Millisekunden (siehe Kapitel 1.7).

Die Phase I bezeichnet eine kurze Repolarisationsphase, die durch die Öffnung spannungsabhängiger, transienter auswärtsgleichrichter (Ito-Kaliumkanäle) und die Inaktivierung der $\mathrm{Na}^{+}-$Kanäle hervorgerufen wird. So kommt es direkt nach dem Aufstrich des Aktionspotentials zu einem kleinen Abfall.

Phase II stellt die Plateau-Phase dar. Das Membranpotential ist aufgrund der Balance zwischen auswärtsgerichteten delayed rectifier - Kalium- ( $\mathrm{K}_{\mathrm{r}}$ und $\left.\mathrm{K}_{\mathrm{s}}\right)$, und einwärtsgerichteten spannungsabhängigen $\mathrm{Ca}^{2+}-$ Kanälen (L-Typ-Kalziumkanäle, ICa) für viele Millisekunden stabil.

Phase III ist die zweite Repolarisationsphase. Der einwärtsgerichtete $\mathrm{Ca}^{2+}$-Strom nimmt ab. Dafür sind zum einen die reduzierte Triebkraft (durch hohe intrazelluläre Kalziumkonzentration), zum anderen eine zeitabhängige Inaktivierung und andere Regulationsmechanismen verantwortlich. Einer dieser Mechanismen ist die Kalziumabhängige Inaktivierung, die durch die $\mathrm{Ca}^{2+} /$ Calmodulinbindung an den Carboxyterminus des lonenkanals zustande kommt (Zühlke und Reuter 1998, Qin et 
al. 1999, Peterson et al. 1999). Gleichzeitig nimmt der auswärtsgerichtete Kaliumstrom ( $\left.\mathrm{IKr}_{\mathrm{K}} \mathrm{I}_{\mathrm{Ks}}\right)$ über die verzögert gleichrichtenden Kalium-Kanäle („delayed rectifer channels“) zu, wobei IKr einen größeren Beitrag zur Repolarisation leistet als IKs, so dass der Ausstrom der Kaliumionen größer ist als der Einstrom der Kalziumionen. Das Membranpotential nimmt am Ende dieser Phase den Wert des Ruhemembranpotentials an.

In Phase IV bleibt das Ruhepotential stabil bis ein erneuter Reiz das Membranpotential erneut depolarisiert und ein weiteres Aktionspotential folgt (Abb. 1.4).

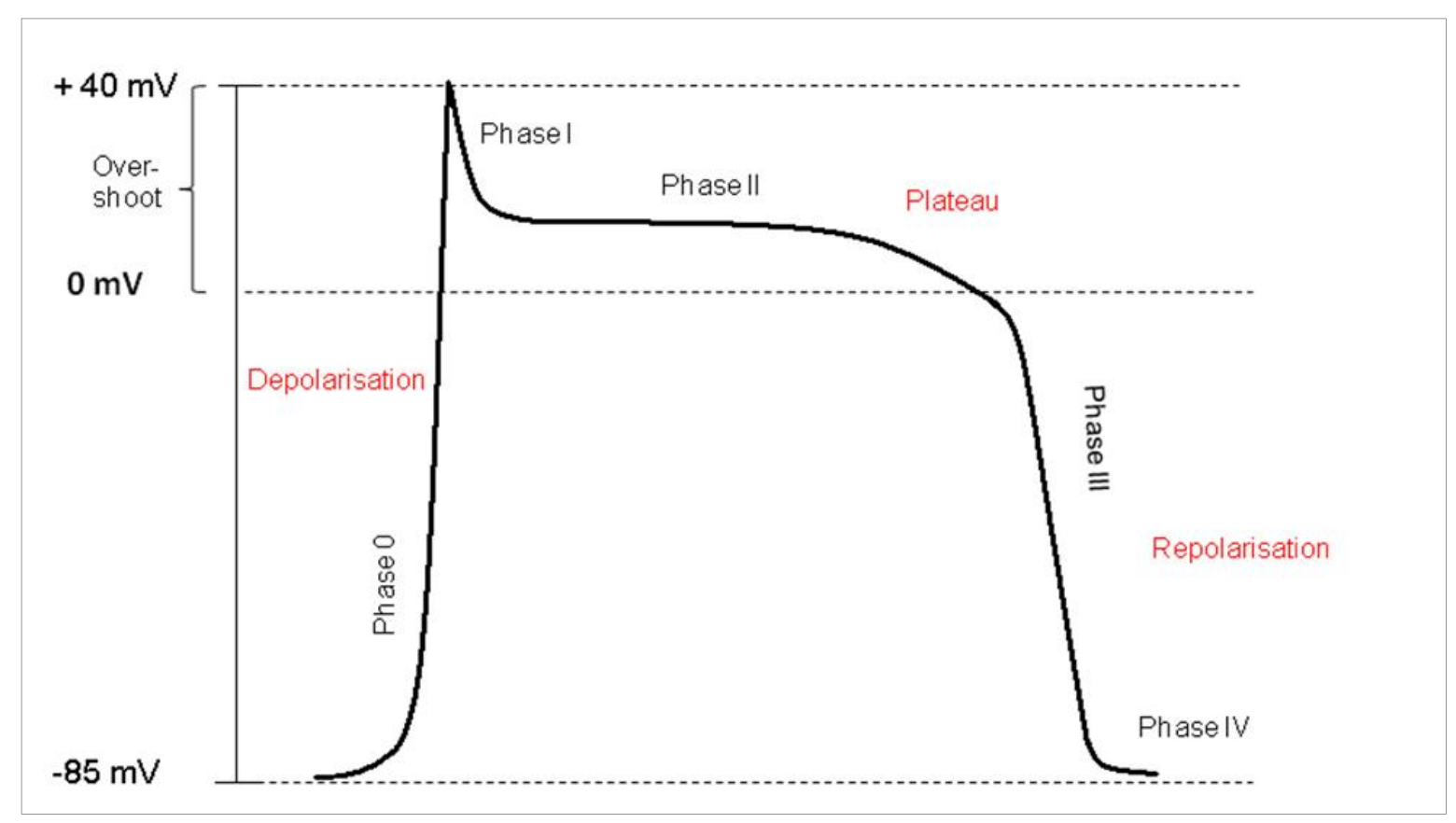

Abb. 1.4: Kurvenverlauf eines Aktionspotentials in einer Herzmuskelzelle (Arbeitsmyokard).

Es sollte beachtet werden, dass es sich bei den hier untersuchten Zellen um Herzmuskelzellen von Mäusen handelt, die bei aller Ähnlichkeit und Vergleichbarkeit zu menschlichen Herzmuskelzellen einige Unterschiede aufzeigen.

Während die normale Herzfrequenz bei Menschen in Ruhe zwischen 56-101 Schlägen pro Minute liegt (Edvardsson et al. 1984, Franz et al. 1987), schlägt das Herz bei Mäusen mit 500-724 Schlägen pro Minute erheblich schneller (Janssen und Smits 2002), entsprechend kürzer ist auch die Aktionspotentialdauer (APD), sie liegt in MausHerzmuskelzellen bei etwa 100 ms (Anumonwo et al. 2001) und ist damit deutlich kürzer ist als die der humanen Kardiomyozyten. Die verkürzte APD ist einmal durch den weniger stark ausgeprägten L-Typ-Ca ${ }^{2+}-$ Strom zu erklären, aber in sehr viel höherem Maße durch anders gestaltete Kaliumkanäle. In humanen Herzmuskelzellen 
wird die Repolarisation (also Phase III des Aktionspotentials) vor allem von den delayed rectifier - Kaliumströmen Iks, die eine langsame Aktivierung, und Ikr, die eine schnelle Aktivierung haben, getragen. In Maus-Myozyten gelingt die schnellere Repolarisation durch die $\mathrm{I}_{\mathrm{K}, \mathrm{slow} 1+2}$ (Nerbonne 2004, Nerbonne et al. 2001); diese Kanäle weisen eine schnelle Aktivierung und eine langsame Deaktivierung auf (Zhou et al. 2003). In Maus-Myozyten spielen die Ito-Kaliumkanäle in der Repolarisation von Vorhof und Ventrikel eine große Rolle (Barry et al. 1998, Guo et al. 1999), während sie in humanen Kardiomyozyten hauptsächlich in der Repolarisation in Phase I ihren Beitrag leisten (Nerbonne 2004).

Während die APD bei Mäusen deutlich kürzer ist, sind die Amplitude, das maximale diastolische Potential und die maximale Aufstrichgeschwindigkeit der APs in Mäusen denen der Menschen sehr ähnlich (Opthof 2001).

Die Abbildung 1.5 veranschaulicht die wesenlichen Unterschiede zwischen Maus- und Mensch-Aktionspotentialen sowie die zugrundeliegenden Kanäle.

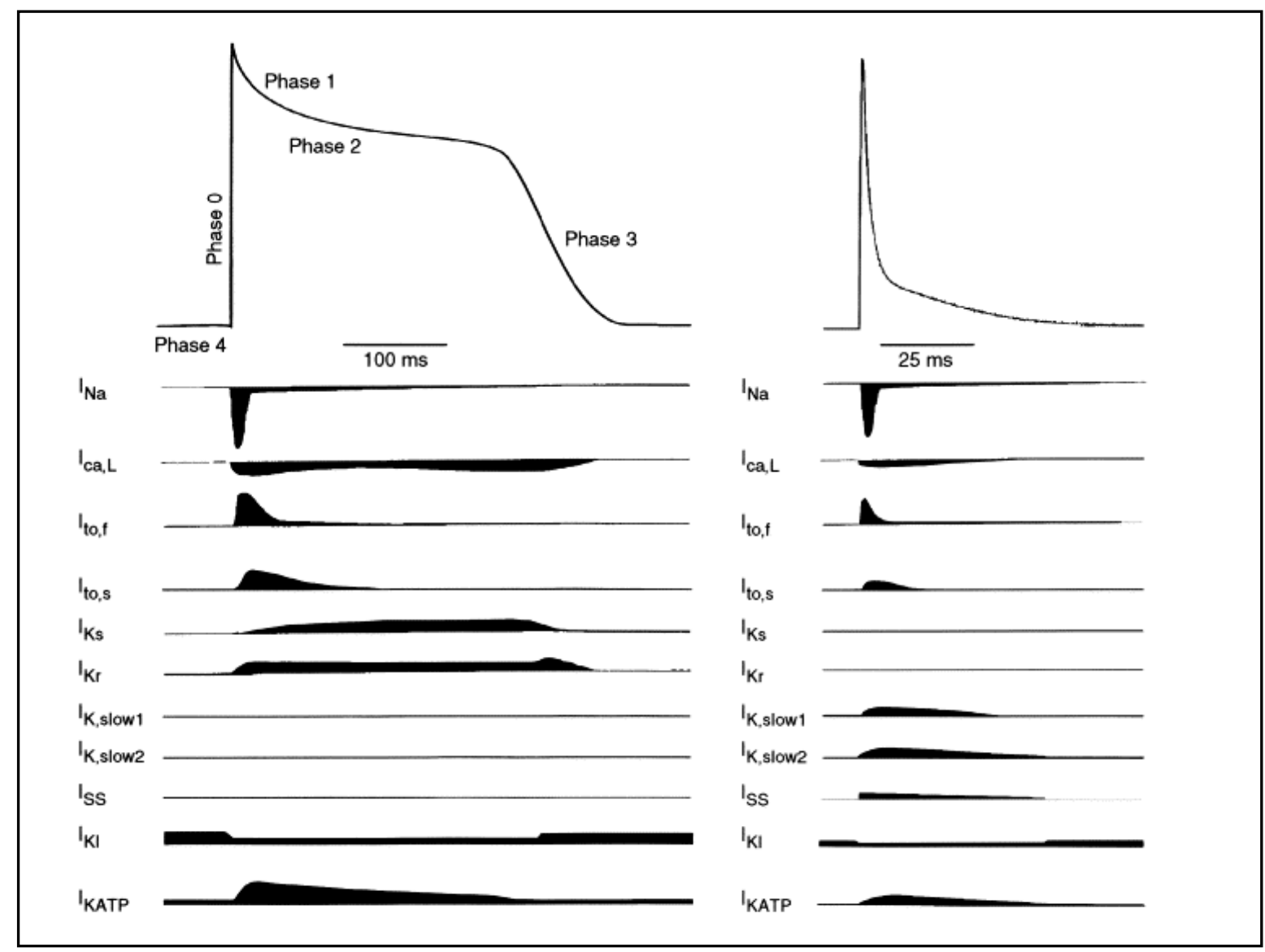

Abb. 1.5: Vergleichende Darstellung des Aktionspotentials und der jeweiligen lonenströme in humanen Kardiomyozyten (links) und Maus-Kardiomyozyten (rechts). Während in humanen Kardiomyozyten Iks und $\mathrm{K}$ Kr einen entscheidenden Beitrag zur Repolarisation leisten, sind diese Kanäle in den MausKardiomyozyten nicht exprimiert, stattdessen gelingt ihre vergleichsweise schnellere Repolarisation über die $I_{k, \text { slow1+2 }}$ und die Iss, sowie einen geringeren $I_{c a}$ (aus Nerbonne 2004, Seite 84). 


\subsubsection{Die Elektromechanische Koppelung}

Als elektromechanische Koppelung bezeichnet man einen Prozess, der von der oben beschriebenen elektrischen Erregung der Herzmuskelzelle zur mechanischen Kontraktion der Myofilamente und damit der gesamten Zelle führt.

Für diesen Prozess entscheidend ist $\mathrm{Ca}^{2+}$, welches sowohl für die elektrische Erregung der Zelle wichtig ist (siehe oben) als auch direkt die Myofilamente aktiviert (Bers 2002 a). Darum liegt es auch nahe, dass Störungen im $\mathrm{Ca}^{2+}$-Haushalt beides, also die Erregungsbildung und -leitung einerseits und die Kontraktilität andererseits, negativ beeinflussen können (Pogwizd et al. 2001). Wichtig ist, dass Kardiomyozyten sowie alle anderen Zellen eine hohe Pufferkapazität für $\mathrm{Ca}^{2+}$ aufweisen. Um die Konzentration des freien intrazellulären $\mathrm{Ca}^{2+}$ von $100 \mathrm{nmol} / \mathrm{l}$ (so wie in der Diastole vorherrschend) auf $1 \mu \mathrm{mol} / \mathrm{l}$ zu steigern, müssen $100 \mu \mathrm{mol} / \mathrm{l} \mathrm{Ca}{ }^{2+}$ hinzugefügt werden. Diese starke Pufferkapazität wird von den diversen $\mathrm{Ca}^{2+}$-bindenden Proteinen der Zelle (wie zum Beispiel Troponin C, SERCA oder Calmodulin) aufrechterhalten (Bers 2002a).

Initialzündung für die Freisetzung von Kalziumionen ins Zytoplasma sind die spannungsabhängigen L-Typ-Kalziumkanäle, die auf dem Sarkolemm entlang der TTubuli liegen und sich während des Aktionspotentials öffnen. Sie ermöglichen einen Kalziumeinstrom, der die Kalziumkonzentration im Diadischen Spalt auf bis zu 50 $\mu \mathrm{mol} / \mathrm{l}$ erhöht (Langer und Peskoff 1996).

Die so entstandene lokale Erhöhung der Kalziumkonzentration in unmittelbarer Nähe der Ryanodin-Rezeptoren (RyR) resultiert in deren Öffnung. Der RyR ist der größte bekannte lonenkanal (>2MDa) und für die Ausschüttung des $\mathrm{Ca}^{2+}$ aus dem $\mathrm{SR}$ während der Systole zuständig (Lanner et al. 2010). Durch diese Ausschüttung kommt es zu einer massiven Freisetzung von Kalzium aus dem SR. Dieser Vorgang wird Kalzium-induzierte Kalziumfreisetzung genannt. So führt die Kombination von Kalziumeinstrom über die L-Typ-Kalziumkanäle und Kalziumfreisetzung via RyR aus dem SR zu einer deutlichen Erhöhung der freien intrazellulären $\mathrm{Ca}^{2+}-$ Konzentration $\left[\mathrm{Ca}^{2+}{ }^{2}\right.$. Hierdurch kommt es via Calmodulin zur Kalziumbindung an Troponin $\mathrm{C}$ der Myofilamente, was die Kontraktion der Myofilamente ermöglicht.

Für die Relaxation der Zelle bzw. der Myofilamente ist es essentiell, dass die hohe $\left[\mathrm{Ca}^{2+}\right]_{i}$ wieder gesenkt wird, so dass $\mathrm{Ca}^{2+}$ vom Troponin $\mathrm{C}$ wieder abdissoziieren kann. 
Auf vier Wegen wird das $\mathrm{Ca}^{2+}$ aus dem Zytosol wieder entfernt. Dazu gehören die SR $\mathrm{Ca}^{2+}$-ATPase (SERCA), die das $\mathrm{Ca}^{2+}$ ins $\mathrm{SR}$ zurückpumpt, der sarkolemmale $\mathrm{Na}^{+} / \mathrm{Ca}^{2+}-$ Austauscher (NCX), welcher $3 \mathrm{Na}^{+}-$Ionen in die eine Richtung und ein $\mathrm{Ca}^{2+}$ Ion in die entgegengesetzte Richtung transportiert, die sarkolemmale $\mathrm{Ca}^{2+}$-Pumpe und der einwärts gerichtete mitochondriale $\mathrm{Ca}^{2+}-$ Kanal (Bers $2002 \mathrm{a}$ ).

Diese vier Mechanismen haben einen jeweils sehr unterschiedlichen Anteil an der Senkung der $\left[\mathrm{Ca}^{2+}\right]$ i. In Herzmuskelzellen von Kaninchen entfernt die SERCA 70\% des überschüssigen $\mathrm{Ca}^{2+}$, der NCX etwa $28 \%$ und die anderen beiden Mechanismen (die sarkolemmale $\mathrm{Ca}^{2+}$-Pumpe und der einwärts gerichtete mitochondriale $\mathrm{Ca}^{2+}-\mathrm{Kanal}$ ) nur $2 \%$. Bei Ratten spielt die SERCA eine deutlich größere Rolle, sie entfernt $92 \%$ des überschüssigen $\mathrm{Ca}^{2+}$, während der $\mathrm{NCX}$ nur $7 \%$ und die sarkolemmale $\mathrm{Ca}^{2+}-\mathrm{Pumpe}$ und der einwärts gerichtete mitochondriale $\mathrm{Ca}^{2+}$-Kanal zusammen nur $1 \%$ beitragen (Bassani et al. 1994). Die in dieser Doktorarbeit untersuchten Maus-Kardiomyozyten gleichen in dieser Hinsicht der Ratte (Bassani et al. 1994), während es sich in humanen Kardiomyozyten etwa so wie beim Kaninchen verhält (Bers 2001).

Wichtig ist, dass die Menge an eingeströmten $\mathrm{Ca}^{2+}$ letztendlich der Menge an wieder entfernten $\mathrm{Ca}^{2+}$ entspricht, da es sonst eine Zunahme oder einen Verlust an $\mathrm{Ca}^{2+}$ für die Zelle mit weitreichenden Folgen bedeuten würde (Bers 2002 b).

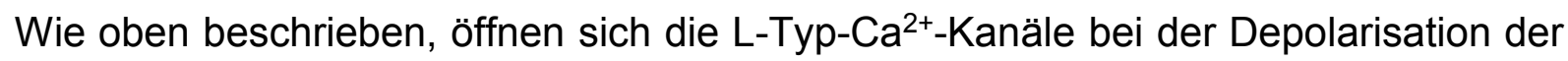
Zelle. Geschlossen werden sie zeitabhängig und durch die $\mathrm{Ca}^{2+}$-abhängige Inaktivierung (siehe oben). Letzterer Effekt ist auf das Calmodulin zurückzuführen. Dieses wird durch die Bindung an $\mathrm{Ca}^{2+}$ aktiviert und bindet wiederum an das Carboxyende des L-Typ-Ca ${ }^{2+}$ Kanals (Peterson et al. 1999, Zühlke und Reuter 1998).

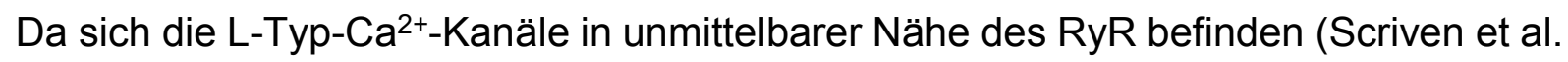
2000), begünstigt also letztendlich die $\mathrm{Ca}^{2+}$-Ausschüttung aus der SR den Schluss der

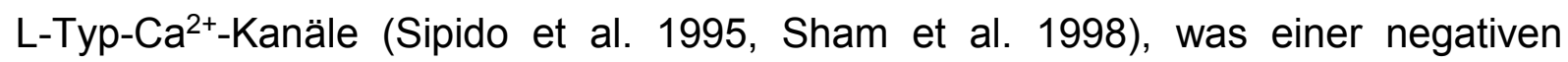
Feedbackregulation entspricht.

Die SERCA, die eine sehr wichtige Rolle bei der Entfernung des $\mathrm{Ca}^{2+}$ aus dem Zytosol spielt, kann durch ihren endogenen Inhibitor Phospholamban gehemmt werden. Dieser bindet im dephosphorylierten Zustand an das Enzym und inhibiert es. Wird PLB jedoch phosphoryliert, z.B. durch CaMKIIסc, führt das zur Dissoziation von SERCA und PLB, was in einer Enthemmung der SERCA resultiert und damit zur einer größeren Aufnahme des freien $\mathrm{Ca}^{2+}$ in das SR führt (Brittsan und Kranias 2000). 
Der bereits erwähnte NCX spielt ebenfalls eine wichtige Rolle für die Kalziumelimination. Dieser Austauscher kann in beiden Richtungen arbeiten. Die Richtung, in der die NCX die lonen bewegt, ist vom elektrochemischen Gradienten abhängig. Unter physiologischen Bedingungen, also bei niedriger $\left[\mathrm{Na}^{+}\right]$, hoher $\left[\mathrm{Ca}^{2+}\right]_{\mathrm{i}}$ oder einem negativen Membranpotential, schafft der NCX $1 \mathrm{Ca}^{2+}-$ Ionen aus der Zelle und befördert dabei $3 \mathrm{Na}^{+}$-Ionen in die Zelle, dieses ist aber ein elektrogener Transport, der das Membranpotential in Richtung positiver Bereiche bewegt.

Die Richtung des lonentransports ändert sich bei hoher [ $\left.\mathrm{Na}^{+}\right]_{i}$ (zum Beispiel durch Digitalispräparate), weniger negativen oder gar positiven Membranpotentiale (zum Beispiel bei verlängerter AP) oder bei niedriger [Ca $\left.{ }^{2+}\right]_{i}$ (Dipla et al. 1999). Allerdings ist der $\mathrm{Ca}^{2+}$-Transient die wichtigste Einflussgröße.

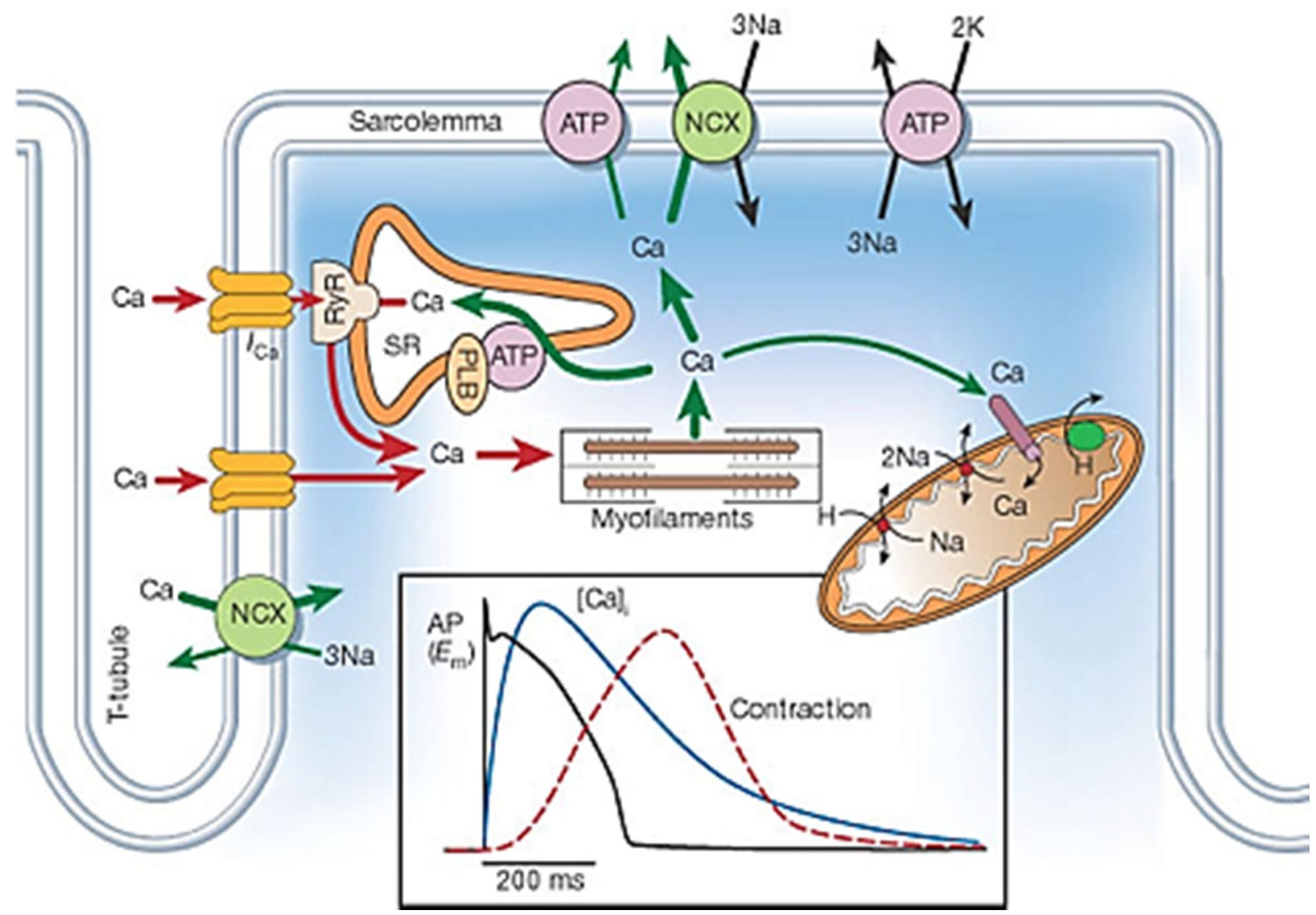

Abb. 1.6: Die elektromechnische Koppelung. Nachdem Kalziumionen während des Aktionspotentials über die spannungsabhängigen L-Typ-Kalziumkanäle des Sarkolemms eingeströmt sind, triggen sie den Kalziumausstrom aus dem SR über die Ryanodin-Rezeptoren (RyR). Die daraus resultierende erhöhte intrazelluläre Kalziumkonzentration enthemmt den Querbrückenzyklus der Myofilamente, was wiederum zur Kontraktion der Zelle führt. In der anschließenden Erschlaffungsphase wird Kalzium über die SERCA und den Natrium-Kalzium-Austauscher wieder aus dem Zytosol entfernt. Im Kasten sind die Kurven eines Aktionspotentials (schwarz), eines Kalzium-Transienten (Blau) und einer isometrischen Kontraktion (Rot) dargestellt, deren zeitlicher Ablauf und Reihenfolge verdeutlicht werden soll (modifiziert nach Bers 2002 b, Seite 198). 
Die Funktionsweise der genannten Proteine kann durch $\beta$-adrenerge Stimulation moduliert werden (Abb. 1.7). Generell führt die $\beta$-adrenerge Stimulation zu einer verstärkten Kontraktion (positiv inotrop) und einer beschleunigten Relaxation (positiv lusitrop).

Die Stimulation des $\beta$-adrenergen Rezeptors führt G-Protein-vermittelt zu einer verstärkten Bildung von zyklischem Adenosinmonophosphat (CAMP), welches wiederum die Proteinkinase A (PKA) aktiviert (Bers 2002b).

Der positiv lusitrope Effekt beruht vor allem auf der Phosphorylierung von Phospholamban durch die aktivierte PKA. So wird Phospholamban gehemmt und die SERCA kann das freie $\mathrm{Ca}^{2+}$ schnell aus dem Zytosol in das SR befördern ( $\mathrm{Li}$ et al. 2000). Dies führt in der Konsequenz zu einem höheren SR-Kalziumgehalt, welcher dann in der nächsten Systole für die Freisetzung zur Verfügung steht und die Kontraktilität erhöht (positiv inotrop). Daneben kommt es zusätzlich zur PKAabhängigen Phosphorylierung des L-Typ Kalziumkanals, welches zu einem verstärkten ICa führt. Des Weiteren kommt es nach PKA-abhängiger Phosphorylierung des RyR zu einer gesteigerten RyR-Öffnungswahrscheinlichkeit. Auch führt die $\beta$ adrenerge Stimulation zu einer direkten Aktivierung der CaMKII (siehe Kapitel 1.3.2), die weitere Proteine phosphoryliert.

All diese Effekte tragen zur Steigerung der in der Systole zur Verfügung stehenden freien zytosolischen Kalziumkonzentration bei und sind damit positiv inotrop wirksam. Was die PKA-Effekte auf den RyR angeht, insbesondere auf die diastolische RyRFunktion, zeigen unterschiedliche Studien allerdings noch recht widersprüchliche Ergebnisse (Marx et al. 2000, Song et al. 2001, Ginsburg und Bers 2004, ViatchenkoKarpinski und Györke 2001). Allgemein akzeptiert ist, dass die erhöhte Öffnungswahrscheinlichkeit des RyR in der Diastole zum $\mathrm{Ca}^{2+}$-Leak aus dem SR und damit zur Entwicklung von Arrhythmien führen kann (siehe Kapitel 1.4.4). 


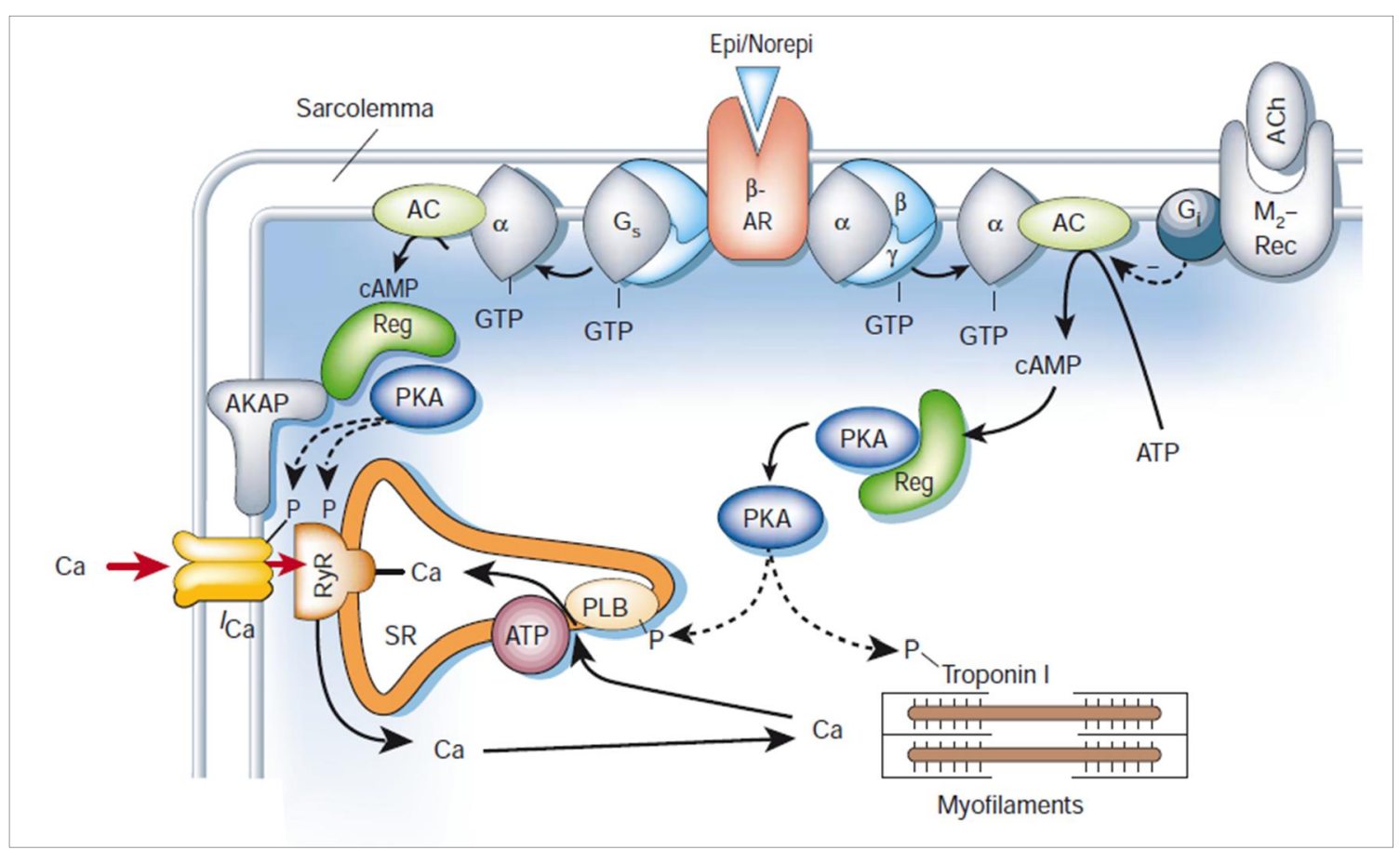

Abb. 1.7: Die $\beta$-adrenerge-Stimulation. Aktivierung des $\beta$-adrenergen Rezeptors führt G-Proteinvermittelt zur Aktivierung der Adenylatzyklase (AC) mit vermehrter cAMP-Bildung, wodurch die PKA aktiviert wird. Diese phosphoryliert dann verschiedene Proteine wie den Ryanodin-Rezeptor (RyR), Phospholamban (PLB) und Troponin I. ACh, Acetylcholin; $\beta$-AR, $\beta$-adrenerger Rezeptor, $\mathrm{M}_{2}$-Rec, M2Muskarinerger Rezeptor, Reg, regulatorische Untereinheit der PKA (aus Bers 2002 b, Seite 203).

Für die Kontraktion der Herzmuskelzelle verantwortlich sind die Myofilamente (Abbildung 1.3). Dabei besitzt das Aktin die Untereinheit Troponin C, welche eine Kalziumbindungsstelle hat. Binden nun vermehrt Kalziumionen aufgrund ihrer erhöhten Konzentration in der Zelle an das Troponin C, verändert dieses seine Lage dergestalt, dass zwischen Aktin und Myosin die Kontaktstelle frei wird (Huxley 1973). Gemäß der Gleitfilamenttheorie gleiten Aktion und Myosin nach den Mechanismen des Querbrückenzyklus aneinander vorbei und verkürzen das Sarkomer (Finer et al. 1994). Die Summe dieser Verkürzungen stellt die Kontraktion der Herzmuskelzelle da. Zur Erschlaffung des Muskels müssen die $\mathrm{Ca}^{2+}$ wieder aus dem Zytosol, wie oben beschrieben, entfernt werden. Sinkt die $\left[\mathrm{Ca}^{2+}\right]$, dissoziieren die $\mathrm{Ca}^{2+}-$ Ionen vom Troponin $\mathrm{C}$ ab und die Tropomyosionmoleküle verlegen auf der Aktinoberfläche wieder die Bindungsstellen für das Myosin (Abb. 1.8). Die Folge ist die Relaxation des Muskels. 


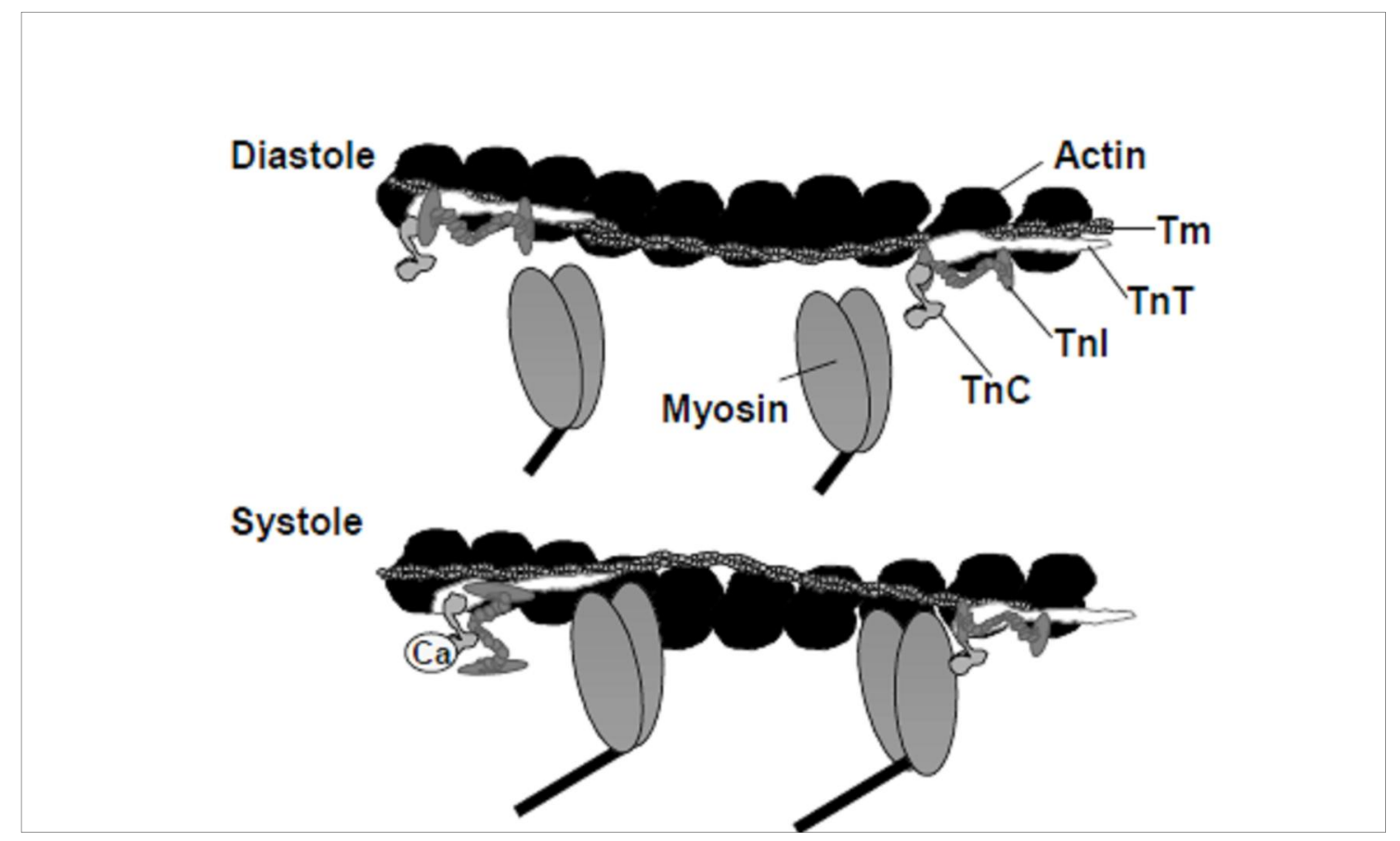

Abb. 1.8: Aktin und Myosin. Im relaxierten Zustand sind die Bindungsstellen durch das Troponin verlegt, die Myosinköpfchen können nicht an das Aktin binden (oben). Die Bindung von $\mathrm{Ca}^{2+}$ an Troponin $\mathrm{C}$ führt dazu, dass die Myosin-Bindungsstelle auf dem Aktinmolekül frei wird, so dass der Myosinkopf an das Aktin binden kann. Durch die Formänderung des Myosinkopfes wird das Aktin am Myosin vorbeigeschoben, dadurch kommt es zu einer Verkürzung des Sarkomers (modifiziert aus Bers 2001, Seite 25).

\subsubsection{Veränderungen im herzinsuffizienten Myokard}

Im Myokard kommt es durch dauerhafte mechanische Überlastung, zum Beispiel infolge von Klappenfehlern, Ischämie, arterieller Hypertonie oder durch die Wirkung humoraler Faktoren wie Angiotensin II, Katecholaminen und BNP (brain natriuretic peptide) zu einer Reihe von Veränderungen. Dieser Vorgang wird kardiales Remodeling genannt.

Neben den makroskopisch sichtbaren Auswirkungen wie der Zunahme der linksventrikulären Masse (Cohn 1995), der Vergrößerung des Kollagengehaltes der extrazellulären Matrix (Weber und Brilla 1991; Weber et al. 1993) und der erhöhten Konzentration an Fibronektin (Farhadian et al. 1996) und Laminin (Morishita et al. 1996) finden im insuffizienten Myokard viele weitere Veränderungen auf subzellularer Ebene statt.

Reaktive Sauerstoffspezies (ROS, siehe Kapitel 1.6) werden im insuffizienten Myokard konstitutiv vermehrt gebildet (Ide et al. 2000; McMurray et al. 1993) und können zu 
einer vermehrten Apoptose führen (Cheng et al. 1995). Der damit einhergehende vermehrte Verlust an kontraktilen Zellen wird durch Hypertrophie der noch vitalen Zellen zu kompensieren versucht.

Auch ist die Expression wichtiger Gene im insuffizienten Myokard verändert. Bereits 1987 konnten GWATHMEY et al. Störungen im Kalziumhaushalt der insuffizienten Myokardzelle aufzeigen. HASENFUSS et al. zeigten dann 1993 erstmals, dass eine reduzierte Expression der SERCA mit der Kalzium-Wiederaufnahme ins sarkoplasmatische Retikulum signifikannt korreliert. Die SERCA ist im insuffizienten Myokard sowohl als Protein als auch auf der mRNA-Ebene herunterreguliert (Ito et al. 1974; Hasenfuss et al. 1994; Pieske et al. 1999; Schillinger et al. 1998). Es konnte auch eine reduzierte Konzentration des natürlichen Inhibitors der SERCA, nämlich des Phospholamban (PLB) aufgezeigt werden, allerdings ist das PLB nicht so stark erniedrigt wie die SERCA (Arai et al. 1993; Meyer et al. 1995), so dass im Verhältnis von SERCA zu PLB letzteres überwiegt. Somit kommt es neben der absoluten zahlenmäßigen Reduktion vonTransportern auch zu einer verminderten Aktivität der verbliebenen Transporter. In Folge sinkt die Kalziumkonzentration im SR, was zu einer reduzierten Verfügbarkeit des Kalziums für die Systole führt.

Auch der RyR scheint im insuffizienten Myokard zwar herunterreguliert zu sein (Matsui et al. 1995 b). Seine Öffnungswahrscheinlichkeit ist jedoch massiv gesteigert (Marx et al. 2000). Dies führt nicht nur zu einer vermehrten systolischen Kalziumfreisetzung aus dem SR, die ohnehin schon stark ausgeschöpft ist, sondern erhöht vor allem den diastolischen SR Kalziumverlust, was zur weiteren Reduktion des SR Kalziumgehaltes beiträgt.

Die $\mathrm{Ca}^{2+}$-Calmodulin-abhängige Proteinkinase II (CaMKII) gehört zu der Gruppe der Kinasen und phosphoryliert im aktivierten Zustand eine Reihe an Enzymen und Ionenkanäle (siehe Kapitel 1.3). Die CaMKII ist im insuffizienten Myokard deutlich stärker exprimiert (Hoch et al. 1999). Im Jahre 2003 zeigten ZHANG et al., dass die chronische CaMKII-Überladung der Zelle bei Mäusen eine Herzinsuffizienz hervorruft. Später konnte gezeigt werden, dass die CaMKII $\delta_{b}$ und CaMKII $\delta_{c}$ (das sind unterschiedliche Splicevarianten der $\delta$-Isoform, siehe Kapitel 1.3) die Genexpression der MEF2 (Myocyte enhancer factor 2)-Luciferase regulieren und eine HDAC4 (Histondeacetylase 4)-Translokation aus dem Zellkern ins Zytoplasma bewirken. So ist die CaMKII direkt an der Hypertrophieentstehung beteiligt (Zhang 2007). 
Gesteigert ist auch Menge und Aktivität des sarkolemmalen Natrium-KalziumAustauschers (Studer et al. 1994; Pogwizd et al. 1999), während die L-TypKalziumkanäle entweder vermindert exprimiert werden (Takahashi et al. 1992) oder unverändert bleiben (Beukelmann et al. 1992).

Vom gestörten Kalziumhaushalt abgesehen, beeinflusst das kardiale Remodeling auch die Natrium- und Kaliumkanäle: So kommt es zu einer geringeren Expression der transienten Kalium-Auswärtsgleichrichter (Beukelmann et al. 1993; Kääb et al. 1998) und zu einer verstärkten Ausprägung des späten Natriumstroms (Valdivia et al. 2005). Beides führt zu einer verlängerten Aktionspotentialdauer (Kääb et al. 1996) und damit zu einer erhöhten Gefahr für Arrhythmien (siehe unten). Die unterschiedlichen Arrhythmiemechanismen werden im Kapitel 1.4 näher erläutert.

Der Natrium-Protonen-Austauscher wird im insuffizienten Myokard etwa doppelt so stark exprimiert (Takewaki et al. 1995) und soll laut einiger Studien ebenfalls für die Hypertrophieentwicklung von entscheidender Bedeutung sein (Engelhardt et al. 2002; Kusumoto et al. 2001). Während manche Studien die intrazelluläre Natriumüberladung in der Herzinsuffizienz nachgewiesen und auf die vermehrte Expression dieses Kanals zurückgeführt haben (Baartscheer et al. 2003), weisen andere Studien auf eine Bedeutung des verstärkten späten Natriumstroms hin (Wagner et al. 2006; Sossalla et al. 2008). Auf der Ebene der Myofilamente weist die myofilamentäre ATPase eine verminderte Aktivität auf (Hasenfuss et al. 1992) und es kann eine Störung der Energiebereitstellung aufgezeigt werden (Schultheiß et al. 1995).

Im insuffizienten Myokard konnte ferner gezeigt werden, dass es zu einer Downregulation der $\beta$-Rezeptordichte kommt (Bristow et al. 1986) und die Aktivität des dazugehörenden Second Messengers cAMP verringert nachweisbar ist. Somit verringert sich der stimulierende Effekt der Katecholaminbindung an den $\beta$ Rezeptoren, was zu einer Beeinträchtigung der Kontraktions- und Relaxationsfähigkeit des Herzens führt.

\section{3 $\mathrm{Ca}^{2+}$-Calmodulin-abhängige Proteinkinase II (CaMKII)}

Die CaMKII ist eine Serin-/Threoninkinase, die durch Kalzium-gebundenes Calmodulin aktiviert wird. In ihrem aktiven Zustand phosphoryliert sie dann viele verschiedene Enzyme, Rezeptoren und lonenkanäle. Die CaMKII wurde ursprünglich im Nervengewebe entdeckt und später auch in Myokardzellen nachgewiesen (Jett et al. 
1987). Von den vier verschiedenen Formen $(\alpha, \beta, \gamma, \delta)$, die von vier unterschiedlichen Genen kodiert werden, ist die im Herzen vorherrschende Isoform die CaMKIIס (Maier und Bers 2002), von der die Splicevariante СаMKII $\delta_{B}$ im Zellkern und CaMKII Zytosol vorzufinden ist (Edman und Schulman 1994).

\subsubsection{Die Struktur der CaMKII}

Jedes einzelne CaMKII-Monomer besteht aus drei verschiedenen Domänen: am aminoterminalen Ende eine katalytische Domäne, eine zentrale regulatorische Domäne mit einer autoinhibitorischen Einheit und am Carboxyterminus eine Assoziationsdomäne (Abb. 1.9). Das gesamte CaMKII-Enzym besteht aus sechs bis zwölf solcher Monomeren (Braun und Schulman 1995), die zusammen eine radähnlich Struktur bilden. Dabei bilden die C-terminalen Assizoiationsdomänen, die für die Entstehung dieser Multimere verantwortlich sind, das Zentrum des Rads und die $\mathrm{N}$-terminalen katalytischen Domänen ragen nach außen (Kanaseki et al. 1991).

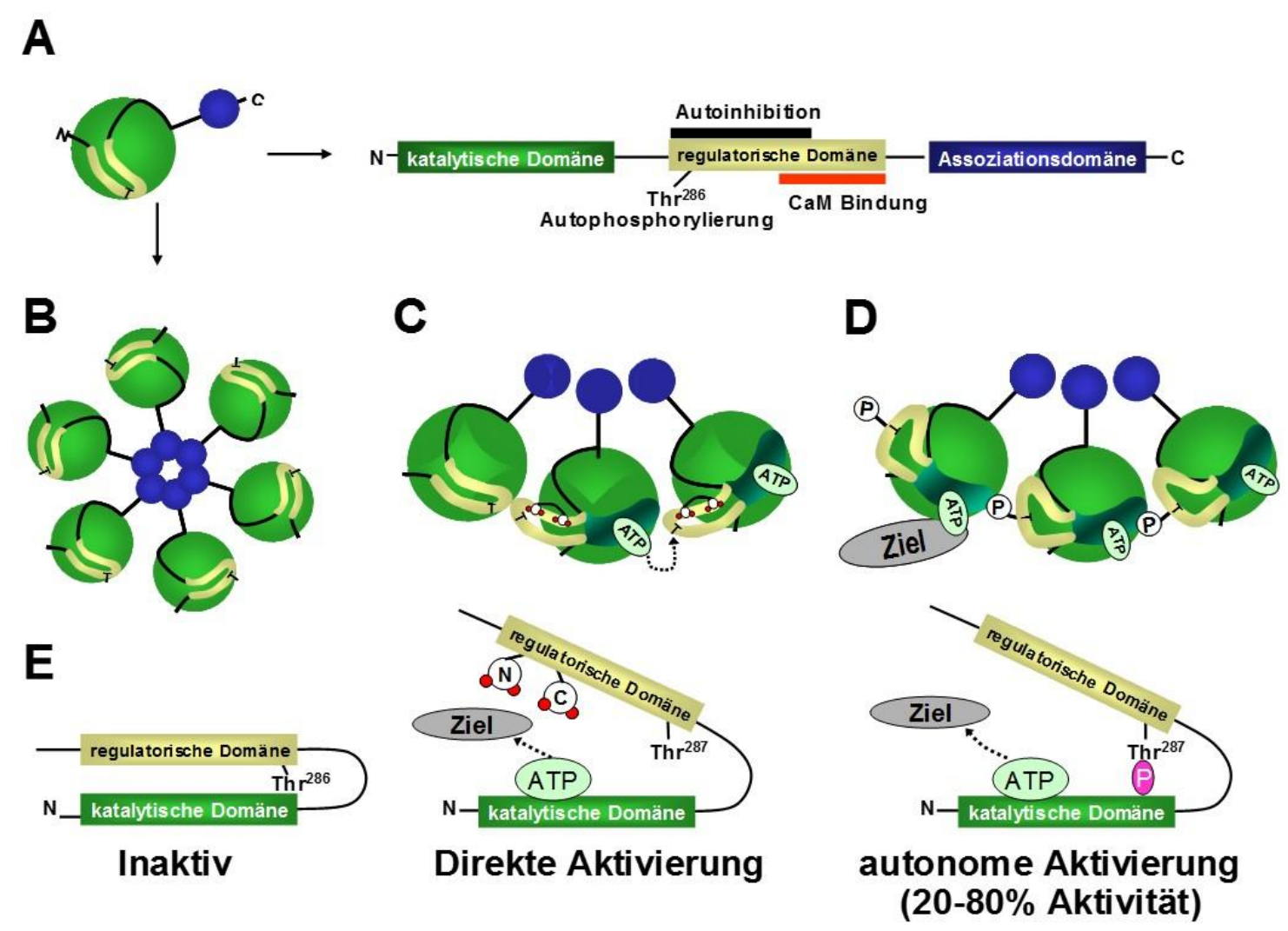

Abb. 1.9: CaMKII. A: Das CaMKII-Monomer mit seinen drei Hauptkomponenten, B: Die Radstruktur geformt aus 6 CaMKII-Monomeren, C: $\mathrm{Ca}^{2+}{ }^{2+}$ Calmodulin bindet an die CaMKII und aktiviert sie, D: Durch die Autophosphorylierung an Thr-286 bleibt die CaMKII auch nach der Abdissoziation von Calmodulin aktiv, E: Schematische Darstellung der inaktiven, aktivierten und autophosphorylierten Form (modifiziert nach Maier und Bers 2002, Seite 924). 


\subsubsection{Die Aktivierung der CaMKII}

Im inaktiven Zustand ist die katalytische Domäne durch die autoinhibitorischen Region der regulatorischen Domäne geblockt, so dass kein Substrat an die katalytische Domäne gebunden werden kann.

Am Anfang der Aktivierung der CaMKII steht die Bindung vom zytosolischen Kalzium an das Calmodulin, wodurch dieses aktiviert wird. Diese Bindung kommt vor allem bei erhöhter zytosolischer Kalziumkonzentration zustande, beispielsweise in Kardiomyozyten während eines Aktionspotentials. Im aktivierten Zustand bindet der Kalzium-Calmodulin-Komplex an die regulatorische Einheit der CaMKII und hebt dadurch die Autoinhibition auf, so dass daraufhin die katalytische Einheit freigelegt wird und diese nach ATP-Spaltung die jeweiligen Substrate phosphorylieren kann. Dabei ist eines dieser Substrate die regulatorische Domäne der benachbarten CaMKIIUntereinheit (Hanson und Schulman 1992, Hanson et al. 1994). Diese Autophosphorylierung an Thr-287 erhöht zum einen die Affinität der CaMKII für Calmodulin auf das 700-Fache, so dass das Calmodulin auch nach Abfall der intrazellulären Kalziumkonzentration an der CaMKII gebunden und damit die Enzymaktivität erhalten bleibt (Meyer et al. 1992). Zum anderen bleibt durch die stattgefundene Autophosphorylierung selbst nach der Abdissoziation des Calmodulin die stattgefundene Konformationsänderung der CaMKII und bis zu 80\% der Aktivität erhalten (Maier und Bers 2002). Die Autophosphorylierung ist somit die langsame, aber in inrer Wirkung anhaltende Reaktion auf kurzandauernde zytosolische Kalziumkonzentrationsschwankungen, also ein Art von Kalziumgedächtnis der Myokardzelle (Hudmon und Schulmann 2002).

Die Aktivierung der CaMKII kann aber auch auf anderem Wege erfolgen: ERICKSON et al. konnten 2008 zeigen, dass es eine $\mathrm{Ca}^{2+}$-unabhängige Aktivierung der CaMKII durch reaktive Sauerstoffspezies (ROS, siehe Kapitel 1.6) gibt, hier kommt es zu einer Oxidierung von Methionin 281/282 in der regulatorischen Domäne. Dieses führt zu einer vergleichbaren Aktivität wie die durch eine Autophosphorylierung hervorgerufene.

Vor kurzem konnte gezeigt werden, dass im Rahmen von akuter Hyperglykämien es zu einer O-Glykosilierung der CaMKII an Ser-279 kommen kann, was ebenfalls zu einer vom $\mathrm{Ca}^{2+}$-Transienten unabhängigen Aktivierung der CaMKII führt (Erickson et al. 2013). Diese Erkenntnis legt somit eine Beteiligung der CaMKII in der 
Pathophysiologie Diabetes-induzierter kardialer und neuronaler Erkrankungen nahe. Abbildung 1.10 zeigt eine Übersicht über die genannten Aktivierungsformen der CaMKII und mögliche Ansatzpunkte für Inhibitoren.

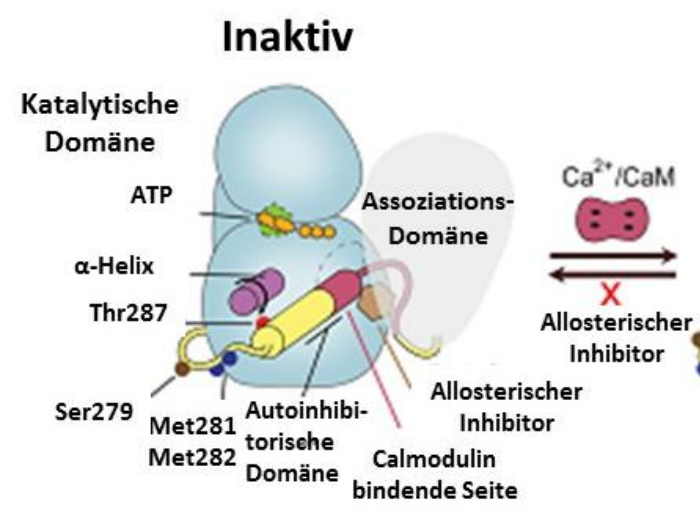

Aktiv

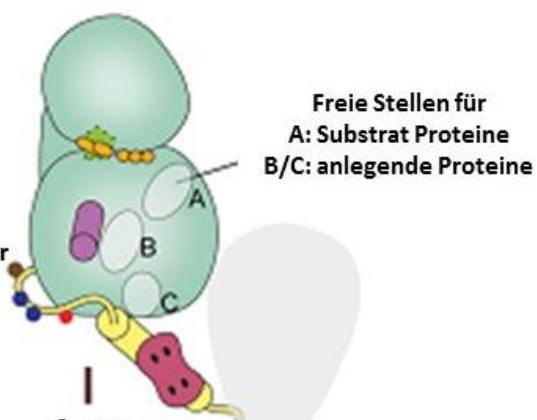

Auto-
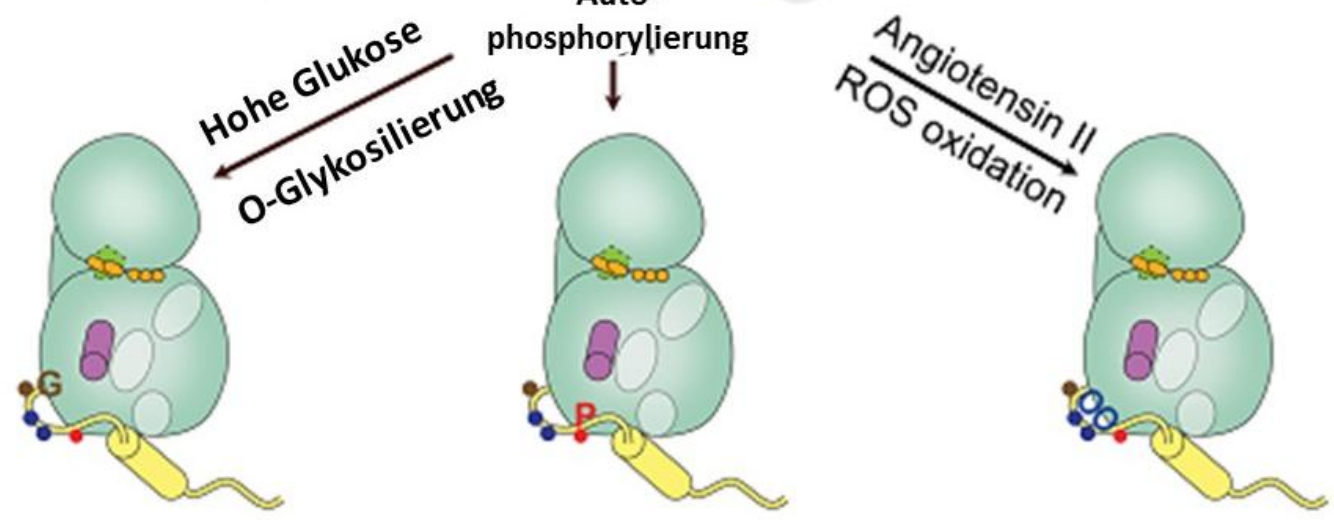

Drei permanent aktive Zustände
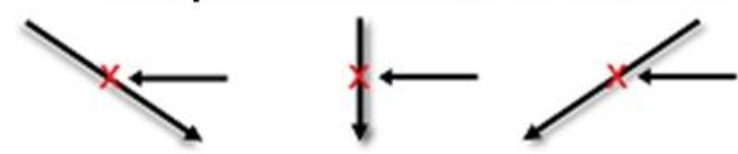

Kompetitive Inhibitoren

\section{Hyperaktivität fördert Herzinsuffizienz und Arrhythmie}

Abb. 1.10: Übersicht über die verschiedenen Wege der CaMKII-Aktivierung (modifiziert nach Pellicena und Schulman 2014).

Aktuelle Studien zeigen, dass CaMKII auch direkt über $\beta$-adrenerge Stimulation NOvermittelt aktiviert werden kann. Diese Aktivierung erfolgt durch eine Nitrosylierung der CaMKII und ist sowohl vom PKA als auch vom $\mathrm{Ca}^{2+}$-Transienten unabhängig (Gutierrez et al. 2013).

\subsubsection{Die Funktion der CaMKII}

Die CaMKII phosphoryliert viele Proteine, die an der elektromechanischen Koppelung beteiligt sind, mit deutlichen funktionellen Konsequenzen. So werden der L-Typ-Ca ${ }^{2+}$ - 
Kanal, der Ryanodinrezeptor (RyR) sowie Phospholamban (PLN) von der CaMKII phosphoryliert. Folglich nimmt die CaMKII als Antwort auf eine erhöhte intrazelluläre $\mathrm{Ca}^{2+}-$ Konzentration Einfluss auf den $\mathrm{Ca}^{2+}$-Einstrom, die $\mathrm{Ca}^{2+}$-Ausschüttung aus dem SR sowie die Wiederaufnahme des zytosolischen $\mathrm{Ca}^{2+}$ in das SR (Maier und Bers 2002). Die Phosphorylierung der L-Typ-Ca ${ }^{2+}-$ Kanäle steigert den Kalziumeinstrom über diese Kanäle, die Phosphorylierung des RyR erhöht die Öffnungswahrscheinlichkeit des Kanals und fördert so die $\mathrm{Ca}^{2+}$-Ausschüttung aus dem SR (Maier et al. 2003), die Phosphorylierung des PLN an Threonin 17 durch CaMKII (Simmerman et al. 1986) führt zu einer Enthemmung der SERCA, die in eine gesteigerten $\mathrm{Ca}^{2+}$-Aufnahme in SR resultiert.

Auch wenn die CaMKII-abhängigen Signaltransduktionswege in der Myokardzelle heute noch nicht vollständig geklärt sind, konnten $\mathrm{HOCH}$ et al. bereits 1999 zeigen, dass im herzinsuffizienten Myokard eine erhöhte CaMKII-Expression und -Aktivität zu verzeichnen ist. 2006 zeigten WAGNER et al., dass die CaMKII den späten $\mathrm{Na}^{+}-$ Einstrom verstärkt, wahrscheinlich durch Phosphorylierung kardialer spannungsabhängiger $\mathrm{Na}^{+}-$Kanäle. Später konnte gezeigt werden, dass diese Phosphorylierung vorrangig im I-II-Linker des $\mathrm{Na}^{+}-$Kanals stattfindet (Aiba et al. 2010), präzise am Serin 571 (Hund et al. 2010). ASHPOLE et al. führten 2012 eine systematische Analyse des I-II-Linker durch und konnten zeigen, dass Serin 516 und Threonin 594 weitere wichtige Phosphorylierungsstellen sind.

Da diese $\mathrm{Na}^{+}-$Kanäle an der Entstehung von Aktionspotentialen wesentlich beteiligt sind, führt eine Modifikation dieser Kanäle zu Veränderungen des $\mathrm{Na}^{+}$-Einstroms während eines Aktionspotentials, damit zu einer veränderten Aktionspotentialmorphologie, die wiederum wahrscheinlich Arrhythmien begünstigt.

Die CaMKII ist auch direkt an der Hypertrophieentstehung beteiligt: Sie kann die Histon-Deacetylasen Typ II (HDACs) phosphorylieren (McKinsey et al. 2000), welche dephosphoryliert die Traskriptionsaktivierung durch MEF-2 hemmen, somit führt die CaMKII zu einer Enthemmung der Transkription (Wu et al. 2006).

\subsubsection{Die Hemmung der CaMKII}

Die CaMKII kann auf unterschiedliche Art und Weise gehemmt werden. In Form einer kompetitiven Hemmung kann beispielsweise das synthetisch hergestellte Peptid 273- 
302 als Pseudosubstrat an das aktive Zentrum der katalytischen Domäne der CaMKII binden und somit dieses für Substrate blockieren (Anderson et a. 1994). Das Peptid 291-317 ist der Calmodulin-Bindungs-Region der CaMKII wiederum strukturverwandt und bindet aktiviertes Calmodulin, so dass dieses nicht mehr die CaMKII aktivieren kann (Anderson et al. 1994, Smith et al. 1990, Payne et al. 1988).

Um die CaMKII in Herzmuskelzellen zu hemmen, werden pharmakologische Substanzen wie KN93 eingesetzt, die ebenfalls kompetitiv die Interaktion von Calmodulin und CaMKII hemmen (Anderson et al. 1998, Bassani et al. 1995). KN93 ist der bislang am häufigsten und im breiten Spektrum verwendete CaMKII-Inhibitor für zelluläre und in vivo Experimente. Es hemmt die CaMKII, indem es an das Holoenzym bindet und dadurch verhindert, dass $\mathrm{Ca}^{2+} /$ Calmodulin mit dem Enzym interagieren und es aktivieren kann. KN-93 hat keine Wirkung auf die Aktivität von bereits aktivierter und autophosphorylierter CaMKII (Sumi et al. 1991). Jedoch zeigt KN93 auch unspezifische Effekte: Es hemmt ebenso wirksam die CaMKI und die CaMKIV (Mochizuki et al. 1993, Enslen et al. 1994), bewirkt eine reversible Hemmung der L-

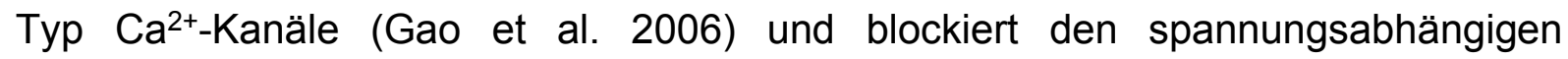
Kaliumstrom (Kv) in den Zellen der glatten Muskulatur (Ledoux et al. 1999). Vor kurzem wurde die inhibitorische Wirkung von KN93 gegenüber 234 Proteinkinasen getestet und es konnte gezeigt werden, dass KN93 noch weitere Targets besitzt (Gao et al. 2013).

CK59 wurde 2007 von KONSTANTOPOULOS et al. entwickelt, es hemmt ähnlich wie KN93 sowohl die CaMKII als auch die L-Typ $\mathrm{Ca}^{2+}-$ Kanäle.

Ein weiterer Peptid-Inhibitor ist das Autocamtid-2-verwandte inhibitorische Peptid (AIP), das deutlich potenter und spezifischer ist als KN93. AIP bindet an der Substratbindenden Stelle des Enzyms und hemmt damit die Autophoyphorylierung des Enzyms (Ishida et al. 1995).

\subsubsection{CaMKII, Herzinsuffizienz und Arrhythmien}

Im insuffizienten Myokard ist eine erhöhte Expression und Aktivität der CaMKII gezeigt worden (Kirchhefer et al. 1999, Hoch et al. 1999), ferner erwies sich auch eine positive Korrelation zwischen der CaMKII-Konzentration und der Kontraktilität im terminalinsuffizienten Myokard (Kirchhefer et al. 1999), so dass die Vermutung nahe liegt, dass es sich um einen Kompensationsmechanismus handelt. 
In transgenen Mäusen konnte einige Jahre später jedoch gezeigt werden, dass die Überexpression von CaMKIIסc eine kardiale Hypertrophie und Herzinsuffizienz mit Störungen im Kalziumhaushalt der Zelle verursacht (Zhang et al. 2003). Vor kurzem konnte darüber hinaus gezeigt werden, dass CaMKIIठc-Knockout-Mäuse vor der Entwicklung der Herzhypertrophie geschützt sind (Backs et al. 2009). LING et al. haben 2009 an Mäusen durch eine Konstriktion der Aorta eine Nachlasterhöhung verursacht. Die sich daraufhin entwickelnde Herzinsuffizienz blieb bei den CaMKIIסcKnockout-Mäusen aus. Diese Arbeiten legen nahe, dass es sich bei der Überexpression der CaMKII im insuffizienten Myokard nicht nur ein Kompensationsmechanismus handelt, sondern diese die Entwicklung der Herzinsuffizienz maßgeblich fördert.

Als Ursache für die Herzinsuffizienz werden verschiedene Mechanismen diskutiert. Eine Phosphorylierung des RyR führt zu einer erhöhten Öffnungswahrscheinlichkeit des Kanals (Maier et al. 2003). Das wiederum stört den Kalziumhaushalt auf zwei Wegen: Zum einen führen die spontanen Öffnungen des RyR zu einem kontinuierlichen diastolischen Kalziumverlust aus dem SR und damit zur Senkung des sarkoplasmatischen $\mathrm{Ca}^{2+}$-Gehalts. Zum anderen führen die vielen spontanen Öffnungen des RyR zu einer zytosolischen Kalziumüberladung der Zelle und zur Aktivierung des $\mathrm{Na}^{+}-\mathrm{Ca}^{2+}$-Austauschers (NCX). Dieser Mechanismus führt zu späten Nachdepolarisationen (DADs, Pogwizd et al. 2001). Als Ursache für frühe Nachdepolarisationen (EADs) wird ein verlängertes Aktionspotential angesehen (Anderson et al. 1998). EADs und DADs können zu zellulären Arrhythmien führen und werden im Kapitel 1.4 näher erläutert. Eine weitere Ursache für CaMKII-bedingte Arrhythmien kann in der oben erwähnten Veränderung von Öffnungswahrscheinlichkeiten der sarkolemmalen lonenkanäle liegen, die sowohl das Aktionspotential formen als auch die elektromechanische Koppelung bedingen (Maier

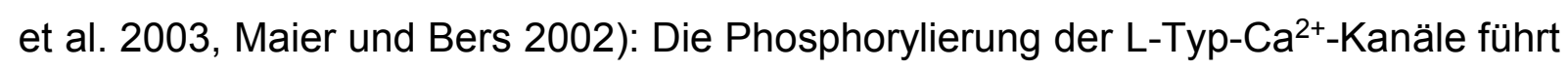
zu einem vermehrten $\mathrm{Ca}^{2+}$-Einstrom und zu einem verlängertem Aktionspotential (Anderson et al. 1998), auch führt die Aktivierung des späten Natriumstroms (INa,late) ebenfalls zu einem verlängerten Aktionspotential (Toischer et al. 2013). Das verlängerte Aktionspotential führt zu EADs und Arrhythmien. 


\section{4 Kardiale Arrhythmien}

Für die bedarfsgerechte Funktion des Herzens ist der Herzrhythmus ein essentieller Steuerungsmechanismus. Störungen des Herzrhythmus sind Veränderungen der elektrischen Tätigkeit des Herzens, die durch eine unregelmäßige Abfolge von Erregungen (Arrhythmie), Abweichungen von der normalen Herzfrequenz (Bradykardien und Tachykardien) oder Störung der einzelnen Herzaktion gekennzeichnet sind (Xiao 2011).

Herzrhythmusstörungen können angeboren oder erworben sein. Degenerative und ischämische Herzerkrankungen sind die häufigsten Ursachen von erworbenen Herzrhythmusstörungen. Beispiele für angeborene Herzrhythmusstörungen sind das Long-QT-Syndrom, das Short-QT-Syndrom oder das Brugada-Syndrom.

Das Long-QT-Syndrom beruht zum größten Teil (je nach Unterform) auf genetischen Fehlbildungen von Kalium- oder Natriumkanälen (Curran et al. 1993, Wang et al. 1995) und führt, wie der Name schon sagt, zu einem verlängerten QT-Intervall im EKG, was eine verzögerte Repolarisation repräsentiert. Im Rahmen dieser verlängerten Repolarisationszeit kann es zur Entwicklung von lebensgefährlichen Arrhythmien kommen (siehe Kapitel 1.4.4).

Das Short-QT-Syndrom, erstmals im Jahre 2000 von GUSSAK et al. beschrieben, zeichnet sich hingegen durch ein besonders kurzes QT-Intervall ( $<330 \mathrm{~ms}$ ) aus, ursächlich hierfür sind ebenfalls Mutationen (gain of function) in den Kaliumkanälen (Giustetto et al. 2006).

Die Ursache des Brugada-Syndroms ist bislang nicht abschließend geklärt. Es geht klinisch mit plötzlichen Todesfällen (v.a. bei Männern), Palpitationen und Synkopen einher. Im EKG sind ST-Streckenhebungen in den rechts-präcordialen Ableitungen $\mathrm{V}_{1}$ $V_{3}$ sichtbar (Nielsen et al. 2013). Bislang werden Mutationen des Natriumkanals dafür verantwortlich gemacht (Chen et al. 1998, siehe Kapitel 1.5.3)

Klinisch unterscheidet man die ventrikulären von den supraventrikulären und bradykarde (<60 Schläge pro Minute) von tachykarden (>100-120 Schlägen pro Minute) Arrhythmien.

Ursache für kardiale Arrhythmien sind Störungen der Erregungsbildung, der Erregungsleitung sowie die Kombination aus beiden (Hoffman 1999). Diese Störungen können wiederum verschiedene zugrunde liegende Ursachen haben. 


\subsubsection{Die Erregungsbildung und -leitung}

Die elektrischen Impulse für die Herztätigkeit entstehen in spezialisierten Zellen, den Schrittmacherzellen. Diese besitzen die Fähigkeit zur Spontandepolarisation und haben somit kein stabiles Ruhemembranpotential. Im Allgemeinen haben alle Zellen des Erregungsleitungssystems, also der Sinusknoten, der AV-Knoten und das ventrikuläre Reizleitungssystem, die Fähigkeit zur Spontandepolarisation. Unter physiologischen Bedingungen allerdings beginnt die Erregungsbildung im Sinusknoten, da dessen Zellen am schnellsten depolarisieren. Der Sinusknoten ist somit der primäre Schrittmacher. Die so generierte Herzfrequenz beträgt in Ruhe 6080/Minute. Da die anderen Schrittmacherzellen passiv von jeder vom Sinusknoten ausgehenden Erregung depolarisiert werden, kommt es physiologischer Weise nicht zu Interferenzen zwischen den verschiedenen Schrittmachern (Renz-Polster und Krautzig 2008 b).

Vom Sinusknoten aus breitet sich die Erregung über die Vorhöfe aus, ohne direkt auf die Ventrikel übergreifen zu können. Die Isolierschicht des Anulus fibrosus grenzt die Vorhöfe elektrischen von den Ventrikeln ab. Nur der AV-Knoten, der im untersten Vorhofseptum liegt, leitet nach einer deutlichen Verzögerung von $70-110 \mathrm{~ms}$ die Erregung an die Ventrikel weiter. Vom AV-Knoten aus wird die Erregung über die HisBündel, Tawara-Schenkel und das Purkinje-Fasernetz auf die Myokardzellen der Kammern weitergeleitet (Renz-Polster und Krautzig 2008 a).

\subsubsection{Störungen der Erregungsbildung}

Kommt es bei ischämischen oder hypoxischen Prozessen zu Veränderungen der Zellmembran, so dass diese undicht wird und den lonengradienten nicht aufrechterhalten kann, verschiebt sich das Ruhemembranpotential der Zelle auf weniger negative Werte und nähert sich damit dem Schwellenpotential des Natriumkanals. Alle so veränderte Myokardzellen können dann eine intrinsische Aktivität entwickeln und so zu vorzeitigen APs und übersteigerter Automatie führen (Zipes 2003).

Abgesehen von dem beschriebenen Mechanismus der abnormen Aktivität stellt die getriggerte Aktivität einen weiteren wichtigen Mechanismus der Arrhythmieentstehung dar. Sie wird wiederum durch Nachdepolarisationen (engl. afterdepolarizations) hervorgerufen (Abb. 1.11), welche depolarisierende spontane Oszillationen des 
Membranpotentials sind. Sie können entweder vor der vollständigen Repolarisation der Zelle stattfinden und werden dann frühe Nachdepolarisationen (early afterdepolarizations, EADs) genannt (Satoh und Zipes 1998) oder sie treten erst in der Phase IV des Aktionspotentials (siehe Kapitel Aktionspotential) auf, wenn das transmembrane Potential wieder den Wert des Ruhemembranpotentials erreicht hat. Im letzteren Falle spricht man von späten Nachdepolarisationen (delayed afterdepolarizations. DADs, Zipes 2003).

Während als Ursache für EADs vor allem die Verlängerung der Aktionspotentialdauer beispielweise durch einen persistierenden depolarisierenden Natrium- oder Kalziumeinstrom und einen verminderten Kaliumausstrom angesehen werden (Tomaselli und Zipes 2004), liegt die Hauptursache für DADs in der spontanen Kalziumfreisetzung aus dem SR. Die spontane Kalziumfreisetzung führt zu einem Anstieg der zytosolischen Kalziumkonzentration, was wiederum den NCX aktiviert. Dieser schleust die $\mathrm{Ca}^{2+}-$ Ionen aus der Zelle und nimmt $\mathrm{Na}^{2+}$-Ionen in die Zelle auf. Führt der aktivierte transiente Einwärtsstrom des NCX zum Erreichen des Schwellenpotentials, wird ein neues AP generiert (Zipes 2003, Bers 2002). Es konnte gezeigt werden, dass die Hemmung der CaMKII die Entwicklung von DADs (Anderson 2002) und EADs (Anderson et al. 1998, WU et al. 2002) deutlich verringern können, was wiederum nahe legt, dass das Enzym CaMKII eine bedeutende Rolle in der Arrhythmieentstehung spielt.
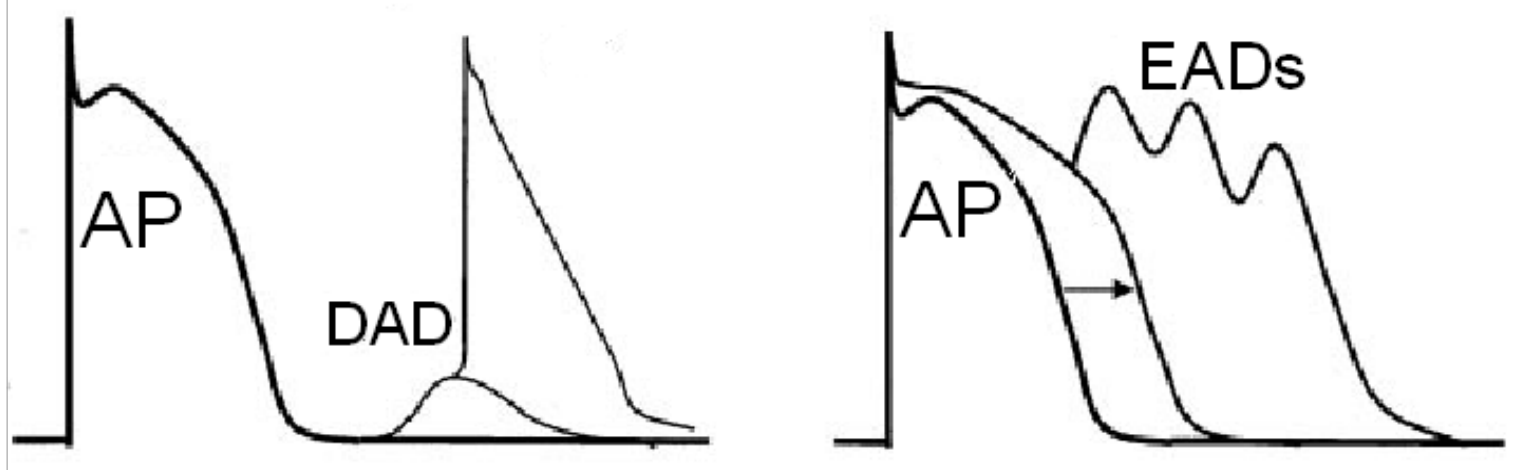

Abb. 1.11: Nachdepolarisationen. Links ist die späte Nachdepolarisation (DAD) dargestellt. Sie entsteht v.a. aufgrund spontaner $\mathrm{Ca}^{2+}$-Freisetzung aus dem SR. Erreicht dabei das Membranpotential der Zelle den Schwellenwert für die $\mathrm{Na}^{+}-\mathrm{Kanäle}$, wird ein neues Aktionspotentials ausgelöst. Rechts sieht man frühe Nachdepolarisationen (EADs). Diese kommen bei verlängerten APs vor und können wie die DADs zu Arrhythmieentstehung beitragen. 
Gemeinsam ist den EADs und DADs die Triggerung durch das vorangehende AP. Ein erwähnenswerter Unterschied liegt darin, dass EADs vor allem bei niedrigen Herzfrequenzen, DADs in erster Linie bei höheren Herzfrequenzen beobachtet werden.

\subsubsection{Störungen der Erregungsleitung}

Breitet sich die Depolarisationswelle langsamer als normal aus oder wird sie teilweise bzw. ganz blockiert, kann es ebenfalls zu Herzrhythmusstörungen führen. Die zwei wichtigen Mechanismen hier sind kreisende Erregungen (Reentry) und Blockierungen. $\mathrm{Zu}$ Blockierungen kommt es, wenn die sarkolemmalen Natriumkanäle sich nicht öffnen, wenn Gap junctions sich schließen, beispielsweise bei Anstieg der intrazellulären Kalziumkonzentration (Weingart 1977) oder durch Narben und Fibrosen.

Kreisende Erregungen entstehen an direkt benachbarten Myokardarealen mit unterschiedlichen elektrophysiologischen Leitungseigenschaften. Man unterscheidet das anatomische vom funktionellen Reentry, bei welchem die Erregung um ein permanent refraktäres Zentrum kreist, dessen Refraktarität wiederum aus der kreisenden Erregung resultiert. Im Gegensatz zum monomorphen Bild des anatomischen Reentry zeigt das funktionelle Reentry eine Variabilität in der Länge der Erregungswellen (Zipes 2003). Andere in der Literatur beschriebenen Reentry-Formen wie anisotropes Reentry, Figure-of-eight-Reentry, Spiral-Wave-Reentry sollen an dieser Stelle nicht weiter ausgeführt werden.

\subsection{Der spannungsabhängige Natriumkanal}

Für alle erregbaren Zellen spielen spannungsabhängige sarkolemmale Natriumkanäle eine entscheidende Rolle. Sie gewährleisten die Depolarisation der Zellmembran, was die Grundlage für Erregung und Fortleitung der Erregung darstellt. Verglichen mit anderen lonenkanälen, die ebenfalls für die Depolarisation von Bedeutung sind, überwiegen die Natriumkanäle zahlenmäßig deutlich mit mehr als 100.000 pro Zelle (Makielski et al. 1987). 


\subsubsection{Aufbau und Funktion des Natriumkanals}

Natriumkanäle bestehen aus einer $\alpha$-Untereinheit, die die eigentliche Durchtrittsstelle für Natriumionen bildet, und zusätzlich 1-3 verschiedene $\beta$-Untereinheiten ( $\beta_{1}, \beta_{2}$ und $\beta_{3}$ ), die regulierende Funktionen haben (Catteral 1992). Die $\alpha$-Untereinheit gehört zu einer lonenkanal-Superfamilie, deren kardiale Isoform Nav1.5 (SCN5A) die mit Abstand am stärksten exprimierte Isoform am Herzen ist.

Die $\alpha$-Untereinheit mit einem Molekulargewicht von ca. 260 kD ist aus vier homologen Domänen (DI-IV) aufgebaut, die jeweils sechs transmembranäre Segmente besitzen (S1-S6). Die eigentliche Pore, deren strukturelle Zusammensetzung sowohl die Leitfähigkeit als auch die Selektivität des Kanals bestimmt, wird durch die Segmente S5 und S6 jeder Domäne gebildet (Marban et al. 1998, Catteral 1992), die extrazelluläre Schleife zwischen den beiden Segmenten (P-Segment) bedingt die Natriumselektivität (Bers 2001).

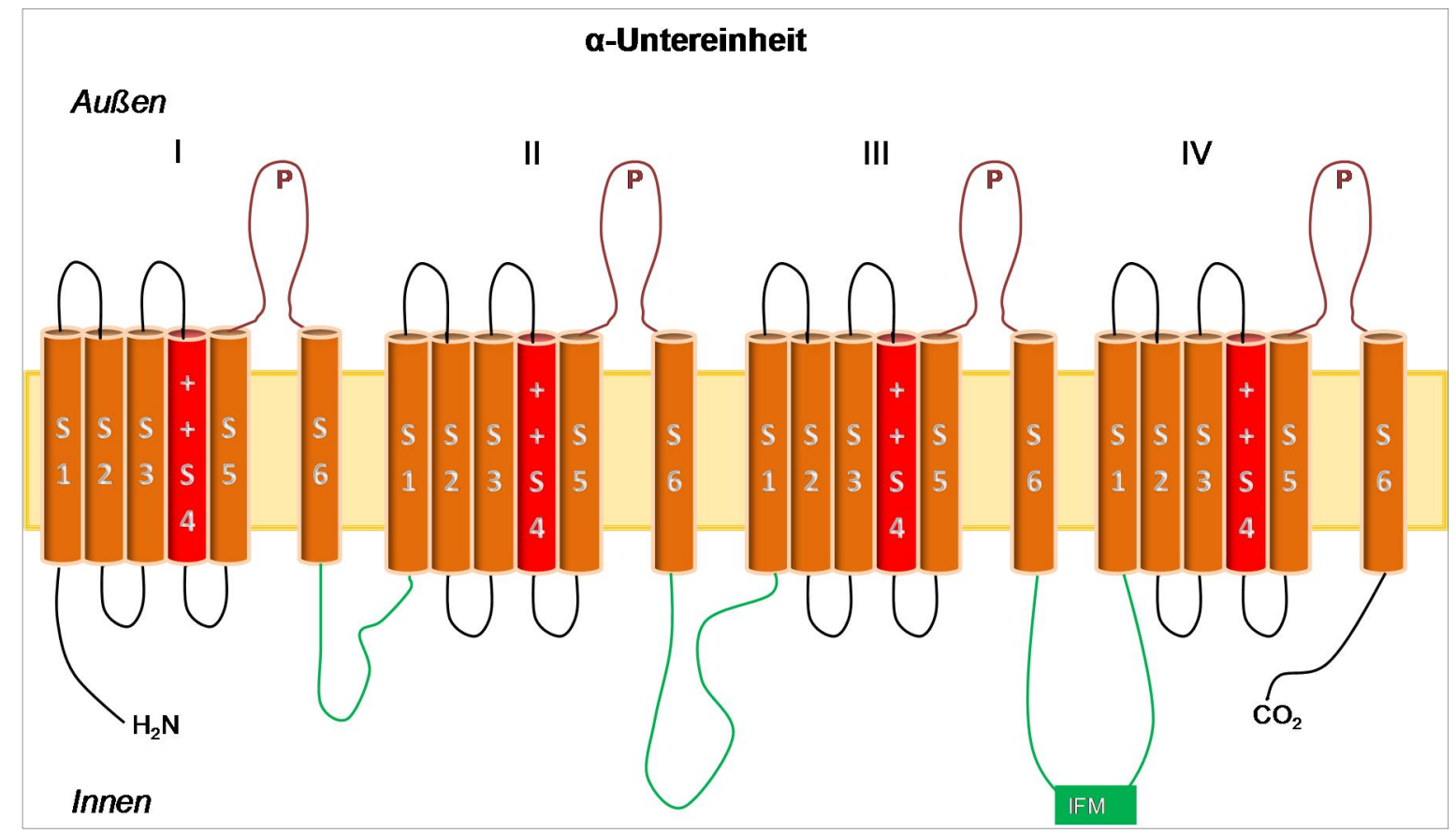

Abb. 1.12: $\alpha$-Untereinheit des Natriumkanals. Dargestellt sind die vier Domänen (IIV) mit den jeweils sechs transmembranen Segmenten (S1-S6). Die Segmente S5 und S6 der jeweiligen Domänen liegen sich gegenüber und bilden die eigentliche Pore, durch welche die Natriumionen einströmen. Die Natriumselektivität wird durch die extrazellulären Schleifen zwischen S5 und S6 (P-Segmente) hervorgerufen (Bers 2001). Das positiv geladene Segment 4 stellt eine Art Spannungssensor dar. Die intrazellulär gelegene IFM-Region auf dem Linker zwischen DIII-DIV ist für die schnelle Inaktivierung des Kanals verantwortlich. 
Das beweglich gelagerte und positiv geladene S4 jeder Domäne dient als Spannungssensor. Auf eine Depolarisation hin öffnet sich der Kanal (Stühmer et al. 1989), indem es zur Verschiebung des S4 nach außen kommt. Diese bewirkt eine Konformationsänderung, die schließlich die Öffnung der Pore nach sich zieht (Bers 2001).

Die durch S4 vermittelte Aktivierung ist direkt an den darauf folgenden Prozess der schnellen Inaktivierung gekoppelt, der innerhalb von wenigen Millisekunden den $\mathrm{Na}^{+}-$ Einstrom beendet (Kontis et al. 1997, Chen et al. 1996, O'Leary et al. 1995). Die Inaktivierung wird wahrscheinlich von einem bestimmten Teil der intrazellulären Verbindung zwischen der Domäne III und IV vermittelt. Diese Region wird durch drei hydrophobe Aminosäuren gebildet: Isoleucin, Phenylalanin und Methionin. Daher wird sie auch als IFM-Region bzw. IFM-Motiv bezeichnet. Sie ist nach einer Aktivierung des Kanals in der Lage, nach kurzer Zeit an die Pore zu binden und über bislang noch nicht geklärten Mechanismen zu einem Schließen der Pore zu führen (Motoike et al. 2004). Es ist sehr wichtig, an dieser Stelle den Zustand des inaktivierten Kanals von dem des geschlossen Kanals zu unterscheiden. Im inaktiven Zustand ist der Kanal geschlossen, jedoch nicht sofort wieder reaktivierbar. Um den Kanal wieder aktivierbar zu machen, muss das S4 zurückbewegt werden, dieses kann nur bei einem negativen Membranpotential erfolgen. Daher bleibt der Kanal solange geschlossen inaktiv, bis das Ruhemembranpotential erreicht wurde.

Durch die sogenannte close-state-Inaktivierung kann der Natriumkanal sogar, ohne sich vorhergeöffnet zu haben, inaktiviert werden (Horn et al. 1999). Das häufig in Studien verwendete Markov Model sieht ein 12-state-model vor: Diese Theorie beschreibt 5 verschiedene geschlossene Zustände des Natriumkanals, 6 inaktivierte Zustände und einen geöffneten Zustand (Armstrong 2006).

Abgesehen von der beschriebenen schnellen Inaktivierung, gibt es noch die intermediäre und die langsame Inaktivierung (Kambouris et al. 1998, Wang et al. 2000). Diese implizieren eine längere Reaktivierungsdauer des Natriumkanals von mehreren Sekunden (Adelman und Palti 1969, Chandler und Meves 1970), welche dazu führt, dass bei wiederholt regelmäßiger zyklischer Aktivierung die Zahl der noch erregbaren Natriumkanäle abnimmt und die Zelle eine verminderte Erregbarkeit aufweist.

Die $\beta$-Untereinheiten haben regulierende Funktionen, die noch nicht definitiv geklärt sind. Es wird vermutet, dass sie die Aktivierung, Inaktivierung und Reaktivierung des 
Kanals beschleunigen können (Makita et al. 1996). LOPEZ-SANTIAGO et al. haben 2007 die Rolle der $\beta_{1}$-Untereinheit mithilfe von Scn1b-Knockout-Mäusen zu erforschen versucht und festgestellt, dass diese Mäuse, bei denen die $\beta_{1}$-Untereinheit nicht regelrecht exprimiert war, im Gegensatz zu Wildtyp-Mäusen einen gesteigerten $\mathrm{Na}^{+}$Strom, eine verlängerte QT-Zeit und ein größeres RR-Intervall im EKG aufzeigen. Die Spannungsabhängigkeit und die grundsätzliche Kinetik des Kanals zeigten allerdings keine Veränderungen in den Scn1b-Knockout-Mäusen.

\subsubsection{Regulationsmechanismen des Natriumkanals}

Die cAMP-abhängige Proteinkinase A (PKA) kann den Natriumkanal an zwei SerinResten an dem Linker zwischen Domäne I und II phosphorylieren (Murphy et al. 1996). Dabei kommt es zu einer Zunahme der Leitfähigkeit dieses Kanals und somit zu einem verstärkten Natriumeinstrom, während die Spannungsabhängigkeit laut einigen Studien unverändert bleibt (Frohnwieser et al. 1997, Schreibmayer et al. 1994).

Die Proteinkinase C (PKC) phosphoryliert ebenfalls den Natriumkanal, allerdings an einem Serinrest an dem Linker zwischen der Domäne III und IV. Die Folge dieser Phosphorylierung ist die Reduzierung des Natriumeinstroms und eine beschleunigte Inaktivierung (Qu et al. 1994, Qu et al. 1996).

Bekannt ist auch eine Regulation des Natriumkanals durch das Calmodulin, welches $\mathrm{Ca}^{2+}$-abhängig an dem IQ-like motif am C-Terminus bindet. Diese Bindung fördert die langsame Inaktivierung des Kanals (Tan et al. 2002).

Kürzlich konnte gezeigt werden, dass der spannungsabhängige Natriumkanal auch von der CaMKII phosphoryliert wird (Wagner et al. 2006, Hund et al. 2010), Es zeigte sich, dass der Natriumstrom durch die CaMKII-abhängige Phosphorylierung deutlich

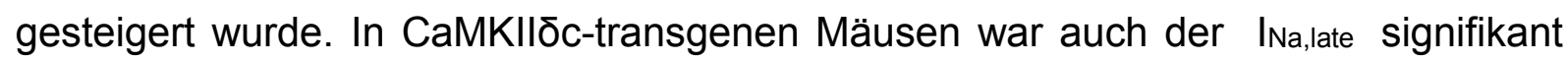
erhöht, während der Spitzennatriumstrom unverändert blieb (Wagner et al. 2006). Die CaMKII-abhängige Regulation des spannungsabhängigen Natriumkanals beeinflusst also die Öffnungswahrscheinlichkeit, jedoch nicht die Menge dieser Kanäle auf der Zellmembran. WAGNER et al. konnten im Rahmen dieser Experimente auch feststellen, dass die CaMKII eine verzögernde Wirkung auf die Erholung des Kanals von der Inaktivierung hatte. Eine andere Arbeitsgruppe konnte zeigen, dass CaMKII teilweise BIv-spectrin-abhängig die Funktion des Natriumkanals beeinflusst, daber 


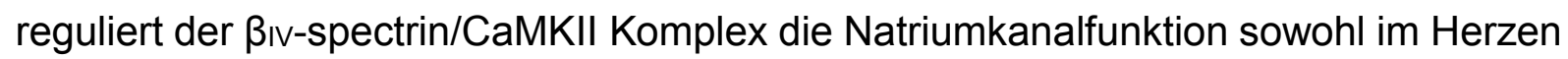
wie auch im Nervensystem (Hund et al. 2010).

Außerdem spielen natürlich die gewebsspezifische Expression der Untereinheiten und Regulationsmechanismen und weitere posttranslationale Modifikationen eine wichtige Rolle in der Funktionsweise des Natriumkanals: Durch das Ubiquitin-ProteasomSystem wird die Anzahl der sarkolemmalen Natriumkanäle reguliert, das 14-3-3n Protein verlagert die Inaktivierungskurve des Kanals in negativere Potentiale und verlangsamt die Erholungsphase, andere Proteine wie die Protein-TyrosinPhosphatase (PTPH1), Telethonin und Plakophilin-2 nehmen ebenfalls Einfluss auf die Kanalfunktion (Abriel 2010).

Im insuffizienten Myokard wird vermehrt durch alternatives Splicing die mRNA der $\alpha-$ Untereinheit verkürzt synthetisiert, welches mittels des sogenannten unfolded protein response (UPR) zu einem nicht-funktionierenden Protein und dadurch einer verminderten Anzahl funktionierender $\mathrm{Na}^{+}-$Kanäle führt (Gao et al. 2013).

Der spannungsabhängige Natriumkanal ist das Ziel einiger Pharmaka bzw. Gifte. Von bestimmten Nervengiften weiß man auch seit Längerem, dass und wie sie den Natriumkanal beeinflussen. Das Tetrodotoxin (TTX) bindet von extrazellulär an der Domäne I an dem Verbindungsstück zwischen S5 und S6 und führt zu einer sehr effektiven Blockierung des Natriumkanals (Lipkind und Fozzard 1994). Seeanemonentoxine (z.B. ATX-II) hemmen die Inaktivierung des Kanals, indem sie an der extrazellulären Verbindung zwischen S3 und S4 der Domäne IV binden (Rogers et al. 1996). Die Bindung von Lokalanästhetika findet wahrscheinlich am S6 der Domäne IV innerhalb der Pore statt (Ragsdale et al. 1994) und führt zu einer beschleunigten Inaktivierung des Kanals (Balser et al. 1996).

\subsubsection{Mutationen des Natriumkanals}

Für das Gen SCN5A, welches für die a-Untereinheit des kardialen Natriumkanals kodiert, sind verschiedene Mutationen bekannt, die zu veränderter Funktion und in der 
Folge einem breiten Spektrum an kardialen Arrhythmien führen können (LehmannHorn und Jurkat-Rott 1999).

Einige dieser Mutationen können zu der erblichen Form des sogenannten Long-QTSyndroms 3 führen. Sie stören die schnelle Inaktivierung des Kanals, was einen anhaltenden Natriumeinstrom während der Plateauphase des Aktionspotentials und eine verzögerte Repolarisation bewirkt (Bennett et al. 1995). Diese Patienten sind anfällig für frühe Nachdepolarisationen, welche in polymorphen ventrikulären Tachyarrhythmien münden können (sogenannte Torsade-de-pointes-Tachykardien). Viele dieser Mutationen betreffen den C-Terminus des Natriumkanals.

Das Brugada-Syndrom (Brugada und Brugada 1992) wird ebenfalls durch eine Reihe an Mutationen des Natriumkanals hervorgerufen, die sich in allen möglichen Regionen des Kanals befinden können (Tan et al. 2003). Diese Mutationen führen entweder zur Expression eines völlig funktionslosen Natriumkanals (Chen et al. 1998) oder zu einer Reduktion der Natriumleitfähigkeit. Es kommt zu einer beschleunigten Repolarisation und im Extremfall zu einer Alles-oder-Nichts-Repolarisation: Entweder der

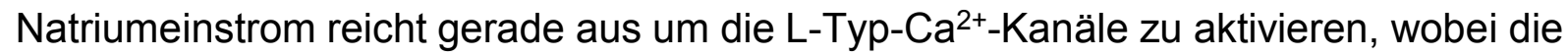
Aktivierung verzögert abläuft mit der Folge eines verlängerten APs („Alles“) oder er ist

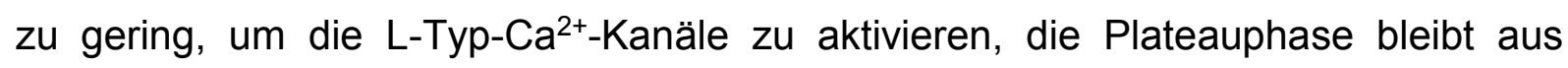
(,Nichts") mit der Folge eines stark verkürzten APs. Das führt zu einer starken Dispersion der Repolarisation zwischen verschiedenen Regionen des Herzens, was sich u.a. in ST-Strecken-Hebungen im EKG manifestieren kann (Antzelevitch 1998).

\subsection{Die NADPH-abhängige Oxidase}

Die NADPH-abhängige Oxidase (Nox) ist ein multimeres transmembranes Enzym und wurde zuerst in Neutrophilen Granulozyten entdeckt, die mithilfe dieses Enzyms zur Zersetzung des phagozytierten Materials reaktive Sauerstoffspezies (ROS), vor allem $\mathrm{O}_{2}^{-}$, herstellen (Babior et al. 2002).

Reaktive Sauerstoffspezies sind definiert als sehr instabile und reaktive Moleküle, die über ein sehr reaktives freies Elektron verfügen und vom Sauerstoff abstammen. Dabei kann man zwischen freien Radikalen wie dem Superoxid $\left(\mathrm{O}_{2}^{-}\right)$und Hydroxidion $\left(\mathrm{OH}^{-}\right)$und Nicht-Radikalen wie dem Wasserstoffperoxid $\left(\mathrm{H}_{2} \mathrm{O}_{2}\right)$ unterscheiden (Kuroda und Sadoshima 2010). 
Nach der ersten Entdeckung der Nox konnte gezeigt werden, dass die Nox in diversen anderen Zellen exprimiert wird, u.a. in Fibroblasten, Endothelzellen und nicht zuletzt in Kardiomyozyten (Brown und Griendling 2009).

\subsubsection{Klassifikation und Struktur der NADPH-abhängigen Oxidase}

Insgesamt lassen sich fünf Isoformen der Nox, also Nox 1-5, und zwei verwandte Oxidasen, Duox1 und Doux2, unterscheiden (Lambeth 2004). Alle Isoformen basieren auf einer katalytischen Einheit und unterschiedlichen regulatorischen Einheiten.

Der Prototyp, die ursprüngliche in Phagozyten entdeckte Nox2, ist Teil eines heterodimeren Membran-gebundenen Cytochrom B-558-Komplexes, welcher aus der katalytischen Untereinheit $\mathrm{gp} 91^{\text {phox }}$ und der regulatorischen Untereinheit $\mathrm{p} 22^{\text {phox }}$ besteht. Hinzukommen zytosolischen Untereinheiten (p40 phox $, p 47^{\text {phox }}, p 67^{\text {phox }}$ und Rac, ein kleines G-Protein). Dabei stellt die gp91phox als ein Membran-integriertes Glykoprotein mit 91kD Molekularmasse die katalytische Domäne dar und beinhaltet an der aminoterminalen transmembranen Region zwei Häms (Komplexverbindungen mit einem Eisenion als Zentralatom und als Ligand ein Porphyrin-Molekül) und NADPH und FAD-bindende Domänen an der C-terminalen zytosolischen Region (Abbildung 1.13). Die NADPH ist die reduzierte Form des Nicotinamidadenindinukleotidphosphats, FAD steht für das Coenzym Flavin-Adenin-Dinukleotid.

Die anderen genannten Bestandteile sind regulatorische Untereinheiten. Die Nox2 ist vor allem auf Plasmamembranen lokalisiert (Brown und Griendling 2009).

Die Nox 1 braucht ebenfalls die regulatorischen Untereinheit $\mathrm{p} 22^{\text {phox }}$, hinzukommen die NOXO1 (NADPH oxidase organizer 1), NOXA1 (NADPH oxidase activator 1) und Rac, die sich alle zu einem Enzymkomplex zusammenfügen (Ambasta et al. 2006, Kajla et al. 2012). Die Nox1 kommt vor allem in der glatten Muskulatur der Gefäße vor (Dikalova et al. 2005).

Die Nox3 kann als Heterodimer mit p22 ${ }^{\text {phox }}$ zusammen funktionieren, ihre Aktivität wird aber durch die Interaktion mit p47 phox und p67 $7^{\text {phox }}$ gesteigert (Hordijk 2006).

Die Nox4 zeigt eine konstitutionelle Aktivität (Martyn et al. 2006) und bindet lediglich p22 ${ }^{\text {phox }}$. Sie ist die Quelle der basalen $\mathrm{O}_{2}$-Produktion (Kuroda et al. 2009). Es konnte gezeigt werden, dass die Nox4 überwiegend in Mitochondrien bzw. in deren Membran lokalisiert ist (Ago et al. 2010). Allerdings sprechen andere Untersuchungen für eine 
Lokalisation im perinukleären endoplasmatischen Retikulum (Zhang et al. 20110). Sie ist aber in der gesunden Herzmuskelzelle nur in geringer Konzentration enthalten (Nabeebaccus et al. 2011).

Die Nox 5 schließlich benötigt keine der bisher erwähnten regulatorischen Einheiten. Sie hat an ihrem aminoterminalen Ende eine Calmodulin-ähnliche Einheit: ein EFMotiv. Das EF-Motiv (auch EF-Hand genannt) ist ein spezifisches Aminosäurenmotiv, das durch die gelandenen Aminosäuren $\mathrm{Ca}^{2+}$ binden kann. Das Binden des $\mathrm{Ca}^{2+}$ resultiert in der Aktivierung des Enzyms (Nabeebaccus et al. 2011). Wie die Nox1 kommt auch die Nox5 vor allem in der glatten Muskulatur der Gefäße vor.

In Kardiomyozyten sind Nox2 (Bendall et al. 2002, Xiao et al. 2002) und Nox4 (Li et al. 2006, Byrne et al. 2003) die vorherrschenden Isoformen.

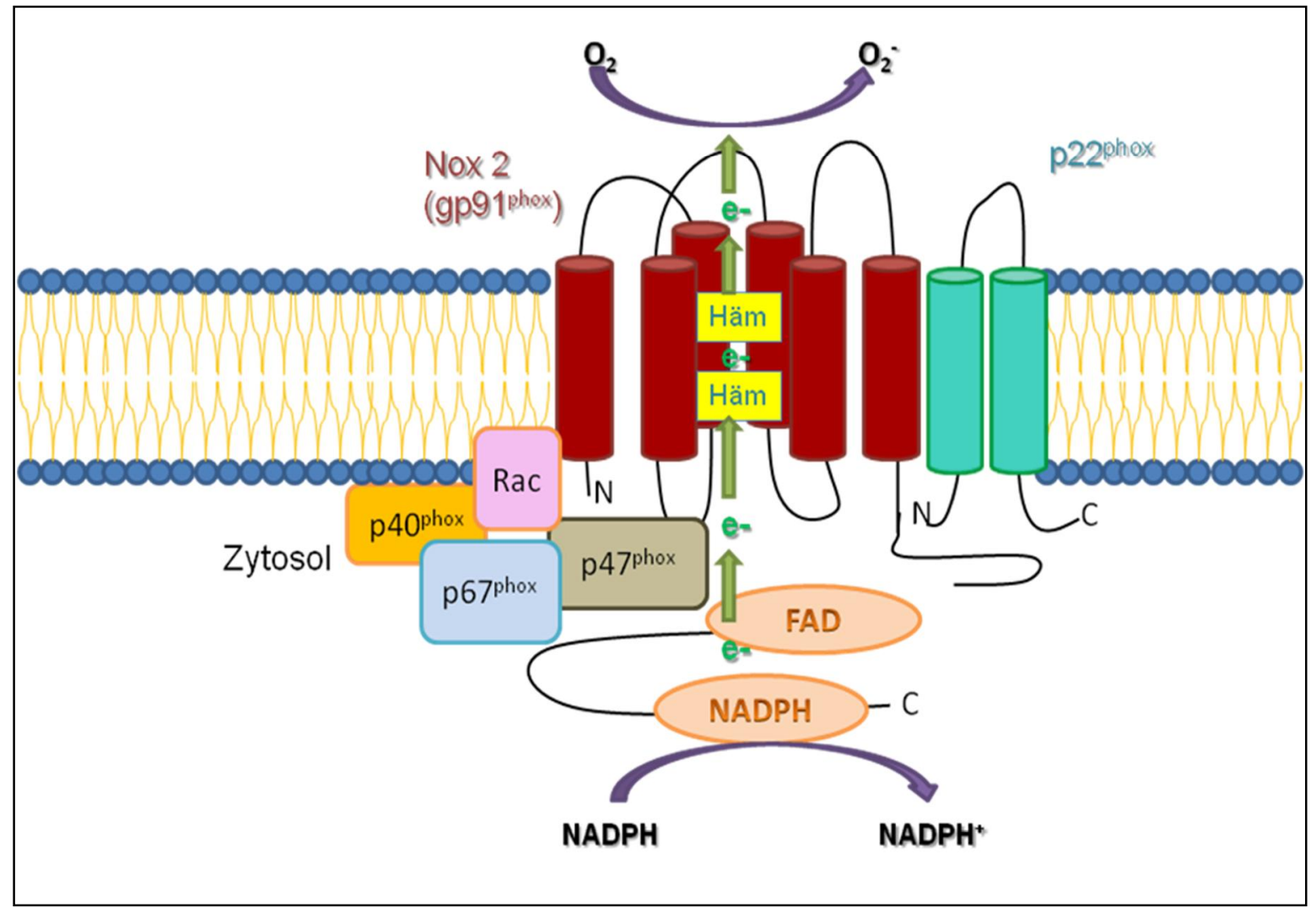

Abb. 1.13: Schematische Darstellung der Nox2, die ein Heterodimer mit dem p22 ${ }^{\text {phox }}$ bildet und zur zytosolischen Seite hin an die regulatorischen Untereinheiten p40 phox, p47 phox, p67phox und Rac gebunden ist. Wie auch andere Isoformen der Nox, besitzt die Nox2 einen kompletten Apparat zum Elektronentransfer. Die NADPH- und FAD-Bindungsstellen (in der Abbildung als Ovale dargestellt) sind zur zytosolischen Seite hin gerichtet. Die roten Zylinder repräsentieren die sechs transmembranen $\alpha$-Helices (Garrido und Griendling 2009, Kuroda und Sadoshima 2010). 


\subsubsection{Aktivierung und Funktion der NADPH-abhängigen Oxidase 2}

Die NADPH-abhängige Oxidase 2 kann in kardiovaskulären Zellen durch diverse Mechanismen aktiviert werden (Lassegue und Clempus 2003, Clempus und Griedling 2006). Ein wichtiger Mechanismus ist die Stimulation G-Protein-gekoppelter Rezeptoren, wie z.B. durch Angiotensin II (Griendling et al. 1994), Endothelin-1 und aadrenerge Agonisten. Daneben sind auch andere Aktivierungen bekannt: durch Wachstumsfaktoren (z.B. VEGF), durch Zytokine, wie z.B. TNF- $\alpha$ (Nabeebacus et al. 2011), durch metabolische Faktoren wie Insulin und Glukose (Akki et al. 2009) oder auch durch mechanische Belastung (Li et al. 2002). PROSSER et al. konnten 2011 zeigen, dass es auch schon bei physiologischer Dehnung der Herzmuskelzelle Microtubuli-vermittelt über eine Mechanotransduktion zu einer Aktivierung der Nox2 kommt. Bekannt war, dass bereits eine kleine Dehnung von 8\% zu einer Zunahme der $\left[\mathrm{Ca}^{2+}{ }^{2}\right.$ führte (Iribe et al. 2009). PROSSER et al. konnten zeigen, dass die Dehnung der Zelle zu einer Aktivierung der Nox2 führt, welche daraufhin vermehrt ROS produziert, diese oxidieren den RyR (Ullrich et al. 2009), woraufhin dieser vermehrt $\mathrm{Ca}^{2+}$ ins Zytosol ausschüttet.

Nicht zuletzt ist zu beachten, dass das Vorhandensein der NADPH als ein ElektronDonor essentiell für die Nox ist; somit beeinflusst die Menge der NADPH ebenfalls die Aktivierung der Nox2 (Gupte 2008). NADPH wird im Zytosol über den Pentosephosphatweg und in den Mitochondrien im Zuge des Krebs-Zyklus generiert (Aon et al. 2010).

Bei einer Aktivierung der Nox2 translozieren die zytosolischen Untereinheiten und binden an den beiden membrangebundenen Einheiten (Abbildung 1.14). Im aktivierten Zustand transferiert der Enzym-Komplex ein Elektron von der NADPH auf ein $\mathrm{O}_{2}$ und produziert damit ein Superoxid, nebenbei wird ein Proton über die Membran gepumpt (Kishida und Klann 2007).

Während die $\mathrm{O}^{2-}$-Produktion von Nox2 als induzierbar gilt, weil die Nox2 nach einer Stimulation eine schnelle und massive Antwort liefert und daher auch "respiratory burst“ genannt wird, finden Veränderungen in der Aktivität der Nox4 auf der Transkriptionsebene statt und zeigen sich somit erst mit einer gewissen zeitlichen Verzögerung (Serrander et al. 2007). 
Die Aktivität von Nox2 führt langfristig zu interstitieller Fibrose und Hypertrophie der Kardiomyozyten (Bendall et al. 2002, Byrne et al. 2003).

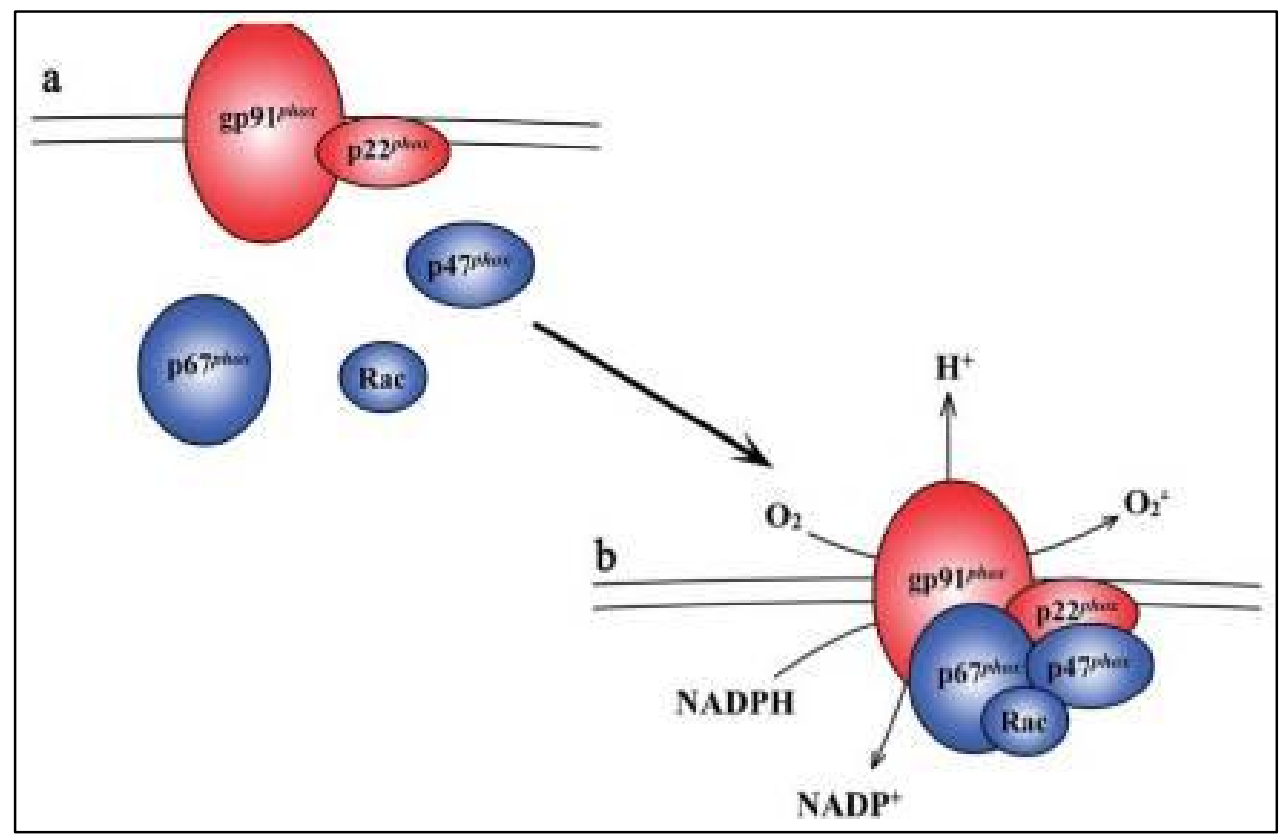

Abb. 1.14: Schematische Darstellung der Membrantranslokation der regulatorischen Untereinheiten. a zeigt den inaktiven und b den aktiven Zustand (aus Kishida und Klann 2007, Seite 21).

\subsubsection{Die Wirkung der ROS auf die Herzmuskelzelle}

ROS oxidieren SH-Gruppen von Cystein- und Methionin-Resten in Proteinen und bewirken so eine Veränderung der Tertiär-/ und Quartärstruktur derselbigen. Die Folge daraus ist eine veränderte Funktion der Proteine (Wagner et al. 2013).

Es gibt zwei Arten der ROS-abhängigen Modifikation der kardialen lonenkanäle: ROS können direkt freie SH-Gruppen in funktional-relevanten Bereichen der lonenkanäle oxidieren oder sie oxidieren Kinasen und Phophatasen, die bekanntermaßen die Funktion der lonenkanäle beeinflussen; zu diesen Kinasen gehören PKA, PKC und CaMKII (Sag et al. 2013). Da ROS sehr reaktive Moleküle sind, ist deren intrazelluläre Diffusion sehr beschränkt und sie können nur sehr nah gelegene Zielstrukturen beeinflussen.

Durch die Oxidation von Methionin 281/282 an der regulatorischen Einheit der CaMKII bewirken ROS eine CaMKII-Aktivierung, die äquivalente Eigenschaften hat wie eine Aktivierung durch Phosphorylierung (Erickson et al. 2008). Die aktivierte CaMKII kann in der Herzmuskelzelle dann die Funktion vieler Proteine verändern, die an der elektromechanischen Koppelung beteiligt sind (siehe Kapitel 1.3.3). 
Die PKA, welche normalerweise durch cAMP aktiviert wird, kann durch ROS am Typ 1 der regulatorischen Einheit oxidiert und somit CAMP-unabhängig aktiviert werden (Brenann et al. 2006). Die PKA reguliert ebenfalls diverse Proteine, die den $\mathrm{Ca}^{2+}-$ Haushalt und somit auch die elektromechanische Koppelung beeinflussen, wie z.B. RyR, PLN und den L-Typ-Ca ${ }^{2+}-K a n a l$. Außerdem kann sie Troponin I phosphorylieren, was die Sensitivität der Myofilamente für $\mathrm{Ca}^{2+}$ reguliert (Ramirez-Correa et al. 2010). Die PKC wird durch niedrige ROS-Konzentrationen $\left(50 \mu \mathrm{mol} / \mathrm{l} \mathrm{H}_{2} \mathrm{O}_{2}\right)$ ebenfalls aktiviert, dabei wird die regulatorische Einheit oxidiert, was zu einer $\mathrm{Ca}^{2+}$-unabhängigen PKCAktivierung führt. Eine sehr hohe ROS-Konzentration (5 mmol/l $\mathrm{H}_{2} \mathrm{O}_{2}$ ) bewirkt eine irreversiblen Hemmung des Enzyms. Die PKC führt u.a. zu einer geringeren $\mathrm{Ca}^{2+}$ Sensitivität der Myofilamente (Wang et al. 2006).

Außerdem wirken ROS auch direkt auf die zellulären lonenkanäle: So steigern ROS den späten Natriumeinstrom (Ma et al. 2005), hemmen die $\mathrm{Na}^{+} / \mathrm{K}^{+}$-ATPase (Kukreja et al. 1990) und bewirken so eine Natriumüberladung des Zytosols. Die erhöhte intrazelluläre Natriumkonzentration führt dazu, dass der $\mathrm{Na}^{+} / \mathrm{Ca}^{2+}$ Austauscher (NCX), der normalerweise 3 Natriumionen entlang des Konzentrationsgefälles von außen nach innen und dabei ein $\mathrm{Ca}^{2+}$-Ion von innen nach außen transportiert, nun in umgekehrter Richtung agiert, weil die treibende Kraft, der Natriumgradient über der Zellmembran, durch die Wirkung der ROS wegfällt. Das Ergebnis ist, dass der NCX $\mathrm{Ca}^{2+}-$ Ionen in die Zelle pumpt anstatt sie aus der Zelle zu schaffen und so die $\mathrm{Ca}^{2+}$ Überladung des Zytosols weiter fördert (Wagner et al. 2003; Wagner et al. 2011; Giordano 2005).

Darüber hinaus steigern ROS die Öffnungswahrscheinlichkeit des RyR (Boraso und Williams 1994) und hemmen die SERCA (Morris und Sulakhe 1997), was insgesamt dann zu einer $\mathrm{Ca}^{2+}$-Überladung im Zytosol führt.

Langfristig führt übersteigerte ROS-Produktion unter anderem zu Zellhypertrophie und Zellapoptose in der Herzmuskelzelle und spielt laut mehrerer Studien eine entscheidende Rolle in der Entwicklung der Herzinsuffizienz (Sawyer et al. 2002, Ide et al. 2000, Suematsu et al. 2003).

\subsubsection{Hemmung der NADPH-abhängigen Oxidase}

Als zwei spezifische Inhibitoren der Nox in vivo haben sich die gp91ds-tat und das Apocynin erwiesen, andere in vitro getestete Inhibitoren sind Diphenyleniodonium, 
Aminoethyl Benzenesulfono Fluoride, S17834, PR39, Proteinkinase C Inhibitoren und VAS2870 (Williams und Griendling 2007). In dieser Arbeit wurde das Diphenyleniodonium (DPI) als Inhibitor der Nox2 verwendet. DPI, ein Flavoproteininhibitor, bindet am Redox-Kernstück und verhindert damit den Elektronentransport (O'Donnell et al 1993, Doussier et al. 1999).

\subsection{Angiotensin II}

Angiotensin II ist ein endogenes zirkulierendes Peptidhormon und der Effektor des Renin-Angiotensin-Systems, welches erstmals 1898 von TIGERSTEDT und BERGMAN beschrieben wurde. Neben seiner bekannten Rolle im Volumen- und Elektrolytenhaushalt und seines vasokonstriktorischen Einflusses auf die glatte Gefäßmuskulatur (Timmermans et al. 1993, Nguyen 2011) konnten diverse Studien auch Einflüsse auf die Kardiomyozten nachweisen (Koch-Weser 1965, Drimal und Boska 1973, Moravec et al. 1990).

Im Rahmen des klassischen Renin-Angiotensin-Systems (RAS) wird das Prohormon Angiotensinogen, welches in der Leber gebildet wird und aus 452 Aminosäuren besteht (Ohkubo et al. 1983), durch das Enzym Renin in Angiotensin I gespalten. Das Substrat Angiotensin I wird weiter gespalten durch das Angiotensin-spaltende Enzym (ACE, angiotensin-converting enzyme). Dabei entsteht das Angiotensin II (Ang II). Dieses aktive Octapeptid wurde erstmals 1940 gleichzeitig von BRAUN-MENÈNDEZ in Argentinien und PAGE und HELMER in den USA entdeckt. Das Renin-AngiotensinSystem hat multiple Effekte auf der Zellebene, über Geweben bis hin zum Organismus. Daher liegt es nahe, dass es auf jeder dieser Ebenen individuell reguliert wird.

Ang II bindet an zwei spezifische und ubiquitär vorkommende G-Protein-gekoppelte Rezeptoren, Ang II-Rezeptor 1 (AT1) und Ang II-Rezeptor 2 (AT2). Die AT1-vermittelte Wirkung auf die glatte Gefäßmuskulatur bewirkt eine Vasokonstriktion, währende die AT2-vermittelte Wirkung genau das Gegenteil, nämlich die Vasodilatation, hervorruft. 


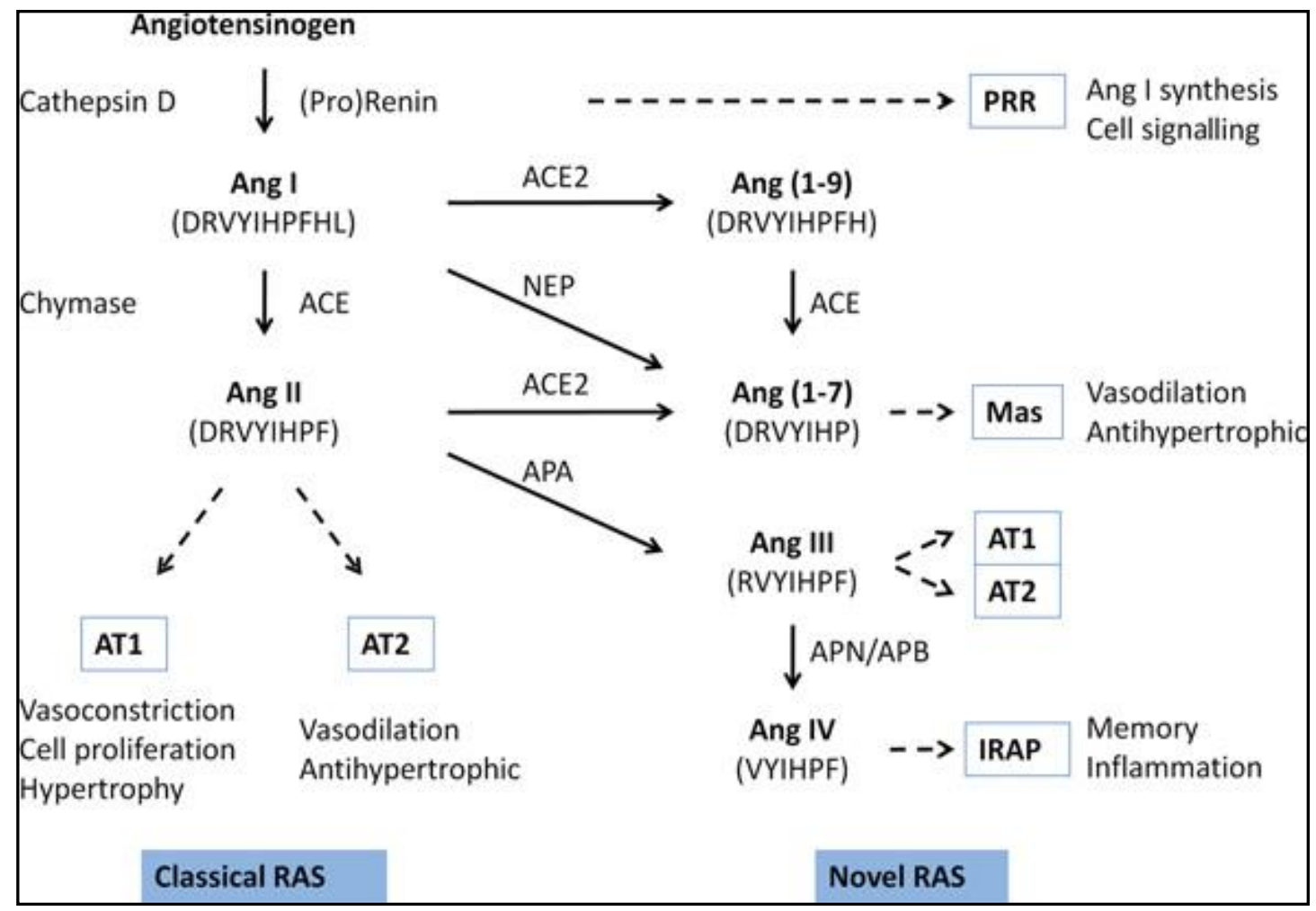

Abb. 1.15: Das klassische (links) und das neue Renin-Angiotensin-System (RAS). Im Rahmen des klassischen RAS wird das Prohormon Angiotensinogen durch das Enzym Renin in Angiotensin I (Ang I) gespalten, welches wiederum durch ACE in Ang II gespalten wird. In bestimmten Geweben oder unter pathophysiologischen Bedingungen können auch die Enzyme Cathepsin D und Chymase diese Spaltungen vornehmen. Ang II agiert über die $A T_{1}$ und $A T_{2}$, welche teilweise gegensätzliche biologische Effekte haben. Das neue Modell des RAS beinhaltet Auswirkungen verschiedener Fragmente des Ang II: Ang-(1-7), Ang III, und Ang IV. Auch das (Pro)renin (PRR) zeigt eigene Effekte auf intrazelluläre Signalkaskaden. APA steht für Aminopeptidase A, APB steht für Aminopeptidase B, APN für Aminopeptidase N, NEP steht für Neutrale Endopeptidase (aus Kumar et al. 2012, Seite 274).

Die Effekte auf den Elektrolyten- und Volumenhaushalt werden durch die induzierte Sekretion des Aldosterons in der Nebenniere hervorgerufen (Nguyen et al. 2011). Das neue Modell des RAS berücksichtigt weitere Fragmente des Ang I und Ang II. Das Heptapeptid Ang (1-7) zum Beispiel ist ein Ligand des G-Protein-gekoppelten Rezeptors Mas (Santos et al. 2003) und führt über den Phosphatidylinositol-3-KinaseSignalweg zur NO-Ausschüttung (Sampaio et al. 2007). Es soll das Ang II - induzierte Remodeling (s.u.) verhindern (Grobe et al. 2007). 


\subsubsection{Die akuten Effekte des Angiotensin II am Herzen}

Die direkten Effekte des Angiotensin II in Kardiomyozyten betreffen vor allem die Kontraktilität, die Arrhythmieentstehung und die Apoptose-Induktion.

Die Effekte auf die kardiale Kontraktilität werden in den verschiedenen Studien kontrovers diskutiert. Während einige Studien dafür sprechen, dass Ang II einen positiv inotropen Effekt hat (Koch-Weserr 1965, Drimal und Boska 1973, Ikenouchi et al. 1994), zeigen andere, dass es keinen Effekt auf die Kontraktilität hat (Ito et al. 1997), während wiederum andere Studien sogar einen unter Umständen negativ inotropen Effekt postulieren ( $\mathrm{Li}$ et al. 1994). Diese Kontroverse kann unter anderem durch Unterschiede zwischen den verschiedenen Spezies zustande kommen (Ishihata und Endoh 1994). Insgesamt geht man von einem positiv inotropen Effekt des Ang II aus, der durch eine höhere intrazelluläre Kalziumkonzentration und/oder durch eine erhöhte Sensitivität der Myofilamente für Kalzium zustande kommen kann (Mattiazzi 1997). In Mäusen, die den Angiotensin II - Rezeptor I überexprimieren, konnte bereits vor einer Hypertrophieentwicklung eine veränderte Kontraktilität in den Kardiomyozyten nachgewiesen werden (Rivard et al 2011), was den Hypertrophie-unabhängigen Effekt des Ang II auf die Kontraktilität der Herzmuskelzellen nahelegt.

Bezüglich des Arrhythmie-begünstigenden Effektes konnte gezeigt werden, dass es durch die Zugabe von 1-2 $\mu \mathrm{M}$ Ang II innerhalb von Minuten verstärkt zu getriggerter Aktivität, vor allem zu EADs, kommt (Zhao et al. 2011). Dabei stimuliert das Ang II über den AT1-Rezeptor die Nox (Palomeque et al. 2009), die daraufhin ROS produziert, welche die CaMKII aktivieren (siehe Kapitel 1.3.2). Diese aktivieren dann die L-Typ$\mathrm{Ca}^{2+}-K a n a ̈ l e ~ u n d ~ d e n ~ s p a n n u n g s a b h a ̈ n g i g e n ~ N a t r i u m k a n a l$, welche wiederum die Entwicklung von getriggerter Arrhythmie beeinflussen (Zhao et al. 2011). In anderen Studien zeigte sich, dass der Einsatz von AT1-Rezeptor-Blockern wie Sartane oder ACE-Hemmern ventrikuläre und supraventrikuläre Arrhythmien signifikant reduzieren (Garg et al. 2006, Makkar et al. 2009).

Der Apoptose-begünstigende Effekt des Ang II tritt zwar nicht nach wenigen Minuten ein, aber bereits 24 Stunden nach der Zugabe von 100 nM Ang II konnte eine Zunahme der apoptotischen Zellen nachgewiesen werden (Schröder et al. 2006). Eine Beteiligung der Nox (Qin et al. 2006) sowie auch der CaMKII (Palomeque et al. 2009) an diesem Effekt des Ang II konnte auch hier gezeigt werden. 


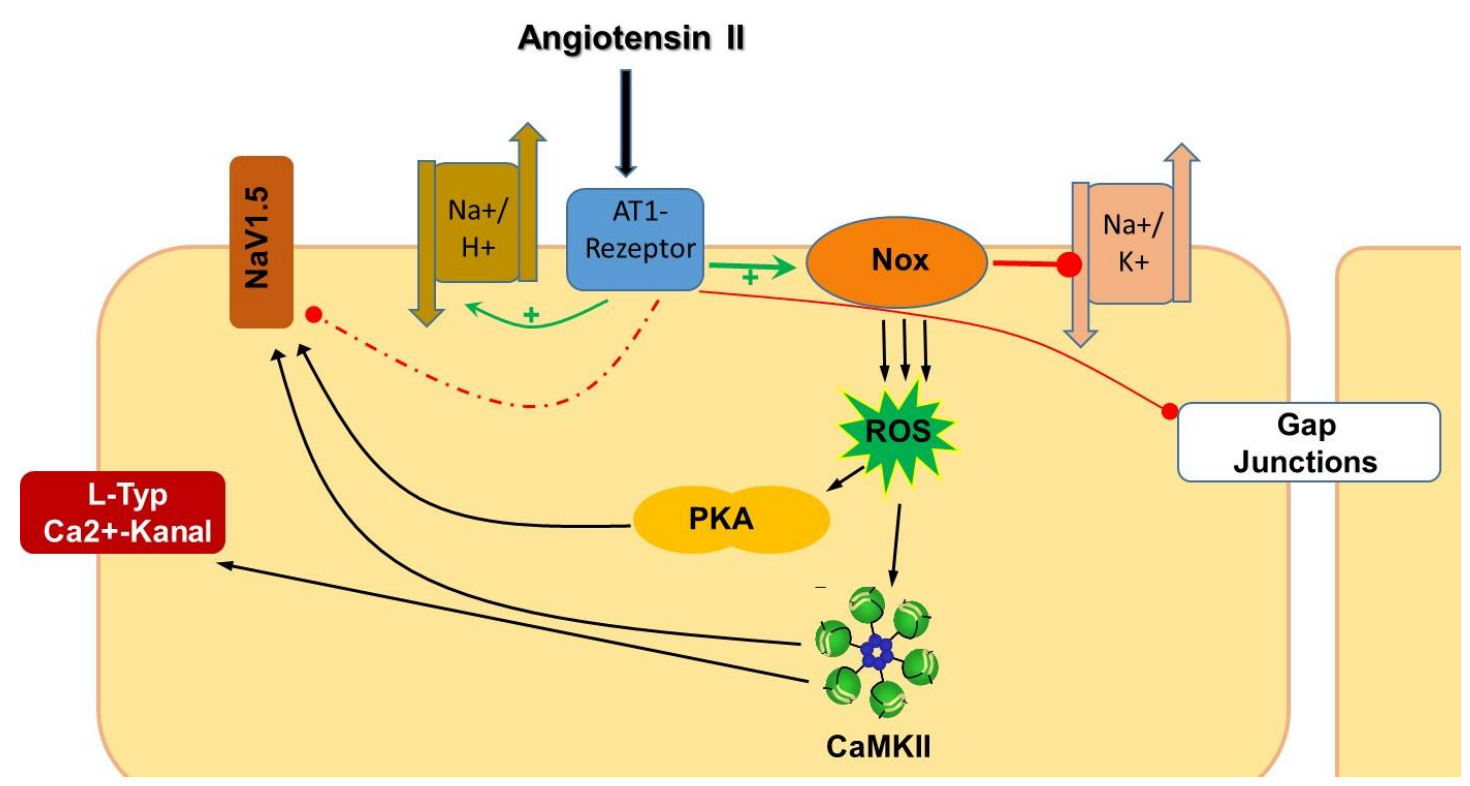

Abb. 1.16: Die Wirkung des Ang II auf die Proteine der Elektromechanischen Koppelung. Über den AT1Rezeptor aktiviert Ang II die Nox, welche vermehrt ROS produziert, die weiderum unter anderem die PKA und die CaMKII aktivieren. Beide Proteine aktivieren den spannungs-abhängigen Natriumkanal (Nav1.5). Allerdings führt eine chronische Stimulation (gestrichelte Linie) mit Ang II zu einer Expressionsabnahme der Nav1.5 im Sarkolemm. Ang II fördert außerdem die Aktivität des $\mathrm{Na}^{+}-\mathrm{H}^{+}-$ Austauschers und vermidert die Leitfähigkeit der Gap junction.

\subsubsection{Die Bedeutung des Angiotensin II für das kardiale Remodeling}

Die Langzeiteffekte des Ang II bewirken durch vermehrte Hypertrophie, Entzündungsreaktion und Fibrose ein kardiales Remodeling, das langfristig die Herzinsuffizienz hervorruft oder verstärkt. Auch führt Ang II zu einem elektrischen Remodeling, indem bestimmte lonenkanäle und -transporter vermehrt aktiviert werden (Abbildung 1.16). Zum Beispiel steigert Ang II die Aktivität des $\mathrm{Na}^{+} \mathrm{H}^{+}$-Austauschers (Matsui et al. 1995 a) und des $\mathrm{Cl} / / \mathrm{HCO}_{3}-$ Austauschers (Camilión de Hurtado et al. 1998), während es eine Inhibition der $\mathrm{Na}^{+}-\mathrm{K}^{+}-\mathrm{Pumpe}$ via PKC-abhängiger Aktivierung der Nox hervorruft (White et al. 2009) und es verstärkt auch den $\mathrm{Ca}^{2+}$-Einstrom über

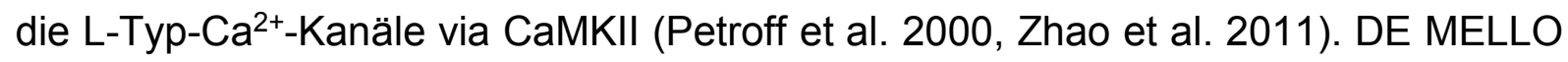
konnte bereits 1996 in kardiomyopathischen Herzmuskelzellen von Hamstern zeigen, dass Ang II die Leitfähigkeit der gap junction signifikant herabsetzt und somit die Erregungsleitung im Herzen stört.

Ang II spielt eine entscheidende Rolle in der Entwicklung kardialer Hypertrophie; es sind dabei mehrere verschiedene Signalkaskaden, u.a. die Proteinkinase $C$ und die Mitogena-aktivierte Proteinkinasen (MAPKs), involviert (Sugden und Clerk 1998). 
Über eine Aktivierung der ADPR-Zyclase führt Ang II zur Aktivierung von Src, PI 3kinase/Akt, und PLC-gamma1/IP(3) und trägt zur kardialen Hypertrophie bei (Gul et al. 2008).

Schon vor vielen Jahren konnte gezeigt werden, dass Ang II die Nox aktivieren kann (Griendling et al. 1994). Die erhöhte ROS-Produktion durch Ang II ist ebenfalls ein entscheidender Faktor für die Hypertrophieentwicklung, da ROS mitogene Effekte auf die Zelle haben und so zu Hypertrophie führen können (Ushio-Fukai et al. 1996). Auch bewirkt Ang II Entzündungsreaktionen ist der Zelle (Mann 2002), welche wiederum zu vermehrter Fibrosebildung führen (Frangogiannis 2004). 


\subsection{Hypothesen und Fragestellungen}

Es ist bekannt, dass Angiotensin II verschiedene Effekte auf die Herzmuskelzelle haben kann, unter anderem über Aktivierung der Nox2 aber auch durch die Wirkung verschiedener Second Messenger. Des Weiteren ist bekannt, dass im Rahmen der Herzinsuffizienzentwicklung Expression und Aktivität der CaMKII gesteigert sind ( $\mathrm{HOCH}$ et al. 1999). Mehr noch, es konnte gezeigt werden, dass eine gesteigert CaMKII-Aktivität die Entwicklung einer kardialen Hypertrophie (ZHANG 2007) und Herzinsuffizienz (Maier 2003) vermittelt. Die Mechanismen der CaMKII-Aktvierung jedoch, wie auch der Einfluss der aktivierten CaMKII auf Aktionspotentiale und Arrhythmogenese sind bisher nur unzureichend erforscht.

In dieser Arbeit möchte ich prüfen:

1. Welche Rolle spielt Ang II bei der Regulation der Aufstrichgeschwindigkeit und Aktionspotentialdauer?

a. Kann Ang II die Aufstrichgeschwindigkeit des Aktionspotentials beschleunigen?

b. Führt die Ang II induzierte Stimulation zu einer signifikanten Veränderung der Aktionspotentialdauer?

2. Welche Rolle spielen Nox2 und CaMKII $\delta_{c}$ bei der Regulation der Aufstrichgeschwindigkeit und der Aktionspotentialdauer?

a. Kann die Ang II induzierte Regulation der Aufstrichgeschwindigkeit durch Hemmung der CaMKII $\delta_{\mathrm{c}}$ oder der Nox2 verhindert werden?

3. Kommt es unter Stimulation durch Ang II zu vermehrter getriggerter Aktivität in Form von EADs oder DADs?

a. Über welchen Mechanismus führt Ang II zu vermehrter Arrhythmie?

b. Welche Rolle spielt dabei die CaMKII $\delta_{c}$ und welche Rolle die Nox2? 


\section{Material und Methoden}

\subsection{Die genetisch veränderte Maus}

Für die Experimente dieser Doktorarbeit wurden zwei Mauslinien (jeweils Wildtyp- und Knockout-Geschwister) untersucht. Es handelt sich dabei um den Knockout der $\delta$ Isoform der CaMKII (CaMKIII---, Backs et al. 2009) und den Knockout der katalytischen Untereinheit der NADPH Oxidase 2 (gp91 phox-- $^{\text {, }}$ Pollock et al. 1995).

\subsubsection{Das Prinzip der Knockout-Maus}

Knockout-Mäuse sind Mäuse, die durch genetische Manipulation (Gene targeting) ein oder mehrere deaktivierte Gene haben. Um diesen Zustand zu erreichen, werden aus Blastozysten von Inzuchtmäusen embryonale Stammzellen entnommen und in vitro kultiviert. Anschließend wird ein Inaktivitätsvektor z.B. durch Elektroporation (mittels eines elektrischen Felds) in die Stammzelle übertragen. Der Inaktivitätsvektor ist ein künstlich hergestellter DNA-Abschnitt, der aus dem zu inaktivierenden Gen besteht, das deergestalt mutiert ist, dass es nicht transkribiert wird (bzw. das entstehende Protein inaktiv ist).

Einige der so behandelten Stammzellen haben durch das natürliche Prinzip der homologen Rekombination den neuen DNA-Abschnitt anstelle des funktionsfähigen Gens in ihre Chromosomen eingebaut. Dieses ist möglich, da die neue und die alte DNA-Sequenz sich sehr ähneln. Die homologe Rekombination tritt jedoch nur sehr selten auf. Deshalb benötigt man einen Resistenzfaktor, der mit dem Gen übertragen wird. Die so veränderte Stammzelle kann nach Inkorporation des mutierten DNA Abschnittes einen Resistenzfaktor für ein Zytostatikum (z.B. Neomycin) exprimieren. Die mit Neomycin behandelten Stammzellen, welche resistent sind können sich weiter teilen und haben gewissermaßen einen Selektionsvorteil, während die Wildtypen „ausselektiert“ werden.

Anschließend werden die erfolgreich veränderten Stammzellen in eine MausBlastozyste übertragen und einer vorbehandelten Empfängermaus (Ammenmaus) eingepflanzt. Die so entstandenen chimären Mäuse, die sowohl veränderte wie nicht 
veränderte Zellen in allen Geweben enthalten, werden mit Wildtyp-Mäusen weiter gekreuzt. Die meisten dabei entstehenden Mäuse sind homozygot gesund, aber einige von innen tragen das veränderte Gen, weil die Ei- bzw. Samenzelle von der eingesetzten Stammzelle stammt. Diese Tiere sind uniform heterozygot und haben im Gegensatz zu den chimären Mäusen in allen Zellen dieselbe genetische Information, nur liegt diese Information in jeder diploiden Zelle einmal in nicht veränderter und einmal in veränderter Form vor (heterozygot). Kreuzt man diese untereinander, erhält man in $25 \%$ der Fälle homozygote Mäuse, die nur noch das inaktive Gen besitzen (Capecchi 1989).

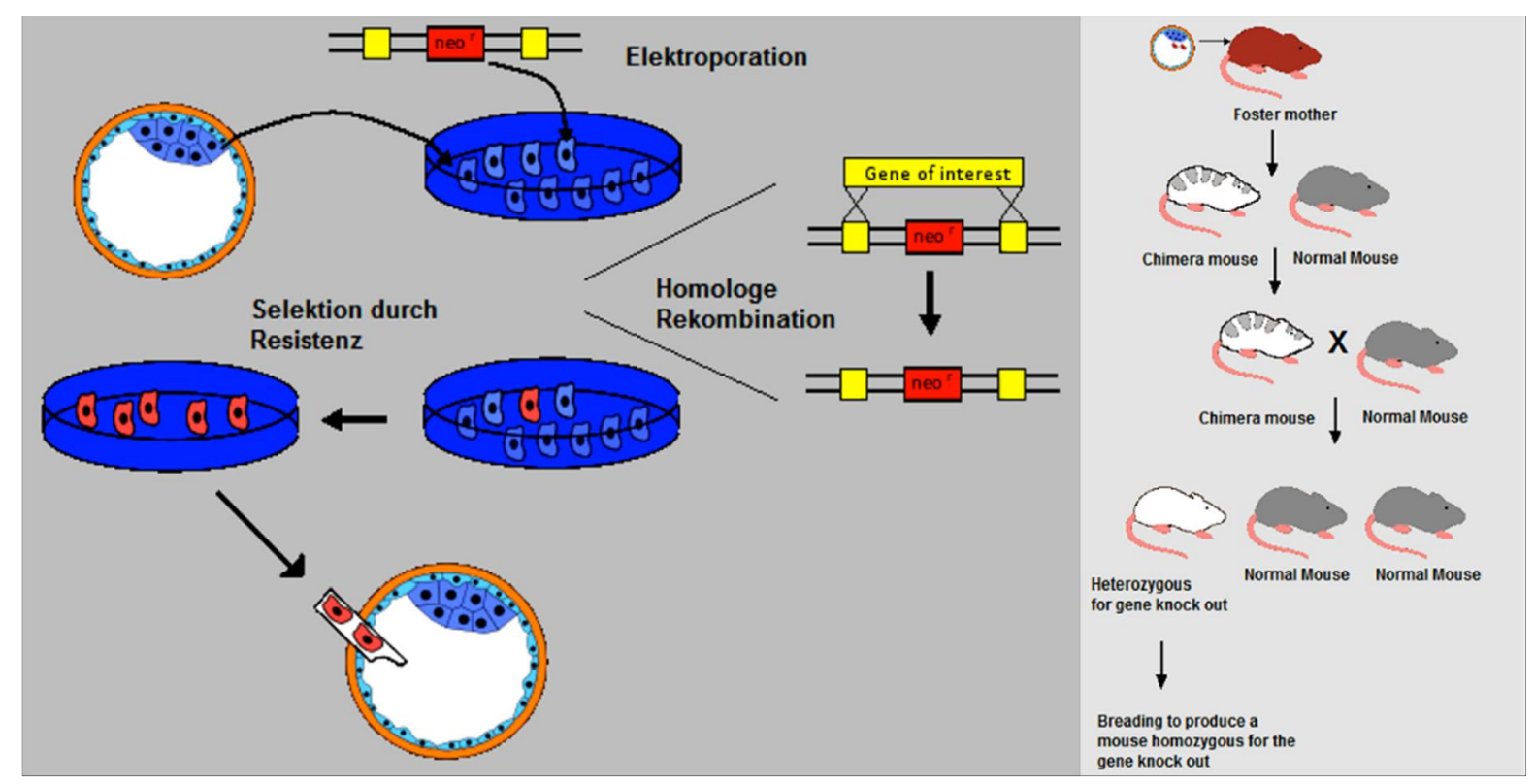

Abb. 2.1: Herstellung der Knockout-Maus schematisch dargestellt (modifiziert nach http://upload.wikimedia.org/wikipedia/commons/thumb/b/bf/Knockout_mouse_production_2.svg/566px -Knockout_mouse_production_2.svg.png)

\subsubsection{Herstellung der CaMKII-Knockout- und der gp91 $1^{\text {phox }}$-Knockout-Maus}

Bis 2009 war die CaMKIla die einzige Isoform der CaMKII, bei der es gelungen war, das dafür codierende Gen in experimentellen Versuchen auszuschalten. 2009 gelang es erstmals, ein entsprechendes Verfahren für die CaMKIIס zu finden, welche die im Myokard häufigste Isoform ist (Backs et al. 2009). Ihre Aktivität wird mit pathologischer Hypertrophie und strukturellen Veränderungen in der Myokardzelle in Verbindung gebracht (siehe Einleitung). 
Das Verfahren zur Ausschaltung des Genprodukts CaMKIIס sieht vor, Exon 1 und 2 des codierenden Gens auszuschalten bzw. herauszuschneiden. Die beiden Exons kodieren für die katalytische Domäne des Proteins und insbesondere für die ATPBindungsstelle. So veränderte homozygote Mäuse exprimieren das CaMKIIठ Protein nicht mehr wie mittels Western Blot - Analysen (Abbildung 2.3) nachgewiesen werden konnte (Backs et al. 2009).

Zum gezielten Entfernen der DNA-Sequenz wurde das Cre/loxP-System eingesetzt (Branda und Dymecki 2004). Dabei werden spezifische Enzyme der Klasse der Rekombinasen benutzt, die den DNA-Abschnitt zwischen zwei zuvor gezielt gesetzten loxP-Sequenzen, die in gleicher Richtung orientiert den Abschnitt mit Exon 1 und Exon 2 flankieren, herausschneiden und die beiden verbleibenden loxP-Enden zusammenfügen (Abbildung 2.2).

Bei dem angewandten Verfahren ist hervorzuheben, dass der NeomycinResistenzfaktor, der benutzt worden ist, um einen Selektionsvorteil zu bieten, dabei ebenfalls herausgeschnitten wurde und das Null-Allel diesen nicht mehr enthält. 


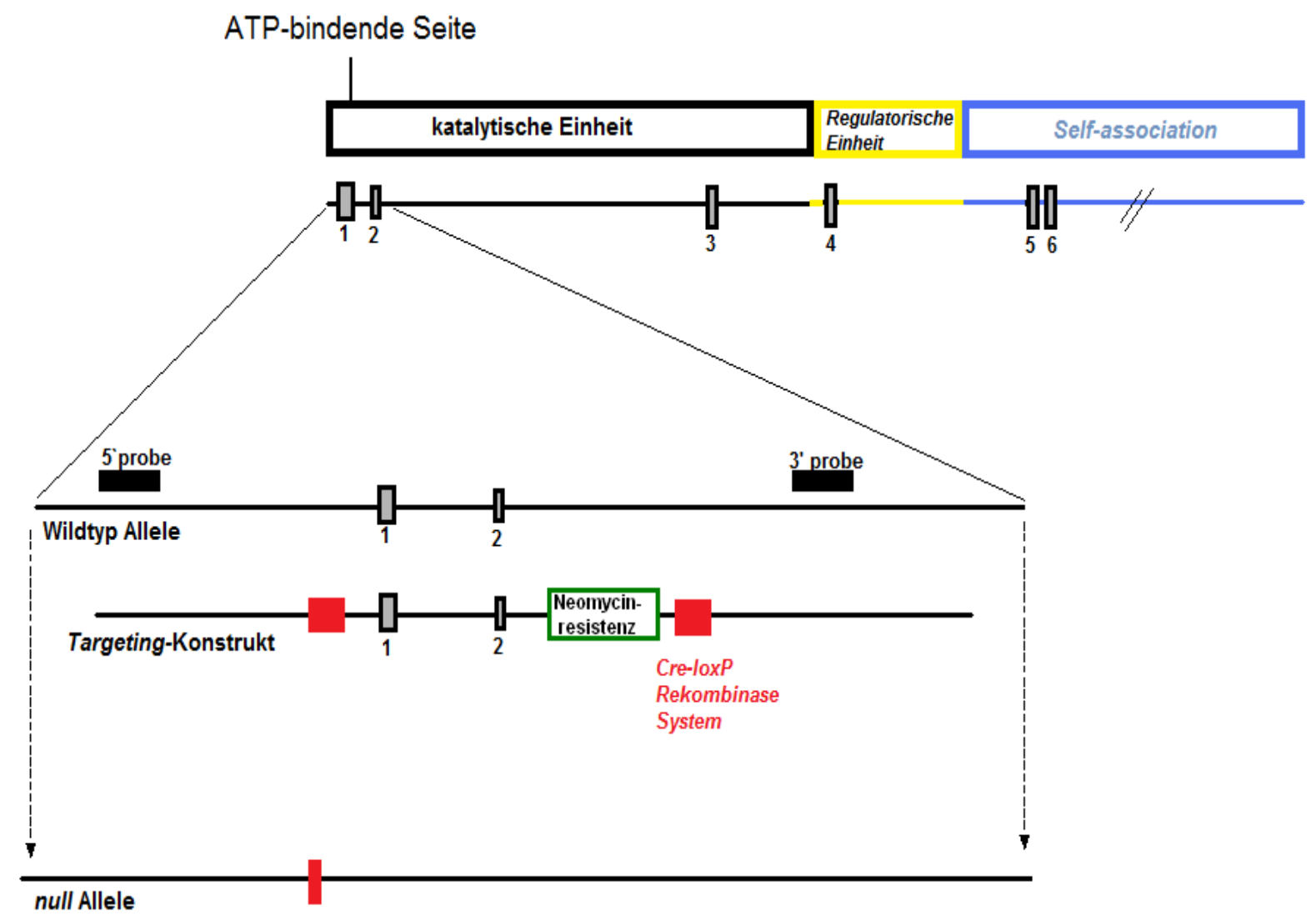

Abb. 2.2: Gene Targeting der CaMKIIס-Knockout-Maus

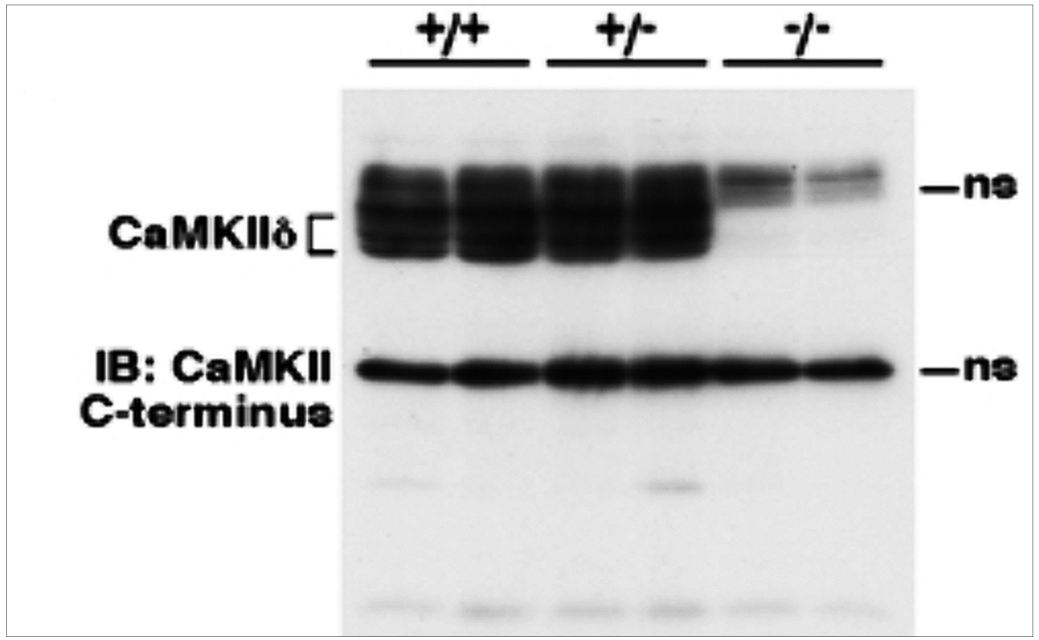

Abb. 2.3: Western Blot-Analysen. Die homozygoten Knockout-Mäuse exprimieren nicht die CaMKII $\delta_{c}$ 


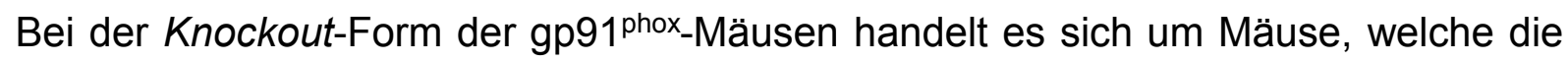
katalytische Einheit gp9 $1^{\text {phox }}$ der NADPH-Oxidase Typ 2 (Nox2) nicht exprimieren. Das entsprechende Gen dafür ist auf dem X-Chromosom lokalisiert (Brockdorff et al. 1988). Zur Ausschaltung dieses Gens fügte man mittels homologer Rekombination das Gen für die Herpes-simplex-Virus-Thymidinkinase so ein, dass es zusammen mit einem neo-Gen den DNA-Abschnitt um Exon 2 und Exon 3 flankiert (Abbildung 2.4) Das Genprodukt eines so mutierten Allels ist dann nicht mehr funktional (Pollock et al. 1995). Anhand der Immunoblotanalyse kann man sehen, dass die mutierten gp91 phox_ Allele nicht zur Expression funktionstüchtiger gp91phox Proteine führen, weder in der Membran noch in der gesamten Zelle (Abbildung 2.5).

\section{gp91 ${ }^{\text {phox }}$ gene}

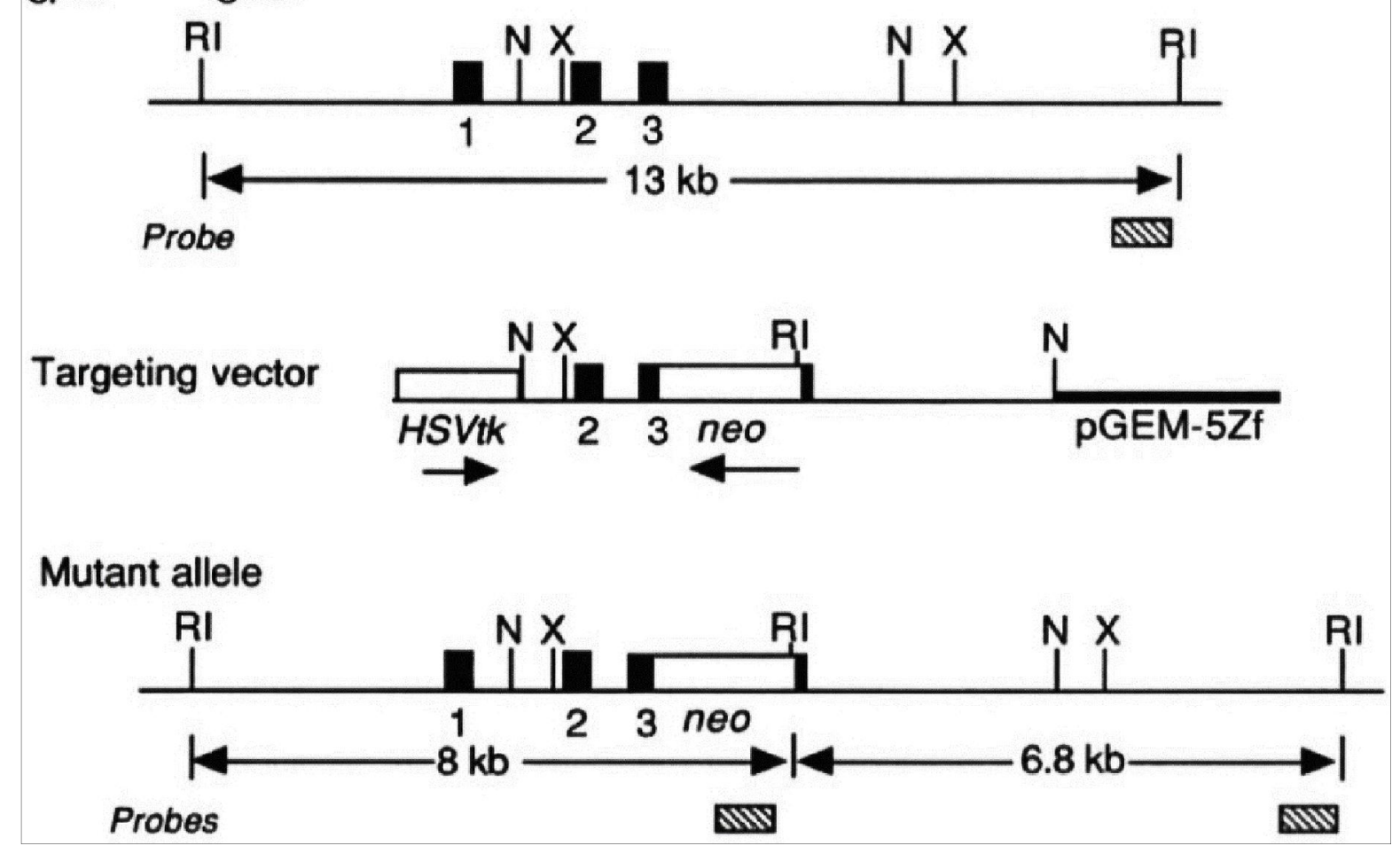

Abb. 2.4: Gene Targeting der gp91phox-Knockout-Maus. Exons sind durchnummeriert, und teilweise abgrenzend angedeuted (RI, EcoRI; X, Xbal; N, Ncol)." Der Targetvektor enthält ein neo-Gen, welches in das 3. Exon eingefügt wurde, und das Gen für die Herpes-simplex-Virus-Thymidinkinase HSVtk (aus Pollock et al. 1995, Seite 203). 


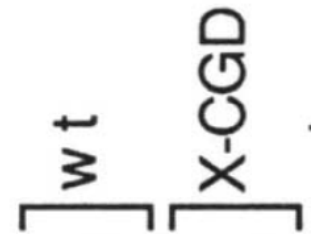

$\mathrm{c} \mathrm{m} \mathrm{c} \mathrm{m}$

Abb. 2.5: Immunoblotanalyse. Hierbei wird vergleichend zwischen Wildtyp-Mäusen (wt) und männlichen Mäusen, die hemizygot für die mutierte gp91 ${ }^{\text {phox_-Allele sind ( } X-C G D)}$ untersucht. Ein Antikörper, der an das exprimierte Protein (als Genprodukt) bindet, wurde hier verwendet, um aufzuzeigen, dass die X-CGD-Mäuse gp91 phox nicht mehr exprimieren. $c$

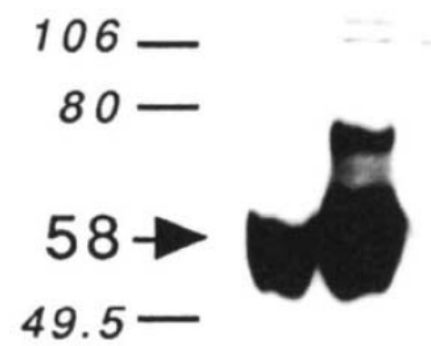
steht für ganze Zelle, $m$ für die Membran (aus Pollock et al. 1995, Seite 204)

Alle Tierexperimente wurden der zuständigen Tierschutzbehörde in Braunschweig angezeigt (Tierversuchsanzeige für die "Tötung von Tieren zu wissenschaftlichen Zwecken" gemäß § 4 TierSchG, Aktenzeichen T2.08 und T14.06, Bezirksregierung Braunschweig, Anzeigender Dr. Harald Kögler) und in Übereinstimmung mit dem "Guide for the Care an Use of Laboratory Animals" (Institute of Laboratory Animal Resources, Commission on Life Sciences, National Research Council, 1996) durchgeführt.

\subsection{Isolation ventrikulärer Mäusemyozyten}

Die Mäuse wurden in einer Glasglocke 500-850 ml Isofluran exponiert, die Menge wurde abhängig von der Größe der Maus gewählt. Reduzierte sich daraufhin die Atemfrequenz und -tiefe ausreichend, so dass dies als Zeichen einer einsetzenden Narkose gewertet werden konnte, wurde zügig das Genick der Maus gebrochen, indem eine Schere in den Nacken der Maus gelegt und mit einem Ruck am Schwanz gezogen wurde.

Als erster Schritt der Herzpräparation wurde die Bauchdecke angehoben und mit einer OP-Schere schräg zu beiden Vorderpfoten hochgeschnitten. Während eine Kornzange das Sternum fixierte, konnte das Zwerchfell durchtrennt und zum Herzen präpariert werden, welches nach Entfernung aus dem Thorax sofort in Tyrodepuffer 
(Tabelle 2-1) überführt und manuell ausgedrückt und durchgespült wurde, um möglichst viel Blut aus den Ventrikeln zu entfernen und Thrombenbildungen vorzubeugen.

Nach Entfernung der Lungenreste wurde das Herz ausgewogen und das HerzgewichtKörpergewicht-Verhältnis bestimmt (siehe Kapitel 3.1). Der verbleibende Stumpf der Aorta wurde kanüliert und erneut durchgespült. Danach wurde das Herz in einer Perfusionsanlage in Form einer modifizierten Langendorff-Apparatur (Langendorff 1895, Abbildung 2.6) für 7-8 Minuten mit einer Enzymlösung (Tabelle 2-1) retrograd perfundiert. Die darin enthaltene Liberase ${ }^{\mathrm{TM}}$ ist ein Gemisch aus Kollagenasen und Proteasen, die ein effizientes Herauslösen der Zellen aus dem Zellverband gewährleisten. Durch diesen Schritt wurden interzelluläre Verbindungen zerstört und eine spätere Überführung der Zellen in Suspension ermöglicht.

Anschließend wurden die Ventrikel genau an der Grenze zum Atrium abgeschnitten. Der ventrikuläre Anteil wurde in einer Stopplösung (Tabelle 2-1) zerschnitten und

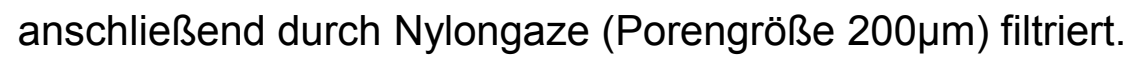

Der letzte Schritt der Zellisolation war der Kalziumaufbau: Dabei wurden die Zellen behutsam steigenden Kalziumkonzentrationen ausgesetzt. Die nichtkalziumtoleranten Zellen, welche sich im Überstand der Suspension befanden, wurden verworfen.

Zum Schluss wurden je $500 \mu \mathrm{l}$ der Zellsuspension auf eine mit Laminin (Laminin L2020 - 1 mg, Bestellnummer: 8200807121, Sigma-Aldrich) beschichtete Versuchskammer verteilt. Laminine sind kollagenähnliche Glykoproteine, die ein Anhaften der Zellen auf der Versuchskammer ermöglichen. Mit Hilfe einer Pipette wird ca. $3 \mu \mathrm{l}$ der Lamininlösung auf die Versuchskammer möglichst flächig verteilt, gibt man danach die Zellsuspension darüber, bleiben die Zellen auf der Versuchskammer haften, so dass der Überstand später leicht durch Ausgießen entfernt werden kann. 


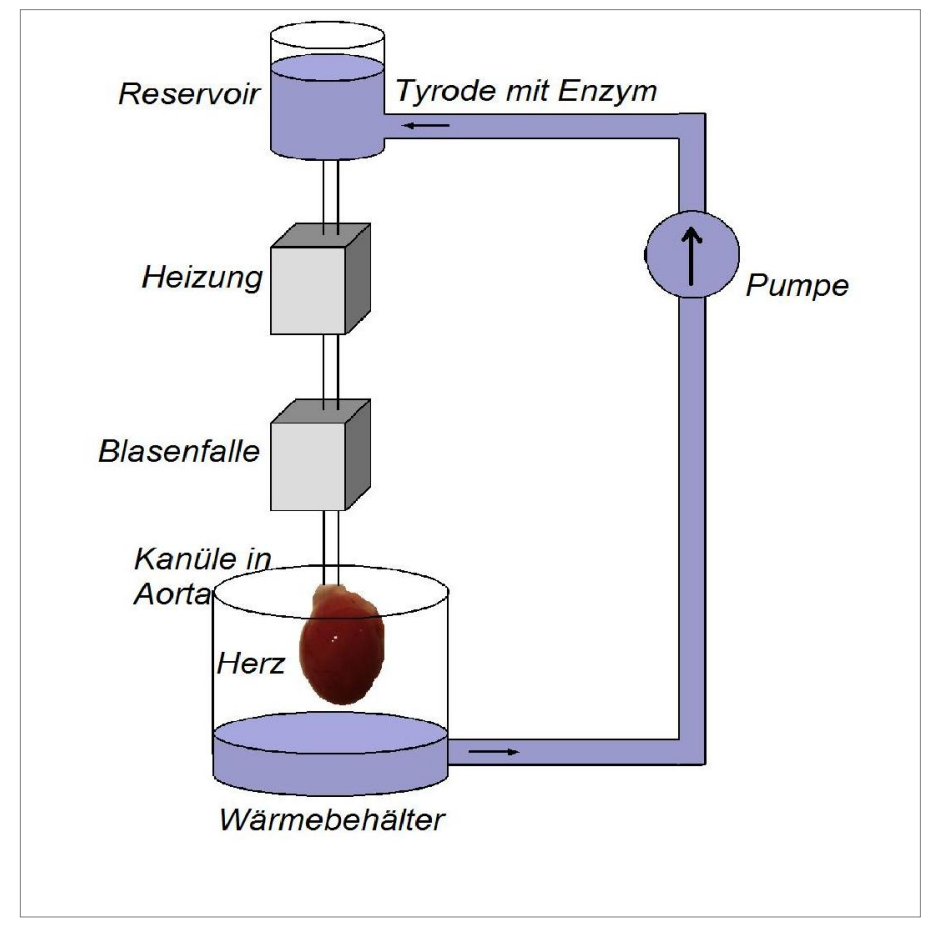

Abb. 2.6: Schematische Darstellung der Perfusionsanlage nach Langendorff (Langendorff 1895). Da sich die Kanüle oberhalb der Aortenklappe befand, wurden die Koronararterien retrograd mit der infundierten Enzymlösung gespült

\begin{tabular}{|c|c|c|c|}
\hline Lösung & Substanz/lon & Konzentration & \\
\hline \multirow{13}{*}{ Tyrodepuffer } & $\mathrm{NaCl}$ & $113 \mathrm{mmol} / \mathrm{l}$ & \multirow{13}{*}{$\begin{array}{c}\text { gelöst in } \mathrm{ddH}_{2} \mathrm{O} \text {; } \\
\mathrm{pH} 7.42 \text { mit } \mathrm{NaOH} \\
\text { bei } 36.5^{\circ} \mathrm{C}\end{array}$} \\
\hline & $\mathrm{KCl}$ & $4,7 \mathrm{mmol} / \mathrm{l}$ & \\
\hline & $\mathrm{KH}_{2} \mathrm{PO}_{4}$ & $0.6 \mathrm{mmol} / \mathrm{l}$ & \\
\hline & $\mathrm{MgSO}_{4} \times 7 \mathrm{H}_{2} \mathrm{O}$ & $1.2 \mathrm{mmol} / \mathrm{l}$ & \\
\hline & $\mathrm{Na}_{2} \mathrm{HPO}_{4} \times 2 \mathrm{H}_{2} \mathrm{O}$ & $0.6 \mathrm{mmol} / \mathrm{l}$ & \\
\hline & Phenolrot & $0.032 \mathrm{mmol} / \mathrm{l}$ & \\
\hline & $\mathrm{NaHCO}_{3}$ & $12 \mathrm{mmol} / \mathrm{l}$ & \\
\hline & $\mathrm{KHCO}_{3}$ & $10 \mathrm{mmol} / \mathrm{l}$ & \\
\hline & HEPES & $10 \mathrm{mmol} / \mathrm{l}$ & \\
\hline & Taurin & $30 \mathrm{mmol} / \mathrm{l}$ & \\
\hline & BDM & $10 \mathrm{mmol} / \mathrm{l}$ & \\
\hline & (2,3-Butadionmonoxim) & & \\
\hline & Glukose & $5.5 \mathrm{mmol} / \mathrm{l}$ & \\
\hline \multirow{3}{*}{ Enzymlösung } & Liberase $^{\mathrm{TM}}$ & $1.5 \mathrm{mg}$ & \multirow{3}{*}{$\begin{array}{l}\text { gelöst in } 20 \mathrm{ml} \\
\text { Tyrodepuffer; } \mathrm{pH} \\
7.42 \text { bei } 36.5^{\circ} \mathrm{C}\end{array}$} \\
\hline & Trypsin & $111.2 \mu \mathrm{l}$ & \\
\hline & $\mathrm{CaCl}_{2}$ & $0.0125 \mathrm{mmol} / \mathrm{l}$ & \\
\hline \multirow[b]{2}{*}{ Stopplösung } & Bovine calf serum & $0.25 \mathrm{ml}$ & \multirow{2}{*}{$\begin{array}{c}\text { gelöst in } 2.25 \mathrm{ml} \\
\text { Tyrode } \\
\mathrm{pH} 7.42 \text { bei } 36.5^{\circ} \mathrm{C}\end{array}$} \\
\hline & $\mathrm{CaCl}_{2}$ & $0.0125 \mathrm{mmol} / \mathrm{l}$ & \\
\hline
\end{tabular}

Tabelle 2-1: Lösungen für die Isolation von ventrikulären Mäusemyozyten. $\mathrm{ddH}_{2} \mathrm{O}$ für zweifach destilliertes $\mathrm{H}_{2} \mathrm{O}$. 


\subsection{Die Patch-Clamp-Technik}

1976 hatten der Biophysiker Erwin Neher und der Mediziner Bert Sakmann eine Methode erforscht, mit der sich Strom durch einzelne lonenkanäle der Zellmembran messen lässt: die Patch-Clamp-Technik (Hamill et al. 1981; Neher und Sakmann, 1976). Diese brachte ihnen 1991 den „Nobelpreis für Physiologie oder Medizin“ ein.

Das Besondere an dieser Methode bestand darin, an einer extrem kleinen Fläche (ca. $1 \mu \mathrm{m}^{2}$ ) bereits sehr kleine Ströme im pA-Bereich mit hoher zeitlicher Auflösung von 100-300 kHz messen zu können.

Heute stellt diese Technik eine der wichtigsten elektrophysiologischen Arbeitsmethoden dar.

Dabei wird eine feine Glaspipette mit einem sehr kleinen Spitzendurchmesser (unter Anlegen eines leichten Überdrucks in der Glaspipette, um ein Verstopfen durch Schmutzpartikel zu vermeiden) vorsichtig an die Zellmembran geführt, bis zwischen der Membran und dem Rand der Glaspipette eine sehr dichte Verbindung entsteht (Gigaseal), die dieses Stück der Membran („patch“) von seiner Umgebung elektrisch isoliert. Das gelingt, wenn der Abstand zwischen der Glaspipette und dem Membranstück so klein wird, dass der Widerstand im Gigaohm-Bereich liegt (Hamill et al. 1981); dann kann praktisch kein Strom mehr fließen und die Stromantwort auf den Kommandospannungspuls wird zu einer geraden Linie. Durch kurzes Anlegen eines Unterdrucks kann die Membran aufgebrochen werden, so dass das Innere der Pipette mit dem Intrazellularraum eine Einheit bildet.

Es werden im Wesentlichen vier Konfigurationen in der Patch-Clamp-Technik unterschieden (Abbildung 2.7): Liegt die Patch-Pipette direkt auf der Zellmembran, spricht man von der "Cell-Attached-“ oder auch "On-Cell-Konfiguration“. Setzt man anschließend Unterdruck an und reißt somit die Zellmembran auf (ruptured patch), hat man die "Whole-Cell-Konfiguration", welche auch diejenige ist, die in dieser Doktorarbeit benutzt wurde. Abgesehen von der beschriebenen ruptured patchMethode, kann die Whole-Cell-Konfuguration auch durch die sogenannte perforated patch - Methode erreicht werden. Dabei wird die Zellmembran nicht durch Unterdruck aufgerissen, sondern chemisch permeabel gemacht, beispielsweise durch Nystatin (Horn und Marty 1988).

Darüber hinaus gibt es die "Inside-Out-Konfiguration“ und die "Outside-OutKonfiguration", welche dadurch entstehen, dass man mit der Pipette ein Stück der 
Zellmembran herausreißt (Hamill et al. 1981). Bei der "Outside-OutKonfiguration" kommt es dabei zur Wiederanlagerung der zerrissenen Membran, wobei ein Patch entsteht, bei dem das ursprüngliche Zelläußere zur Badlösung gerichtet ist. Bei der "Inside-Out-Konfiguration“ wird durch Unterdruck in der Pipette oder Überdruck in der Badlösung verhindert, dass sich der Patch verändert, so dass das ursprünglich Zellinnere zur Badlösung gerichtet ist. Die zur Badlösung gerichtete Seite kann nun durch Lösungswechsel gezielt verändert werden. Außerdem gibt es an der Anlage die Möglichkeit, entweder mit der "Current-Clamp-“ oder mit der "VoltageClamp-Technik" zu arbeiten. Bei der Current-Clamp-Technik wird das Membranpotential (im Sinne einer Spannung) gemessen, während der Verstärker einen gewünschten Strom einstellt (clamp). Das ist die in dieser Doktorarbeit verwendete Methode.

Daneben gibt es noch die Möglichkeit, die Spannung einer Zelle (also das Membranpotential) auf einen bestimmten Wert festzuhalten und den dabei fließenden Strom zu messen, die "Voltage-Clamp-Technik“. Diese Technik eignet sich zur Messung bestimmter lonenströme (wie INa oder $I_{\mathrm{Ca}}$ ). In dieser Doktorarbeit wurden Aktionspotentiale an Kardiomyozyten von Mäusen untersucht.

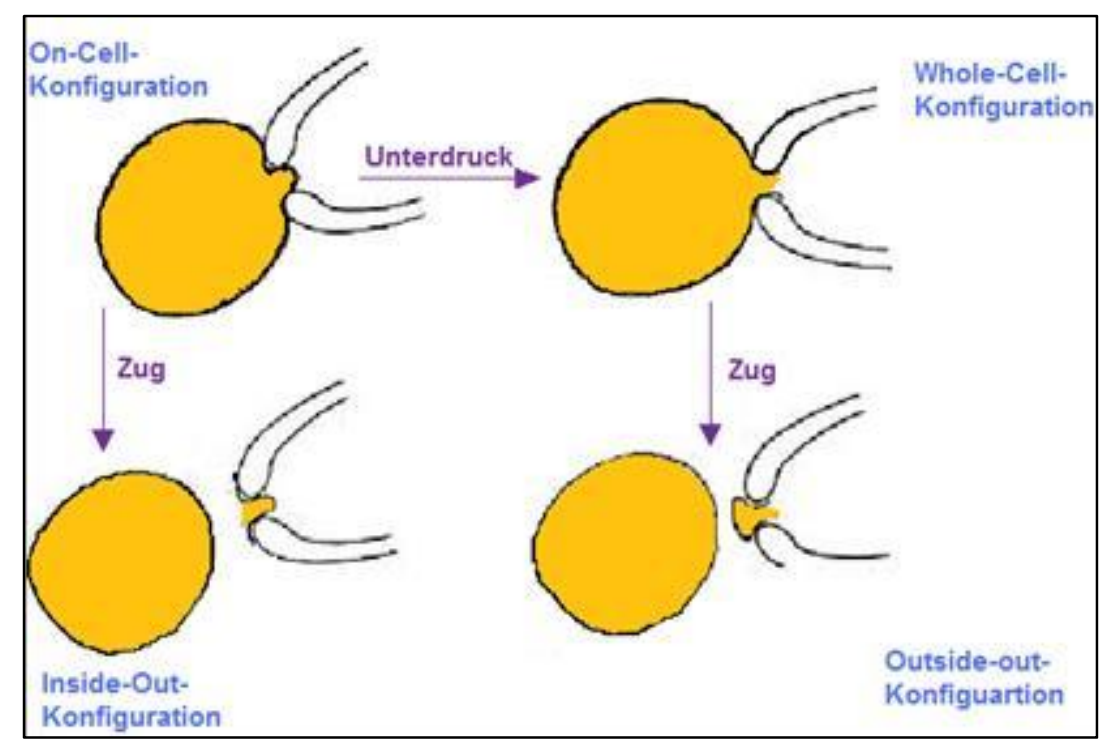

Abb. 2.7: Die vier Konfigurationsformen

\subsubsection{Das Patch-Clamp-Setup}

Über einem inversen Mikroskop (Nikon Eclipse TE-200) mit 200-facher Gesamtvergrößerung (20 x Objektiv und $10 \times$ Okular) befand sich ein Objekttisch mit 
einer Aussparung in der Mitte, in der die Versuchskammer platziert werden konnte. An dem Objekttisch war der Pipettenhalter samt Pipettenelektrode, Mikromanipulator und einem Anschluss für Über- bzw. Unterdruck befestigt. Durch den Steuerungshebel wurde der Mikromanipulator exakt im dreidimensionalen Raum gesteuert. Somit konnte die Pipettenelektrode auf die Versuchskammer bewegt und sehr genau oberhalb einer Zelle positioniert werden.

Die beiden Elektroden, die Pipetten- und die Referenzelektrode, waren über einen Vorverstärker mit einem Patch-Clamp-Verstärker (EPC 10 von HEKA Elektronik Dr. Schulze $\mathrm{GmbH}$ ) mit integriertem AD/DA-Wandler verbunden. Dadurch konnte das Signal gefiltert, verstärkt und umgewandelt werden. Die Datenaufnahme in den Computer erfolgte durch das Programm Patchmaster 2.0 (HEKA Elektronik).

Der gesamte Messplatz wurde auf zwei Wegen abgeschirmt: Ein schwingungsgedämpfter Tisch schützte vor etwaigen Gebäudeschwingungen und ein Faradaykäfig bot Abschirmung vor elektrischen Störquellen. Sämtliche Netzgeräte waren außerhalb positioniert (Abbildung 2.8).

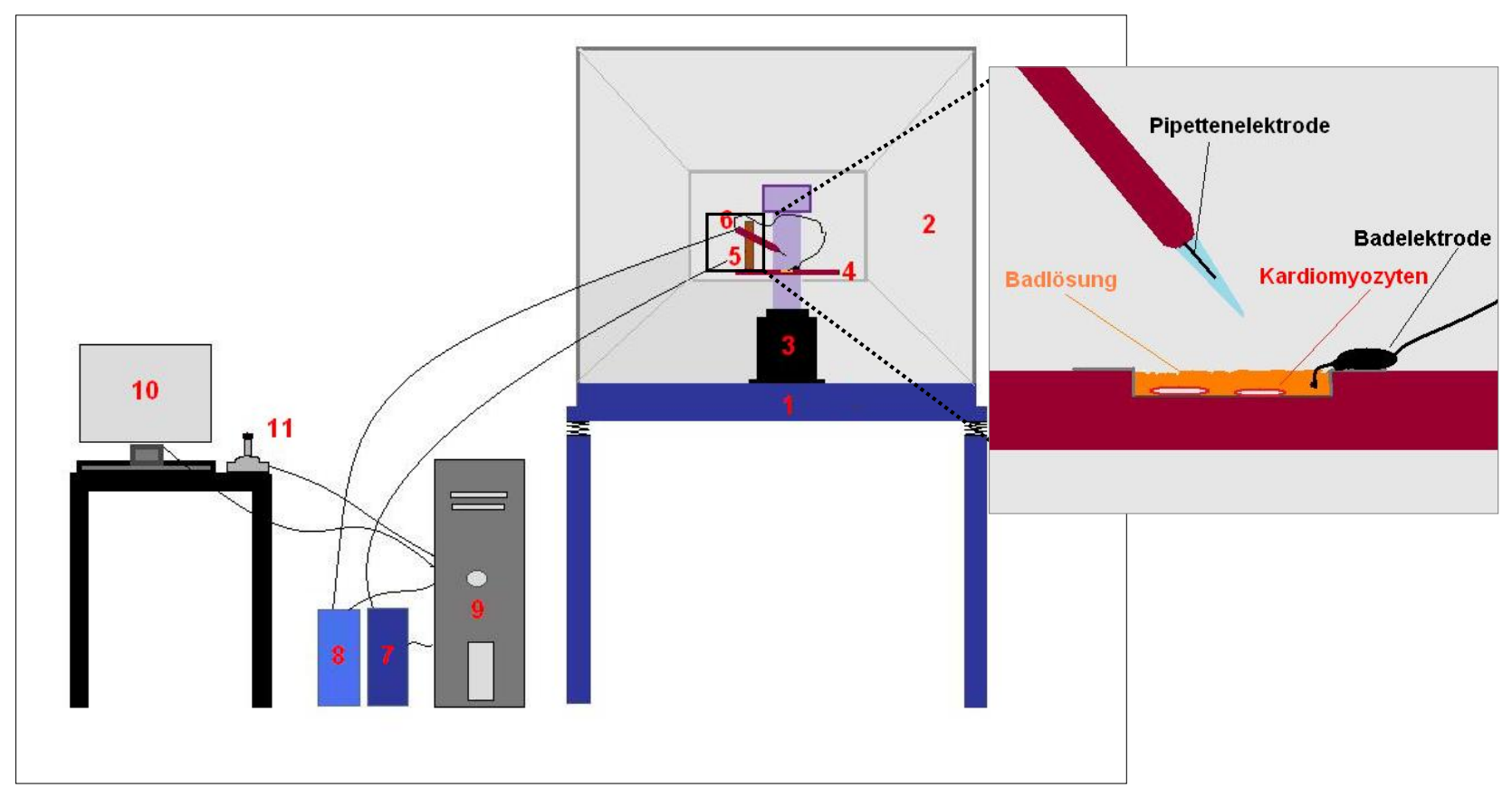

Abb. 2.8: Schematische Darstellung des Patch-Clamp-Setups, 1 Schwingungsgedämpfter Tisch, 2 Faradaykäfig, 3 inverses Mikroskop,4 Objekttisch mit Aussparung für Versuchskammer (gelb) und Badelektrode (schwarz), 5 Vorverstärker mit Pipettenhalter, 6 Motoreinheit des Mikromanipulators, 7 Steuereinheit des Mikromanipulators, 8 Patch-Clamp-Verstärker (Amplifier), 9 Computer, 10 Monitor, 11 Steuerungshebel. 


\subsubsection{Lösungen}

In Tabelle 2-2 sind die Zusammensetzungen der verwendeten Bad- und Pipettenlösungen aufgeführt.

Badlösung: Nachdem sich die Zellen in der Zellsuspension auf den Versuchskammern "gesetzt" hatten (dafür wurde ein Zeitraum von etwa 15 Minuten eingehalten) und durch das Laminin auf den Kammern fixiert worden waren, wurde der übrige nicht fixierte Rest der Zellsuspension durch Ausgießen verworfen und durch die Badlösung, eine isotone, modifizierte Tyrode-Lösung, ersetzt. Die lonenzusammensetzung der Badlösung entsprach der des physiologischen Extrazellulärraumes.

Pipettenlösung: Die Lösung in den Pipetten sollte von der lonenzusammensetzung und Osmolalität her den physiologischen intrazellulären lonenkonzentrationen ähneln, da die Pipette nach dem rupturing (siehe unten) mit dem Inneren der Zelle eine Einheit bildete. Dabei wurde auch darauf geachtet, dass sich die Osmolarität beider Lösungen nicht stark voneinander unterschied, damit Zellgrößenveränderungen durch Schwellung oder Schrumpfung vermieden und die Häufigkeit erfolgreicher Giga-Seal Ausbildung gesteigert werden konnte.

Da die beiden Lösungen unterschiedliche Zusammensetzungen hinsichtlich mobiler und immobiler lonen aufweisen, entsteht bei deren Zusammentreffen ein sogenanntes Liquid Junction Potential (auch Diffusionspotential genannt). Dabei kommt es zur partiellen Diffusion der mobilen lonen. Jedes lon, das von der einen Lösung in die andere Lösung diffundiert, erzeugt durch seinen Transfer eine Potentialdifferenz: Wenn also z.B. ein $\mathrm{K}^{+}$-Ion aus der Pipettenlösung (mit der höheren Konzentration an $\mathrm{K}^{+}$) in die Badlösung (mit der niedrigeren Konzentration an $\mathrm{K}^{+}$) diffundiert, wird die Pipettenlösung dadurch negativ und die Badlösung positiv geladen. An der Stelle des Zusammentreffens dieser beiden Lösungen entsteht eine Potentialdifferenz, die dann Liquid Junction Potential genannt wird.

Ist der Kontakt der Pipette mit der Zellmembran sehr dicht (z.B. beim Gigaseal), können die lonen der Pipettenlösung und der Badlösung nicht gut diffundieren, somit sind die Leak-Ströme und das Liquid Junction Potential gering; in On-Cell Konfiguration ist auch der gemessene Serienwiderstand (Series Resistance) des Systems sehr hoch. In der Whole-Cell-Konfiguration kommt es allerdings wieder zur Ausbildung von Leak-Strömen und eines Liquid junction potentials, welches einen Messfehler verursachen kann. 
So können die Werte des Liquid Junction Potentials, der Leak-Ströme und des Serienwiderstand eine Aussage über die Qualität des Pipetten-Zell-Kontakts treffen. Durch das verwendete Patchmaster Programm konnte eine Verfälschung der Messdaten durch das Liquid junction potential ausgeglichen werde. Leck-Ströme oder Serienwiderstand wurden jedoch nicht kompensiert.

\begin{tabular}{|c|c|c|c|}
\hline Lösung & Substanz/lon & Konzentration & \\
\hline \multirow{6}{*}{ Badlösung } & $\mathrm{NaCl}$ & $140 \mathrm{mmol} / \mathrm{l}$ & \multirow{6}{*}{$\begin{array}{l}\text { gelöst in dd } \mathrm{H}_{2} \mathrm{O} \\
\text { pH } 7.4 \\
\text { mit } \mathrm{NaOH} \\
\text { (bei RT) }\end{array}$} \\
\hline & $\mathrm{KCl}$ & $4 \mathrm{mmol} / \mathrm{l}$ & \\
\hline & $\mathrm{MgCl}_{2}$ & $1 \mathrm{mmol} / \mathrm{l}$ & \\
\hline & Glukose & $10 \mathrm{mmol} / \mathrm{l}$ & \\
\hline & $\mathrm{CaCl}_{2}$ & $1 \mathrm{mmol} / \mathrm{l}$ & \\
\hline & HEPES & $5 \mathrm{mmol} / \mathrm{l}$ & \\
\hline \multirow{9}{*}{ Pipettenlösung } & K-Aspartat & $120 \mathrm{mmol} / \mathrm{l}$ & \multirow{9}{*}{$\begin{array}{l}\text { gelöst in } \mathrm{ddH}_{2} \mathrm{O} \\
\text { pH } 7.2 \\
\text { mit } \mathrm{KOH} \\
\text { (bei RT) }\end{array}$} \\
\hline & $\mathrm{NaCl}$ & $7 \mathrm{mmol} / \mathrm{l}$ & \\
\hline & $\mathrm{KCl}$ & $8 \mathrm{mmol} / \mathrm{l}$ & \\
\hline & $\mathrm{MgCl}_{2}$ & $1 \mathrm{mmol} / \mathrm{l}$ & \\
\hline & Mg-ATP & $5 \mathrm{mmol} / \mathrm{l}$ & \\
\hline & EGTA & $1 \mathrm{mmol} / \mathrm{l}$ & \\
\hline & $\mathrm{CaCl}_{2}$ & $\begin{array}{l}0.2 \mathrm{mmol} / \mathrm{l} \\
(40 \mathrm{nM} \text { freie }[\mathrm{Ca}])\end{array}$ & \\
\hline & Li-GTP & $0.3 \mathrm{mmol} / \mathrm{l}$ & \\
\hline & HEPES & $10 \mathrm{mmol} / \mathrm{l}$ & \\
\hline
\end{tabular}

Tabelle 2-2: Bad- und Pipettenlösung für die Messung von Aktionspotentialen mit der Patch-ClampTechnik (RT steht für Raumtemperatur, dd $\mathrm{H}_{2} \mathrm{O}$ für zweifach destilliertes $\mathrm{H}_{2} \mathrm{O}$ ).

\subsubsection{Pipetten und Elektroden}

Für die Patchpipette wurden Borosilikatglaskapillaren (TW150F-3 World Precision Instruments, Inc.) mit einem Außendurchmesser von 1,5 mm, Innendurchmesser 1,2 $\mathrm{mm}$ und einer Länge von $76 \mathrm{~mm}$ verwendet. Diese wurden auf einem Pipettenziehgerät der Firma Zeitz-Instruments GmbH (DMZ Universal Puller) direkt vor jedem Messvorgang frisch auseinandergezogen (Abbildung 2.9). So entstanden aus einer Glaskapillare zwei Pipetten.

Um optimale Messbedingungen für eine AP-Messung $\mathrm{zu}$ haben, sollten die Pipettenspitzen nach Befüllen mit der Pipettenlösung und Eintauchen in die Badlösung einen Widerstand zwischen 2,5 und $6 \mathrm{M} \Omega$ aufweisen. Der Widerstand der Pipette war im Wesentlichen von dem Durchmesser der Pipettenöffnung und der Länge der Pipette 
abhängig und diese ließen sich durch Variation von Zugkraft, Hitze, Zuglänge und Intervall zwischen den Zügen bestimmen. Oftmals waren es mehrere Züge notwendig, um die gewünschte Pipettenform zu erreichen.

Wichtig war, dass jede Pipette nur einmal verwendet wurde, da ihre Öffnung für eine Sealbildung frei von jeglichen Membranresten sein musste.

Die Messelektrode bestand aus chloriertem Silberdraht, die Badelektrode aus einem Silberquader mit chlorierter Oberfläche.
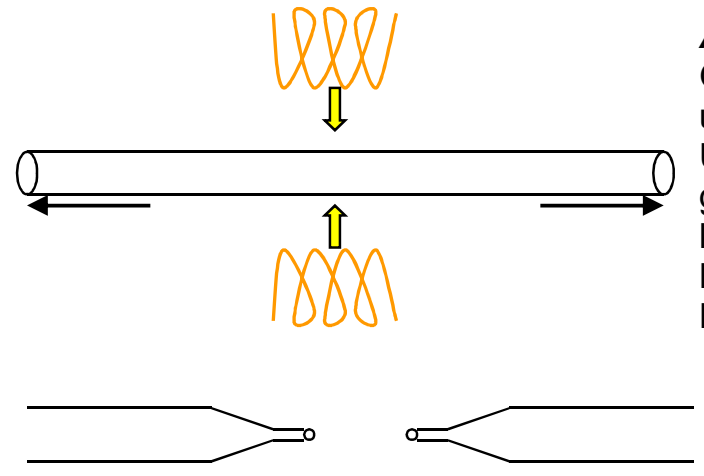

Glaspipetten
Abb. 2.9: Das Prinzip des Pipettenziehgeräts. Die Glaskapillaren werden horizontal eingelegt, so dass sich ungefähr ihre Mitte auf Höhe des Glühelementes befindet. Unter Erhitzung werden die beiden Enden auseinander gezogen. Die Parameter Hitze, Zugkraft und Zugintervall können variiert werden und bestimmen in ihrer Kombination die Länge und den Durchmesser der Pipettenspitzen.

\subsubsection{Versuchsdurchführung}

Zunächst wurde die Versuchskammer auf den Objekttisch platziert. Die Zellen, die durch Laminin auf der Kammer fixiert waren, befanden sich in der Badlösung (siehe Tab 2-2). Mit dem inversen Mikroskop wurde auf der Kammer nach einer geeigneten Zelle gesucht. Hatte man eine möglichst stabile Zelle gefunden (die sich dadurch auszeichnet, dass sie nicht unregelmäßig kontrahiert, ihre Querstreifung regelmäßig angeordnet und ihre Kontur möglichst glatt war), wurde die frischgezogene Glaspipette mit Pipettenlösung gefüllt und an den Pipettenhalter so angebracht, dass die Messelektrode sich in der Pipette befand und mit der Spitze in die Pipettenlösung ragte (Abbildung 2.10). Die Badelektrode wurde an einer Ecke der Versuchskammer in die Badlösung getaucht.

Um die Pipettenspitze vor Verunreinigungen möglichst gut zu schützen und auch die spätere Annährung an die Zelle zu erleichtern, wurde ein leichter Überdruck angelegt, was ein gewisses Druckpolster (im Sinne eines Druckgradienten) vor der Zelle erzeugte. Unter Sichtkontrolle wurde die Pipette über der Zelle in Badlösung eingetaucht und mithilfe des Mikromanipulators möglichst genau der Zelle angenähert. Der letzte Schritt dieser Annährung erfolgte unter Beobachtung des Widerstandes am Oszilloskop. Erhöhte sich der Widerstand plötzlich auf ungefähr das Doppelte, war dies 
ein Zeichen, dass die Pipette der Zelle sehr nah gekommen war. Um dann einen lückenlosen Kontakt zwischen Zelle und Pipettenspitze herzustellen, wurde der Überdruck abgelassen (und evtl. noch etwas Unterdruck angelegt) bis es zu einem sogenannten Gigaseal kam. Das ist der Zustand, in dem der Widerstand zwischen den Elektroden im Giga- $\Omega$-Bereich liegt und nur sehr kleine Ströme fließen. Durch das kurze Anlegen eines größeren Unterdruckes wurde der Membranteil innerhalb der Pipettenöffnung zerstört (rupturing) und so die Whole-Cell-Konfiguration hergestellt. In dieser Konfiguration können Ströme und Spannungen über die gesamte Zellmembran gemessen werden. Anschließend wurde etwa fünf Minuten abgewartet, damit sich die Ionen in der Pipette und in der Zelle gleichmäßig verteilen konnten (Abbildung 2.11). Erwies sich die Zelle in dieser Zeit als stabil genug, indem sie ihr Ruhemembranpotential weiterhin aufrecht erhielt und nicht starb, wurden im CurrentClamp-Modus mittels kurzer Rechteckimpulse (ca. 1-4 ms Dauer, ca. 800 pA Amplitude) Aktionspotentiale ausgelöst und das Membranpotential als Funktion der Zeit überwacht. Dabei erfolgte die Stimulation mit variabler Frequenz $(0,25$ bis $3 \mathrm{~Hz})$.

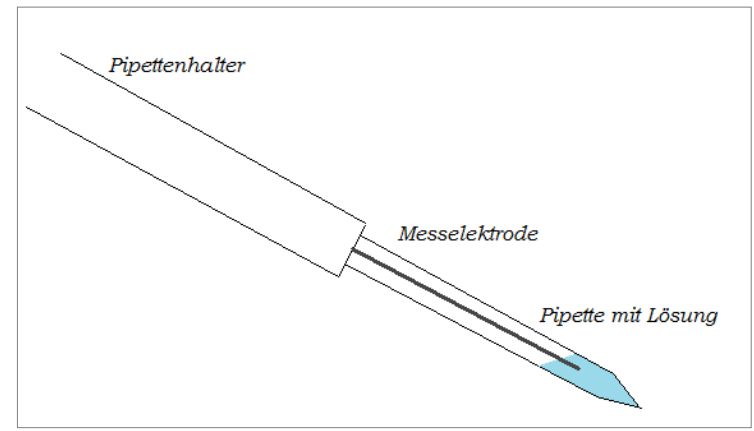

Abb. 2.10: Darstellung der Pipette am Pipettenhalter. Die Messelektrode ragt mit der Spitze in die Pipettenlösung.

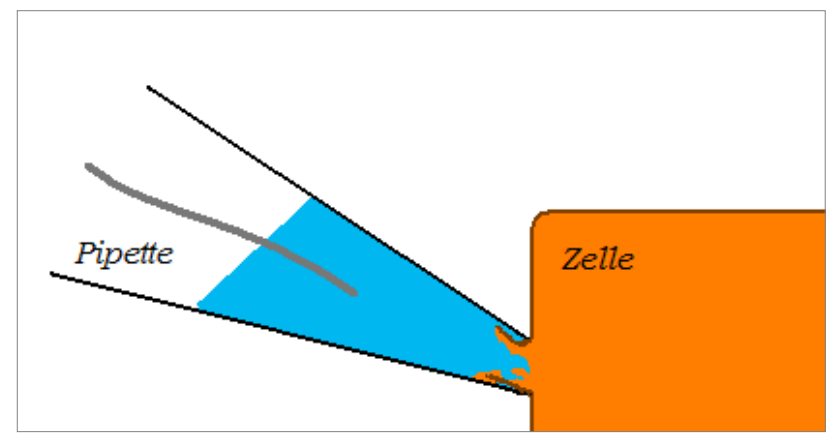

Abb. 2.11: Schematische Darstellung von Pipette und Zelle nach dem rupturing. Der Intrazellularraum und das Innere der Pipette bilden eine Einheit 


\subsection{Pharmakologische Interventionen}

Die verwendeten Substanzen wurden in Dimethylsulfoxid (DMSO) gelöst und in die Badlösung in den entsprechenden Mengen hinzugefügt. Da DMSO selbst gewisse Radikalfängereigenschaften nachgewiesen werden konnten (Koulkes-Pujo et al. 1981), wurden Kontrollexperimente durchgeführt, bei denen die gleiche Menge DMSO, jedoch keine (anderen) pharmakologischen Substanzen verwendet wurden (Vehikel). Bei jeder Versuchskammer wurde vor Beginn der Messungen eine Einwirkzeit von ca. 10 Minuten eingehalten, in denen die jeweiligen Stoffe der Badlösung ihre Wirkung auf die Kardiomyozyten entfalten konnten.

\subsubsection{Angiotensin II (human)}

Angiotensin II (verwendete Konzentration: $1 \mu \mathrm{mol} / \mathrm{l}$, Bestellnummer: A9525-10MG, Molekulargewicht $1046,81 \mathrm{~g} / \mathrm{mol}$,) ist ein natürlich vorkommendes Hormon im menschlichen Körper. Angiotensinogen wird in der Leber gebildet und über mehrere enzymatische Abspaltungsprozesse zu Angiotensin II verarbeitet. Angiotensin II hat im menschlichen Körper multiple Effekte auf das Zentrale Nervensystem, die Gefäße, die Niere und Nebenniere und auf das Myokard (siehe Einleitung Kapitel 1.3.4).

\subsubsection{Diphenyliodoniumchlorid (DPI)}

Diphenyliodoniumchlorid (verwendete Konzentration $10 \mu \mathrm{mol} / \mathrm{l}$, Bestellnummer 43085$5 \mathrm{G}$, Molekulargewicht 316,57 $\mathrm{g} / \mathrm{mol}$ ) ist ein spezifischer NADPH-Oxidase-2-Hemmer (Ragan und Bloxham 1977).<smiles>Clc1ccccc1[Te]c1ccccc1</smiles> 


\subsection{Datenerfassung und Auswertung}

Die Daten der Patch-Clamp-Messungen wurden mit der Software Patchmaster ${ }^{\mathrm{TM}}$ (HEKA Elektronik, Dr. Schulze GmbH) erfasst. Anschließend wurden die verwertbaren Daten mit dem Programm Clampfit weiter bearbeitet. Aus der gesamten Registrierung wurden die auszuwertenden Aktionspotentiale markiert und in Microsoft Excel importiert. Dort erfolgte die endgültige Analyse der Registrierungen im Hinblick auf die Parameter Aktionspotential-Aufstrichgeschwindigkeit, maximal positives Membranpotential, maximal negatives Membranpotential, Aktionspotentialamplitude und Aktionspotentialdauer. Letztere wurde untergliedert in die Dauer bis zur Repolarisation auf 90\%, 80\%, 50\% bzw. 30\% der Aktionspotentialamplitude (APD 90, 80,50 , bzw. 30).

Der Standardfehler (S.E.M.) wurden wie folgt berechnet:

$$
\text { S.E.M. }=\sqrt{\frac{\sigma^{2}}{n}}=\frac{\sigma}{\sqrt{n}}
$$

( $\sigma$ = Standardabweichung; $\sigma^{2}=$ Varianz; $\mathrm{n}=$ Anzahl der Beobachtungen $)$

Außerdem wurden die beobachteten Arrhythmien notiert und qualitativ und quantitativ miteinander verglichen:

Die isolierte adulte Herzmuskelzelle wies keine Spontanaktivität auf, so dass vor jedem registrierten Aktionspotential eine elektrische Stimulation mit 100-200 pA erfolgen musste. Erreichte die Zelle dann dadurch ihr Schwellenpotential, löste sie ein Aktionspotential aus, welches registriert wurde.

Diese Stimulationen wurden je nach Protokoll nacheinander in einer Frequenz von 3 $\mathrm{Hz}, 2 \mathrm{~Hz}, 1 \mathrm{~Hz}, 0,5 \mathrm{~Hz}$ und $0,25 \mathrm{~Hz}$ durchgeführt. Jede Zelle, die für die Arrhythmiemessung ausgewertet worden ist, musste vier Mal die Abfolge von diesen fünf Protokollen überstehen (d.h. sie durfte nicht vorher sterben). Kam es in dieser Zeit zu frühen oder späten Nachdepolarisationen (Early After Depolarization, EAD; Delayed After Depolarization DAD; siehe Einleitung), wurden diese registriert und ausgewertet. 
Die Endauswertung, statistische Testung und die graphische Darstellung wurde mit Hilfe von GraphPad Prism ${ }^{\mathrm{TM}}$ (GraphPad Software Inc., San Diego, USA) erstellt.

Die statistische Auswertung erfolgte mittels t-Test, als Post-hoc-Analyse kam ein Student-Newman-Keuls-Test zum Einsatz und ein Zwei-Wege-ANOVA für longitudinale Daten mit mehreren Gruppen.

Eine Irrtumswahrscheinlichkeit von $p<0,05$ wurde als statistisch signifikant angesehen. 


\section{Ergebnisse}

Um den Einfluss der CaMKII $\delta_{c}$ auf das Aktionspotential und die Arrhythmogenese zu untersuchen, wurden Kardiomyozyten von Mäusen, denen das Gen für die CaMKIII $\delta_{c}$ fehlt $\left(\mathrm{CaMKII}_{\mathrm{c}^{-}}{ }^{-1}\right.$ ), mit Kardiomyozyten ihrer Wildtypwurfgeschwister vergleichend getestet. Außerdem wurden die Zellen beider Gruppen mit Ang II bzw. DPI (als Nox2 - Inhibitor) behandelt, um die generelle Ang II-Wirkung und ggf. eine Nox2 unabhängige Ang II-Wirkung zu erfassen.

Ferner sollte der Einfluss der Nox2 auf das Aktionspotential und die Arrhythmogenese weiter untersucht werden, daher wurden Kardiomyozyten von Mäusen, denen ein

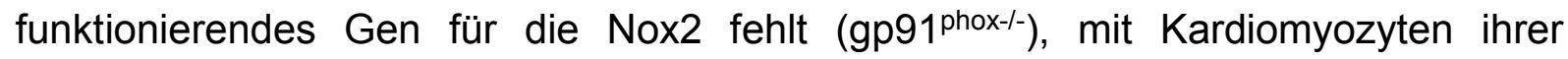
Wildtypwurfgeschwister verglichen. Auch hier wurden die Zellen beider Gruppen teilweise mit Ang II behandelt, um ggf. einen Nox2 - abhängigen Effekt des Ang II aufzuzeigen.

\subsection{Auswertung der Herz-Körpergewichtverhältnisse von CaMKII/ c- und gp91 $^{\text {phox }}$-Mäusen}

Um zu testen, ob es zwischen den einzelnen Genotypen der untersuchten Mäuse Unterschiede hinsichtlich Herzgewicht, Körpergewicht, Herz-Körpergewichtsverhältnis, Alter oder Geschlecht gibt, sind in der Tabelle 3.1 die jeweiligen Mittelwerte und Standardfehler (SEM) aufgeführt. Zwischen dem Wildtyp und seinem zugehörigen Knockout bestehen keine signifikanten Unterschiede in dem HerzKörpergewichtverhältnis. Allerdings zeigt sich, dass das Herz-Körpergewichtverhältnis bei den CaMKIIIC-Mäusen (WT und Knockout) tendenziell größer ist als bei den gp91 phox-Mäusen. Der Grund dafür könnte auch in ihrem etwas höheres Alter liegen: Im Durchschnitt sind die CaMKIIIc-Mäuse sieben Wochen älter. 


\begin{tabular}{|c|c|c|c|c|c|}
\hline Genotyp (N) & $\begin{array}{l}\text { Herz- } \\
\text { gewicht } \\
\text { [mg] }\end{array}$ & $\begin{array}{l}\text { Körper- } \\
\text { gewicht } \\
\text { [g] }\end{array}$ & $\begin{array}{l}\mathrm{HW} / \mathrm{BW} \\
{[\mathrm{mg} / \mathrm{g}]}\end{array}$ & $\begin{array}{l}\text { Alter } \\
\text { [Woche] }\end{array}$ & $\begin{array}{l}\text { Männlich } \\
\text { Meiblich }\end{array}$ \\
\hline WT gp91phox (12) & $\begin{array}{r}188,1 \\
\pm 5,58\end{array}$ & $\begin{array}{l}26,88 \\
\quad \pm 0,74\end{array}$ & $\begin{array}{l}7,076 \\
\pm 0,23\end{array}$ & $\begin{array}{r}12,92 \\
\pm 0,63\end{array}$ & $10 / 2$ \\
\hline gp91 phox-/- $(6)$ & $\begin{array}{l}187,8 \\
\pm 10,25\end{array}$ & $\begin{array}{l}24,86 \\
\pm 0,16\end{array}$ & $\begin{array}{l}7,019 \\
\pm 0,51\end{array}$ & $\begin{array}{l}12,6 \\
\pm 1,12\end{array}$ & $5 / 1$ \\
\hline WT CaMKII $\delta_{c}(17)$ & $\begin{array}{l}211,3 \\
\quad \pm 12,28\end{array}$ & $\begin{array}{r}26,42 \\
\pm 1,4\end{array}$ & $\begin{array}{l}8,085 \\
\pm 0,46\end{array}$ & $\begin{array}{l}19,88 \\
\pm 0,76\end{array}$ & $14 / 3$ \\
\hline CaMKIII $\delta_{c}^{-/-}(11)$ & $\begin{array}{l}178,3 \\
\pm 13,48\end{array}$ & $\begin{array}{l}23,4 \\
\quad \pm 1,97\end{array}$ & $\begin{array}{l}8,259 \\
\quad \pm 0,45\end{array}$ & $\begin{array}{l}20,73 \\
\pm 1,77\end{array}$ & $9 / 2$ \\
\hline
\end{tabular}

Tabelle 3-1: Basale Charakteristika der untersuchten Mäuse. Aufgeführt sind die Wildtyp-

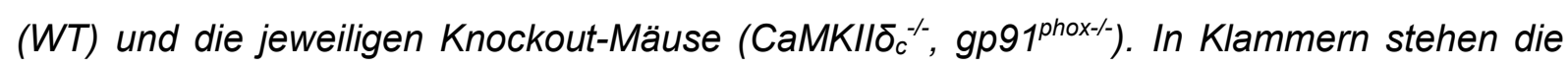
Anzahl (N) der untersuchten Mäuse. Zu beachten ist, dass von einer Maus bis zu vier Zellen verwendet worden sind. Herzgewicht und Körpergewicht der WT-Mäuse zeigen verglichen mit ihrem zugehörigen Knockout keine signifikanten Unterschiede.

\subsection{Angiotensin II beschleunigt die maximale Aufstrich- geschwindigkeit $\left(V_{\max }\right)$ des Aktionspotentials}

Die Aufstrichgeschwindigkeit in der Phase 0 des Aktionspotentials stellt ein Maß für die $\mathrm{Na}^{+}-$Kanalfunktion dar. Als $\mathrm{V}_{\max }$ wird die maximale Aufstrichgeschwindigkeit während der Phase 0 bezeichnet. Sie ist der Quotient aus Spannungsänderung pro Zeiteinheit $(\mathrm{dU} / \mathrm{dt})$ in $\mathrm{V} / \mathrm{s}$.

Die Aktionspotentiale in den Herzmuskelzellen der Maus wurden mittels der PatchClamp-Technik gemessen (siehe Kapitel 2.3). Die Abbildung 3.1 zeigt beispielhaft die Originalregistrierung eines Aktionspotentials. 


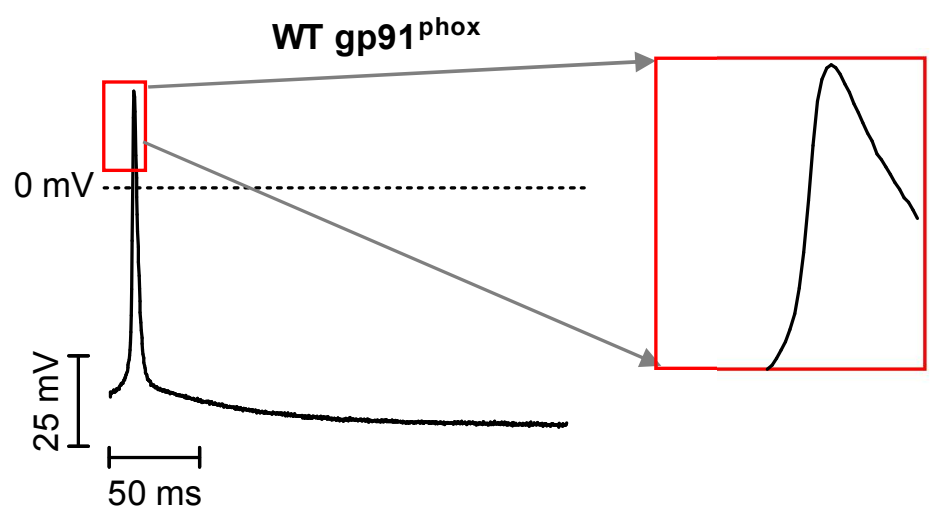

Abb. 3.1: Beispiel für die Originalregistrierung eines Aktionspotentials und die vergrößerte Darstellung des Aktionspotential-Aufstrichs. Hierbei handelt es sich um das Aktionspotential einer WTgp91 phoxHerzmuskelzelle.

Bei einer Stimulationsfrequenz von $0,5 \mathrm{~Hz}$ kommt es unter Ang II Exposition (10 min, $1 \mu \mathrm{mol} / \mathrm{L}$ ) zum Anstieg der $V_{\max }$ auf $92,51 \pm 10,98 \mathrm{~V} / \mathrm{s}$ ( $\mathrm{n}=19$; vs. Vehikel $60,61 \pm 6,70$ $\mathrm{V} / \mathrm{s}, \mathrm{n}=18$; siehe Abb. 3.2), der in der statistischen Untersuchung mit einem ZweiWege-ANOVA eine ausgeprägte Signifikanz aufweist $(p<0,001)$.

Ang II ist in der Lage die NADPH Oxidase 2 (Nox2) zu aktivieren. Um zu testen, ob Ang II via Nox2 zum $V_{\max }$-Anstieg führt, wurde als pharmakologischer Inhibitor Diphenyleniodoniumchlorid (DPI) eingesetzt. Unter DPI Exposition (10 min, $1 \mu \mathrm{mol} / \mathrm{L}$ ) führte Ang II lediglich zu einer $V_{\max } 65,6 \pm 15,11 \mathrm{~V} / \mathrm{s}(\mathrm{n}=4$, siehe Abb. 3.2), somit konnte Ang II unter Inhibition der Nox2 zu keinem signifikanten Anstieg der $V_{\max }$ führen. Verglichen mit der $V_{\max }$ der Zellen, die lediglich mit Ang II behandelt worden sind, zeigt sich eine statistisch signifikante Senkung der $\bigvee_{\max }$ in Herzmuskelzellen in Anwesenheit von DPI und Ang II ( $p<0,05$; Zwei-Wege-ANOVA). 
WT gp91 ${ }^{\text {phox }}$

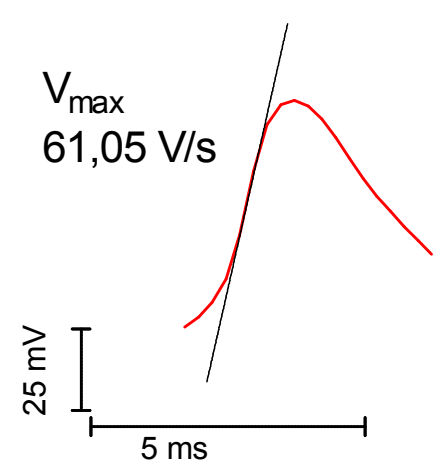

WT gp91 $91^{\text {phox }}$
+ Ang II

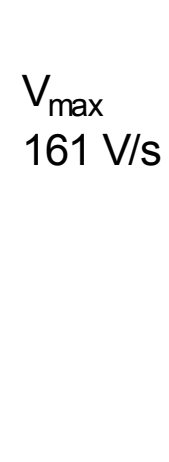

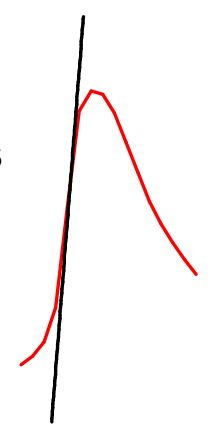

WT gp $91^{\text {phox }}$

+ Ang II + DPI

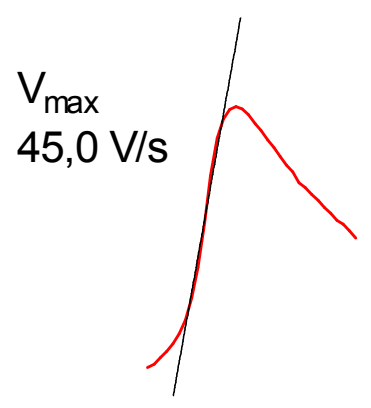

Abb. 3.2: Vergleich der $V_{\max }$ anhand von vergrößerten Originalregistrierungen. Ganz links ist die Messung basal, in der Mitte nach Stimulation mit Ang II und rechts in Anwesenheit von DPI. Die angegebenen $V_{\max }$ beziehen sich auf die beispielhafte Originalregistrierung und sind keine Mittelwerte für die Gruppe. Die schwarze Tangente dient als Hilfslinie, um den Anstieg zu verdeutlichen. Man erkennt, dass in Anwesenheit von Ang II die maximale Anstiegsgeschwindigkeit $\left(V_{\max }\right)$ gesteigert ist. Die abgebildeten Aktionspotentiale sind bei einer Stimulationsfrequenz von 0,5 Hz entstanden.

Da DPI als pharmakologischer Inhibitor möglicherweise unspezifische Effekte aufweist, wurde der Einfluss der Nox2 auf die Ang II-induzierte $V_{\max }$-Steigerung zusätzlich in Mäusen untersucht, denen das Gen der katalytischen Untereinheit der Nox2 fehlt (gp91 ${ }^{\text {phox-l- }}$ ). Hier zeigte sich, dass Ang II die $V_{\max }$ nicht wieder steigern konnte $(51,77 \pm 12,41 \mathrm{~V} / \mathrm{s}, \mathrm{n}=6$; vs. Vehikel $58,41 \pm 12,40 \mathrm{~V} / \mathrm{s}, \mathrm{n}=6$; Stimulationsfrequenz von $0,5 \mathrm{~Hz}$, siehe $A b b$. 3.3) und somit keine signifikante Veränderung der maximalen Aufstrichgeschwindigkeit (Zwei-Wege-ANOVA, t-Test).

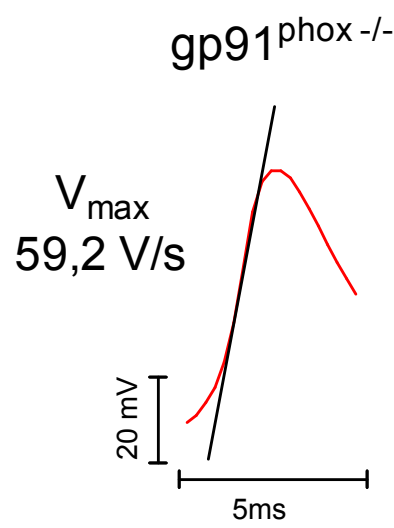$$
\text { gp91 } 1^{\text {phox }-/-}+\text { Ang II }
$$

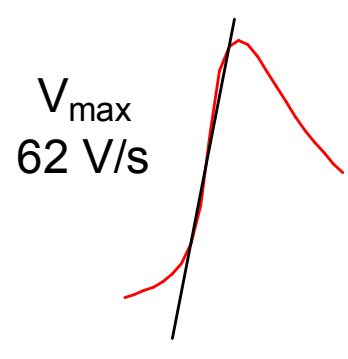

Abb. 3.3: Vergleich der $V_{\max }$ bei gp91 ${ }^{\text {phox--- }-M a ̈ u s e n ~ a n h a n d ~ v o n ~ O r i g i n a l r e g i s t r i e r u n g e n ~ o h n e ~(l i n k s) ~ u n d ~}$ mit der Hinzugabe von Ang II (rechts). Beide Kurven zeigen einen ähnlichen Anstieg. Die schwarze Linie dient als Hilfslinie zur Verdeutlichung des Anstiegs. Die angegebenen $\bigvee_{\max }-$ Werte beziehen sich auf die beispielhafte Originalregistrierung und sind keine Mittelwerte für die Gruppe. 
Der direkte Vergleich der $V_{\max }$ unter Ang II-Wirkung zwischen der gp91 ${ }^{\text {phox-I--Maus und }}$ ihrer Geschwister-Wildtyp-Maus zeigt, dass die $V_{\max }$ den Kardiomyozyten der Knockout-Maus, die das Gen für die katalytische Untereinheit der Nox2 nicht besitzt, signifikant niedriger ist als in den Zellen der Wildtyp-Maus $(p<0,001$; Zwei-WegeANOVA).

Die Aktionspotentiale wurden bei 5 verschiedenen Stimulationsfrequenzen gemessen, um eine mögliche Frequenz-Abhängigkeit zu erfassen. Abbildung 3.4 zeigt, dass die Frequenz, mit der die Zelle zu einem Aktionspotential stimuliert wurde, keinen signifikanten Einfluss auf den $\bigvee_{\text {max }}$ besitzt (Zwei-Wege-ANOVA mit Post-Hoc-Analyse). Abbildung 3.4 zeigt eine Übersicht über die $V_{\max }$ der jeweiligen Gruppen bei unterschiedlichen Frequenzen.

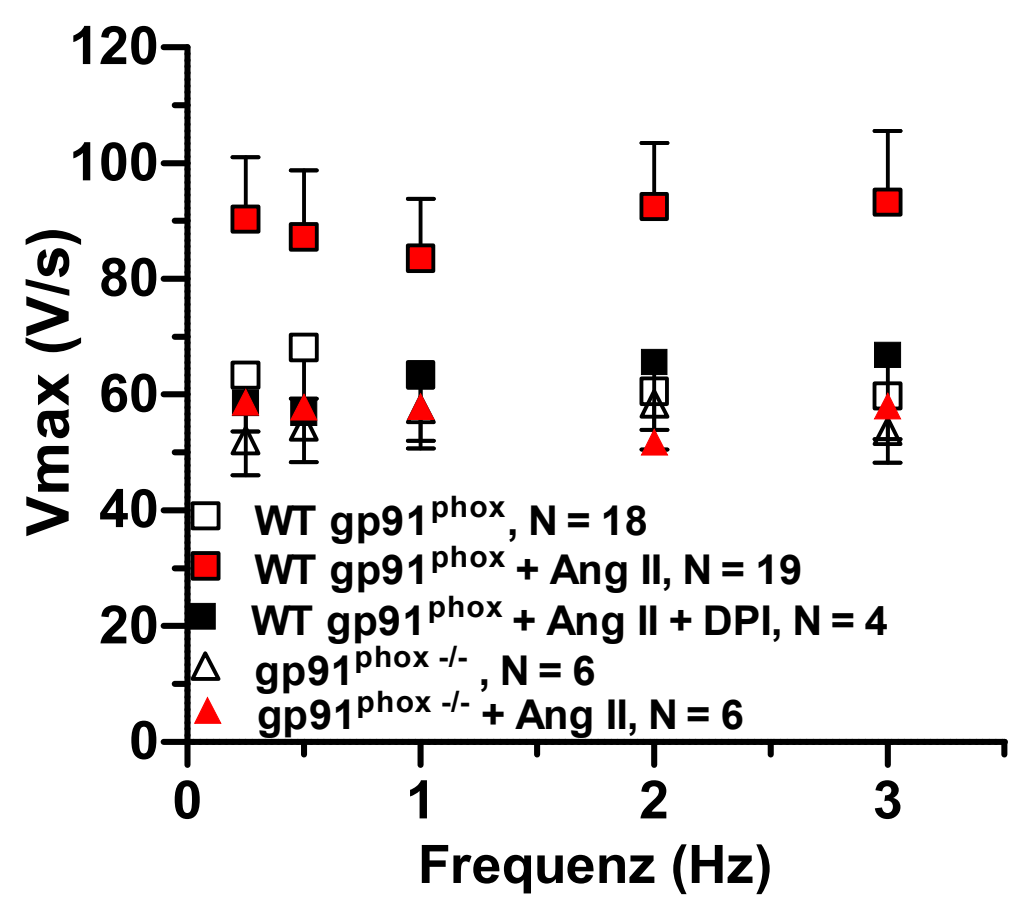

Abb. 3.4: Gemessen wurden die Aktionspotentiale bei den Stimulationsfrequenzen $0,25 \mathrm{~Hz}, 0,5 \mathrm{~Hz}, 1$ $\mathrm{Hz}, 2 \mathrm{~Hz}$ und $3 \mathrm{~Hz}$. Die Abbildung gibt eine Übersicht über die $\mathrm{V}_{\max }$ der verschieden Gruppen bei unterschiedlichen Frequenzen. Man sieht bei allen Frequenzen die signifikante Zunahme der $V_{\max }$ bei Hinzugabe von Angiotensin II zur Wildtyp-Mauszelle, die aber auch genauso deutlich wieder zurückgeht bei der Hinzugabe von DPI zu Ang II. In der Knockout-Maus bleibt diese Veränderung aus. Zwischen den verschiedenen Frequenzen zeichnet sich kein signifikanter Unterschied ab. 
Um eine Abhängigkeit der Ang II - Effekte von der CaMKII $\delta_{c}$ zu untersuchen, wurden analog zu den oben beschriebenen Messungen Aktionspotentiale von Wildtyp-Mäusen mit Aktionspotentialen von Mäusen, denen das Gen für die CaMKIII $\delta_{c}$ fehlt $\left(\right.$ CaMKII $\delta_{c}^{---}$), vergleichend untersucht.

Abbildung 3.5 zeigt zunächst die Messungen in der Wildtyp-Maus: Unter Ang II Exposition (10 min, $1 \mu \mathrm{mol} / \mathrm{L})$ steigt die Aufstrichgeschwindigkeit $\left(V_{\max }\right)$ des Aktionspotentials auf $99,34 \pm 10,36 \mathrm{~V} / \mathrm{s}(\mathrm{n}=13$; vs. Vehikel $64,15 \pm 8,98 \mathrm{~V} / \mathrm{s}, \mathrm{n}=14$ ) und zeigt damit eine signifikante Zunahme $(p<0,05$; Zwei-Wege-ANOVA). Unter Hinzugabe von DPI (10 min, $1 \mu \mathrm{mol} / \mathrm{L})$ sinkt der Mittelwert für die Aufstrichgeschwindigkeit signifikant auf $69,64 \pm 11,75 \mathrm{~V} / \mathrm{s}(n=6 ; p<0,05)$.

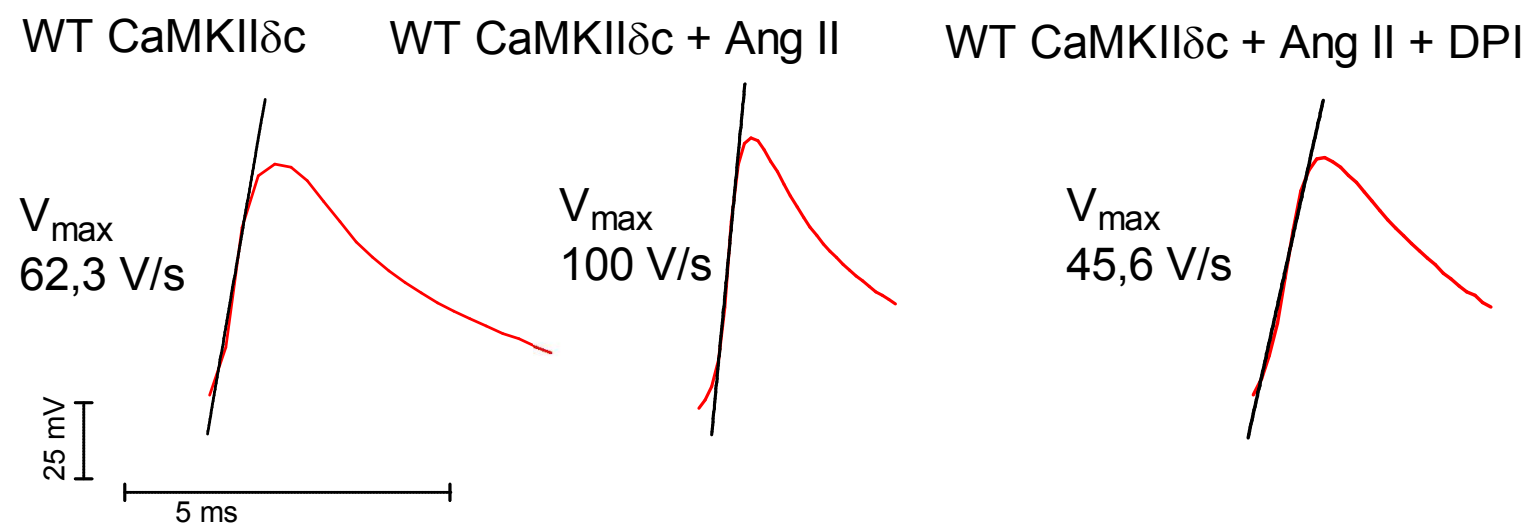

Abb. 3.5: Vergleich der $V_{\max }$ anhand von vergrößerten Originalregistrierungen. Exemplarische Darstellung des ersten Abschnittes der Aktionspotentiale, die bei Wildtyp-CaMKII $\delta_{c}$-Mäusen gemessen wurden; links sieht man die basale Messung, in der Mitte mit Hinzugabe von Ang II und ganz rechts mit Ang II und DPI. Die angegebenen $V_{\max }$ beziehen sich auf das Beispiel und sind keine Mittelwerte für die Gruppe. Die abgebildeten Aktionspotentiale sind bei einer Stimulationsfrequenz von $0,5 \mathrm{~Hz}$ entstanden.

Interessanterweise konnte bei der Untersuchung der Kardiomyozyten von CaMKIII ${ }_{c}^{-1-}$ -Mäusen ebenfalls unter Ang II-Exposition (10 min, $1 \mu \mathrm{mol} / \mathrm{L}$ ) ein signifikanter Anstieg der $V_{\max }$ auf $104,26 \pm 13,75 \mathrm{~V} / \mathrm{s}$ ( $n=12$; vs. Vehikel 70,69 $\pm 10,98 \mathrm{~V} / \mathrm{s}, \mathrm{n}=9$ ) verzeichnet werden ( $p<0,05$; Ein-Wege-ANOVA). Fügte man aber zusätzlich zum Ang II den NoxInhibitor DPI (10 min, $1 \mu \mathrm{mol} / \mathrm{L}$ ) hinzu, nahm die Aufstrichgeschwindigkeit wiederum mit 76,92 $\pm 20,69 \mathrm{~V} / \mathrm{s}(n=6)$ signifikant ab ( $p<0,05$ vs. CaMKIII $\delta^{-1-}+$ Ang II). Abb. 3.6 stellt diese Effekte graphisch dar. 


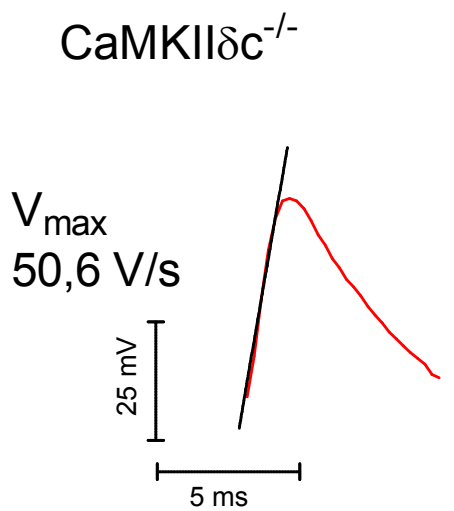

$$
\begin{aligned}
& \text { CaMKII } \delta c^{-/-} \\
& + \text {Ang II }
\end{aligned}
$$

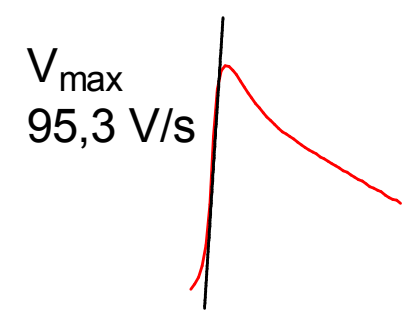

CaMKII $\delta c^{-/-}$

+ Ang II + DPI

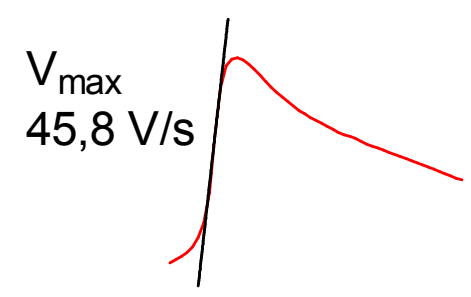

Abb. 3.6: Vergleich der $V_{\max }$ anhand von vergrößerten Originalregistrierungen. Exemplarische Darstellung des ersten Abschnittes der Aktionspotentiale, die bei CaMKII $\delta_{c}{ }^{-1-}$-Mäusen gemessen wurden; links sieht man die basale Messung, in der Mitte mit Hinzugabe von Ang II und ganz rechts mit Ang II und DPI. Die angegebenen $V_{\max }$ beziehen sich auf das Beispiel und sind keine Mittelwerte für die Gruppe. Die abgebildeten Aktionspotentiale sind bei einer Stimulationsfrequenz von $0,5 \mathrm{~Hz}$ entstanden.

Auch hier wurden die Aktionspotentiale bei unterschiedlichen Stimulationsfrequenzen gemessen, um eine mögliche Abhängigkeit der gemessenen Werte von der Stimulationsfrequenz zu untersuchen. Einen signifikanten Unterschied bezüglich der $V_{\max }$ gab es zwischen den jeweiligen Frequenzen nicht (Zwei-Wege-ANOVA). Abbildung 3.7 zeigt eine Übersicht über die $V_{\max }$-Mittelwerte in Abhängigkeit von den jeweiligen Frequenzen.
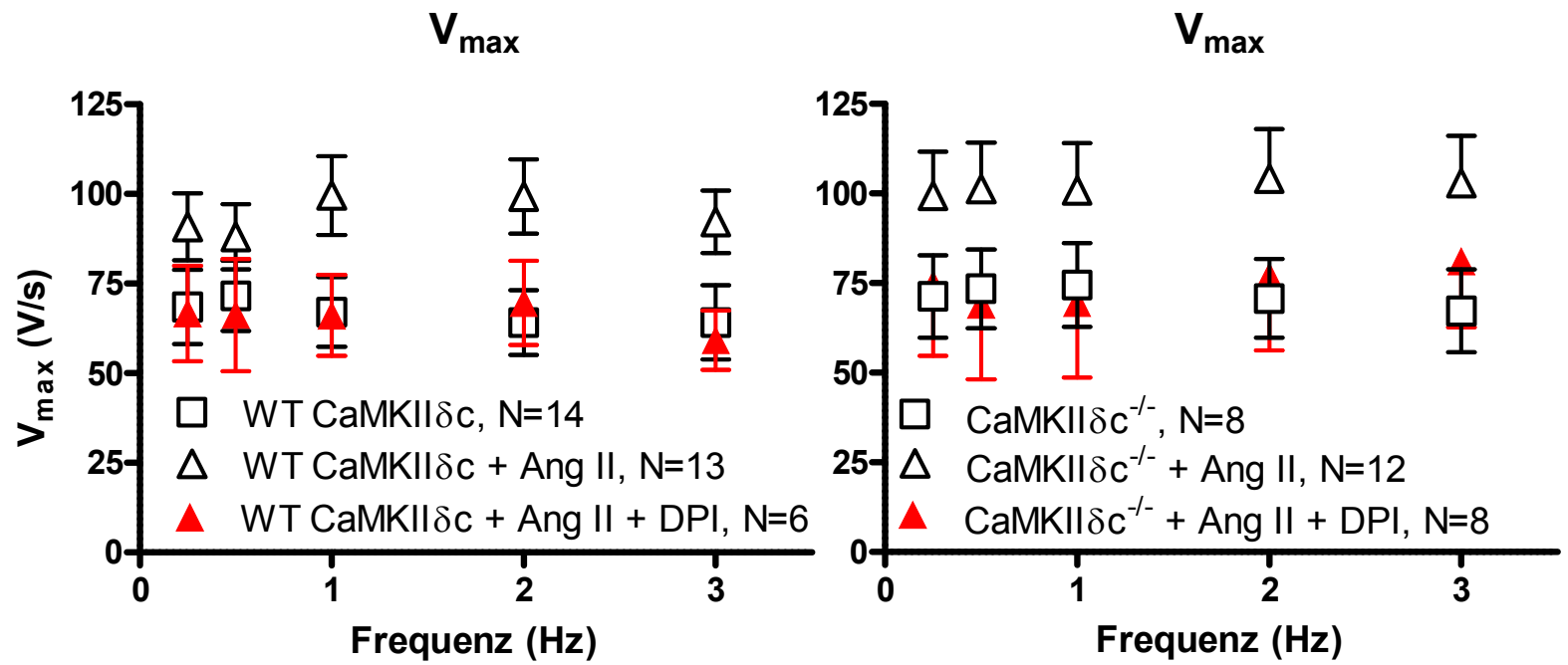

Abb. 3.7: Gemessen wurden die Aktionspotentiale bei den Stimulationsfrequenzen $0,25 \mathrm{~Hz}, 0,5 \mathrm{~Hz}, 1$ $\mathrm{Hz}, 2 \mathrm{~Hz}$ und $3 \mathrm{~Hz}$. Die Abbildung gibt eine Übersicht über die $\mathrm{V}_{\max }$ der verschieden Gruppen bei unterschiedlichen Frequenzen. Links: Wildtyp-CaMKII $\delta_{c}$, rechts: CaMKII $\delta_{c}{ }^{-1}$. 
In der Abbildung 3.8 sind in einem Säulendiagramm alle gemessenen $V_{\text {max }}$-Mittelwerte (und die jeweiligen SEM) vergleichend dargestellt.

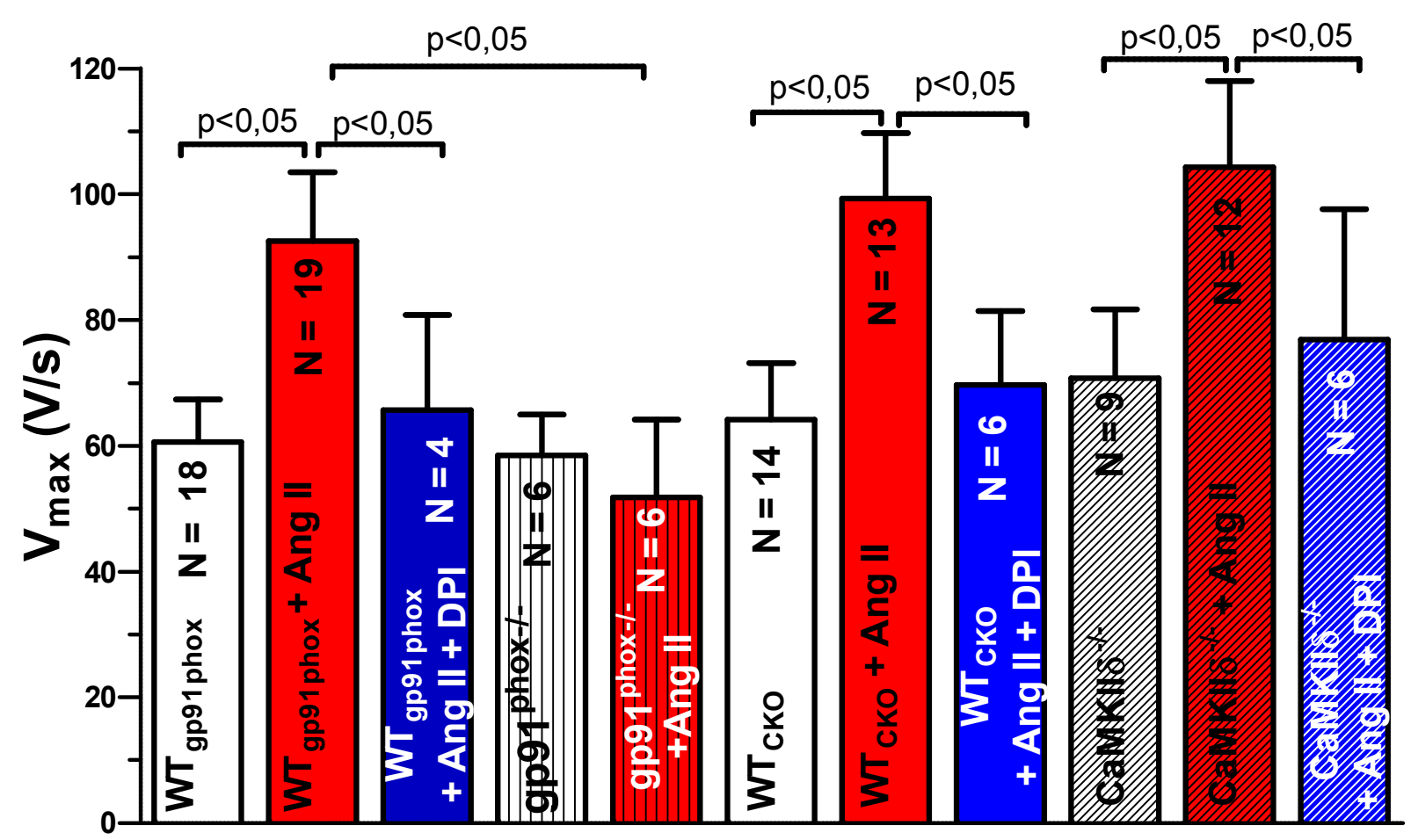

Abb. 3.8: Säulendiagramm zur Übersicht über die $V_{\max }$-Mittelwerte bei einer Stimulationsfrequenz von $0,5 \mathrm{~Hz}$. Angegeben sind die P-Werte aus Ein-Wege-ANOVA.

Zusammenfassend lässt sich also feststellen, dass die $\mathrm{V}_{\max }$, die wiederum die $\mathrm{Na}^{+}-$ Kanalfunktion in der Aktionspotentialbildung darstellt, in Wildtyp-Mäusen unter Ang II signifikant zunimmt. Interessanterweise zeigt sich dieser Anstieg der Vmax unter Ang II Exposition auch bei den Mäusen, denen das Gen für die CaMKII $\delta_{c}$ fehlt $\left(\right.$ CaMKII $\left._{c}{ }^{-/-}\right)$. Bei pharmakologischer Hemmung der Nox2 durch DPI sowie in Mäusen, denen das Gen für die katalytische Funktion der Nox2 fehlt, führt die Ang II Exposition allerdings zu keiner signifikanten Steigerung der $V_{\max }$.

\subsection{Angiotensin II hat keinen Einfluss auf die Aktionspotential- dauer}

Die Dauer eines Aktionspotentials kann die Entstehung von Arrhythmien maßgeblich mitbestimmen, indem eine Verlängerung derselben zur Wiederöffnung spannungsabhängiger Kalziumkanäle und frühen Nachdepolarisationen führen kann (siehe Kapitel 1.4). 
Um den Einfluss von Ang II auf die Aktionspotentialdauer zu untersuchen, wurde die Dauer bis zur 80\%igen Repolarisation (APD 80) der Aktionspotentiale als Maß für die Aktionspotentialdauer gemessen.

Um mögliche Veränderungen der APD 80 unter der Gabe von Ang II zu erfassen, aber auch um die Rolle der Nox2 hier zu prüfen, wurden wieder basale Messungen, Messungen mit Ang II und letztlich auch Messungen mit Ang II und DPI vergleichend durchgeführt. Außerdem erfolgte auch hier der Vergleich zwischen dem Wildtyp und dem jeweiligen Knockout.

Interessanterweise beträgt unter Ang II Exposition die ADP 80 in Kardiomyozyten der

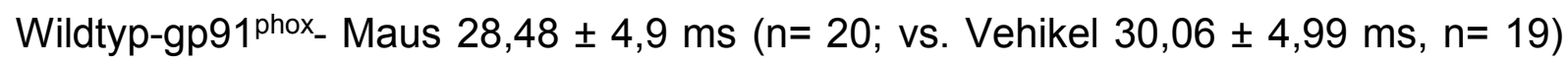
und zeigt damit in der statistischen Analyse mittels Zwei-Wege-ANOVA keine signifikante Veränderung. Ebenso wenig führt die Hinzugabe von DPI zu einer signifikanten Veränderung $(32,5 \pm 4,32 \mathrm{~ms}, \mathrm{n}=4)$.

In den Kardiomyozyten der Mäuse, denen das Gen für die katalytische Einheit der Nox2 fehlt (gp91 phox-I-Mäuse), führt die Ang II Exposition (10 min, $1 \mu \mathrm{mol} / \mathrm{L}$ ) eine APD 80 von $20,5 \pm 6,20 \mathrm{~ms}$ (vs. Vehikel 20,86 $\pm 3,38 \mathrm{~ms}$ ) und damit keine signifikante Änderung der APD 80.

Vergleicht man jedoch die unbehandelten Wildtyp-Mäuse mit den entsprechenden Knockout-Mäusen (gp91 phox-l-), scheinen die Kardiomyozyten der Knockout-Mäuse mit $20,86 \pm 3,38$ ms eine tendenziell kürzere APD 80 aufzuweisen (vs. Wildtyp-gp91 phox_ Maus $28,48 \pm 4,9 \mathrm{~ms}$ ), allerdings zeigt die statistische Untersuchung dieser beiden Gruppen keinen signifikanten Unterschied ( $p>0,05$; Ein-Wege-ANOVA).

Der Vergleich zwischen verschiedenen Stimulationsfrequenzen führte zu keinerlei signifikanten Unterschieden. Die Abbildung 3.9 zeigt frequenzabhängig die jeweiligen Mittelwerte für APD 80. 


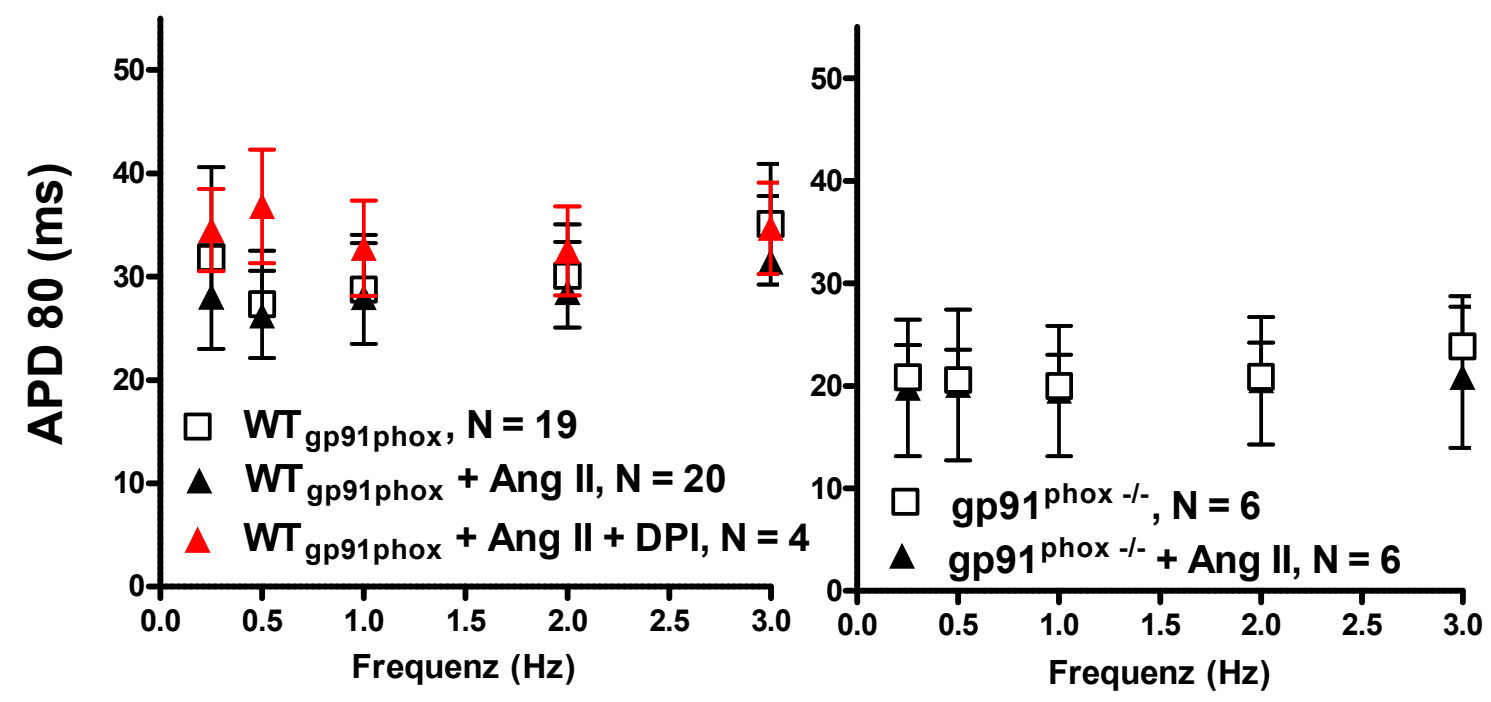

Abb. 3.9: APD 80. Links die WT gp91phox, rechts gp91phox-- . Man sieht bei keiner der aufgeführten Frequenzen eine signifikante Veränderung der APD 80 unter pharmakologischer Intervention. Zwischen den verschiedenen Frequenzen besteht kein signifikanter Unterschied (multiple Zwei-Wege-ANOVA).

Um die Abhängigkeit der APD von der CaMKII $\delta_{c}$ zu prüfen, wurde analog zu den oben beschriebenen Messungen die APD 80 in Mäusen, denen das Gen für das Enzym CaMKIII $\delta_{c}$ fehlt, vergleichend zum entsprechenden Wildtyp gemessen. Auch hier wurden die Messungen der APD 80 basal, nach Hinzugabe von Ang II (10 min, $1 \mu \mathrm{mol} / \mathrm{L}$ ) und nach Hinzugabe von Ang II und DPI (10 min, $1 \mu \mathrm{mol} / \mathrm{L}$ ) verglichen. Abbildung 3.10 zeigt die jeweiligen Mittelwerte in Abhängigkeit von der Frequenz.
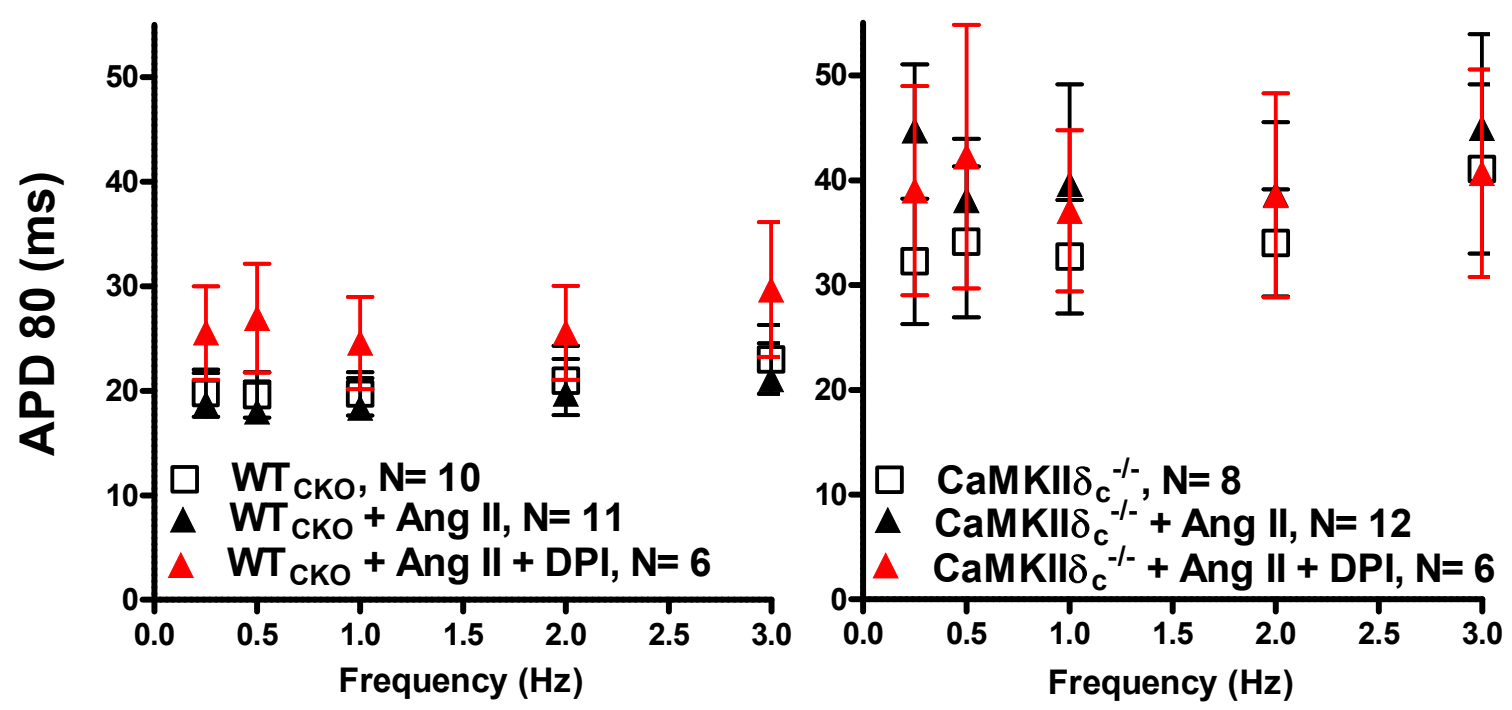

Abb. 3.10: : APD 80 in der Wildtyp- (links) und der Knockout-CaMKII $\delta_{c}$ (rechts) -Maus. Es sind keine signifikanten Unterschiede zwischen den verschieden Gruppen zu verzeichnen. Auch zeigt sich keine signifikante frequenzabhängige Veränderung. WTcko steht für den Wildtyp der CaMKIIסc. 
Unter Ang II - Exposition beträgt in den Kardiomyozyten der Wildtyp-CaMKIII $\delta_{c}$ - Maus der Mittelwert für die APD 80 19,68 $\pm 3,34$ ms ( $n=11$; vs. Vehikel 20,98 $\pm 3,32 \mathrm{~ms}, \mathrm{n}=$ 10) und zeigt damit keine signifikante Veränderung.

Für die kombinierte Gabe von Ang II und DPI beträgt der Mittelwert der APD 80 25,54 $\pm 4,49 \mathrm{~ms}(n=6)$. Hier scheint sich eine tendenzielle Verlängerung der APD 80 abzuzeichnen, die allerdings statistisch nicht signifikant ist $(p>0,05$, Ein-WegeANOVA).

In den Kardiomyozyten der Mäuse, denen das Gen für die Expression der CaMKIII $\delta_{c}$

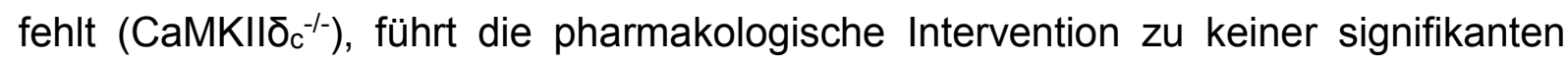
Veränderung der APD 80: Unter Ang II Exposition (10 min, $1 \mu \mathrm{mol} / \mathrm{L}$ ) beträgt der Mittelwert der APD 80 in den Kardiomyozyten der CaMKII $\delta_{\mathrm{c}}{ }^{-1-}$-Mäuse 38,65 $\pm 6,88 \mathrm{~ms}$ ( $n=12$; vs. Vehikel $34,03 \pm 5,1 \mathrm{~ms}, n=8$ ), welcher keine signifikante Veränderung zeigt. Bei Hinzugabe von Ang II und DPI (10 min, $1 \mu \mathrm{mol} / L)$ beträgt der Mittelwert für die ADP 80 in den Kardiomyozyten der CaMKII $\delta_{\mathrm{c}}{ }^{-1-}$-Mäusen 38,56 $\pm 9,74 \mathrm{~ms}$ ( $\mathrm{n}=6$; vs. CaMKII $\delta_{c}{ }^{-1-}+$ Ang II 38,65 $\pm 6,88 \mathrm{~ms} ; \mathrm{p}>0,05$; t-Test).

Vergleicht man allerdings den Wildtyp mit dem entsprechenden Knockout, so zeigen sich durchaus signifikante Unterschiede: In den Kardiomyozyten der CaMKII $\delta_{\mathrm{c}}{ }^{-1-}$ sind die APD $80 \mathrm{im}$ Vergleich zum Wildtyp signifikant verlängert $(p<0,05$; $t$-Test; siehe Abbildung 3.11).

Auch unter Ang II - Exposition ist die APD 80 in den Kardiomyozyten der CaMKII $\mathrm{c}_{\mathrm{c}}^{-1-}$ Mäuse 38,65 $\pm 6,88$ ms signifikant länger als in Zellen der Wildtyp-Mäuse unter Ang IIExposition ( $p<0,05$, t-Test) und zeigt damit auch im Vergleich zu dem entsprechenden Wildtyp eine signifikante Verlängerung der APD 80 ( $p<0,05$; t-Test, siehe Abbildung 3.11). 


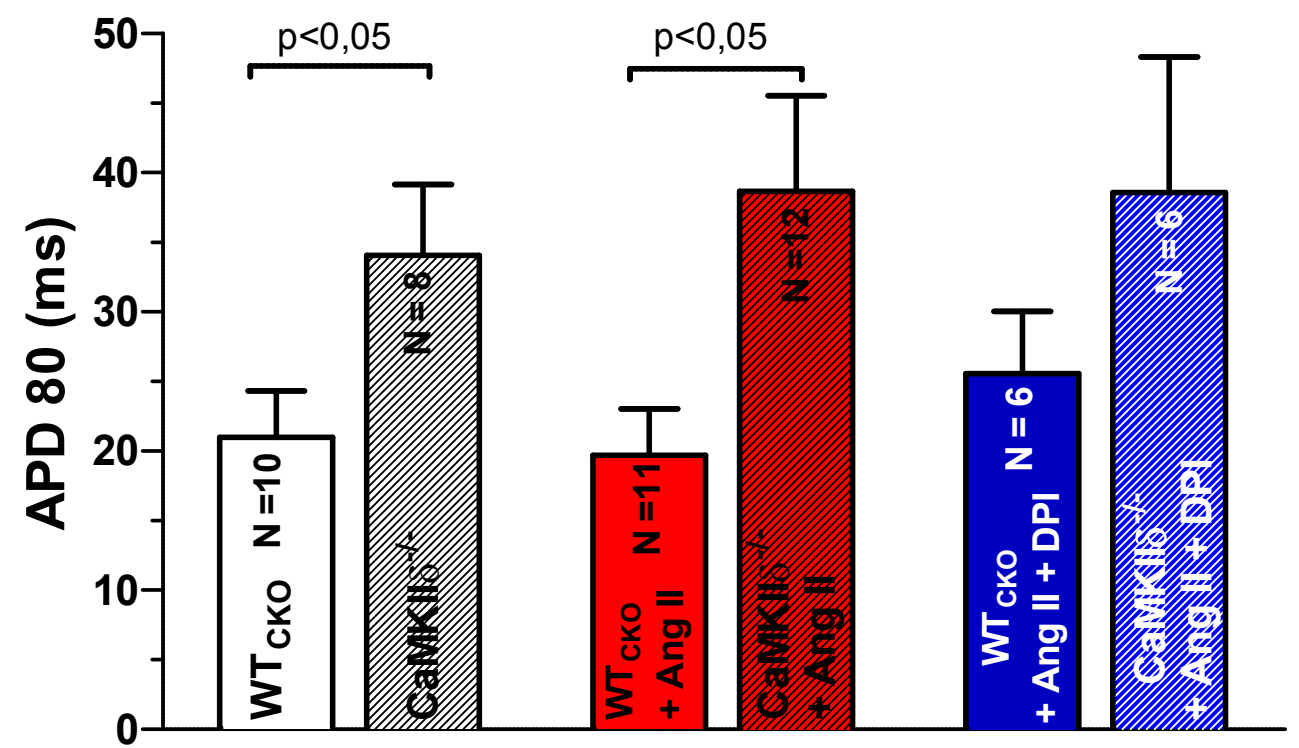

Abb. 3.11: Säulendiagramm zum Vergleich der APD 80 der Wildtypmäuse mit den CaMKII $\delta_{c}^{-1-M a ̈ u s e n . ~}$ Nebeneinander abgebildet sind die basalen Messungen (links), die Messungen unter Ang II-Exposition (mittig) und die Messungen unter DPI-Exposition. WTCKO steht für den Wildtyp der CaMKIII $\delta_{\mathrm{c}}$. Angegeben sind die P-Werte aus Ein-Weg-ANOVA.

Abbildung 3.12 zeigt eine Übersicht über die Veränderungen der APD 80.

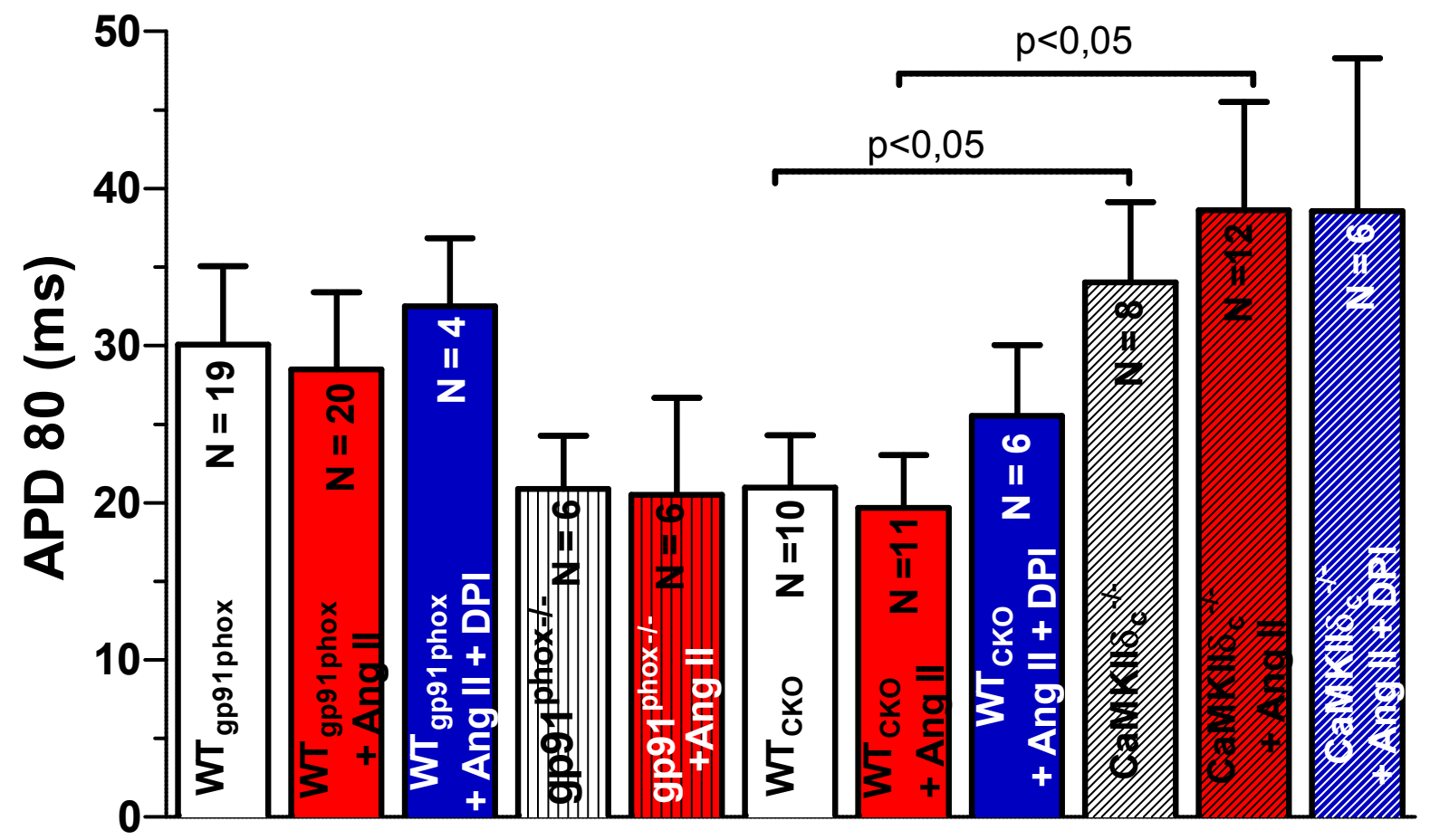

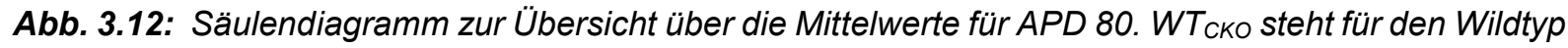
$\operatorname{der}$ CaMKII $\delta_{c}$. CaMKIII--- steht für die Knockout-Mäuse, die das Enzym CaMKII $\delta_{c}$ nicht ausbilden. Über den jeweiligen Säulen ist die Anzahl der untersuchten Zellen $(N)$ angegeben. Angeggeben sind die PWerte aus Ein-Weg-ANOVA. 
Zusammenfassend hat die Ang II-Exposition keinen Effekt auf die Aktionspotentialdauer (in Form von APD 80 gemessen) gezeigt. Auch die Inhibition der Nox2 hat die Aktionspotentialdauer nicht beeinflusst. Allein die Abwesenheit der CaMKII $\delta_{c}$ konnte zu einer signifikanten Verlängerung der APD 80 führen. 


\subsection{Synopsis aller AP-Parameter und zugehörigen Messvariablen}

Zusätzlich zu $V_{\max }$ und APD 80 sind auch andere Parameter, nämlich Systole (maximale systolische Spannung), Diastole (minimale diastolische Spannung), Duration (Aktionspotentialdauer), Amplitude (Aktionspotentialamplitude), APD 30 (Dauer des Aktionspotentials bis zur 30\%igen Repolarisation), APD 50 (Dauer des Aktionspotentials bis zur 50\%igen Repolarisation) und APD 90 (Dauer des Aktionspotentials bis zur 90\%igen Repolarisation), gemessen und verglichen worden.

\begin{tabular}{|c|c|c|c|c|c|c|c|c|c|c|c|}
\hline & \multicolumn{3}{|c|}{ WT gp91 phox } & \multicolumn{2}{|c|}{ gp91 $1^{\text {phox-l- }}$} & \multicolumn{3}{|c|}{ WT CaMKIIסc } & \multicolumn{3}{|c|}{ CaMKIIסc ${ }^{-1-}$} \\
\hline & $\begin{array}{c}\text { DMSO } \\
N=20 \\
N_{\text {Maus }}=7\end{array}$ & $\begin{array}{c}\text { Ang II } \\
N=20 \\
N_{\text {Maus }}=6\end{array}$ & $\begin{array}{c}\text { Ang II } \\
+\mathrm{DPI} \\
\mathrm{N}=4 \\
\mathrm{~N}_{\text {Maus }}=2\end{array}$ & $\begin{array}{c}\text { DMSO } \\
\\
\mathrm{N}=6 \\
\mathrm{~N}_{\text {Maus } 3}\end{array}$ & $\begin{array}{c}\text { Ang II } \\
N=6 \\
N_{\text {Maus }}=3\end{array}$ & $\begin{array}{c}\text { DMSO } \\
N=14 \\
N_{\text {Maus }}=8\end{array}$ & $\begin{array}{c}\text { Ang II } \\
N=13 \\
N_{\text {Maus }}=8\end{array}$ & $\begin{array}{c}\text { Ang II } \\
+D P I \\
N=7 \\
N_{\text {Maus }}=4\end{array}$ & $\begin{array}{c}\text { DMSO } \\
N=10 \\
N_{\text {Maus }}=5\end{array}$ & $\begin{array}{c}\text { Ang II } \\
N=12 \\
N_{\text {Maus }}=6\end{array}$ & $\begin{array}{c}\text { Ang II } \\
+\mathrm{DPI} \\
\mathrm{N}=5 \\
\mathrm{~N}_{\text {Maus }}=3\end{array}$ \\
\hline & \begin{tabular}{|l}
23,02 \\
$(3,78)$
\end{tabular} & $\begin{array}{l}26,61 \\
(3,36)\end{array}$ & $\begin{array}{l}16,73 \\
(6,78)\end{array}$ & $\begin{array}{l}20,31 \\
(4,94)\end{array}$ & $\begin{array}{l}25,72 \\
(5,58)\end{array}$ & \begin{tabular}{|l|}
23,93 \\
$(4,17)$
\end{tabular} & $\begin{array}{l}34,51 \\
(3,25)\end{array}$ & $\begin{array}{l}33,07 \\
(5,30)\end{array}$ & $\begin{array}{l}28,83 \\
(5,08)\end{array}$ & $\begin{array}{l}34,98 \\
(5,01)\end{array}$ & $\begin{array}{l}29,38 \\
(9,03)\end{array}$ \\
\hline $\begin{array}{c}\text { Diastole } \\
{[\mathrm{mV}]}\end{array}$ & \begin{tabular}{|l}
$-63,26$ \\
$(1,00)$
\end{tabular} & $\begin{array}{l}-65,00 \\
(1,71)\end{array}$ & $\begin{array}{r}-70,05 \\
(1,48)\end{array}$ & $\begin{array}{l}-67,06 \\
(1,77)\end{array}$ & $\begin{array}{l}-65,16 \\
(2,02)\end{array}$ & \begin{tabular}{|}
$-66,33$ \\
$(2,02)$
\end{tabular} & $\begin{array}{l}-68,42 \\
(1,15)\end{array}$ & $\begin{array}{c}-62,03 \\
(0,83)\end{array}$ & $\begin{array}{l}-65,48 \\
(1,53)\end{array}$ & $\begin{array}{l}-66,40 \\
(1,69)\end{array}$ & $\begin{array}{l}-64,48 \\
(1,85)\end{array}$ \\
\hline $\begin{array}{c}\text { Amplitude } \\
{[\mathrm{mV}]}\end{array}$ & $\begin{array}{l}86,29 \\
(3,27)\end{array}$ & $\begin{array}{l}91,62 \\
(3,45)\end{array}$ & $\begin{array}{l}86,78 \\
(6,25)\end{array}$ & $\begin{array}{l}87,38 \\
(3,92)\end{array}$ & $\begin{array}{l}90,88 \\
(6,50)\end{array}$ & $\begin{array}{l}90,26 \\
(3,63)\end{array}$ & $\begin{array}{l}102,9 \\
(3,28)\end{array}$ & $\begin{array}{l}95,09 \\
(4,92)\end{array}$ & $\begin{array}{l}94,30 \\
(5,10)\end{array}$ & $\begin{array}{l}101,4 \\
(4,29)\end{array}$ & $\begin{array}{l}93,85 \\
(8,62)\end{array}$ \\
\hline $\begin{array}{c}\text { Duration } \\
{[\mathrm{ms}]}\end{array}$ & $\begin{array}{c}117,2 \\
(8,6)\end{array}$ & $\begin{array}{l}117,7 \\
(12,1)\end{array}$ & $\begin{array}{l}109,1 \\
(8,83)\end{array}$ & $\begin{array}{l}80,33 \\
(7,58)\end{array}$ & $\begin{array}{l}90,33 \\
(5,60)\end{array}$ & $\begin{array}{l}116,3 \\
(10,0)\end{array}$ & $\begin{array}{l}94,65 \\
(13,5)\end{array}$ & $\begin{array}{l}93,86 \\
(8,08)\end{array}$ & $\begin{array}{l}118,4 \\
(12,7)\end{array}$ & $\begin{array}{l}110,9 \\
(11,6)\end{array}$ & $\begin{array}{l}115,6 \\
(17,7)\end{array}$ \\
\hline $\begin{array}{c}\text { ADP } 30 \\
{[\mathrm{~ms}]}\end{array}$ & $\begin{array}{c}4,04 \\
(0,46)\end{array}$ & $\begin{array}{c}4,00 \\
(0,54)\end{array}$ & $\begin{array}{c}3,81 \\
(0,48)\end{array}$ & $\begin{array}{c}3,88 \\
(0,69)\end{array}$ & $\begin{array}{c}4,42 \\
(0,87)\end{array}$ & $\begin{array}{c}5,98 \\
(1,38)\end{array}$ & $\begin{array}{c}4,79 \\
(1,19)\end{array}$ & $\begin{array}{c}5,50 \\
(1,67)\end{array}$ & $\begin{array}{l}6,45 \\
1,85)\end{array}$ & $\begin{array}{c}6,60 \\
(1,53)\end{array}$ & $\begin{array}{l}10,15 \\
(2,76)\end{array}$ \\
\hline $\begin{array}{l}\text { ADP } 50 \\
{[\mathrm{~ms}]}\end{array}$ & \begin{tabular}{|c}
7,08 \\
$(0,94)$
\end{tabular} & $\begin{array}{c}7,11 \\
(1,07)\end{array}$ & $\begin{array}{c}6,56 \\
(0,56)\end{array}$ & $\begin{array}{c}6,92 \\
(1,26)\end{array}$ & $\begin{array}{c}7,92 \\
(1,86)\end{array}$ & $\begin{array}{l}10,11 \\
(2,18)\end{array}$ & $\begin{array}{c}9,87 \\
(2,36)\end{array}$ & $\begin{array}{c}9,86 \\
(2,42)\end{array}$ & $\begin{array}{l}13,18 \\
(3,76)\end{array}$ & $\begin{array}{l}13,17 \\
(2,96)\end{array}$ & $\begin{array}{l}19,10 \\
(5,49)\end{array}$ \\
\hline $\begin{array}{l}\text { ADP } 80 \\
\text { [ms] }\end{array}$ & \begin{tabular}{|l}
30,06 \\
$(4,99)$
\end{tabular} & $\begin{array}{l}28,48 \\
(4,90)\end{array}$ & $\begin{array}{l}32,50 \\
(4,32)\end{array}$ & $\begin{array}{l}20,88 \\
(3,38)\end{array}$ & $\begin{array}{l}20,50 \\
(6,20)\end{array}$ & $\begin{array}{l}20,98 \\
(3,32)\end{array}$ & $\begin{array}{c}19,68 \\
(3,4)\end{array}$ & $\begin{array}{l}25,54 \\
(4,49)\end{array}$ & $\begin{array}{l}34,03 \\
(5,10)\end{array}$ & $\begin{array}{l}38,65 \\
(6,88)\end{array}$ & $\begin{array}{l}38,56 \\
(9,74)\end{array}$ \\
\hline $\begin{array}{l}\text { ADP } 90 \\
\text { [ms] }\end{array}$ & \begin{tabular}{|l}
63,41 \\
$(6,87)$
\end{tabular} & $\begin{array}{l}65,85 \\
(9,39)\end{array}$ & $\begin{array}{l}63,94 \\
(5,58)\end{array}$ & $\begin{array}{l}39,96 \\
(3,97)\end{array}$ & $\begin{array}{l}42,79 \\
(5,87)\end{array}$ & $\begin{array}{l}53,82 \\
(5,70)\end{array}$ & $\begin{array}{l}51,92 \\
(11,9)\end{array}$ & $\begin{array}{l}52,25 \\
(6,42)\end{array}$ & $\begin{array}{l}72,02 \\
(10,2)\end{array}$ & $\begin{array}{l}65,42 \\
(8,17)\end{array}$ & $\begin{array}{l}70,65 \\
(13,7)\end{array}$ \\
\hline $\begin{array}{l}V_{\max } \\
{[\mathrm{V} / \mathrm{s}]}\end{array}$ & \begin{tabular}{|l}
60,61 \\
$(6,70)$
\end{tabular} & $\begin{array}{l}92,51 \\
(10,9)\end{array}$ & $\begin{array}{l}65,63 \\
(15,1)\end{array}$ & $\begin{array}{l}58,42 \\
(6,54)\end{array}$ & $\begin{array}{l}51,77 \\
(12,4)\end{array}$ & $\begin{array}{l}64,15 \\
(8,98)\end{array}$ & $\begin{array}{l}99,34 \\
(10,4)\end{array}$ & $\begin{array}{l}69,65 \\
(11,7)\end{array}$ & $\begin{array}{l}70,69 \\
(11,0)\end{array}$ & $\begin{array}{l}104,3 \\
(13,8)\end{array}$ & $\begin{array}{l}76,93 \\
(20,7)\end{array}$ \\
\hline
\end{tabular}

Tab. 3-2: Übersichtstabelle über alle AP-Parameter. Aufgeführt sind die jeweiligen Mittelwerte, in Klammern steht der jeweilige Standardfehler des Mittelwertes (SEM). N steht für die Anzahl der gemessenen Zellen innerhalb der Gruppe, $\mathrm{N}_{\text {Maus }}$ steht für die Anzahl der Mäuse, deren Kardiomyozyten (maximal 3 pro Maus) gemessen wurden. 
Die Aktionspotentiale sind mit der Patch-Clamp-Methode (in Whole-Cell-Konfiguration) gemessen worden. Um methodische Probleme auszuschließen, ist es wichtig an dieser Stelle auch die Messvariablen Membrankapazität (C-slow), Serienwiderstand (R-Series) und Liquid-Junction-Potential aufzuzeigen. Tabelle 3-3 zeigt eine Übersicht über diese Messvariablen (als Mittelwerte mit den jeweiligen Standardfehler).

\begin{tabular}{|c|c|c|c|c|c|c|c|c|c|c|c|}
\hline & $\overline{\text { W1 }}$ & gp91 & phox & gp9 & phox-l- & $\mathbf{W T}$ & CaMl & $\overline{\langle l| \delta_{c}}$ & & aMKIID & $c^{-/-}$ \\
\hline & $\begin{array}{c}\text { DMSO } \\
N=20 \\
N \text { Maus }=7\end{array}$ & $\begin{array}{c}\text { Ang II } \\
\mathrm{N}=20 \\
\mathrm{~N}_{\text {Maus }}=6\end{array}$ & $\begin{array}{c}\text { Ang II } \\
+\mathrm{DPI} \\
\mathrm{N}=4 \\
N_{\text {Maus }}=2\end{array}$ & $\begin{array}{c}\text { DMSO } \\
\begin{array}{l}\mathrm{N}=6 \\
\mathrm{~N} \text { Maus3 }\end{array}\end{array}$ & $\begin{array}{c}\text { Ang II } \\
\mathrm{N}=6 \\
\mathrm{~N}_{\text {Maus }}=3\end{array}$ & $\begin{array}{c}\text { DMSO } \\
\mathrm{N}=14 \\
\mathrm{~N}_{\text {Maus }}=8\end{array}$ & $\begin{array}{c}\text { Ang II } \\
N=13 \\
N_{\text {Maus }}=8\end{array}$ & $\begin{array}{c}\text { Ang II } \\
+ \text { DPI } \\
N=7 \\
N_{\text {Maus }}=4\end{array}$ & $\begin{array}{c}\text { DMSO } \\
\mathrm{N}=10 \\
N_{\text {Maus }}=5\end{array}$ & $\begin{array}{c}\text { Ang II } \\
N=12 \\
N_{\text {Maus }}=6\end{array}$ & $\begin{array}{c}\text { Ang II } \\
+ \text { DPI } \\
N=5 \\
N_{\text {Maus }}=3\end{array}$ \\
\hline $\begin{array}{c}\text { Membran } \\
\text {-kapazität } \\
{[\mathrm{pF}]}\end{array}$ & \begin{tabular}{|l}
223,0 \\
$(10,0)$
\end{tabular} & $\begin{array}{l}221,6 \\
(16,5)\end{array}$ & $\begin{array}{l}219,3 \\
(9,13)\end{array}$ & $\begin{array}{l}224,0 \\
(34,4)\end{array}$ & $\begin{array}{l}255,0 \\
(16,3)\end{array}$ & $\begin{array}{l}253,4 \\
(14,7)\end{array}$ & $\begin{array}{l}221,7 \\
(12,2)\end{array}$ & $\begin{array}{l}223,1 \\
(20,8)\end{array}$ & $\begin{array}{l}233,1 \\
(25,2)\end{array}$ & $\begin{array}{l}245,8 \\
(20,2)\end{array}$ & $\begin{array}{l}231,5 \\
(28,4)\end{array}$ \\
\hline $\begin{array}{l}\text { Serien- } \\
\text { wider- } \\
\text { stand } \\
\text { [pF] }\end{array}$ & \begin{tabular}{|c}
10,96 \\
$(1,45)$
\end{tabular} & $\begin{array}{l}11,59 \\
(0,93)\end{array}$ & $\begin{array}{l}13,30 \\
(4,60)\end{array}$ & $\begin{array}{l}9,033 \\
(0,84)\end{array}$ & $\begin{array}{c}9,90 \\
(0,86)\end{array}$ & $\begin{array}{l}20,31 \\
(4,70)\end{array}$ & $\begin{array}{c}13,16 \\
(1,13)\end{array}$ & $\begin{array}{l}11,12 \\
(1,16)\end{array}$ & $\begin{array}{c}19,37 \\
(3,46)\end{array}$ & $\begin{array}{c}11,62 \\
(1,23)\end{array}$ & $\begin{array}{c}13,42 \\
(0,87)\end{array}$ \\
\hline $\begin{array}{c}\text { Liquid } \\
\text { Junction } \\
\text { Potential } \\
{[\mathrm{mV}]}\end{array}$ & \begin{tabular}{||l}
48,04 \\
$(3,32)$
\end{tabular} & $\begin{array}{l}49,39 \\
(2,65)\end{array}$ & $\begin{array}{l}46,83 \\
(5,50)\end{array}$ & $\begin{array}{l}54,57 \\
(9,75)\end{array}$ & $\begin{array}{l}48,44 \\
(5,73)\end{array}$ & $\begin{array}{l}45,61 \\
(4,53)\end{array}$ & $\begin{array}{l}39,19 \\
(2,94)\end{array}$ & $\begin{array}{l}46,78 \\
(3,20)\end{array}$ & $\begin{array}{l}40,00 \\
(5,87)\end{array}$ & $\begin{array}{l}44,69 \\
(6,05)\end{array}$ & $\begin{array}{l}49,06 \\
(3,85)\end{array}$ \\
\hline
\end{tabular}

Tab. 3-3: Übersichtstabelle über die Messvariablen. Aufgeführt sind die jeweiligen Mittelwerte, in Klammern stehen die Standardfehler (SEM).

\subsection{Angiotensin II steigert signifikant die Häufigkeit von späten Nachdepolarisationen.}

Um einen möglichen direkten proarrhythmischen Effekt des Ang II auf die Herzmuskelzelle aufzuzeigen, wurden die Zellen über einen bestimmten Zeitraum hinweg regelmäßig stimuliert (siehe Material und Methoden). Kam es in dieser Zeit zu frühen oder späten Nachdepolarisationen (Early After Depolarization, EAD; Delayed After Depolarization DAD; siehe Einleitung), wurden diese registriert und ausgewertet. Dabei wurden sowohl die Anzahl der Zellen, die Arrhythmien aufwiesen, als auch die Anzahl der aufgetretenen Nachdepolarisationen pro Minute erfasst. Es handelte sich bis auf eine Ausnahme immer um späte Nachdepolarisationen. 


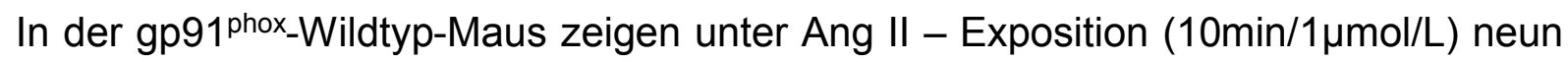
von den 20 gemessenen Zellen Arrhythmien, das sind $45 \%$ aller Zellen (vs. Vehikel 4 von 15 Zellen arrhythmisch, das entspricht 27\%). Die statistische Analyse mittels tTest wies eine signifikante Steigerung der Anzahl der aufgetretenen Nachdepolarisationen pro Minute unter Ang II auf $(p<0,05)$. Um eine mögliche Nox2 Abhängigkeit des proarrhythmischen Effekts des Ang II aufzudecken, wurden die Versuche unter Ang II Exposition mit zusätzlicher pharmakologischer Inhibition der Nox2 durch DPI durchgeführt. Hier zeigte keine der vier gemessenen Zellen Arrhythmien auf. Auch konnte in Zellen der Mäuse, die das aktive Enzym Nox2 nicht besitzen (gp91 ${ }^{\text {phox-I- }}$ ), keine Arrhythmien registriert werden: weder in den neun basal gemessen, noch in den fünf unter Ang II Exposition gemessenen Zellen. Abbildung 3.13 zeigt zunächst exemplarisch Originalregistrierungen der 5 Gruppen. Abbildung 3.14 stellt graphisch die Anzahl der aufgetretenen Nachdepolarisationen pro Minute dar. Eine graphische Übersicht über Anzahl der arrhythmischen Zellen bietet die Abbildung 3.18.

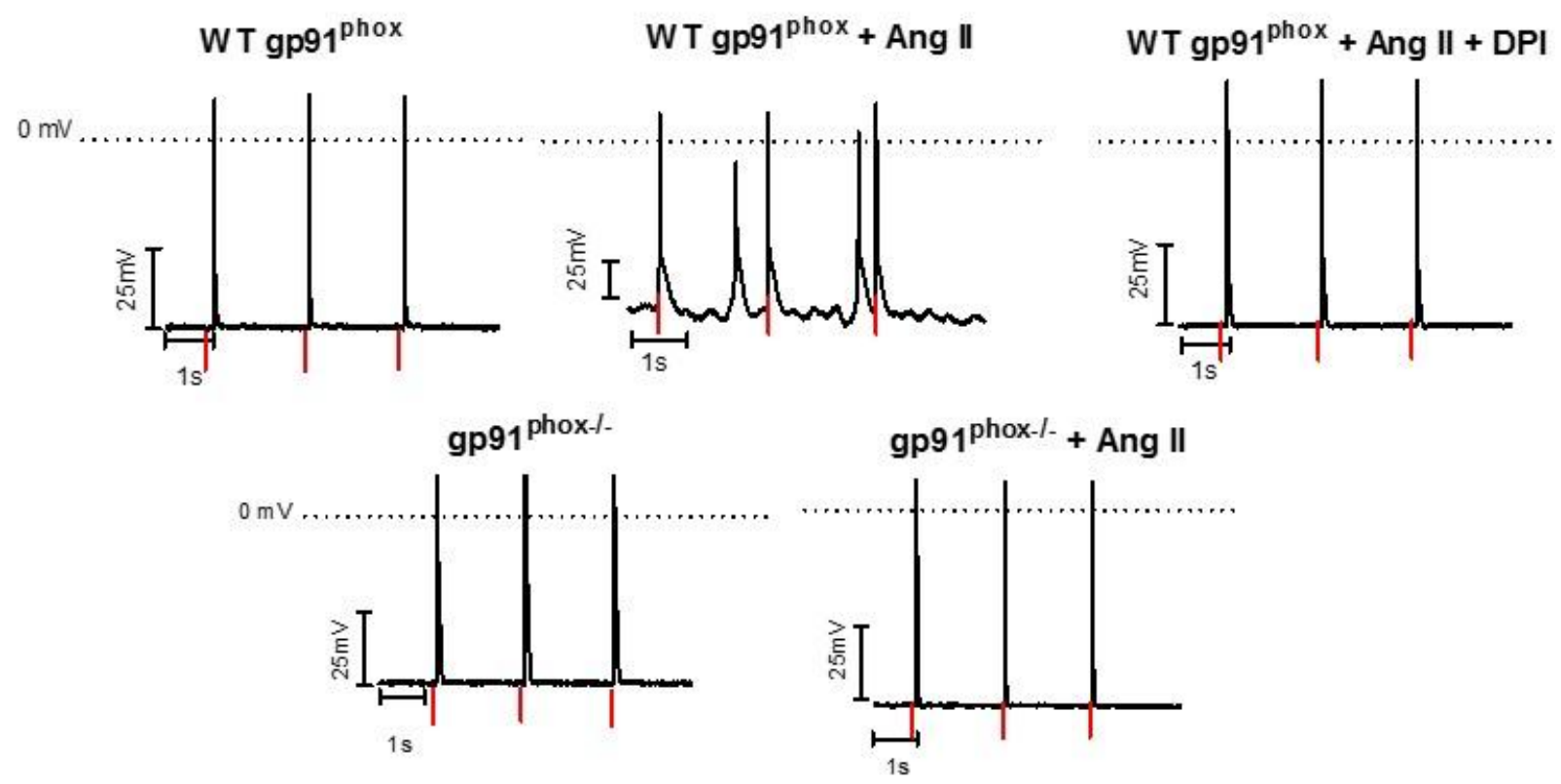

Abb. 3.13: Originalregistrierungen von jeweils drei stimulierten Aktionspotentialen (rote Linie markiert den Stimulus). In der Registrierung der gp91 phox + Ang II sieht man zwei DADs, die jeweils nach einem stimulierten Aktionspotential kommen. Diese Aktionspotentiale wurden bei einer Stimulationsfrequenz von $0,5 \mathrm{~Hz}$ registriert. 


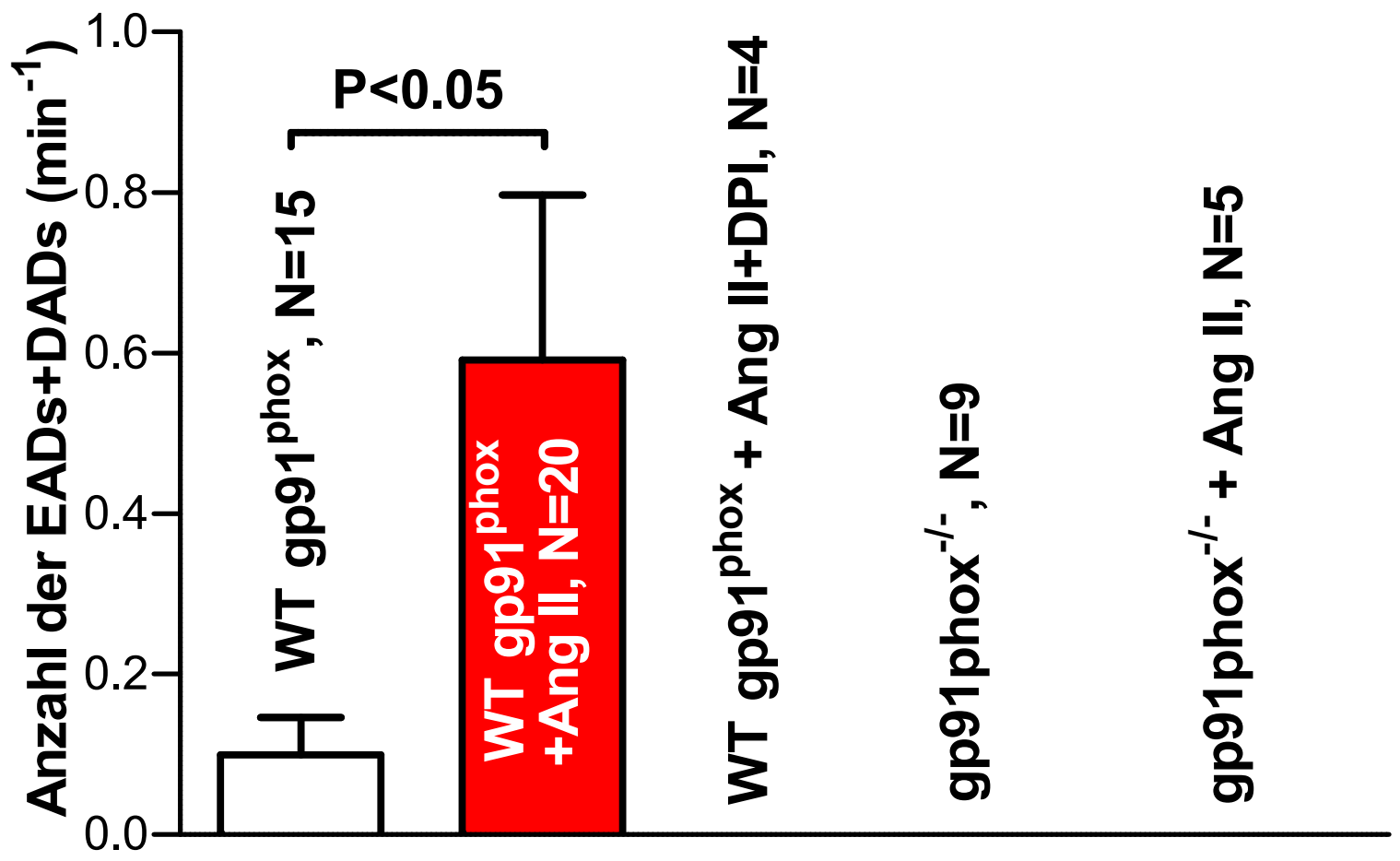

Abb. 3.14: Anzahl der EADs und DADs pro Minute. Es zeigt sich eine signifikante Zunahme der Arrhythmieentwicklung in den gp91 phox-Wildtypmäusen unter Ang II - Exposition (t-Test, p<0,05). In Anwesenheit von DPI waren keine Arrhyhtmien nachweisbar. Dieses gilt auch für die gp91phox Knockout-Maus, die ebenfalls bei der Exposition mit Ang II keine Arrhythmien aufgewiesen hat.

Um eine mögliche Abhängigkeit der Ang II Wirkung von der CaMKII $\delta_{c}$ zu prüfen, wurden analog zu den oben genannten Messungen die Zellen der CamKIII $\delta_{c}-W i l d t y p-$ Mäuse basal und unter Ang II - Exposition (10 min, $1 \mu \mathrm{mol} / \mathrm{L}$ ) vergleichend untersucht und die Anzahl der aufgetretenen Arhythmien sowie die Zahl der arrhythmischen Zellen gemessen. Unter dem Einfluss des Ang II zeigten $36 \%$ der gemessenen Zellen Arrhythmien (4 von 11 gemessen Zellen zeigten DADs), verglichen mit den basalen Messungen ohne Ang II, bei denen es in einem von 15 Fällen zu der Entwicklung von Nachdepolarisationen kam (entspricht 7\% arrhythmische Zellen im Vehikel). Betrachtet man die Anzahl der registrierten Nachdepolarisationen pro Minute, zeigt das eine signifikante Zunahme der Arrhythmieentwicklung unter Ang II-Exposition (tTest, $p<0,05)$. Abbildung 3.16 stellt graphisch die Anzahl der registrierten DADs und EADs pro Minute dar.

Sechs Zellen wurden mit Angiotensin II und DPI behandelt, von diesen zeigte keine Zelle Arrhythmien. 
Diese Ergebnisse wurden verglichen mit der Arrhythmieentwicklung in den Herzmuskelzellen von Mäusen, denen das Enzym CaMKII $\delta_{c}$ fehlt $\left(\mathrm{CaMKII}_{\mathrm{c}^{-l}}\right)$. Unter Ang II - Exposition kam es in diesen bei 2 von 9 Zellen zu Arrhythmien, das entspricht $22 \%$ (im Vehikel zeigte eine von sieben Zellen Arrhythmien, das entspricht 14\%). Unter den 6 CaMKII $\delta_{c}^{-1-Z e l l e n, ~ d i e ~ m i t ~ A n g i o t e n s i n ~ I I ~ u n d ~ D P I ~ b e h a n d e l t ~ w o r d e n ~ s i n d, ~ z e i g t ~}$ keine Zelle Arrhythmien.

Abbildung 3.15 zeigt exemplarisch die Originalregistrierungen der CaMKII $\delta_{c}-W i l d t y p-$ und -Knockout-Mäuse (CaMKII $\left.\delta_{c}^{-1-}\right)$.
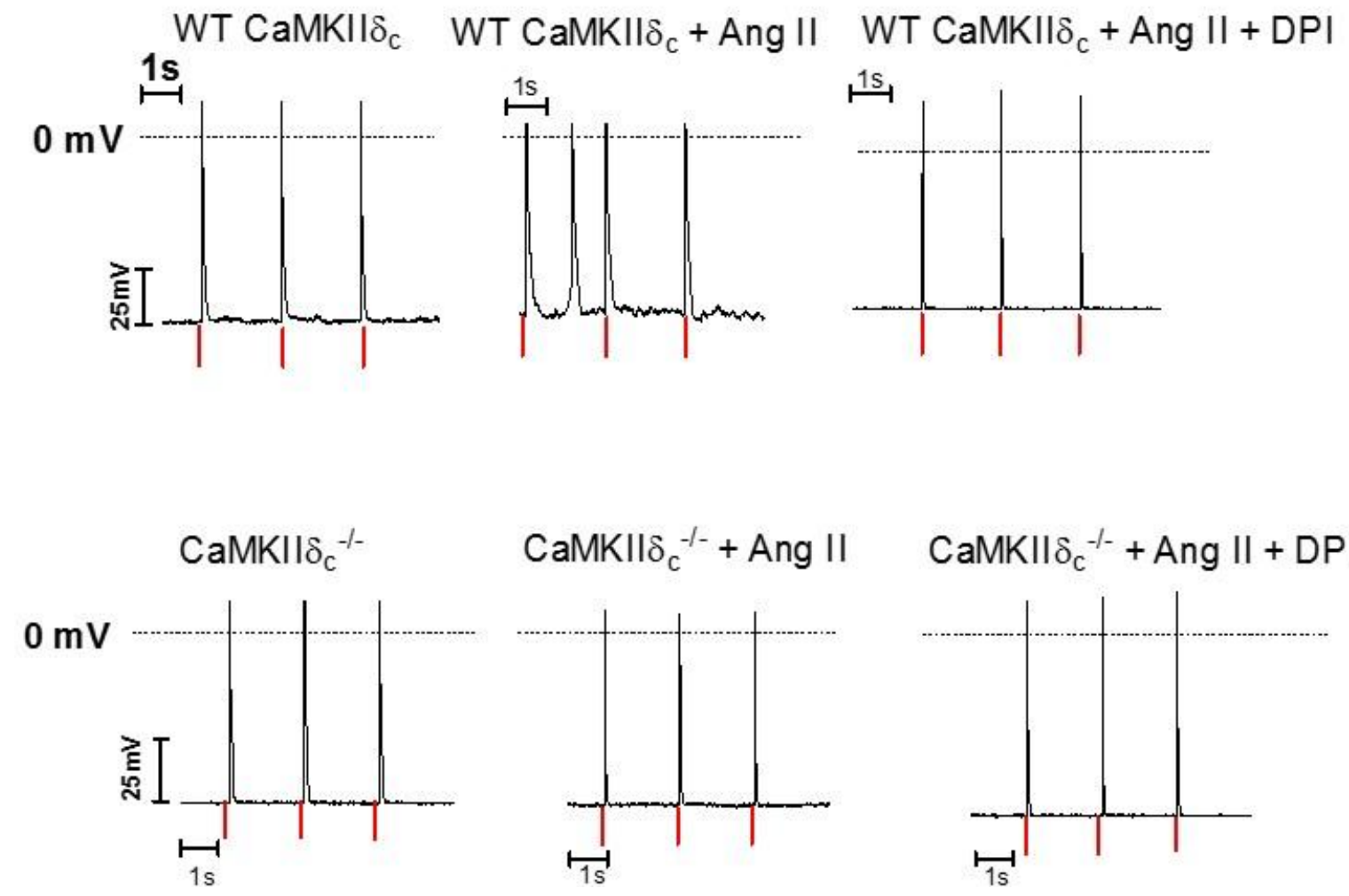

Abb. 3.15: Originalregistrierungen von jeweils drei stimulierten Aktionspotentialen (rote Linie markiert den Stimulus). In der Registrierung der Wildtyp (WT)-CaMKII $\delta_{c}+$ Ang II sieht man eine Nachdepolarisation (DAD), die nach einem stimulierten Aktionspotential kommt. 


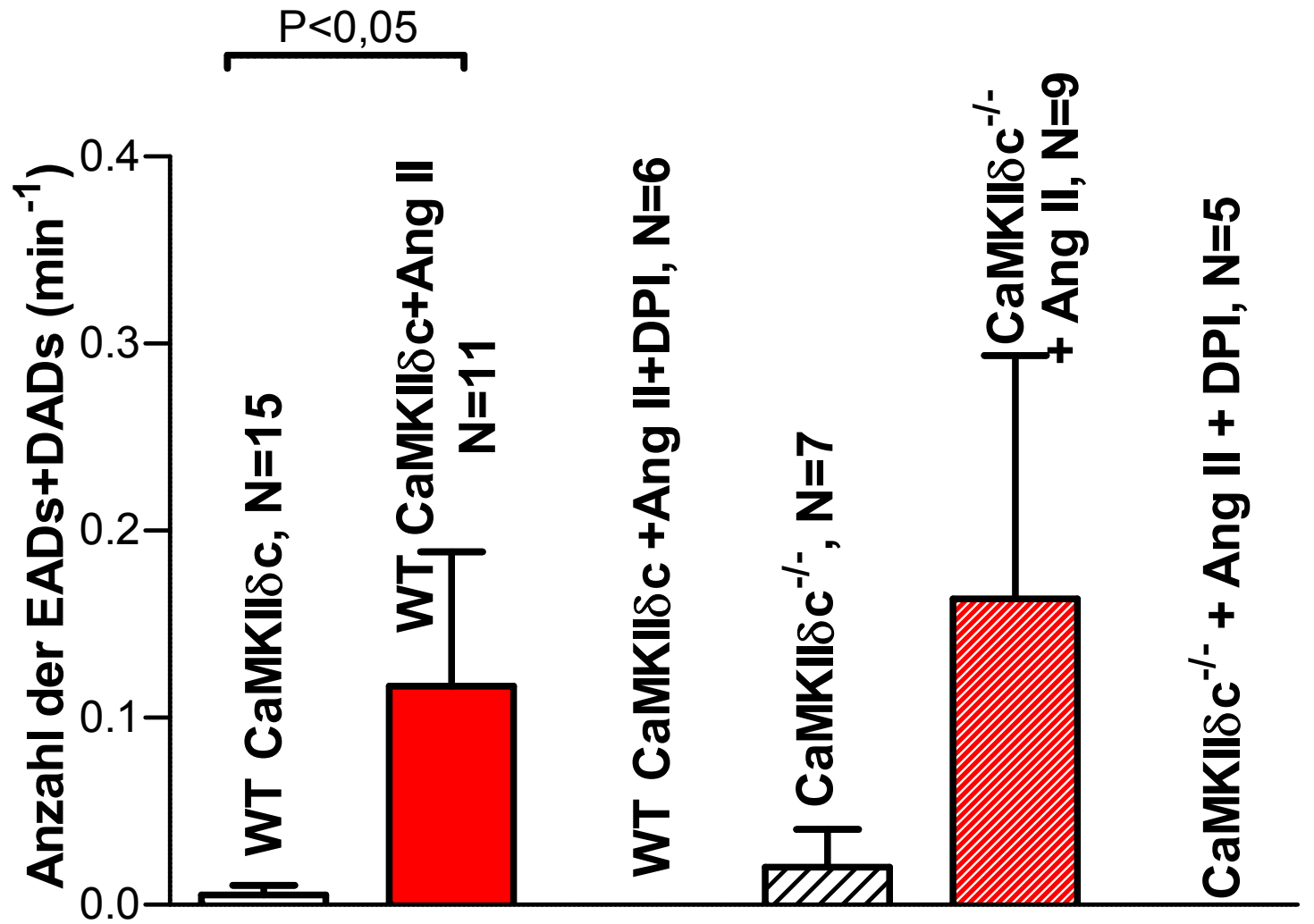

Abb. 3.16: Anzahl der EADs und DADs pro Minute. Es zeigt sich eine signifikante Zunahme der

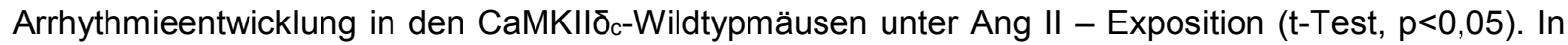

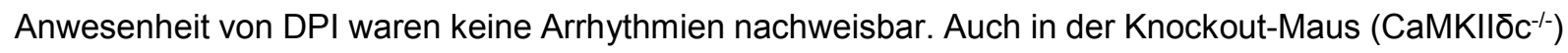
zeichnet sich eine Zunahme der Arrhythmieentwicklung bei der Zugabe von Ang II ab, dieser Trend ist allerdings statistisch nicht signifikant. 


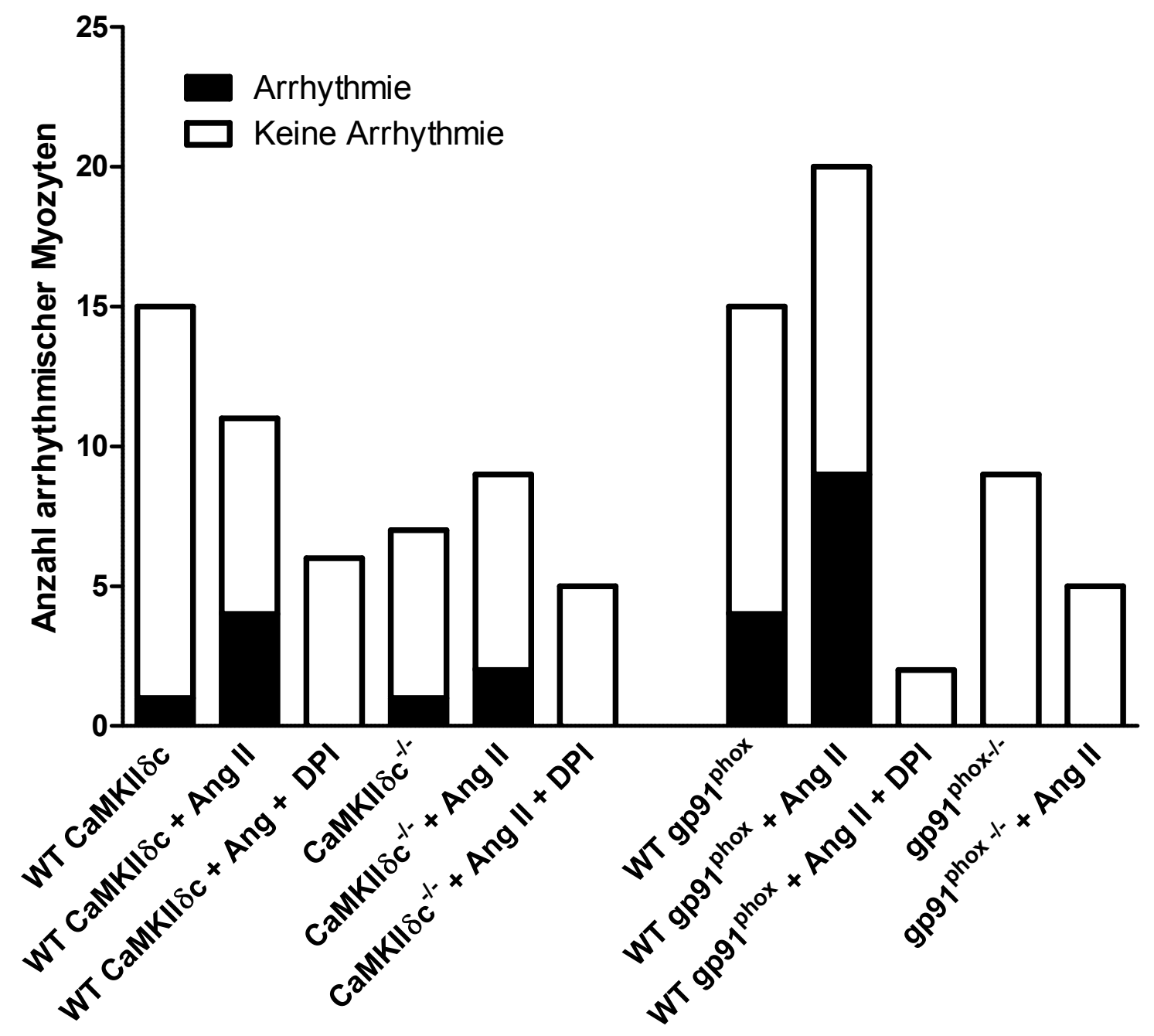

Abb. 3.17: Säulendiagramm zur Veranschaulichung des Anteils arrhythmischer Zellen pro Gruppe. Die Säulen repräsentieren die Anzahl der für die Arrhythmiemessung erfassten Zellen, der schwarze Anteil der Säule steht für die Zellen, die im Laufe der Beobachtungszeit mindestens eine Nachdepolarisation gezeigt haben. Signifikante Unterschiede zwischen den Gruppen ist aufgrund der für den Chi-QuadratTest nötigen Zellzahl nicht gefunden worden.

Zusammenfassend kann man unter dem Einfluss von Ang II von einem signifikanten Anstieg der Arrhythmieentwicklung sprechen sowohl in den Wildtyp-Mäusen der

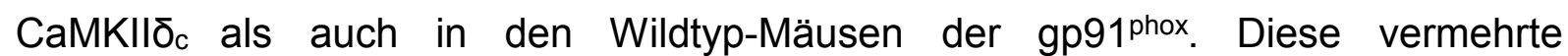
Arrhythmiebildung geht zurück durch das Ausschalten der Nox2 sowohl durch die pharmakologische Inhibition als auch in den genetisch veränderten Mäusen, die das aktive Enzym Nox2 nicht besitzen. In diesen Fällen führt Ang II zu keiner vermehrten Arrhythmiebildung. 


\section{Diskussion}

In der vorliegenden Arbeit konnte gezeigt werden, dass das pathophysiologisch relevante Hormon Angiotensin II bei Herzmuskelzellen der Maus zu einer deutlichen Veränderung der Aktionspotentialmorphologie und einer signifikanten Steigerung der Häufigkeit von zellulären Arrhythmien führt. Dabei kommt es zu einer Beschleunigung der maximalen AP-Aufstrichgeschwindigkeit, welche ein Maß für die Natriumkanalfunktion darstellt (siehe Kapitel 3.2, siehe Abb. 3.8). Diese Beschleunigung ist abhängig von einer funktionstüchtigen NAPDH Oxidase 2 (Nox2), da sowohl pharmakologische Hemmung (DPI) als auch genetischer Knockout (gp91phox ${ }^{-/}$) diese Ang II - Wirkung verhindern konnten (siehe Abbildung 3.8). Interessanterweise steigert Ang II über einen ebenfalls Nox2-abhängigen Mechanismus die Häufigkeit von späten Nachdepolarisationen (siehe Kapitel 3.4, Abbildung $3.14,3.16$ ), was mit der veränderten Natriumkanalfunktion in Zusammenhang stehen könnte. Diese Ergebnisse können bezüglich der Therapie kardialer Arrhythmien von großer klinischer Bedeutung sein.

\subsection{Angiotensin II beschleunigt die maximale Aufstrich- geschwindigkeit des Aktionspotentials, verändert aber nicht die Aktionspotentialdauer}

Das Aktionspotential wird von zahlreichen lonenströmen beeinflusst. In Phase 0 ist der schnelle Natriumeinstrom für die Depolarisation verantwortlich. Dabei steht die Geschwindigkeit der Depolarisation (Aufstrich des Aktionspotentials) in direktem Zusammenhang mit der Stärke des Natriumeinstroms (Berecki et al. 2010). In der vorliegenden Arbeit führt die Exposition von ventrikulären Kardiomyozyten der Maus mit Angiotensin II (1 $\mu \mathrm{mol} / \mathrm{l}) \mathrm{zu}$ einer 1,5-Fachen Steigerung der maximalen APAufstrichgeschwindigkeit (siehe Abb. 3.8). Nach meinem Kenntnisstand zeigte ich hier erstmalig den steigernden Effekt des Ang II auf die maximale Aufstrichgeschwindigkeit des Aktionspotentials ventrikulärer Myozyten. Diese Ergebnisse konnten kürzlich veröffentlicht werden (Wagner et al. 2014). Einen ähnlich steigernden Effekt auf die maximale Aufstrichgeschwindigkeit zeigen Acetylcholin und Noradrenalin (Verkerk et 
al. 2012): In der Arbeit von VERKERK und Kollegen wurden isolierte atriale KaninchenMyozyten mit jeweils $1 \mu \mathrm{M}$ Acetylcholin bzw. $1 \mu \mathrm{M}$ Noradrenalin behandelt und das Aktionspotential dieser Zellen mittels Patch-Clamp-Technik gemessen. Beide Substanzen konnten dabei die maximale Aufstrichgeschwindigkeit steigern, wobei die Steigerung der maximalen Aufstrichgeschwindigkeit durch die NoradrenalinExposition zweifach so stark ausgeprägt war wie die durch die Acetylcholin-Exposition. Die Autoren mutmaßten, dass hierfür eine hyperpolarisierende Wirkung der

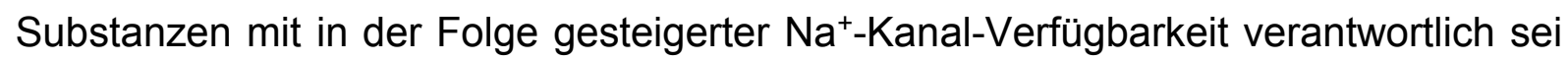
(Verkerk et al. 2012). Als mögliche Ursache für die hyperpolarisierende Wirkung der beiden genannten Substanzen sehen die Autoren die $\beta$-adrenerge Aktivierung bestimmter Kaliumkanäle. In der vorliegenden Arbeit konnte unter Ang II - Exposition hingegen kein signifikanter hyperpolarisierender Effekt auf die Myokardzellen beobachtet werden (siehe Tabelle 3.2).

VERKERK et al. führten die gesteigerte maximale Aufstrichgeschwindigkeit auf einen erhöhten Natriumstrom zurück. Diese Annahme wird von zahlreichen anderen Untersuchungen bestätigt: Bereits 1955 stellte Weidmann die Hypothese auf, dass die Aufstrichgeschwindigkeit des Aktionspotentials von der Stärke des Stroms spannungsabhängiger Natriumkanäle abhängt. Zahlreiche folgende Untersuchungen zeigten, dass die maximale Aufstrichgeschwindkeit des Aktionspotentials in Myozyten als ein Maß für deren Natriumkanalfunktion dienen kann (Hondeghem 1985, Cohen et al. 1985, Kléber 2005, Berecki et al. 2010). Dieser Zusammenhang konnte auch in unserer Arbeitsgruppe gezeigt werden: Die Exposition von Kardiomyozyten mit Ang II führte dabei einer Steigerung des Spitzennatriumstroms (Wagner et al. 2014). Moorman et al. haben bereits 1989 Patch-Clamp-Versuche an ventrikulären Myozyten von Ratten durchgeführt, um die Wirkung des Ang II auf die Funktion der kardialen Natriumkanäle zu untersuchen. Sie konnten feststellen, dass durch die externe Hinzugabe von Ang II $(2 \mu \mathrm{M})$ der Spitzennatriumstrom in der Strom-SpannungsBeziehung gesteigert wurde: In den durchgeführten Einzelkanalexperimenten wurde die Öffnungsfrequenz der Kanäle durch Ang II erhöht, die Latenzzeit vor dem ersten Öffnen der Kanäle verringert und der Spitzennatriumstrom erhöht. Auch Nilius et al. zeigten 1989 einen steigernden Effekt des Ang II auf die Natriumkanalfunktion: In ventrikulären Myozyten von Meerschweinchen führte die Hinzugabe von Ang II (1 $\mu \mathrm{M})$ in Einzelkanalexperimenten zu einer erhöhten Öffnungswahrscheinlichkeit und einer verzögerten Inaktivierung der Natriumkanäle von im Durchschnitt 1,1 $\pm 0,1 \mathrm{~ms}$ in 
Kontrollmessungen auf 5,6 \pm 1,6 ms unter Ang II - Exposition. Somit scheint Ang II das Öffnungsverhalten der $\mathrm{Na}^{+}-$Kanäle zu beeinflussen, denn eine Steigerung des

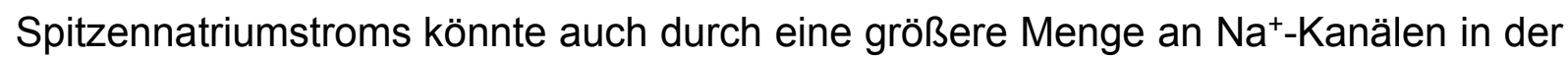
Membran erklärt werden, nicht jedoch die Beeinflussung von Aktivierung und Inaktivierung. Diese Ang II - Wirkung auf das Öffnungsverhalten des Kanals konnte auch von unserer Arbeitsgruppe bestätigt werden (Wagner et al. 2014): So wurde gezeigt, dass Ang II zu einer beschleunigten Aktivierung und einer Steigerung des späten Natriumstroms führt (Wagner et al. 2014). Der Steigerung des späten Natriumstroms wird eine wichtige Bedeutung in der Entwicklung kardialer Arrhythmien zugesprochen, da sie sowohl zu einer Verlängerung des APD führt als auch eine $\mathrm{Na}^{+}-$ Überladung der Zelle verursacht (Ashpole et al. 2012, Wagner et al. 2014, Antzelevitch et al. 2014). Darauf werde ich in einem separaten Abschnitt (siehe Kapitel 4.4) näher eingehen.

Auf der anderen Seite kommt es jedoch auch zu einer beschleunigten intermediären $\mathrm{Na}^{+}$-Kanal-Inaktivierung und einer verzögerten Erholung aus der intermediären Inaktivierung, so dass nicht generell von einer verzögerten Inaktivierung gesprochen werden kann. Diese Kombination aus verstärktem spätem Natriumstrom und beschleunigter intermediärer Inaktivierung ist kein Wiederspruch und wurde bereits für einige natürlich vorkommende $\mathrm{Na}^{+}-$Kanalmutationen beschrieben (Veldkamp et al. 2000; Bezzina et al. 1999).

Die Ang II - abhängige Regulation des $\mathrm{Na}^{+}-$Kanals ist komplex, da hieran offenbar mehrere Signalkaskaden mit zum Teil antagonistischen Wirkungen beteiligt sind. Eine Hemmung des membranständigen $\mathrm{AT}_{1}$ ist eine Möglichkeit, um die weiterführenden Effekte des Ang II über diesen Rezeptor gleichmäßig an einem frühen Punkt der Signalkaskade zu inhibieren. KIM et al. haben 2012 die Wirkung des Telmisartan, ein AT 1 - Blocker, auf den kardialen spannungsabhängigen $\mathrm{Na}^{+}-$Kanal getestet und festgestellt, dass dieser die Inaktivierung des Kanals verzögert. Diese Versuche wurden an Myokardzellen und perfundierten Herzen von 8-Wochen alten SpragueDawley-Ratten durchgeführt. Allerdings muss man beachten, dass Ang II auch über andere Rezeptoren an der Zelle Veränderungen bewirken kann, und daher die alleinige Hemmung des $\mathrm{AT}_{1}$ nicht die gesamte Wirkung des Ang II aufhebt. Über den Einfluss von Ang II auf die Inaktivierung des spannungsabhängigen Natriumkanals gibt es bislang keine konkreten Daten. 
Abgesehen von Ang II können auch andere Substanzen und Proteine die $\mathrm{Na}^{+}-$ Kanalfunktion steigern: Die Proteinkinase A kann, als ein Effektor der $\beta$-adrenergen Stimulation, durch Phosphorylierung des Kanals dessen Leitfähigkeit steigern, ohne einen Einfluss auf das Öffnungsverhalten zu haben (Gutierrez et al. 2013; siehe Kapitel 1.5.2)

Dieser Effekt lässt sich pharmakologisch durch den Einsatz von Isoproterenol, einem Sympathomimetikum, hervorrufen. Ebenso vermag die CaMKII den $\mathrm{Na}^{+}-\mathrm{Kanal} \mathrm{zu}$ phosphorylieren und ihre Funktion zu steigern (siehe Kapitel 1.5.2). Eine interessante Untersuchung identifiziert Apelin, ein Ligand des G-Protein-gekoppelten Angiotensin II - like - Rezeptors, als eine Substanz, die eine Steigerung der $\mathrm{Na}^{+}-$Kanalfunktion in Herzventrikelzellen des Hundes hervorruft (Chamberland et al. 2010). Dabei wird gezeigt, dass das mittlere Aktivierungspotential der $\mathrm{Na}^{+}-$Kanäle um -6,8 \pm 0,6 mV (für apelin-13) bzw. $17 \pm 1 \mathrm{mV}$ (für apelin-17) gesenkt wird; das bedeutet, dass die Kanäle schon bei negativeren Potentialen aktiviert werden.

Interessanterweise konnte anhand von H9c2-Myokardzellen gezeigt werden, dass die chronische Ang II - Exposition auf Transkriptionsebene im Sinne einer negativen Rückkopplung zu einer geringeren Expression des $\mathrm{Na}^{+}-\mathrm{Kanals}$ führt (Shang et al. 2008).

Zusätzlich zu der Steigerung der AP-Aufstrichgeschwindigkeit haben wir die Wirkung der Ang II - Exposition der Zellen bezüglich der Aktionspotentialdauer (als APD 80 gemessen) untersucht. Wie man der Abbildung 3.12 entnehmen kann, konnte in der vorliegenden Arbeit keine Ang II - induzierte signifikante Veränderung der APD 80 gezeigt werden. Dem widerspricht eine Studie, die an insuffizienten Herzmuskelzellen von Hamstern durchaus eine Verlängerung der APD bei Ang II - Exposition verzeichnen konnte, während die Kontrolluntersuchungen an gesunden HamsterKardiomyozyten eine weniger stark ausgeprägte Verlängerung der APD zeigten (De Mello 2011). Vergleicht man die Ergebnisse dieser Studie mit denen der vorliegenden Arbeit, muss man vor allem berücksichtigen, dass wir gesunde Herzmuskelzellen von Mäusen untersucht haben; De Mello konnte die größeren Veränderungen der Aktionspotentialdauer durch Ang II in den insuffizienten Herzmuskelzellen zeigen. Außerdem können Speziesunterschiede (Hamster vs. Maus) mit Unterschieden in der Expression der lonenkanäle eine Rolle spielen. 
Es ist bekannt, dass eine Verlängerung des Aktionspotentials durch eine prolongierte Plateauphase gekennzeichnet ist, die hauptsächlich durch einen vermehrten $\mathrm{Ca}^{2+}$ Einwärtsstrom oder durch einen verminderten $\mathrm{K}^{+}$-Auswärtsstrom entstehen kann. Welchen Einfluss hat Ang II auf diese lonenströme?

In der vorliegenden Arbeit kam es durch die Ang II - Wirkung zwar zu keiner Verlängerung des APD kam, jedoch zeigten die weiterführenden Versuche in der gleichen Arbeitsgruppe, dass Ang II den Kalziumstrom verstärkt (Wagner et al. 2014). Diese Erkenntnis wird durch anderen Studien unterstützt: PETROFF et al. zeigten bereits 2000 eine Funktionssteigerung der L-Typ-Ca ${ }^{2+}-$ Kanäle durch Ang II. Ähnliche Ergebnisse konnten TSAl et al. 2011 anhand der HL-1-Zelllinie zeigen: In diesen Herzmuskelzellen konnte unter Ang II - Einfluss eine vermehrte Expression an L-Typ$\mathrm{Ca}^{2+}-$ Kanälen gezeigt werden. Auch De Mello und Gerena haben 2008 einen steigernden Effekt des Ang II auf den peak L-Typ-Ca ${ }^{2+}-$ Kanal-Strom gezeigt, welcher durch Eplerenon abgemildert werden konnte.

Aus den Ergebnissen von De Mello aus dem Jahre 1998, geht hervor, dass Ang II die Inaktivierung des $\mathrm{Ca}^{2+}$-Einstroms während des Aktionspotentials beschleunigt und somit den $\mathrm{Ca}^{2+}$-Einstrom insgesamt verringert. Bei diesen Versuchen wurde allerdings Ang II intrazellulär (durch die Pipettenlösung) hinzugefügt. Später konnte de Mello zeigen, dass extrazellulär hinzugefügtes Ang II lediglich zu einer Steigerung des peak ICa führt, während intrazellulär hinzugegebenes Ang II zum einen eine gesteigerte peak Ica hervorruft, aber zum anderen auch die Inaktivierung des Ica steigert (De Mello und Monterrubio 2004). Letzteres führen die Autoren auf eine vermehrte Ausschüttung von $\mathrm{Ca}^{2+}$ aus dem SR zurück, die durch eine $\mathrm{Ca}^{2+}$-induzierte Hemmung des L-Typ-Ca ${ }^{2+}$ Kanals zu einer Inaktivierung des Ica führt.

ALVIN et al. konnten 2011 zwar einen steigernden Effekt des Ang II auf den Spitzenstrom des L-Typ- $\mathrm{Ca}^{2+}-$ Kanals im hypertrophierten Myokard feststellen. Jedoch zeigte sich dieser Effekt nicht im gesunden Myokard. Zu bedenken ist stets, dass bei den genannten Studien und Experimenten unterschiedliche Spezies bzw. Zelllinien verwendet worden sind: Während Petroff et al. ihre Untersuchungen in KatzenMyozyten durchführten und Tsai et al. die HL-1 Zelllinie verwendeten, fanden die Untersuchungen von Alvin et al. in Herzmuskelzellen von Ratten statt. Speziesübergreifend konnte der verminderte L-Typ-Ca ${ }^{2+}-$ Kanal-Strom im hypertrophierten Myokard nachgewiesen werden (Bouron et al. 1992; Nuss und Houser 1991; Shi et al. 
2007). Was jedoch die Ang II - Wirkung auf diese Kanäle im gesunden Myokard angeht, unterscheiden sich die Ergebnisse der Studien bislang noch.

Die Tatsache, dass ich in der vorliegenden Arbeit keine Verlängerung der APD nachweisen konnte, lässt also den Schluss zu, dass Ang II möglicherweise neben der gezeigten Steigerung des L-Typ-Ca ${ }^{2+}-$ Stroms gleichzeitig zu einer Aktivierung

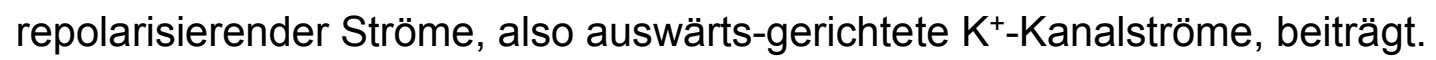

Von den auswärtsgerichteten $\mathrm{K}^{+}-$Kanälen sind drei Kanäle maßgeblich an der Repolarisation beteiligt: Das Kanalprotein $\mathrm{Kv} 11.1$ (von $\mathrm{KCNH} 2$ codiert) ist für den spannungsabhängigen $\mathrm{I}_{\mathrm{rr}}$ verantwortlich, der kurz nach der initialen Repolarisation, in Gang gesetzt und nur sehr langsam inaktiviert wird (Schmitt et al. 2014). Das Kanalprotein Kv7.1 (vom KCNQ1 codiert) ist ebenfalls ein spannungs-abhängiger Kaliumkanal, der bei positiveren Potentialen ab -20 mV langsam aktiviert wird, und ist für den Iks verantwortlich. Dieser Kaliumstrom wird kaum inaktiviert, so dass er über die gesamte Repolarisationsphase über fortbesteht (Jespersen et al. 2005). Der dritte wichtige Kaliumstrom, der $\mathrm{I}_{\mathrm{k} 1}$, welcher von den Kanalproteinen $\mathrm{K}_{\mathrm{ir}} 2 . \mathrm{x}$ gebildet wird, leistet seinen Beitrag an der Repolarisation, bei Membranpotentialen negativer als $40 \mathrm{mV}$ (Lopatin und Nichols 2001). Ik1 ist insbesondere bei Werten um das Ruhemembranpotantial aktiv und spielt eine wichtige Rolle bei der Aufrechterhaltung desselben. Diese Kaliumströme sind sowohl für die Phase III (Repolarisation) als auch Phase IV (Ruhephase) verantwortlich, in der letzteren wirken sie möglichen späten Nachdepolarisationen entgegen (Schmitt et al. 2014).

Bezüglich der Ang II - Wirkung auf den repolarisierenden Kaliumstrom ist die Studienlage differenziert $z u$ betrachten: Während manche Studien von einen verstärkten Iks unter Ang II - Exposition in Vorhofmyozyten von Meerschweinchen berichten, welche zu einer verkürzten APD führt (Zankov et al. 2006), postulieren andere (im gleichen Tiermodell) eine PKC-vermittelte Inhibition des Iks durch Ang II ( $\mathrm{Si}$ et al. 2013). Auch WANG et al. zeigten 2008 eine Inhibition des Ikr durch Ang II in Ventrikelmyozyten der Meerschweinchen. DOMENIGHETTI et al. 2007 konnten in Maus-Myozyten eine signifikante Reduktion des einwärtsgerichteten Kaliumausstroms (IK1) durch Ang II zeigen, welche zu einer QT- und APD-Verlängerung führt. Hier fand

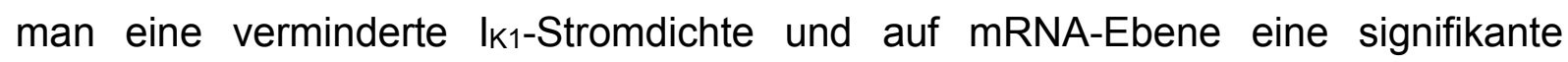
Reduktion der Kaliumkanal-Untereinheiten Kir2.1 und Kir2.2.

2012 veröffentlichte DE MELLO eine interessante Arbeit, die zeigte, dass der steigernde Effekt des Ang II auf den Kaliumstrom bei mechanischer Dehnung des 
Kardiomyozyten rückgängig war. Diese Versuche wurden an Ratten-Myozyten durchgeführt.

Was also den Einfluss des Ang II auf die APD angeht, ist die aktuelle Studienlage noch recht widersprüchlich. Um die Studien miteinander zu vergleichen, sollten neben methodischen Unterschieden (Applikation des Ang II intrazellulär vs. extrazellulär; Ventrikelzellen vs. Vorhofzellen), vor allem mögliche Unterschiede zwischen den verwendeten Spezies (Maus, Meerschweinchen, Hamster, Ratte, Kaninchen), berücksichtigt werden. Hier spielen die o.g. unterschiedlichen Expressionen der lonenkanäle eine entscheidende Rolle.

Zusammenfassend bleibt zu sagen, dass Ang II durch seine pleiotropen Wirkungen auf eine Vielzahl von Signaltransduktionskaskaden Veränderungen an den unterschiedlichen Ionenströmen hervorrufen kann.

\subsection{Die Bedeutung der Nox2 und der Serin-/Threonin- Proteinkinasen für die Ang II - Wirkung auf Aktionspotentialaufstrich und Natriumkanalfunktion}

Es stellt sich die Frage: Welcher Mechanismus ist für die Ang II - abhängige Aktivierung des Spitzennatriumstroms bedeutsam?

Ang II bindet an den G-Protein-gekoppelten Rezeptor $A T_{1}$, welcher dann die intrazellulären Wirkungen vermittelt (siehe Kapitel 1.7). Allerdings wissen wir heute, dass teilweise auch G-Protein-unabhängig intrazelluläre Signalwege, vermutlich ßArrestin-vermittelt, in Gang gesetzt werden können (Lymperopoulos und Negussie 2013). Während die genauen intrazellulären Mechanismen noch ungeklärt sind, weiß man seit längerem, dass Ang II über den AT1-Rezeptor viele Signalwege wie PLC $\beta$ PKC, Adenylylcyclase-cAMP, ERK 1/2 und JAK/STAT aktiviert (Thomas et al. 1996). Auch konnte eine Aktivierung der Nox2 durch Ang II gezeigt werden (Griendling et al. 1994; Zafari et al. 1998; de Gasparo 2002; Mollnau et al. 2002; Bendall et al. 2002). Da die Nox2 in Kardiomyozyten die prädominierende Quelle für ROS ist, stellte sich die Frage, ob möglicherweise die Nox2-abhängige ROS-Produktion an der Aktivierung des Spitzennatriumstroms beteiligt sein könnte. 
Ein anderer Grund für diese Frage ist, dass ROS entscheidend an der Regulation von Serin/Threoninkinasen beteiligt sind und wir bereits wissen, dass PKA und CaMKII für die Regulation des Na-Kanals von großer Bedeutung sind.

Um diese Fragen zu beantworten, haben wir die Rolle der Nox2 für die Ang Il-abhänge Beschleunigung der AP-Aufstrichgeschwindigkeit näher untersucht.

Wir konnten feststellen, dass die steigernde Wirkung von Ang II auf die Aufstrichgeschwindigkeit bei pharmakologischer Inhibition der Nox2 sowie auch bei genetischem Knockout (gp91 phox-l) ) ausbleibt (siehe Abb. 3.8).

Die aktivierte Nox2 produziert vermehrt ROS. So stellt sich als nächstes die Frage, ob diese direkt einen Einfluss auf den Natriumkanal haben, zumal die $\alpha$-Untereinheit des Natriumkanals (Nav1.5) bekanntermaßen Methionin-Reste besitzt, die durch ROS direkt oxidiert werden (Kassmann et al. 2008); oder ob es der Vermittlung anderer Enzyme, die einen Einfluss auf den Natriumkanal haben, bedarf. Dazu zählen die cAMP-abhängige Proteinkinase A (PKA), die Proteinkinase C (PKC) und die CaMKII (Sag et al. 2013). Für diese Enzyme ist bekannt, dass sie eine regulierende Wirkung durch posttranslationale Modifikation (i.e. Phosphorylierung) auf den spannungsabhängigen Natriumkanal haben.

WAGNER et al. konnten 2006 erstmals zeigen, dass der spannungsabhängige Natriumkanal auch von der CaMKII phosphoryliert und maßgeblich reguliert wird. Dabei konnte gezeigt werden, dass die Inaktivierung der Natriumkanäle durch CaMKII verstärkt, die Erholung von der Inaktivierung verlangsamt und somit insgesamt die Verfügbarkeit des Natriumkanals verringert wird. Der späte Natriumstrom hingegen zeigte sich deutlich gesteigert.

Wenig später fanden AIBA et al. 2010 den intrazellulären Linker zwischen der Domäne I und II als Ziel der CaMKII-Phosphorylierung, genauer noch konnten HUND et al. 2010 durch Funktionsanalysen von Nav1.5-Mutanten das Serin 571 als CaMKIIPhosphorylierungsstelle identifizieren. Zusätzlich konnten letztere zeigen, dass $\beta_{I V-}$ Spektrin als wichtiges Ankerprotein die Lokalisation von Nav1.5 im Sarkolemm sowie ihre Interaktion mit der CaMKII bedingt. Interessanterweise konnte eine Folgearbeit derselben Arbeitsgruppe wenig später zeigen, dass die Phosphorylierung von Serin 571 bei Herzinsuffizienz gesteigert ist (Koval et al. 2012). ASHPOLE et al. bestätigten 2012 diese Ergebnisse und zeigten, dass die CaMKII den Natriumkanal mehrfach 
phosphoryliert, unter anderem an den Stellen Thr-594 und Ser-516 des I-II-Linkers. Darüberhinaus konnten sie auch wichtige Erkenntnisse über die funktionelle Bedeutung der CaMKII-abhängigen Phosphorylierung des Ser-571, Thr-594 und Ser516 zeigen: In HEK293-Zellen, welche die nicht-phosphorylierbaren Mutanten (S571A, S516A, T594A) exprimieren, war die CaMKII-abhängige Linksverschiebung der Natriumkanalverfügbarkeitskurve nicht mehr nachweisbar. Obwohl die Bedeutung der CaMKII für die Regulation des Öffnungsverhaltens groß zu sein scheint, konnten diese Arbeiten jedoch keine Beeinflussung des Spitzennatriumstroms nachweisen, der ja maßgeblich für die Aufstrichgeschwindigkeit des APs verantwortlich ist. Damit ist vereinbar, dass auch in der vorliegenden Arbeit kein Unterschied der Ang II - Wirkung auf die Aufstrichgeschwindigkeit im genetischen Knockout (CaMKII---) vergleichend mit den Messung in Wildtypzellen (siehe Abbildung 3.8) gefunden wurde. Somit müssen wir für die Wirkung auf den Spitzennatriumstrom und den AP-Aufstrichgeschwindigkeit einen CaMKII-unabhängigen Signalweg des Nox2-vermittelten steigernden Effektes von Ang II annehmen.

Interessanterweise ist aber von einer weiteren Serin-/Threonin-Proteinkinase bekannt, dass sie den Spitzennatriumstrom signifikant steigern kann: Die PKA kann die Leitfähigkeit des Natriumkanals steigern, indem sie den Natriumkanal an zwei SerinResten, Ser-525 und Ser-528, an dem Linker zwischen Domäne I und II phosphoryliert (Murphy et al. 1996). Damit kommt es zu einem verstärkten Natriumeinstrom, während die Spannungsabhängigkeit wahrscheinlich unverändert bleibt (Frohnwieser et al. 1997, Schreibmayer et al. 1994). Diese Arbeiten zeigen, dass die aktivierte PKA den Spitzennatriumstrom um $42 \pm 5 \%$ steigern kann. Auch ZHOU et al. zeigten 2000 eine PKA-abhängige Steigerung des Spitzennatriumstroms durch eine beschleunigte Aktivierung der Natriumkanäle. Dieses kann für die beschleunigte Erregungsweiterleitung im Herzen unter sympathischer Stimulation von Bedeutung sein (Nattel et al. 2007). Auch die Menge der funktionierenden sarkolemmalen Nav1.5 ist durch die PKA erhöht (Zhou et al. 2000, Zhou et al. 2002, Hallaq et al. 2006).

WAGNER et al. konnten 2014 zeigen, dass eine Inhibition der PKA den gezeigten Effekt des Ang II auf den Spitzennatriumstrom verhindern konnte. Somit ist eine Nox2abhänge direkte Oxidation des $\mathrm{Na}^{+}-$Kanals eher nicht für den beobachteten Effekt auf den Spitzennatriumstrom und die AP-Aufstrichgeschwindigkeit verantwortlich, sondern eine Nox2-abhänge PKA-Aktivierung, welche in der Folge den $\mathrm{Na}^{+}-$Kanal reguliert. 
Die PKC phosphoryliert ebenfalls den Natriumkanal, allerdings ist die Folge dieser Phosphorylierung ein reduzierter Natriumeinstrom und eine beschleunigte Inaktivierung (Qu et al. 1994). Hier findet die Phosphorylierung an Ser-1503 in dem Linker zwischen der Domäne III und IV statt (Qu et al. 1996). Dabei scheint die PKCabhängige Wirkung auf Nav1.5 vor allem zu einer Reduktion der Anzahl funktionstüchtiger Natriumkanäle im Sarkolemm zu führen (Hallaq et al. 2012). Da in der vorliegenden Arbeit eine Ang II - Nox2 - abhängige Aktivierung des Spitzennatriumstroms verzeichnet wird, ist eine Beteiligung der PKC, welche den Natriumstrom nachweislich reduziert, unwahrscheinlich.

Somit muss man von einem Nox2- und PKA-abhängigen Signalweg in der Ang IIinduzierten Steigerung der Aufstrichgeschwindigkeit über eine Erhöhung des Spitzennatriumstroms ausgehen.

\subsection{Die Bedeutung der Nox2 und der CaMKII für die Aktionspotentialdauer}

Im Hinblick auf die APD zeigte das Vorhandensein bzw. die Inhibition der Nox2 in der vorliegenden Arbeit keine signifikante Wirkung (siehe Abb. 3.12).

Dabei konnten andere Studien durchaus eine Nox-abhängige Wirkung auf die an der APD beteiligten lonenkanälen feststellen: AMBERG et al. zeigten 2010 eine Stimulation der vaskulären L-Typ-Ca ${ }^{2+}-K a n a ̈ l e ~ d u r c h ~ R O S$, die bei Inhibition der Nox ausblieb. Diese Ergebnisse konnten durch die Arbeit von WAGNER et al. 2014 bestätigt werden: Hier zeigte sich in ventrikulären Zellen eine Steigerung des peak Ica, welche durch die Ang II - Exposition Nox2-abhängig hervorgerufen wurde. ZENG et al. untersuchten 2008 die Stimulation der Nox durch Endothelin-1 und die daraus

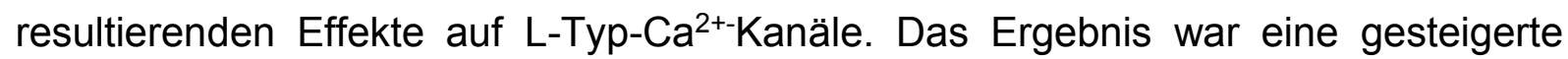
Funktion der L-Typ-Ca ${ }^{2+-K a n a ̈ l e ~ d u r c h ~ v o n ~ d e r ~ N o x ~ s t a m m e n d e n ~ R O S . ~ D i e s e ~}$ Ergebnisse wurden zwei Jahre später in einer weiteren Arbeit derselben Arbeitsgruppe bestätigt: 2010 untersuchten ZENG et al. die Stimulation der L-Typ-Ca ${ }^{2+-K a n a ̈ l e ~ d u r c h ~}$ die Nox und konnten zeigen, dass PKC in dieser Signalkaskade eine wichtige Rolle spielt. Da der L-Typ-Ca ${ }^{2+}-K a n a l$ wesentlich für die Aktionspotentialdauer verantwortlich ist, erwarten wir eine Verlängerung der Aktionspotentialdauer bei Stimulation der LTyp-Ca ${ }^{2+-}$ Kanäle. Laut den genannten Studien ist die Nox in der Lage, den L-Typ-Ca ${ }^{2+-}$ 
Kanal zu stimulieren, das wiederum müsste $\mathrm{zu}$ einer verlängerten Aktionspotentialdauer führen, was allerdings durch die Ergebnisse dieser Arbeit nicht bestätigt wird: Hier scheint weder die Aktivierung der Nox2 durch Ang II noch die Inhibierung durch DPI bzw. der genetischen Verlust einer funktionierenden Nox2 eine Wirkung auf die APD zu haben. Möglicherweise hat Ang II neben den steigernden Effekt auf die L-Typ- $\mathrm{Ca}^{2+-}$ Kanäle auch auf andere lonenkanäle eine Wirkung, so dass sich ggf. die depolarisierenden und die repolarisierenden Wirkungen aufheben. Ein anderer Grund könnte die ohnehin verkürzte APD der Maus-Kardiomyozyten im Gegensatz zu humanen Kardiomyozyten sein, die durch die unterschiedliche Zusammensetzung der lonenkanäle zustande kommt (siehe Abb. 1.5).

Unabhängig von der Stimulation durch Ang II konnte in der vorliegenden Arbeit festgestellt werden, dass die CaMKII $\delta_{c}{ }^{-/}-$Mäuse signifikant längere APD (gemessen als APD 80) aufweisen (siehe Abb.3.11). Diese Beobachtung legt nahe, dass die CaMKII $\delta_{c}$ eine wesentliche Rolle in der Modulation der APD hat. Eine Arbeit von WAGNER et al. aus dem Jahr 2009 liefert mögliche Erklärungen dafür: Es wurden anhand von Mäusen- und Kaninchen-Myokard die Wirkung der CaMKII auf die Kaliumkanäle untersucht und festgestellt, dass die CaMKII zum Teil gegensinnige Effekte auf die unterschiedlichen Kaliumkanälen hat. Unter anderem aktiviert die CaMKII den IK1, welche einer von drei wichtigen Kaliumströmen in der Repolarisationsphase ist. Somit trägt also die CaMKII zur Repolarisation bei, im Umkehrschluss bewirkt ein Ausfall der CaMKII eine verzögerte Repolarisation und somit eine Verlängerung der APD. Außerdem geht aus der gleichen Arbeit von WAGNER et al. hervor, dass die CaMKII die Erholungsphase der lo von der Inaktivierung beschleunigt. Es liegt nahe, dass bei unterschiedlicher Ausprägung der verschiedenen Kaliumkanäle je nach Spezies, eine CaMKII-Überexpression zur Verlängerung oder auch Verkürzung der APD führen kann. Für eine verlängernde Wirkung der CaMKII auf die APD sprechen die Beobachtungen, dass die CaMKII sowohl den $I_{\mathrm{Na}}$,late steigert (Wagner et al. 2006) als auch den $\mathrm{I}_{\mathrm{Ca}}$ (Kohlhaas et al. 2006).

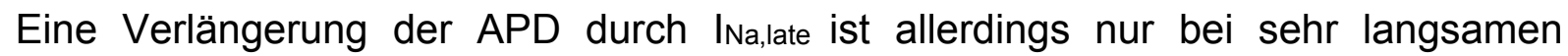
Herzfrequenzen entscheidend. Eine andere Studie konnte eine Verkürzung der APD durch CAMKII-Inhibition erreichen ( $\mathrm{Li}$ et al. 2006). Auf der anderen Seite kamen GRANDI et al. 2007 zu dem Ergebnis, dass, wenn man alle Effekte der CaMKII auf den Natrium-, Kalium- und Kalzium-Strom zusammennimmt, es insgesamt durch die CaMKII-Wirkung zu einer Verkürzung der APD kommt. Auch weiß man heutzutage, 
dass die Phase II des Aktionspotential, welche für den Hauptanteil der Aktionspotentialdauer verantwortlich ist, u.a. von einer Spannungs- und CaMKIIabhängigen langsamen Inaktivierung des L-Typ-Ca ${ }^{2+}$-Kanals terminiert wird (Bers und Perez-Reyes 1999). Das unterstützt die vorliegenden Beobachtungen dieser Arbeit.

Es besteht also weiterhin der Bedarf nach weiteren Untersuchungen, was die Wirkung des Enzyms CaMKII auf die APD angeht. Stets sind die Speziesunterschiede zu berücksichtigen und auch die Tatsache, dass die CaMKII an sehr vielen lonenkanälen (RyR, L-Typ-Ca2+-Kanal, K+-Kanäle, $\mathrm{Na}^{+}-$Kanäle) und Enzymen (z.B. Phospholamban) modulierend einwirkt und daher der Effekt auf die APD stets als Summe vieler einzelner Modulationen zu betrachten ist (Grandi et al. 2007).

\subsection{Es kommt unter Stimulation durch Ang II zu vermehrter getriggerter Aktivität in Form von DADs}

In der vorliegenden Arbeit konnten wir zeigen, dass es durch die Ang II - Exposition der Kardiomyozyten vermehrt zu getriggerter Aktivität, vor allem DADs, kommt (siehe Abb. 3.14 und Abb. 3.16). Dieser Effekt ist aufgehoben in Kardiomyozyten, die keine funktionierende Nox2 besitzen oder mit dem pharmakologischen Inhibitor der Nox2 (DPI) behandelt sind (siehe Abb. 3.14). Diese Ergebnisse legen nahe, dass Ang II Nox2-abhängig zu vermehrter getriggerter Aktivität in Kardiomyozyten führt.

Kardiale Arrhythmien lassen sich auf eine gestörte Aktivität von lonenkanälen bzw. transportern zurückführen. Besonders anfällig ist die Plateauphase des Aktionspotentials, während der depolarisierende und repolarisierende Ströme die Balance halten. Eine ausreichend starke Reaktivierung von Ica würde hier zu frühen Nachdepolarisationen (EADs) führen (Sipido et al. 1995). Je länger die Plateauphase ist, desto größer die Wahrscheinlichkeit eines solchen Ereignisses. Die Plateauphase wird verlängert, wenn entweder die depolarisierenden Ströme, Ica und/oder INa, gesteigert sind, oder die repolarisierenden Ströme vermindert; dazu zählen $I_{\text {to, }} I_{\mathrm{Kr}}$, I I ss und IK1.

Ein anderer wichtige Mechanismus der Arrhythmogenese sind diastolische Kalziumfreisetzungen aus dem SR (auch $\mathrm{Ca}^{2+}$-Sparks genannt). Diese entstehen durch eine gesteigerte Öffnungswahrscheinlichkeit des RyR. Die Folge hieraus ist eine 
Aktivierung des NCX. Dieser schleust die $\mathrm{Ca}^{2+}$-Ionen aus der Zelle und nimmt $\mathrm{Na}^{+}-$ Ionen in die Zelle auf. Führt der aktivierte transiente $\mathrm{Na}^{+}$-Einwärtsstrom des NCX zum Erreichen des Schwellenpotentials, generiert die Zelle ein neues Aktionspotential, welches als DAD imponiert (Zipes 2003, Bers 2002). Dabei hängt die Öffnungswahrscheinlichkeit des RyR von der Kalziumkonzentration des SR und im dyadischen Spalt ab. Eine Überladung mit Kalzium, wie sie im Übrigen bei der Herzinsuffizienz vorliegt, führt zu einer immensen Steigerung der Öffnungswahrscheinlichkeit des RyR, welche dann zu späten Nachdepolarisationen führen kann (Marx et al. 2000).

Zusammengefasst führen eine Verlängerung des AP sowie eine Kalziumüberladung der Zelle zu getriggerter Aktivität. Einschränkend muss man dazu sagen, dass nicht allein die Dauer des Aktionspotentials entscheidend für das Auftreten von EADs ist, sondern die genaue Morphologie des Aktionspotentials in der Phase III (Hondeghem et al. 2001).

Im Rahmen der zugrunde liegenden Arbeit wurden bis auf eine Ausnahme nur DADs verzeichnet. Die naheliegende Begründung für das Fehlen der EADs ist die sehr kurze APD der Mausmyozyten von ca. 100 ms (Anumonwo et al. 2001). Die verzeichneten DADs zeigten sich vor allem in den Wildtyp-Kardiomyozyten, welche mit Ang II behandelt worden sind (siehe Abb. 3.16). Welche arrhythmogene Wirkung geht also von Ang II aus?

Bereits 1989 zeigte eine tierexperimentelle Studie von WESSELING et al. den vorteilhaften Einsatz von ACE-Hemmern gegen die Arrhythmieentwicklung bei Herzinsuffizienz. Die arrhythmogene Wirkung des Ang II ist seit dem in vielen Studien gezeigt worden (Zhao et al. 2011, Bapat et al. 2012, Garg et al. 2006, Makkar et al. 2006). YASUNO et al. führten 2013 Versuche an Wildtyp- und AT1-Knockout-Mäusen durch, bei denen sie durch transverse Konstriktion der Aorta eine kardiale Hypertrophie hervorruften, und konnten feststellen, dass obwohl beide Maus-Gruppen eine kardiale Hypertrophie entwickelten, die Wildtyp-Mäuse aber mehr Arrhythmien aufzeigten. Dieses Ergebnis demonstriert eine Ang II - abhängige Arrhythmieentwicklung, die über $A T_{1}$ vermittelt wird. So zeigen unsere Ergebnisse sowie auch die der genannten Studien eindeutig eine Arrhythmie-steigernde Wirkung von Ang II.

Wie oben bereits ausführlich aufgeführt, wissen wir heute um die aktivierende Wirkung von Ang II auf die Nox2. Die Abhängigkeit der arrhythmogenen Wirkung von Ang II von 
einer funktionierenden Nox2 konnte in einigen Studien gezeigt werden (Garrido und Griendling 2009; Zhao et al. 2011). Auch die Ergebnisse dieser Arbeit bestätigen die Annahme, dass Ang II durch eine Aktivierung der Nox2 zur Entwicklung von Arrhythmien führt. Doch auf welchem Wege führt die Stimulation der Nox2 durch Ang II zu vermehrter DAD-Bildung in der Zelle?

Die von der Nox2 stammenden ROS sind in der Lage, den RyR zu oxidieren: PROSSER et al. zeigten 2011 in einer aufwendigen Arbeit, dass die aktivierte Nox2, welche in Nachbarschaft zu den RyRs lokalisiert ist, durch ihre ROS-Produktion zu einer Oxidierung des RyR führt, welche daraufhin eine vermehrte $\mathrm{Ca}^{2+}$-Ausschüttung ins Zytosol bewirkt und den oben beschriebenen Mechanismus der DAD-Bildung in Gang setzt. Allerdings wurde hier die Nox2 nicht über Ang II stimuliert, sondern durch mechanische Dehnung. Möglicherweise liegt der gesteigerten Arrhythmogenese in der vorliegenden Arbeit ein ähnlicher Mechanismus zugrunde, nur dass hier die Nox2 über pharmakologische Stimulation und nicht Dehnungsreiz aktiviert wird.

Allerdings weiß man auch, dass nicht nur die Oxidierung des RyR zu einer erhöhten Öffnungswahrscheinlichkeit des Kanals führt, sondern auch die Phosphorylierung durch die CaMKII (Maier et al. 2003). Auch andere Arbeitsgruppen haben eine Beteiligung der CaMKII in diesem Signalweg feststellen können (Palomeque et al. 2009; Erickson et al. 2008). Eine umfangreiche Studie konnte demonstrieren, dass Ang II durch Aktivierung der Nox2 zu vermehrter ROS-Produktion und über die Aktivierung der CaMKII durch die ROS zu eine Erhöhung des späten INa und des ICa,L führt. Das Endergebnis dieser Effekte war eine gesteigerte Arrhythmieneigung (Zhao et al. 2011). Diese Signalkaskade ließ sich hierbei sowohl durch Lorsartan (ein AT1Blocker) als auch durch Apocynin (ein Nox-Hemmer), KN-93 (ein CaMKII-Inhibitor),

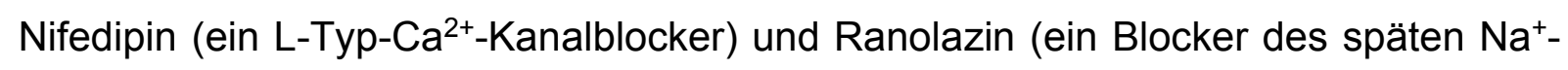
Stroms) effektiv unterbrechen (Zhao et al. 2011). Diese Ergebnisse wurden durch die Arbeit von WAGNER et al. 2014 bestätigt. Ein großer Unterschied der Ergebnisse von ZHAO et al., verglichen mit der vorliegenden Arbeit, ist, dass ZHAO et al. vor allem EADs gemessen haben, während in der vorliegenden Arbeit fast alle beobachteten Arrhythmien DADs waren. Eine mögliche Erklärung für diesen Unterschied könnten speziesabhängige Unterschiede in der Expression wichtiger lonenkanäle und damit deutliche Unterschiede in der APD-Morphologie sein. In der erwähnten Arbeit der Arbeitsgruppe um Zhao wurden Kaninchen-Myozyten verwendet, die physiologischerweise eine deutlich längere APD aufgrund eines stärker ausgeprägten L-Typ-Ca ${ }^{2+}$ 
Stroms haben und daher gewissermaßen einen besseren „Nährboden“ für EADs bieten.

In der vorliegenden Arbeit konnte in der Abwesenheit der CaMKIIסc (also in den CaMKII $\delta \mathrm{c}^{-1-}$-Myozyten) Ang II keine signifikante Steigerung der Anzahl der DADs herbeirufen. Dieses würde für eine Beteiligung der CaMKIIסc in der Ang ॥ induzierten, Nox2-abhängigen Arrhythmieentstehung sprechen.

Bereits 2006 konnten WAGNER et al. in Mäusen mit transgener CaMKIIסcÜberexpression eine gesteigerte Neigung zu ventrikulären Arrhythmien zeigen. Gerade bei niedrigen Herzfrequenzen führte CaMKII durch die Steigerung des INa,late zu einer Verlängerung der APD mit gesteigerter Häufigkeit von EADs, was mittels Computermodell-Analysen gezeigt werden konnte (Grandi et al. 2007; Hashambhoy et al. 2011). TOISCHER et al. konnten 2013 zeigen, dass die APD-Verlängerung und auch die Arrhythmieentwicklung sowohl durch die Hemmung des INa,late als auch die der CaMKII abgewandt werden.

$\mathrm{Da}$ in der vorliegenden Arbeit allerdings keine Verlängerung der APD festgestellt werden konnte und dennoch CaMKII-abhängig getriggerte Aktivität nachzuweisen war, muss es einen von der APD unabhängigen Mechanismus der CaMKIl-induzierten Arrhythmieentwicklung geben: Die CaMKIIJc steigert nachweislich den späten Natriumstrom (Wagner et al. 2011, Wagner et al. 2014), wodurch es zu einer zellulären Überladung der Zelle mit $\mathrm{Na}^{+}$-Ionen kommt. Das wiederum kann durch den Umkehrtransportmodus des NCX zu einer Kalziumüberladung der Zelle und somit auch des SR führen. Hieraus entstehen vermehrt $\mathrm{Ca}^{2+}$-Sparks, welche dann wiederum die Entstehung von DADs begünstigen. Die verschiedenen zellulären CaMKIIabhängigen Mechanismen der Arrhythmieentstehung sind in der Abbildung 4.1. schematisch zusammengefasst dargestellt. 


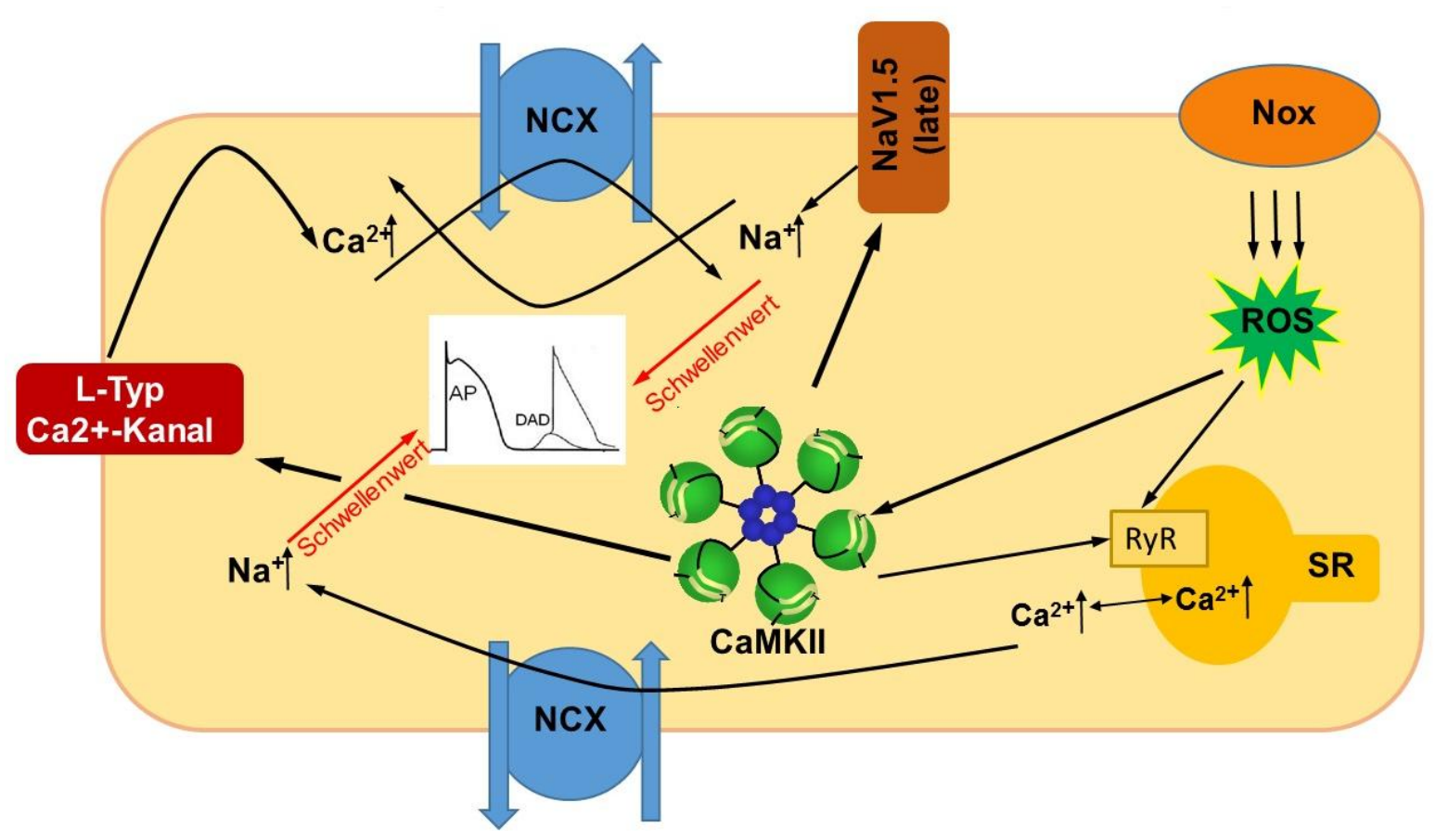

Abb. 4.1: Die Bedeutung der CaMKIl für die zelluläre Arrhythmie. Über eine Aktivierung der Nox entstandene ROS können zum einen den RyR oxidieren und zum anderen die CaMKII aktivieren, welche dann den RyR phosphoryliert. Beides führt zu einer Aktivierung des RyR, was wiederum eine Überladung des SR mit $\mathrm{Ca}^{2+}$ zur Folge hat. Das führt zu diastolischen $\mathrm{Ca}^{2+}-\mathrm{Sparks}$, die eine Überladung des Zytosols mit $\mathrm{Ca}^{2+}$ zur Folge haben. Das führt zu einer Aktivierung des $\mathrm{NCX}$ und damit zu einer $\mathrm{Na}^{+}-$ Überladung der Zelle. Ist dabei dann der Schwellenwert überschritten, generiert die Zelle ein neues Aktionspotential, was sich als eine späte Nachdepolarisation präsentiert. Auch kann die aktivierte CaMKII durch eine gesteigerte Funktion des Ica durch den L-Typ-Ca ${ }^{2+}-K a n a l$ führen, was zu einer $\mathrm{Ca}^{2+}$ Überladung des Zytosols führt und den oben beschriebenen Vorgang in Gang setzt. Auch die Steigerung des $I_{N a \text {,late }}$ führt über eine Erhöhung des intrazellulären $\mathrm{Na}^{+} \mathrm{zu}$ einer (durch die reverse Aktivität des $\mathrm{NCX}$ ) zu einer $\mathrm{Ca}^{2+}-$ Überladung, welche wieder die Entstehung von Arrhyhtmien begünstigt. 


\section{Zusammenfassung}

Die CaMKIIIc und Nox2 sind zwei Enzyme, welche im insuffizienten Myokard überexprimiert sind. Ich konnte hier zeigen, dass sowohl die Nox2 als auch die CaMKIIIc das Aktionspotential in ventrikulären Herzmuskelzellen modulieren können. Die maximale Aufstrichgeschwindigkeit in der Phase I des Aktionspotentials kann durch Ang II Nox2-abhängig signifikant gesteigert werden. Dieser Effekt findet CaMKIIIc-unabhängig statt. Auf die Dauer des Aktionspotentials hatte die Zugabe von Ang II keinen Einfluss, auch die Inhibition der Nox2 führte zu keinem signifikanten Unterschied in der APD. Jedoch kommt es bei Fehlen der CaMKIIסc zu einer signifikanten Verlängerung der APD.

Für die Arrhythmieentwicklung, die sich durch eine Ang II - Stimulation als deutlich gesteigert gezeigt hat, ist eine funktionierende Nox2 essentiell. Da in den Zellen mit einem genetischen Ausfall der CaMKIIסc (trotz verlängerter APD) keine signifikante Steigerung der Arrhythmieentwicklung unter Ang II - Exposition gezeigt werden konnte, kann man vermuten, dass die CaMKIIסc ebenfalls in dieser Signalkaskade eine Rolle spielt.

Die Entwicklung von Arrhythmien ist im insuffizienten Myokard häufig und kann zu lebensbedrohlichen Ereignissen führen. Obwohl bereits vieles über das kardiale Remodeling im Rahmen der Herzinsuffizienzentwicklung erforscht ist, sind weiterhin viele intrazellulären Mechanismen, welche die Chronifizierung und v.a. die Arrhythmieentwicklung in diesem Zusammenhang hervorrufen oder begünstigen bis heute nicht gänzlich geklärt. Die genaue Kenntnis über diese Mechanismen, zu der die vorliegende Arbeit einen Beitrag zu leisten versucht, könnte uns in Zukunft ermöglichen, ein Fortschreiten der Erkrankung und die Arrhythmieentwicklung zu verhindern. 


\section{Literaturverzeichnis}

Abriel H (2010): Cardiac sodium channel $\mathrm{Na}(\mathrm{v}) 1.5$ and interacting proteins: Physiology and pathophysiology. J Mol Cell Cardiol $\underline{48}, 2-11$.

Adelman WJ Jr, Palti Y (1969): The influence of external potassium on the inactivation of sodium currents in the giant axon of the squid, Loligo pealei. J Gen Physiol $\underline{53}$, 685703.

Ago T, Kuroda J, Pain J, Fu C, Li H, Sadoshima J (2010): Upregulation of Nox4 by hypertrophic stimuli promotes apoptosis and mitochondrial dysfunction in cardiac myocytes. Circ Res 106, 1253-1264.

Aiba T, Hesketh GG, Liu T, Carlisle R, Villa-Abrille MC, O'Rourke B, Akar FG, Tomaselli GF (2010): $\mathrm{Na}+$ channel regulation by $\mathrm{Ca} 2+/$ calmodulin and $\mathrm{Ca} 2+/$ calmodulin-dependent protein kinase II in guinea-pig ventricular myocytes. Cardiovasc Res 85, 454-463.

Akki A, Zhang M, Murdoch C, Brewer A, Shah AM (2009): NADPH oxidase signaling and cardiac myocyte function. $\mathrm{J}$ Mol Cell Cardiol $\underline{47}, 15-22$.

Alvin Z, Laurence GG, Coleman BR, Zhao A, Hajj-Moussa M, Haddad GE (2011): Regulation of L-type inward calcium channel activity by captopril and angiotensin II via the phosphatidyl inositol 3-kinase pathway in cardiomyocytes from volume-overload hypertrophied rat hearts. Can J Physiol Pharmacol $\underline{89}$, 206-215.

Ambasta RK, Schreiber JG, Janiszewski M, Busse R, Brandes RP (2006): Noxa1 is a central component of the smooth muscle NADPH oxidase in mice. Free Radic Biol Med 41, 203-201.

Amberg GC, Earley S, Glapa SA (2010): Local regulation of arterial L-type calcium channels by reactive oxygen species. Circ Res $\underline{107}, 1002-1010$. 
Anderson ME (2002): Calmodulin and the philosopher's stone: Changing $\mathrm{Ca} 2+$ into arrhythmias. J Cardiovasc Electrophysiol 13, 195-197.

Anderson ME, Braun AP, Schulman H, Premack BA (1994): Multifunctional $\mathrm{Ca} 2+/$ calmodulin-dependent protein kinase mediates $\mathrm{Ca}(2+)$-induced enhancement of the L-type Ca2+ current in rabbit ventricular myocytes. Circ Res $\underline{75}$, 854-861.

Anderson ME, Braun AP, Wu Y, Lu T, Wu Y, Schulman H, Sung RJ (1998): KN-93, an inhibitor of multifunctional $\mathrm{Ca}++/$ calmodulin-dependent protein kinase, decreases early afterdepolarizations in rabbit heart. J Pharmacol Exp Ther 287, 996-1006.

Antzelevitch C (1998): The Brugada syndrome. J Cardiovasc Electrophysiol $\underline{9}, 513-$ 516 .

Antzelevitch C, Nesterenko V, Shryock JC, Rajamani S, Song Y, Belardinelli L (2014): The role of late I $\mathrm{Na}$ in development of cardiac arrhythmias. Handb Exp Pharmacol $\underline{221}, 137-168$.

Anumonwo JM, Tallini YN, Vetter FJ, Jalife J (2001): Action potential characteristics and arrhythmogenic properties of the cardiac conduction system of the murine heart. Circ Res $\underline{89}$, 329-335.

Aon MA, Cortassa S, O'Rourke B (2010): Redox-optimized, R.O.S. balance: a unifying hypothesis. Biochem. Biophys Acta 1797, 865-877.

Arai M, Alpert NR, MacLennan DH, Barton P, Periasamy M (1993): Alterations in sarcoplasmic reticulum gene expression in human heart failure. A possible mechanism for alterations in systolic and diastolic properties of the failing myocardium. Circ Res 72, 463-469.

Armstrong CM (2006): Na channel inactivation from open and closed states. Proc Natl Acad Sci USA 103, 17991-17996. 
Ashpole NM, Herren AW, Ginsburg KS, Brogan JD, Johnson DE, Cummins TR, Bers DM, Hudmon A (2012): Ca2+/calmodulin-dependent protein kinase II (CaMKII) regulates cardiac sodium channel NaV1.5 gating by multiple phosphorylation sites. J Biol Chem 287, 19856 -19869.

Baartscheer A, Schumacher CA, van Borren MM, Belterman CN, Coronel R, Fiolet JW (2003): Increased $\mathrm{Na}+/ \mathrm{H}+-e x c h a n g e$ activity is the cause of increased $[\mathrm{Na}+] \mathrm{i}$ and underlies disturbed calcium handling in the rabbit pressure and volume overload heart failure model. Cardiovasc Res $\underline{57}$, 1015-1024.

Babior BM, Lambeth JD, Nauseef W (2002): The neutrophil NAPDH oxidase. Arch Biochem Biophys $\underline{397}$, 342-344.

Backs J, Backs T, Neef S, Kreusser MM, Lehmann LH, Patrick DM, Grueter CE, Qi X, Richardson JA, Hill JA (2009): The delta isoform of CaM kinase II is required for pathological cardiac hypertrophy and remodeling after pressure overload. Proc Natl Acad Sci U S A 106, 2342-2347.

Balser JR, Nuss HB, Romashko DN, Marban E, Tomaselli GF (1996): Functional consequences of lidocaine binding to slow-inaktivated sodium channels. J Gen Physiol 107, 643-658.

Bapat A, Nguyen TP, Lee JH, Sovari AA, Fishbein MC, Weiss JN, Karagueuzian HS (2012): Enhanced sensitivity of aged fibrotic hearts to angiotensin II- and hypokalemiainduced early afterdepolarization-mediated ventricular arrhythmias. Am J Physiol Heart Circ Physiol 302, H2331- H2340.

Barry DM, Xu H, Schuessler RB, Nerbonne JM (1998): Functional knockout of the transient outward current, long-QT syndrome, and cardiac remodeling in mice expressing a dominant-negative Kv4 alpha subunit. Circ Res 83, 560 - 567.

Bassani JW, Bassani RA, Bers DM (1994): Relaxation in rabbit and rat cardiac cells: species-dependent differences in cellular mechanisms. J Physiol $\underline{476}, 279-293$ 
Bassani RA, Mattiazzi A, Bers DM (1995): CaMKII is responsible for activity-dependent acceleration of relaxation in rat ventricular myocytes. Am J Physiol 268, 703-712.

Bendall JK, Cave AC, Heymes C, Gall N, Shah AM (2002): Pivotal role of a gp91(phox)-containing NADPH oxidase in angiotensin Il-induced cardiac hypertrophy in mice. Circulation $\underline{105}, 293-296$.

Bennett PB, Yazawa K, Makita N, Georgr AL Jr (1995): Molecular mechanism for an inherited cardiac arrhythmia. Nature $\underline{376}, 683-685$.

Berecki G, Wilders R, de Jonge B, van Ginneken AC, Verkerk AO (2010): Reevaluation of the action potential upstroke velocity as a measure of the $\mathrm{Na}+$ current in cardiac myocytes at physiological conditions. PLoS One $\underline{5}$, e15772.

Bers DM. (2001): Excitation-contraction coupling and cardiac contractile force. 2nd ed. Kluwer Academic Publishers. Dordrecht, The Netherlands.

Bers DM (2002 a): Calcium and cardiac rhythms: physiological and pathophysiological. Circ Res $\underline{90}, 14-17$.

Bers DM (2002 b): Cardiac excitation-contraction coupling. Nature $\underline{415}, 198-205$.

Bers DM, Perez-Reyesa E (1999): Ca Channels in cardiac myocytes: structure and function in $\mathrm{Ca}$ influx and intracellular Ca release. Cardiovasc Res $\underline{42}, 339-360$.

Bezzina C, Veldkamp MW, van Den Berg MP, Postma AV, Rook MB, Viersma JW, van Langen IM, Tan-Sindhunata G, Bink-Boelkens MT, van Der Hout AH (1999): A single $\mathrm{Na}+$ channel mutation causing both long-QT and Brugada syndromes. Circ Res $\underline{85}$, 1206-1213.

Birkeland JA, Sejersted OM, Taraldsen T, Sjaastad I (2005): EC-coupling in normal and failing hearts. Scand Cardiovasc J $\underline{39}, 13-23$. 
Boraso A, Williams AJ (1994): Modification of the gating of the cardiac sarcoplasmatic reticulum $\mathrm{Ca}^{2+}$ - release channel by $\mathrm{H}_{2} \mathrm{O}_{2}$ and dithiothreitol. Am J Physiol $\underline{267}, \mathrm{H} 1010-$ H1016.

Bouron A, Potreau D, Raymond G (1992): The L type calcium current in single hypertrophied cardiomyocytes isolated from the right ventricle of ferret heart. Cardiovasc Res $\underline{26}$, 662-670.

Branda CS, Dymecki SM (2004): Talking about a revolution: The impact of site-specific recombinases on genetic analyses in mice. Dev Cell $\underline{6}, 7-28$.

Braun AP, Schulman H (1995): The multifunctional calcium/calmodulin-dependent protein kinase: from form to function. Annu Rev Physiol 57, 417-445.

Braun-Menendez E, Fasciolo JC, Leloir LF, Muñoz JM (1940): The substance causing renal hypertension. J Physiol 98, 283-298.

Braunwald E, Bristow MR (2000): Congestive heart failure: fifty years of progress. Circulation 102, 14-23.

Bristow MR, Ginsburg R, Umans V, Fowler M, Minobe W, Rasmussen R, Zera P, Menlove R, Shah P, Jamieson S (1986): Beta 1- and beta 2-adrenergic-receptor subpopulations in nonfailing and failing human ventricular myocardium: coupling of both receptor subtypes to muscle contraction and selective beta 1-receptor downregulation in heart failure. Circ Res $\underline{59}$, 297-309.

Brittsan AG, Kranias EG (2000): Phospholamban and cardiac contractile function. J Mol Cell Cardiol. 32, 2131-2139.

Brockdorff N, Fisher EM, Orkin SH, Lyon MF, Brown SD (1988): Localization of the human $\mathrm{X}$-linked gene for chronic granulomatous disease to the mouse $\mathrm{X}$ chromosome: implications for X-chromosome evolution. Cytogenet Cell Genet $\underline{48}$, 124-125. 
Brown AM, Lee KS, Powell T (1981): Sodium currents in single rat heart muscle cells. J Physiol (Lond) $\underline{318}$, 479-500.

Brown DI, Griendling KK (2009): Nox proteins in signal transduction. Free Radiac Biol Med $\underline{47}, 1239-1253$.

Brugada P, Brugada J (1992): Right bundle branch block, persistent ST segment elevation and sudden cardiac death: a distinct clinical and electrocardiographic syndrome. A multicenter report. J AM Coll Cardiol 20, 1391-1396.

Byrne JA, Grieve DJ, Bendall JK, Li JM, Gove C, Lambeth JD, Cave AC, Shah AM (2003): Contrasting roles of NADPH oxidase isoforms in pressure-overload versus angiotensin II-induced cardiac hypertrophy. Circ Res $\underline{93}$, 802-805.

Camilión de Hurtado MC, Alvarez BV, Pérez NG, Ennis IL, Cingolani HE (1998): Angiotensin II activates $\mathrm{Na}$-independent $\mathrm{Cl}^{-}-\mathrm{HCO} 3-e x c h a n g e$ in ventricular myocardium. Circ Res $\underline{82}, 473-481$.

Capecchi MR (1989): Altering the genome by homologous recombination. Science 244:1288-1292.

Catterall WA (1992): Cellular and molecular biology of voltage-gated sodium channels. Physiol Rev $\underline{72}$, 15-48.

Chamberland C, Barajas-Martinez H, Haufe V, Fecteau MH, Delabre JF, Burashnikov A, Antzelevitch C, Lesur O, Chraibi A, Sarret P (2010): Modulation of canine cardiac sodium current by Apelin. J Mol Cell Cardiol 4ㅇ, 694-701.

Chandler WK, Meves H (1970): Evidence for two types of sodium conductance in axons perfused with sodium fluoride solution. J Physiol 211, 653-678.

Chen LQ, Santarelli V, Horn R, Kallen RG (1996): A unique role for the S4 segment of domain 4 in the inactivation of sodium channels. J Gen Physiol 108, 549-556. 
Chen Q, Kirsch GE, Zhang D, Brugada R, Brugada J, Brugada P, Potenza D, Moya A, Borggrefe M, Breithardt G (1998): Genetic basis and molecular mechanism for idiopathic ventricular fibrillation. Nature $\underline{392}, 293-296$.

Cheng W, Li B, Kajstura J, Li P, Wolin MS, Sonnenblick EH, Hintze TH, Olivetti G, Anversa P (1995): Stretch-induced programmed myocyte cell death. J Clin Invest $\underline{96}$, 2247-2259.

Clempus RE, Griendling KK (2006): Reactive oxygen species signaling in vascular smooth muscle cells. Cardiovasc Res $\underline{71}$, 216-225.

Cohen IS, Datyner NB, Gintant GA, Mulrine NK, Pennefather P (1985): A note on the relation of maximum upstroke velocity to peak inward current recorded by the voltage clamp. Circ Res 57, 482-484.

Cohn JN (1995): Structural basis for heart failure. Ventricular remodeling and its pharmacological inhibition. Circulation 91, 2504-2507.

Curran M, Atkinson D, Timothy K, Vincent GM, Moss AJ, Leppert M, Keating M (1993): Locus heterogeneity of autosomal dominant long QT syndrome. J Clin Invest $\underline{92}, 799$ 803.

De Gasparo M (2002): Angiotensin II and nitric oxide interaction. Heart Fail Rev 7, 347358.

De Mello WC (1996): Renin-angiotensin system and cell communication in the failing heart. Hypertension $\underline{27}, 1267-1272$.

De Mello WC (1998): Intracellular angiotensin II regulates the inward calcium current in cardiac myocytes. Hypertension 32, 76-82.

De Mello WC (2011): Intracrine action of angiotensin II in the intact ventricle of the failing heart: angiotensin II changes cardiac excitability from within. Mol Cell Biochem 358, 309-315. 
De Mello WC (2012): Mechanical stretch reduces the effect of angiotensin II on potassium current in cardiac ventricular cells of adult Sprague Dawley rats. On the role of AT1 receptors as mechanosensors. J Am Soc Hypertens $\underline{6}$, 369-374.

De Mello WC, Monterrubio J (2004): The influence of intracellular and extracellular angiotensin II on the L-type calcium current in the failing heart. Hypertension $\underline{44}, 360$ 364.

De Mello WC, Gerena Y (2008). Eplerenone inhibits the intracrine and extracellular actions of angiotensin II on the inward calcium current in the failing heart. On the presence of an intracrine renin angiotensin aldosterone system. Regul Pept 151, 5460.

Dikalova A, Clempus R, Lassèque B, Cheng G, McCoy J, Dikalov S, San Martin A, Lyle A, Weber DS, Weiss D (2005): Nox1 overexpression potentiates angiotensin IIinduced hypertension and vascular smooth muscle hypertrophy in transgenic mice. Circulation 112, 2668-2676.

Dipla K, Mattiello JA, Margulies KB, Jeevanandam V, Houser SR (1999): The sarcoplasmic reticulum and the $\mathrm{Na}+/ \mathrm{Ca} 2+$ exchanger both contribute to the $\mathrm{Ca} 2+$ transient of failing human ventricular myocytes. Circ Res $\underline{84}, 435-444$.

Domenighetti AA, Boixel C, Cefai D, Abriel H, Pedrazzini T (2007): Chronic angiotensin II stimulation in the heart produces an acquired long QT syndrome associated with IK1 potassium current downregulation. J Mol Cell Cardiol $\underline{42}$, 63-70.

Doussiere J, Gaillard J, Vignais PV (1999): The heme component of the neutrophil NADPH oxidase complex is a target for aryliodonium compounds. Biochemistry $\underline{38}$, 3694-3703.

Drimal J, Boska D (1973): Effects of angiotensin-II on myocardial mechanics and contractile state of heart muscle. Eur J Pharmacol 21, 130-138. 
Edman CF, Schulman H (1994): Identification and characterization of delta B-CaM kinase and delta $\mathrm{C}$-CaM kinase from rat heart, two new multifunctional $\mathrm{Ca} 2+/$ calmodulin-dependent protein kinase isoforms. Biochim Biophys Acta 1221, 89101.

Edvardsson N, Hirsch I, Olsson SB (1984): Right ventricular monophasic action potentials in healthy young men. Pacing Clin Electrophysiol $\underline{7}, 813-821$.

Engelhardt S, Hein L, Keller U, Klämbt K, Lohse MJ (2002): Inhibition of $\mathrm{Na}(+)-\mathrm{H}(+)$ exchange prevents hypertrophy, fibrosis, and heart failure in beta(1)-adrenergic receptor transgenic mice. Circ Res $\underline{90}$, 814-819.

Enslen H, Sun P, Brickey D, Soderling SH, Klamo E, Soderling TR (1994): Characterization of $\mathrm{Ca} 2+/$ calmodulin-dependent protein kinase IV. Role in transcriptional regulation. J Biol Chem 269, 15520-15527.

Erickson JR, Joiner ML, Guan X, Kutschke W, Yang J, Oddis CV, Bartlett RK, Lowe JS, O'Donnell SE, Aykin-Burns N (2008): A dynamic pathway for calcium-independent activation of CaMKII by methionine oxidation. Cell $\underline{133}, 462-474$.

Erickson JR, Pereira L, Wang L, Han G, Ferguson A, Dao K, Copeland RJ, Despa F, Hart GW, Ripplinger CM, Bers DM (2013): Diabetic hyperglycaemia activates CaMKII and arrhythmias by O-linked glycosylation. Nature $\underline{502}, 372-376$.

Farhadian F, Contard F, Sabri A, Samuel JL, Rappaport L (1996): Fibronectin and basement membrane in cardiovascular organogenesis and disease pathogenesis. Cardiovasc Res $\underline{32}$, 433-442.

Finer JT, Simmons RM, Spudich JA (1994): Single myosin molecule mechanics: piconewton forces and nanometre steps. Nature $\underline{368}, 113-119$.

Frangogiannis NG (2004): Chemokines in the ischemic myocardium: from inflammation to fibrosis. Inflamm Res $\underline{53}, 585-595$. 
Franz MR, Bargheer K, Rafflenbeul W, Haverich A, Lichtlen PR (1987): Monophasic action potential mapping in human subjects with normal electrocardiograms: direct evidence for the genesis of the T wave. Circulation $\underline{75}$, 379-386.

Frohnwieser B, Chen LQ, Schreibmayer W, Kallen RG (1997): Modulation of the human cardiac sodium channel alpha-subunit by cAMP-dependent protein kinase and the responsible sequence domain. J Physiol 498, 309-318.

Gao G, Xie A, Zhang J, Herman AM, Jeong EM, Gu L, Liu M, Yang KC, Kamp TJ, Dudley SC (2013): Unfolded protein response regulates cardiac sodium current in systolic human heart failure. Circ Arrhythm Electrophysiol $\underline{6}, 1018-1024$.

Gao L, Blair LA, Marshall J (2006): CaMKIl-independent effects of KN93 and its inactive analog KN92: reversible inhibition of L-type calcium channels. Biochem Biophys Res Commun $\underline{345}$, 1606-1610.

Garg S, Narula J, Marelli C, Cesario D (2006): Role of angiotensin receptor blockers in the prevention and treatment of arrhythmias. Am J Cardiol 97, 921-925.

Garrido AM, Griendling KK (2009): NADPH oxidases and angiotensin II receptor signaling. Mol Cell Endocrinol. 302, 148-158.

Ginsburg KS, Bers DM (2004): Modulation of excitation-contraction coupling by isoproterenol in cardiomyocytes with controlled SR Ca2+ load and $\mathrm{Ca} 2+$ current trigger. J Physiol 556, 463-480.

Giordano FJ (2005): Oxygen, oxidative stress, hypoxia, and heart failure. J Clin Invest $\underline{115}, 500-508$.

Giustetto C, Di Monte F, Wolpert C, Borggrefe M, Schimpf R, Sbragia P, Leone G, Maury P, Anttonen O, Haissaguerre M, Gaita F (2006): Short QT syndrome: clinical findings and diagnostic-therapeutic implications. Eur Heart J 27, 2440-2447. 
Goodson P, Kumar A, Jain L, Kundu K, Murthy N, Koval M, Helms MN (2012): Nadph oxidase regulates alveolar epithel sodium channel activity and lung fluid balance in vivo via O־2 signaling. Am J Physiol Lung Cell Mol Physiol 302, 410-419.

Grandi E, Puglisi JL, Wagner S, Maier LS, Severi S, Bers DM (2007): Simulation of Ca-calmodulin-dependent protein kinase II on rabbit ventricular myocyte ion currents and action potentials. Biophys $\mathrm{J} \underline{93}, 3835-3847$.

Griendling KK, Minieri CA, Ollerenshaw JD, Alexander RW (1994): Angiotensin II stimulates NADH and NADPH oxidase activity in cultured vascular smooth muscle cells. Circ Res $\underline{74}, 1141-1148$.

Grobe JL, Mecca AP, Lingis M, Shenoy V, Bolton TA, Machado JM, Speth RC, Raizada MK, Katovich MJ (2007): Prevention of angiotensin II-induced cardiac remodeling by angiotensin-(1-7). Am J Physiol Heart Circ Physiol 292, 736-742.

Gul R, Kim SY, Park KH, Kim BJ, Kim SJ, Im MJ, Kim UH (2008): A novel signaling pathway of ADP-ribosyl cyclase activation by angiotensin II in adult rat cardiomyocytes. Am J Physiol Heart Circ Physiol 295, 77-88.

Guo W, Xu H, London B, Nerbonne JM (1999): Molecular basis of transient outward $\mathrm{K}+$ current diversity in mouse ventricular myocytes. J Physiol (Lond) $\underline{521}, 587-599$.

Gupte SA (2008): Glucose-6-phosphate dehydrogenase: a novel therapeutic target in cardiovascular diseases. Curr Opin Investig Drugs $\underline{9}$, 993-1000.

Gussak I, Brugada P, Brugada J, Wright RS, Kopecky SL, Chaitman BR, Bjerregaard P (2000): Idiopathic short QT interval: a new clinical syndrome? Cardiology 94, 99102.

Gutierrez DA, Fernandez-Tenorio M, Ogrodnik J, Niggli E (2013): NO-dependent CaMKII activation during $\beta$-adrenergic stimulation of cardiac muscle. Cardiovasc Res 100, 392-401. 
Gwathmey JK, Copelas L, MacKinnon R, Schoen FJ, Feldman MD, Grossman W, Morgan JP (1987): Abnormal intracellular calcium handling in myocardium from patients with end-stage heart failure. Circ Res $\underline{61}, 70-76$.

Hallaq H, Yang Z, Viswanathan PC, Fukuda K, Shen W, Wang DW, Wells KS, Zhou J, Yi J, Murray KT (2006): Quantitation of protein kinase A-mediated trafficking of cardiac sodium channels in living cells. Cardiovasc Res $\underline{72}, 250-261$.

Hallaq H, Wang DW, Kunic JD, Georg AL Jr, Wells KS, Murray KT (2012): Activation of protein kinase $\mathrm{C}$ alters the intracellular distribution and mobility of cardiac $\mathrm{Na}+$ channels. Am J Physiol Heart Circ Physiol 302, H782-789.

Hamill, OP, Marty A, Neher E, Sakmann B, Sigworth FJ (1981): Improved patch-clamp techniques for high-resolution current recording from cells and cellfree membrane patches. Pflugers Archiv Eur. J. Physiol 391, 85-100.

Hanson J, Huxley HE (1953): Structural basis of the cross-striations in muscle. Nature 172, $530-532$

Hanson PI, Schulman H (1992): Inhibitory autophosphorylation of multifunctional $\mathrm{Ca} *$ calmodulindependent protein kinaseanalyzed bysitedirected mutagenesis. J. Biol. Chem 267, 17216-17224.

Hanson PI, Meyer T, Stryer L, Schulman H (1994): Dual role of calmodulin in autophosphorylation of multifunctional CaM kinase may underlie decoding of calcium signals. Neuron $\underline{12}, 943-956$

Hasenfuss G, Mulieri LA, Leavitt BJ, Allen PD, Haeberle JR, Alpert NR (1992): Alteration of contractile function and excitation-contraction coupling in dilated cardiomyopathy. Circ Res $\underline{70}, 1225-1232$.

Hasenfuss G, Pieske B, Holubarsch C, Alpert NR, Just H (1993): Excitation-contraction coupling and contractile protein function in failing and nonfailing human myocardium. Adv Exp Med Biol 346, 91-100. 
Hasenfuss G, Reinecke H, Studer R, Meyer M, Pieske B, Holtz J, Holubarsch C, Posival H, Just H, Drexler H (1994): Relation between myocardial function and expression of sarcoplasmic reticulum $\mathrm{Ca}(2+)$-ATPase in failing and nonfailing human myocardium. Circ Res $\underline{75}$, 434-442.

Hashambhoy YL, Winslow RL, Greenstein JL (2011): CaMKII-dependent activation of late INa contributes to cellular arrhythmia in a model of the cardiac myocyte. Conf Proc IEEE Eng Med Biol Soc. 2011, 4665-4668.

Hoch B, Meyer R, Hetzer R, Krause EG, Karczewski P (1999): Identification and expression of delta-isoforms of the multifunctional $\mathrm{Ca} 2+/$ calmodulin-dependent protein kinase in failing and nonfailing human myocardium. Circ Res $\underline{84}$, 713-721.

Hoffman BF (1999): Cardiac arrhythmias: what do we need to know about basic mechanisms? J Cardiovasc Electrophysiol 10, 414-416.

Hondeghem LM, Clarkson CW, Matsubara T (1985): Is tetrodotoxin block of cardiac sodium channels voltage dependent? Proc West Pharmacol Soc $\underline{28}$, 9-10.

Hondeghem LM, Carlsson L, Duker G (2001): Instability and triangulation of the action potential predict serious proarrhythmia, but action potential duration prolongation is antiarrhythmic. Circulation $\underline{103}$, 2004-2013.

Hoppe UC, Böhm M, Dietz R, Hanrath P, Kroemer HK, Osterspey A, Schmaltz AA, Erdmann E (2005): Leitlinien zur Therapie der chronischen Herzinsuffizienz. Z Kardiol 94, 488-509.

Hordijk PL (2006): Regulation of NADPH oxidases: the role of Rac proteins. Circ Res $\underline{98}, 453-462$.

Horn R (1999): The dual role of calcium: pore blocker and modulator of gating. Proc Natl Acad Sci $\underline{96}, 3331-3332$. 
Horn R, Marty A (1988): Muscarinic activation of ionic currents measured by a new whole-cell recording method. J Gen Physiol 92, 145-159.

Hudmon A, Schulman H (2002): Structure-function of the multifunctional Ca2+/calmodulin-dependent protein kinase II. Biochem J $\underline{364}$, 593-611.

Hund TJ, Koval OM, Li J, Wright PJ, Qian L, Snyder JS, Gudmundsson H, Kline CF, Davidson NP, Cardona N, Rasband MN, Anderson ME, Mohler PJ (2010): A $\beta(I V)-$ spectrin/CaMKII signaling complex is essential for membrane excitability in mice. J Clin Invest $\underline{120}, 3508-3519$.

Huxley AF (1973): A note suggesting that the cross-bridge attachment during muscle contraction may take place in two stages. Proc R Soc Lond B Biol Sci $\underline{183}$, 83-86.

Ide T, Tsutsui H, Kinugawa S, Suematsu N, Hayashidani S, Ichikawa K, Utsumi H, Machida Y, Egashira K, Takeshita A (2000): Direct evidence for increased hydroxyl radicals originating from superoxide in the failing myocardium. Circ Res $\underline{86}, 152-157$.

Ikenouchi H, Barry WH, Bridge JH, Weinberg EO, Apstein CS, Lorell BH (1994): Effects of angiotensin II on intracellular $\mathrm{Ca} 2+$ and $\mathrm{pH}$ in isolated beating rabbit hearts and myocytes loaded with the indicator indo-1. J Physiol $\underline{480}, 203-215$.

Iribe G, Ward CW, Camelliti P, Bollensdorff C, Mason F, Burton RA, Garny A, Morphew MK, Hoenger A, Lederer WJ, Kohl P (2009): Axial stretch of rat single ventricular cardiomyocytes causes an acute and transient increase in $\mathrm{Ca} 2+$ spark rate. Circ Res. 104, 787-795.

Ishida A, Kameshita I, Okuno S, Kitani T, Fujisawa H (1995): A novel highly specific and potent inhibitor of calmodulin-dependent protein kinase II. Biochem Biophys Res Commun. $\underline{212}, 806-812$.

Ishihata A, Endoh M (1995): Species-related differences in inotropic effects of angiotensin II in mammalian ventricular muscle: receptors, subtypes and phosphoinositide hydrolysis. Br J Pharmacol 114, 447-453. 
Ito N, Kagaya Y, Weinberg EO, Barry WH, Lorell BH (1997): Endothelin and angiotensin II stimulation of $\mathrm{Na}+-\mathrm{H}+$ exchange is impaired in cardiac hypertrophy. $\mathrm{J}$ Clin Invest $\underline{\text { 99, }}$ 125-135.

Ito Y, Suko J, Chidsey CA (1974): Intracellular calcium and myocardial contractility. V. Calcium uptake of sarcoplasmic reticulum fractions in hypertrophied and failing rabbit hearts. J Mol Cell Cardiol $\underline{6}, 237-247$.

Janssen BJ, Smits JF (2002): Autonomic control of blood pressure in mice: basic physiology and effects of genetic modification. Am J Physiol Regul Integr Comp Physiol $\underline{282}, 1545-1564$.

Jespersen T, Grunnet M, Oelsen SP (2005): The KCNQ1 potassium channel: from gene to physiological function. Physiology $\underline{20}$, 408-416.

Jett MF, Schworer CM, Bass M, Soderling TR (1987): Identification of membranebound calcium, calmodulin-dependent protein kinase II in canine heart. Arch Biochem Biophys 255, 354-360.

Kääb S, Nuss HB, Chiamvimonvat N, O'Rourke B, Pak PH, Kass DA, Marban E, Tomaselli GF (1996): Ionic mechanism of action potential prolongation in ventricular myocytes from dogs with pacing-induced heart failure. Circ Res $\underline{78}, 262-273$.

Kääb S, Dixon J, Duc J, Ashen D, Näbauer M, Beuckelmann DJ, Steinbeck G, McKinnon D, Tomaselli GF (1998): Molecular basis of transient outward potassium current downregulation in human heart failure: a decrease in Kv4.3 mRNA correlates with a reduction in current density. Circulation $\underline{98}, 1383-1393$.

Kajla S, Mondol AS, Nagasawa A, Zhang Y, Kato M, Matsuno K, Yabe-Nishimura C, Kamata T (2012): A crucial role for Nox 1 in redox-dependent regulation of Wnt- $\beta$ catenin signaling. FASEB J $\underline{26}$, 2049-2059. 
Kambouris NG, Hastings LA, Stepanovic S, Marban E, Tomaselli GF, Balser JR (1998): Mechanistic link between lidocaine block and inactivation probed by outer pore mutations in the rat micro1 skeletal muscle sodium channel. J Physiol $\underline{512}$, 693-705.

Kanaseki T, Ikeuchi Y, Sugiura H, Yamauchi T (1991): Structural features of Ca2+/calmodulin-dependent protein kinase II revealed by electron microscopy. J Cell Biol $\underline{115}, 1049-1060$.

Kassmann M, Hansel A, Leipold E, Birkenbeil J, Lu SQ, Hoshi T, Heinemann SH (2008): Oxidation of multiple methionine residues impairs rapid sodium channel inactivation. Pflugers Arch 456, 1085-1095.

Kim HK, Youm JB, Lee SR, Lim SE, Lee SY, Ko TH, Long le T, Nilius B, Won du N, Noh JH, Ko KS, Rhee BD, Kim N, Han J (2012): The angiotensin receptor blocker and PPAR-y agonist, telmisartan, delays inactivation of voltage-gated sodium channel in rat heart: novel mechanism of drug action. Pflugers Arch. 464, 631-643.

Kim J, Ghosh S, Lui H, Tateyama M, Kass RS, Pitt GS (2004): Calmodulin mediates Ca2+ sensitivity of sodium channels. J. Biol Chem $\underline{279}$, 45004-45012.

Kirchhefer U, Schmitz W, Scholz H, Neumann J (1999): Activity of cAMP-dependent protein kinase and $\mathrm{Ca} 2+/$ calmodulin-dependent protein kinase in failing and nonfailing human hearts. Cardiovasc Res $\underline{42}$, 254-261.

Kishida KT, Klann E (2007): Sources and Targets of Reactive Oxygen Species in Synaptic Plasticity and Memory. Antioxid Redox Signal $\underline{9}$, 233-244.

Kléber AG (2005): The shape of the electrical action-potential upstroke: a new aspect from optical measurements on the surface of the heart. Circ Res $\underline{97}$, 204-206.

Koch-Weser J (1965): Nature of the inotropic action of Angiotensin on ventricular myocardium. Circ Res 16 , 230-237. 
Kohlhaas M, Zhang T, Seidler T, Zibrova D, Dybkova N, Steen A, Wagner S, Chen L, Brown J, Bers D, Maier L (2006): Increased sarcoplasmic reticulum calcium leak but unaltered contractility by acute CaMKII overexpression in isolated rabbit cardiac myocytes. Circ Res 98, 235-244.

Konstantopoulos N, Marcuccio S, Kyi S, Stoichevska V, Castelli LA, Ward CW, Macaulay SL (2007): A purine analog kinase inhibitor, calcium/calmodulin-dependent protein kinase II inhibitor 59, reveals a role for calcium/calmodulin-dependent protein kinase II in insulin-stimulated glucose transport. Endocrinology 148, 374-385.

Kontis KJ, Rounaghi A, Goldin AL (1997): Sodium channel activation gating is affected by substitutions of voltage sensor positive charges in all four domains. J Gen Physiol 110, 391-401.

Korbmacher C, Greger R, Brenner B, Silbernagel S: Die Zelle als Grundbaustein, in: Physiologie, Band V; hrsg. von Klinke R, Pape HC, Silbernagel S. Georg Thieme Verlag, Stuttgart/New York 2005, 14-48.

Koval OM, Snyder JS, Wolf RM, Pavlovicz RE, Glynn P, Curran J, Leymaster ND, Dun W, Wright PJ, Cardona N (2012): Ca2+/Calmodulin-dependent protein kinase II-based regulation of voltage-gated $\mathrm{Na}+$ channel in cardiac diesease. Circulation $\underline{126}$, 20842094.

Kukreja RC, Weaver AB, Hess ML (1990): Sacrolemmal Na(+)-K(+)-ATPase: inactivation by neutrophil-derived free radicals and oxidants. Am J Physiol 259, H13301336.

Kumar R, Thomas CM, Yong QC, Chen W, Baker KM (2012): The intracrine reninangiotensin system. Clin. Sci (Lond) $\underline{123}$, 273-284.

Kuroda J, Sadoshima J (2010): NADPH oxidase and cardiac failure. J Cardiovasc TransI Res $\underline{3}$, 314-320. 
Kuroda J, Ago T, Matsushima S, Zhai P, Schneider MD, Sadoshima J (2010): NADPH oxidase $x$ (NOX4) is a major source of oxidative stress in the failing heart. Proc Natl Acad Sci USA 107, 15565-15570.

Kusumoto K, Haist JV, Karmazyn M (2001): $\mathrm{Na}(+) / H(+)$ exchange inhibition reduces hypertrophy and heart failure after myocardial infarction in rats. Am J Physiol Heart Circ Physiol 280, 738-745.

Lambeth (2004): NOX enzymes and the biology of reactive oxygen. Nat Rev Immunol 4, 181-189.

Langendorff O (1895): Untersuchungen am überlebenden Säugetierherzen. Pflügers Arch 61, 291-332.

Langer GA, Peskoff A (1996): Calcium concentration and movement in the diadic cleft space of the cardiac ventricular cell. Biophys $\mathrm{J} \underline{70}, 1169-1182$.

Lanner JT, Georgiou DK, Joshi AD, Hamilton SL (2010): Ryanodine receptors: structure, expression, molecular details, and function in calcium release. Cold Spring Harb Perspect Biol 2, a003996.

Lassègue $B$, Clempus RE (2008): Vascular NAD(P)H oxidases: specific features, expression, and regulation. Am J Physiol Regul Integr Comp Physiol 285, 277-297.

Ledoux J, Chartier D, Leblanc N (1999): Inhibitors of calmodulin-dependent protein kinase are nonspecific blockers of voltage-dependent $\mathrm{K}+$ channels in vascular myocytes. J Pharmacol Exp Ther 290, 1165-1174.

Lehmann-Horn F, Jurkat-Rott K (1999): Voltage-gated ion channels and hereditary disease. Physiol Rev $\underline{79}$, 1317-1372.

Li J, Marionneau C, Zhang R, Shah V, Hell JW, Nerbonne JM, Anderson ME (2006): Calmodulin kinase II inhibition shortens action potential duration by upregulation of $\mathrm{K}+$ currents. Circ Res 99, 1092-1099. 
Li JM, Gall NP, Grieve DJ, Chen M, Shah AM (2002): Activation of NADPH oxidase during progression of cardiac hypertrophy to failure. Hypertension $\underline{40}$, 477-484.

Li L, Desantiago J, Chu G, Kranias EG, Bers DM (2000): Phosphorylation of phospholamban and troponin I in beta-adrenergic-induced acceleration of cardiac relaxation. Am J Physiol Heart Circ Physiol 278, 769-779.

Li P, Sonnenblick EH, Anversa P, Capasso JM (1994): Length-dependent modulation of ANG II inotropism in rat myocardium: effects of myocardial infarction. Am J Physiol 266, 779-786.

Ling H, Zhang T, Pereira L, Means CK, Cheng H, Gu Y, Dalton ND, Peterson KL, Chen $\mathrm{J}$, Bers D (2009): Requirement for $\mathrm{Ca}^{2+} /$ Calmodulin-dependent kinase II in the transition from pressure overload-induced cardiac hypertrophy to heart failure in mice. J Clin Invest $\underline{119}, 1230-1240$.

Lipkind GM, Fozzard HA (1994): A structural model of the tetrodotoxin and saxitoxin binding site of the $\mathrm{Na}+$ channel. Biophys $\mathrm{J} \underline{66}, 1-13$.

Liquori ME, Christenson RH, Collinson PO, Defilippi CR (2014): Cardiac biomarkers in heart failure. Clin Biochem pii: S0009-9120(14)00062-9.

Lloyd-Jones DM, Larson MG, Leip EP, Beiser A, D'Agostino RB, Kannel WB, Murabito JM, Vasan RS, Benjamin EJ, Levy D; Framingham Heart Study (2002): Lifetime risk for developing congestive heart failure: the Framingham Heart Study. Circulation $\underline{106}$, 3068-3072.

Lopatin AN, Nichols CG (2001): Inward rectifiers in the heart: an update on I(K1). J Moll Cell Cardiol $\underline{33}, 625-638$.

Lopez-Santiago LF, Meadows LS, Ernst SJ, Chen C, Malhotra JD, McEwen DP, Speelman A, Noebels JL, Maier SK, Lopatin AN, Isom LL (2007): Sodium channel 
Scn1b null mice exhibit prolonged QT and RR intervals. J Mol Cell Cardiol $\underline{43}, 636-$ 647.

Lymperopoulos A, Negussie S (2013): $\beta$ Arrestins in cardiac G protein-coupled receptor signaling and function: partners in crime or "good cop, bad cop"? Int J Mol Sci 14 , 24726-24741.

Ma JH, Lou AT, Zhang PH (2005): Effect of hydrogen peroxide on persistent sodium current in guinea pig ventricular myocytes. Acta Pharmacol Si $\underline{26}$, 828-834.

Maeda S, Tsukihara T (2011): Structure of the gap junction channel and its implications for its biological functions. Cell Mol Life Sci $\underline{68}, 1115-1129$.

Maier LS, Bers DM (2002): Calcium, calmodulin, and calcium-calmodulin kinase II: heartbeat to heartbeat and beyond. J Mol Cell Cardiol 34, 919-939.

Maier LS, Zhang T, Chen L, DeSantiago J, Brown JH, Bers DM (2003): Transgenic CaMKIIdeltaC overexpression uniquely alters cardiac myocyte $\mathrm{Ca} 2+$ handling: reduced SR Ca2+ load and activated SR Ca2+ release. Circ Res 92, 904-911.

Maier SK, Westenbroek RE, Schenkman KA, Feigl EO, Scheuer T, Catterall WA (2002): An unexpected role for brain-type sodium channels in coupling of cell surface depolarization to contraction in the heart. Proc Natl Acad Sci USA 99, 4073-4078.

Makielski JC, Sheets MF, Hanck DA, January CT, Fozzard HA (1997): Sodium current in voltage clamped internally perfused canine cardiac Purkinje cells. Biophys $\mathrm{J} \underline{52}, 1-$ 11.

Makita N, Bennett PB, George AL Jr (1996): Molecular determinants of beta 1 subunitinduced gating modulation in voltage-dependent $\mathrm{Na}+$ channels. J Neurosci $\underline{16}, 7117-$ 7127. 
Makkar KM, Sanoski CA, Spinler SA (2009): Role of angiotensin-converting enzyme inhibitors, angiotensin II receptor blockers, and aldosterone antagonists in the prevention of atrial and ventricular arrhythmias. Pharmacotherapy $\underline{29}, 31-48$.

Makowski L, Caspar DL, Phillips WC, Goodenough DA (1977): Gap junction structures. II. Analysis of the x-ray diffraction data. J Cell Biol 74, 629-645.

Mamenko M, Zaika O, llatovskaya DV, Staruschenko A, Pochynyuk O (2012): Angiotensin II increases activity of the epithelial $\mathrm{Na}+$ channel $(\mathrm{ENaC})$ in distal nephron additively to aldosterone. J Biol Chem 287, 660-671.

Mann DL (2002): Angiotensin II as an inflammatory mediator: evolving concepts in the role of the renin angiotensin system in the failing heart. Cardiovasc Drugs Ther $\underline{16}, 7$ 9.

Marban E, Yamagishi T, Tomaselli GF (1998): Structure and function of voltage-gated sodium channels. J Physiol $\underline{508}, 647-657$.

Martyn KD, Frederick LM, von Loehneysen K, Dinauer MC, Knaus UG (2006): Functional analysis of Nox4 reveals unique characteristics compared to other NADPH oxidases. Cell Signal $\underline{18}, 69-82$.

Marx SO, Reiken S, Hisamatsu Y, Jayaraman T, Burkhoff D, Rosemblit N, Marks AR (2000): PKA phosphorylation dissociates FKBP12.6 from the calcium release channel (ryanodine receptor): defective regulation in failing hearts. Cell 101, 365-376.

Matsui H, Barry WH, Livsey C, Spitzer KW (1995 a): Angiotensin II stimulates sodiumhydrogen exchange in adult rabbit ventricular myocytes. Cardiovasc Res $\underline{29}, 215-221$.

Matsui H, MacLennan DH, Alpert NR, Periasamy M (1995 b): Sarcoplasmic reticulum gene expression in pressure overload-induced cardiac hypertrophy in rabbit. Am J Physiol 268, 252-258. 
Mattiazzi A (1997): Positive inotropic effects of angiotensin II. Increases in intracellular $\mathrm{Ca} 2+$ or changes im myoflilament $\mathrm{Ca} 2+$ responsiveness? J Pharmacol Toxicol Methods $\underline{37}$, 205-214.

McKinsey TA, Zhang CL, Lu J, Olson EN (2000): Signal-dependent nuclear export of a histone deacetylase regulates muscle differentiation. Nature $\underline{408}$, $106-111$.

McMurray J, Chopra M, Abdullah I, Smith WE, Dargie HJ (1993): Evidence of oxidative stress in chronic heart failure in humans. Eur Heart J $\underline{14}$, 1493-1498.

Meyer M, Schillinger W, Pieske B, Holubarsch C, Heilmann C, Posival H, Kuwajima G, Mikoshiba K, Just H, Hasenfuss G (1995): Alterations of sarcoplasmic reticulum proteins in failing human dilated cardiomyopathy. Circulation $\underline{92}, 778-784$.

Meyer T, Hanson PI, Stryer L, Schulman H (1992): Calmodulin trapping by calciumcalmodulin-dependent protein kinase. Science 256, 1199-1201.

Mochizuki H, Ito T, Hidaka H (1993): Purification and characterization of $\mathrm{Ca}^{2+} /$ calmodulin-dependent protein kinase $\mathrm{V}$ from rat cerebrum. J Biol Chem $\underline{268}$, 9143-9147.

Mollnau H, Wendt M, Szöcs K, Lassègue B, Schulz E, Oelze M, Li H, Bodenschatz M, August M, Kleschyov AL (2002): Effects of angiotensin II infusion on the expression and function of $\mathrm{NAD}(\mathrm{P}) \mathrm{H}$ oxidase and components of nitric oxide/cGMP signaling. Circ Res $\underline{90}, 58-65$.

Moorman JR, Kirsch GE, Lacerda AE, Brown AM (1989): Angiotensin II modulates cardiac $\mathrm{Na}+$ channels in neonatal rat. Circ Res $\underline{65}, 1804-1809$.

Moravec CS, Schluchter MD, Paranandi L, Czerska B, Stewart RW, Rosenkranz E, Bond M (1990): Inotropic effects of angiotensin II on human cardiac muscle in vitro. Circulation 82, 1973-84. 
Morishita N, Kusachi S, Yamasaki S, Kondo J, Tsuji T (1996): Sequential changes in laminin and type IV collagen in the infarct zone - immunohistochemical study in rat myocardial infarction. Jpn Circ J $\underline{60}, 108-114$.

Morris TE, Sulakhe PV (1997): Sarcoplasmatic reticulum $\mathrm{Ca}^{2+}$ - pump dysfunction in rat cardiomyocytes briefly exposed to hydroxyl radicals. Free Radic Biol Med 22, 37-47.

Motoike HK, Liu H, Glaaser IW, Yang AS, Tateyama M, Kass RS (2004): The Na+ channel inactivation gate is a molecular complex: a novel role of the $\mathrm{COOH}$-terminal domain. J Gen Physiol 123, 155-165.

Murphy BJ, Rogers J, Perdichizzi AP, Colvin AA, Catterall WA (1996): cAMPdependent phosphorylation of two sites in the alpha subunit of the cardiac sodium channel. J Biol Chem 271, 28837-28843.

Nabeebaccus A, Zhang M, Shah AM (2011): NAPDH oxidases and cardiac remodeling. Heart Fail Rev $\underline{16}$, 5-12.

Neher E, Sakmann B (1976): Single-channel currents recorded from membrane of denervated frog muscle fibres. Nature $\underline{260}, 799-802$.

Nerbonne JM (2004): Studying cardiac arrhythmias in the mouse--a reasonable model for probing mechanisms? Trends Cardiovasc Med 14, 83-93.

Nerbonne JM, Nichols CG, Schwarz TL, Escande D (2001): Genetic manipulation of cardiac $\mathrm{K}(+)$ channel function in mice: what have we learned, and where do we go from here? Circ Res $\underline{89}$, 944-956.

Nguyen G (2011): Renin and prorenin receptor in hypertension: what's new? Curr Hypertens Rep 13, 79-85.

Nielsen MW, Holst AG, Olesen SP, Olesen MS (2013): The genetic component of Brugada syndrome. Front Physiol 4, 179. 
Nilius B, Tytgat J, Albitz R (1989): Modulation of cardiac Na channels by angiotensin II. Biochim Biophys Acta 1014, 259-262.

Nuss HB, Houser SR (1991): Voltage dependence of contraction and calcium current in severely hypertrophied feline ventricular myocytes. J Mol Cell Cardiol 23, 717-726.

NYHA: Diseases of the Heart and Blood Vessels: Nomenclature and Criteria for Diagnosis. $6^{\text {th }}$ ed. The Criteria Committee of the New York Heart Association, Boston, Little Brown, 1964).

O'Donnell BV, Tew DG, Jones OT, England PJ (1993): Studies on the inhibitory mechanism of iodonium compounds with special reference to neutrophil NADPH oxidase. Biochem J 290, 41-49.

Ohkubo H, Kageyama R, Ujihara M, Hirose T, Inayama S, Nakanishi S (1983): Cloning and sequence analysis of cDNA for rat angiotensinogen. Proc Natl Acad Sci U S A $\underline{80}$, 2196-2200.

O'Leary ME, Chen LQ, Kallen RG, Horn R (1995): A molecular link between activation and inactivation of sodium channels. J Gen Physiol 106, 641-658.

Opthof T (2001): Function and structure of the mouse sinus node: nothing you can see that isn't shown. Cardiovasc Res $\underline{52}, 1-4$.

Page IH, Helmer OM (1940): A crystalline pressor substance (angiotonin) resulting from the reaction between renin and renin-activator. J Exp Med 71, 29-42.

Palomeque J, Rueda OV, Sapia L, Valverde CA, Salas M, Petroff MV (2009): Angiotensin II-induced oxidative stress resets the $\mathrm{Ca} 2+$ dependence of $\mathrm{Ca}+-$ calmodulin protein kinase II and promotes a death pathway conserved across different species. Circ Res 105, 1204-1212. 
Payne ME, Fong YL, Ono T, Colbran RJ, Kemp BE, Soderling TR, Means AR (1988): Calcium/calmodulin-dependent protein kinase II. Characterization of distinct calmodulin binding and inhibitory domains. J Biol Chem $\underline{263}$, 7190-7195.

Pellicena P, Schulman H (2014): CaMKII inhibitors: from research tools to therapeutic agents. Front Pharmacol $\underline{5}$, Article 21 .

Peterson BZ, DeMaria CD, Adelman JP, Yue DT (1999): Calmodulin is the Ca2+ sensor for $\mathrm{Ca} 2+-$ dependent inactivation of L-type calcium channels. Neuron $\underline{22}, 549$ 558

Petroff MG, Aiello EA, Palomeque J, Salas MA, Mattiazzi A (2000): Subcellular mechanisms of the positive inotropic effect of angiotensin II in cat myocardium. J Physiol $\underline{529}, 189-203$.

Pieske B, Maier LS, Bers DM, Hasenfuss G (1999): Ca2+ handling and sarcoplasmic reticulum $\mathrm{Ca} 2+$ content in isolated failing and nonfailing human myocardium. Circ Res $\underline{85}, 38-46$.

Pogwizd SM, Qi M, Yuan W, Samarel AM, Bers DM (1999): Upregulation of $\mathrm{Na}(+) / \mathrm{Ca}(2+)$ exchanger expression and function in an arrhythmogenic rabbit model of heart failure. Circ Res $\underline{85}$, 1009-1019.

Pogwizd SM, Schlotthauer K, Li L, Yuan W, Bers DM (2001): Arrhythmogenesis and contractile dysfunction in heart failure: Roles of sodium-calcium exchange, inward rectifier potassium current, and residual beta-adrenergic responsiveness. Circ Res $\underline{88}$, 1159-1167.

Pollock JD, Williams DA, Gifford MA, Li LL, Du X, Fisherman J, Orkin SH, Doerschuk CM, Dinauer MC (1995): Mouse model of X-linked chronic granulomatous disease, an inherited defect in phagocyte superoxide production. Nat Genet $\underline{9}$, 202-209.

Prosser BL, Ward CW, Lederer WJ (2011): X-ROS signaling: rapid mechanochemo transduction in heart. Science $\underline{333}, 1440-1445$. 
Qin F, Patel R, Yan C, Liu W (2006): NADPH oxidase is involved in angiotensin IIinduced apoptosis in $\mathrm{H} 9 \mathrm{C} 2$ cardiac muscle cells: effects of apocynin. Free Radic Biol Med $\underline{40}, 236-246$.

Qin N, Olcese R, Bransby M, Lin T, Birnbaumer L (1999): Ca2+-induced inhibition of the cardiac Ca2+ channel depends on calmodulin. Proc Natl Acad Sci USA 96, 24352438.

Qu Y, Rogers J, Tanada T, Scheuer T, Catterall WA (1994): Modulation of cardiac Na+ channels expressed in a mammalian cell line and in ventricular myocytes by protein kinase C. Proc Natl Acad Sci USA 91, 3289-3293.

Qu Y, Rogers JC, Tanada TN, Catterall WA, Scheuer T (1996): Phosphorylation of $\mathrm{S} 1505$ in the cardiac $\mathrm{Na}+$ channel inactivation gate is required for modulation by protein kinase C. J Gen Physiol $\underline{108}$, 375-379.

Ragan Cl, Bloxham DP (1977): Specific labelling of a constituent polypeptide of bovine heart mitochondrial reduced nicotinamide-adenine dinucleotide-ubiquinone reductase by the inhibitor diphenyleneiodonium. Biochem J $\underline{163}, 605-615$.

Ragsdale DS, McPhee JC, Scheuer T, Catterall WA (1994): Molecular determinants of state-dependent block of $\mathrm{Na}+$ channels by local anesthetics. Science $\underline{265}, 1724-1728$.

Ramirez-Correa GA, Cortassa S, Stanley B, Gao WD, Murphy AM (2010): Calcium sensitivity, force frequency relationship and cardiac troponin I: Critical role of PKA and PKC phosphorylation sites. J Mol Cell Cardiol 48, 943-953.

Renz-Polster H, Krautzig S.: Erregungsbildung; in: Basislehrbuch Innere Medizin, 4. Auflage; hrsg v. Renz-Polster H, Krautzig S. unter Mitarbeit namenhafter Autoren; Urban \& Fischer Verlag, München, 2008, 36. 
Renz-Polster H, Krautzig S.: Der Herzzyklus; in: Basislehrbuch Innere Medizin, 4. Auflage; hrsg v. Renz-Polster H, Krautzig S. unter Mitarbeit namenhafter Autoren; Urban \& Fischer Verlag, München, 2008, 37.

Rivard K, Grandy SA, Douillette A, Paradis P, Nemer M, Allen BG, Fiset C (2011): Overexpression of type 1 angiotensin II receptors impairs excitation-contraction coupling in the mouse heart. Am J Physiol Heart Circ Physiol 301, 2018-2027.

Rogers JC, Qu Y, Tanada TN, Scheuer T, Catterall WA (1996): Molecular determinants of high affinity binding of alpha-scorpion toxin and sea anemone toxin in the S3-S4 extracellular loop in domain IV of the $\mathrm{Na}+$ channel alpha subunit. J Biol Chem $\underline{271}$, 15950-15962.

Sag CM, Wagner S, Maier LS (2013): Role of oxidants on calcium and sodium movement in healthy and diseased cardiac myocytes. Free Radic Biol Med $\underline{63}$, 338349.

Sampaio WO, Souza dos Santos RA, Faria-Silva R, da Mata Machado LT, Schiffrin EL, Touyz RM (2007): Angiotensin-(1-7) through receptor Mas mediates endothelial nitric oxide synthase activation via Akt-dependent pathways. Hypertension $\underline{49}, 185$ 192.

Santos RA, Simoes e Silva AC, Maric C, Silva DM, Machado RP, de Buhr I, HeringerWalther S, Pinheiro SV, Lopes MT, Bader M (2003): Angiotensin-(1-7) is an endogenous ligand for the $G$ protein-coupled receptor Mas. Proc Natl Acad Sci USA 100, 8258-8263.

Satoh T, Zipes DP (1998): Cesium-induced atrial tachycardia degenerating into atrial fibrillation in dogs: atrial torsades de pointes? J Cardiovasc Electrophysiol $\underline{9}$, 970-975.

Sawyer DB, Siwik DA, Xiao L, Pimentel DR, Singh K, Colucci WS (2002): Role of oxidative stress in myocardial hypertrophy and failure. J Mol Cell Cardiol $\underline{34}, 379-388$. 
Schillinger W, Lehnart SE, Prestle J, Preuss M, Pieske B, Maier LS, Meyer M, Just H, Hasenfuss $\mathrm{G}$ (1998): Influence of SR $\mathrm{Ca}(2+)-A T P a s e$ and $\mathrm{Na}(+)-\mathrm{Ca}(2+)$-exchanger on the force-frequency relation. Basic Res Cardiol 93, 38-45.

Schmitt N, Grunnet M, Olesen SP (2014): Cardiac potassium channel subtypes: new roles in repolarization and arrhythmia. Physiol Rev $\underline{94}$, 609-653.

Schreibmayer W, Wallner M, Lotan I (1994): Mechanism of modulation of single sodium channels from skeletal muscle by the beta 1-subunit from rat brain. Pflugers Arch $\underline{426}, 360-362$.

Schröder D, Heger J, Piper HM, Euler G (2006): Angiotensin II stimulates apoptosis via TGF-beta1 signaling in ventricular cardiomyocytes of rat. J Mol Med (Berl) $\underline{84}, 975-$ 985.

Schultheiss HP, Schulze K, Schauer R, Witzenbichler B, Strauer BE (1995): Antibodymediated imbalance of myocardial energy metabolism. A causal factor of cardiac failure? Circ Res $\underline{76}, 64-72$.

Scriven DR, Dan P, Moore ED (2000): Distribution of proteins implicated in excitationcontraction coupling in rat ventricular myocytes. Biophys $\mathrm{J} \underline{79}, 2682-2691$.

Selemidis S, Sobey CG, Wingler K, Schmidt HH, Drummond GR (2008): NADPH oxidases in the vasculature: molecular features, roles in disease and pharmacological inhibition. Pharmacol Ther 120, 254-291.

Serrander L, Cartier L, Bedard K, Banfi B, Lardy B, Plastre O, Sienkiewicz A, Fórró L, Schlegel W, Krause KH (2007): NOX4 activity is determined by mRNA levels and reveals a unique pattern of ROS generation. Biochem $\mathrm{J} \underline{406}, 105-114$.

Sham JS, Song LS, Chen Y, Deng LH, Stern MD, Lakatta EG, Cheng H (1998): Termination of $\mathrm{Ca} 2+$ release by a local inactivation of ryanodine receptors in cardiac myocytes. Proc Natl Acad Sci USA 95, 15096-15101. 
Shang LL, Sanyal S, Pfahnl AE, Jiao Z, Allen J, Liu H, Dudley SC Jr (2008): NFkappaB-dependent transcriptional regulation of the cardiac scn5a sodium channel by angiotensin II. Am J Physiol Cell Physiol 294, 372-379.

Shi CX, Wang YH, Dong F, Zhang YJ, Xu YF (2007): Transmural L-type calcium current in a pressure-overloaded mouse model with heart failure. Sheng Li Xue Bao $\underline{59}, 19-26$.

Si M, Xu J, Zhang F, Wang C, Du X, Zhang H (2013): Involvement of protein kinase A and $C$ in norepinephrine- and angiotensin II- induced modulation of cardiac IKs. Pharmacology $\underline{92}$, 217-226.

Simmerman HK, Collins JH, Theibert JL, Wegener AD, Jones LR (1986): Sequence analysis of phospholamban. Identification of phosphorylation sites and two major structural domains. J Biol Chem 61, 13333-13341.

Sipido KR, Callewaert G, Carmeliet E (1995): Inhibition and rapid recovery of Ca2+ current during $\mathrm{Ca} 2+$ release from sarcoplasmic reticulum in guinea pig ventricular myocytes. Circ Res $\underline{76}, 102-109$.

Sjöstrand FS, Andersson-Cedergren E, Dewey MM (1958): The ultrastructure of the intercalated discs of frog, mouse and guinea pig cardiac muscle. J Ultrastruct Res 1 , 271-287

Smith MK, Colbran RJ, Soderling TR (1990): Specificities of autoinhibitory domain peptides for four protein kinases. Implications for intact cell studies of protein kinase function. J Biol Chem 265, 1837-1840.

Song LS, Wang SQ, Xiao RP, Spurgeon H, Lakatta EG, Cheng H (2001): betaAdrenergic stimulation synchronizes intracellular $\mathrm{Ca}(2+)$ release during excitationcontraction coupling in cardiac myocytes. Circ Res $\underline{88}, 794-801$.

Sossalla S, Wagner S, Rasenack EC, Ruff H, Weber SL, Schöndube FA, Tirilomis T, Tenderich G, Hasenfuss G, Belardinelli L, Maier LS (2008): Ranolazine improves 
diastolic dysfunction in isolated myocardium from failing human hearts--role of late sodium current and intracellular ion accumulation. J Mol Cell Cardiol $\underline{45}, 32-43$.

Studer R, Reinecke H, Bilger J, Eschenhagen T, Böhm M, Hasenfuss G, Just H, Holtz J, Drexler H (1994): Gene expression of the cardiac $\mathrm{Na}(+)-\mathrm{Ca} 2+$ exchanger in endstage human heart failure. Circ Res $\underline{75}$, 443-453.

Stühmer W, Conti F, Suzuki H, Wang XD, Noda M, Yahagi N, Kubo H, Numa S (1989): Structural parts involved in activation and inactivation of the sodium channel. Nature 339, 597-603.

Suematsu N, Tsutsui H, Wen J, Kang D, Ikeuchi M, Ide T, Hayashidani S, Shiomi T, Kubota T, Hamasaki N (2003): Oxidative stress mediates tumor necrosis factor-alphainduced mitochondrial DNA damage and dysfunction in cardiac myocytes. Circulation 107, 1418-1423.

Sugden PH, Clerk A (1998): "Stress-responsive" mitogen-activated protein-kinase (cJun N-terminal kinases and p38 mitogen-activated protein kinases) in the myocardium. Circ Res 83, 345-352.

Sumi M, Kiuchi K, Ishikawa T, Ishii A, Hagiwara M, Nagatsu T, ... (1991): The newly synthesized selective Ca2+/calmodulin dependent protein kinase II inhibitor KN-93 reduces dopamine contents in PC12h cells. Biochem Biophys Res. Commun $\underline{181}$, 968-975.

Sun P, Yue P, Wang WH (2012): Angiotensin II stimulates epithelial sodium channels in the cortical collecting duct of the rat kidney. Am J Physiol Renal Physiol 302, 679687.

Takahashi T, Allen PD, Lacro RV, Marks AR, Dennis AR, Schoen FJ, Grossman W, Marsh JD, Izumo S (1992): Expression of dihydropyridine receptor (Ca2+ channel) and calsequestrin genes in the myocardium of patients with end-stage heart failure. J Clin Invest $\underline{90}$, 927-935. 
Takemura Y, Goodson P, Bao HF, Jain L, Helma MN (2010): Rac1-mediated NADPH oxidase release of 02 - regulates epithelial sodium channel activity in the alveolar epithelium. Am J Physiol Lung Cell Mol Physiol 298, 509-520.

Takewaki S, Kuro-o M, Hiroi Y, Yamazaki T, Noguchi T, Miyagishi A, Nakahara K, Aikawa M, Manabe I, Yazaki Y (1995): Activation of $\mathrm{Na}(+)-\mathrm{H}+$ antiporter (NHE-1) gene expression during growth, hypertrophy and proliferation of the rabbit cardiovascular system. J Mol Cell Cardiol 27, 729-742.

Tan HL, Kupershmidt S, Zhang R, Stephanovic S, Roden DM, Wilde AA, Anderson ME, Balser JR (2002): A calcium sensor in the sodium channel modulates cardiac excitability. Nature $\underline{415}, 442-447$.

Tan HL, Bezzina CR, Smith JP, Verkerk AO, Wilde AA (2003): Genetic control of sodium channel function. Cardiovasc Res $\underline{57}$, 961-973.

Thom T, Haase N, Rosamond W, Howard VJ, Rumsfeld J, Manolio T, Zheng ZJ, Flegal K, O'Donnell C, Kittner S (2006): American Heart Association Statistics Committee and Stroke Statistics Subcommittee. Heart disease and stroke statistics--2006 update: a report from the American Heart Association Statistics Committee and Stroke Statistics Subcommittee. Circulation 113, 85-151.

Thomas WG, Thekkumkara TJ, Baker KM (1996): Cardiac effects of All. AT1A receptor signaling, desensitization, and internalization. Adv Exp Med Biol 396, 59-69.

Tigerstedt R, Bergman P (1898): Niere und Kreislauf. Skand. Arch. Physiol. $\underline{8}, 223-$ 271.

Timmermans PB, Wong PC, Chiu AT, Herblin WF, Smith RD (1993): New perspectives in angiotensin system control. J Hum Hypertens $\underline{7}$, 19-31. 
Toischer K, Hartmann N, Wagner S, Fischer TH, Herting J, Danner BC, Sag CM, Hund TJ, Mohler PJ, Belardinelli L (2013): Role of late sodium current as a potential arrhythmogenic mechanism in the progression of pressure-induced heart disease. J Mol Cell Cardiol 61,111-122.

Tomaselli GF, Zipes DP (2004): What causes sudden death in heart failure? Circ Res 95, 754-763.

Tsai CT, Chiang FT, Chen WP, Hwang JJ, Tseng CD, Wu CK, Yu CC, Wang YC, Lai LP, Lin JL (2011): Angiotensin II induces complex fractionated electrogram in a cultured atrial myocyte monolayer mediated by calcium and sodium-calcium exchanger. Cell Calcium $\underline{49}$, 1-11.

Ullrich ND, Fanchaouy M, Gusev K, Shirokova N, Niggli E (2009): Hypersensitivity of excitation-contraction coupling in dystrophic cardiomyocytes. Am J Physiol Heart Circ Physiol 297, H1992-2003.

Unwin PN, Zampighi G (1980): Structure of the junction between communicating cells. Nature $\underline{283}, 545-549$.

Ushio-Fukai M, Zafari AM, Fukui T, Ishizaka N, Griendling KK (1996): p22phox is a critical component of the superoxide-generating NADH/NADPH oxidase system and regulates angiotensin II-induced hypertrophy in vascular smooth muscle cell. J BBiol Chem 271, 23317-23321.

Valdivia CR, Chu WW, Pu J, Foell JD, Haworth RA, Wolff MR, Kamp TJ, Makielski JC (2005): Increased late sodium current in myocytes from a canine heart failure model and from failing human heart. J Mol Cell Cardiol $\underline{38}$, 475-483.

Vassilev PM, Scheuer T, Catterall WA (1988): Identification of an intracellular peptide segment involved in sodium channel inactivation. Science 241, 1658-1661. 
Veldkamp MW, Viswanathan PC, Bezzina C, Baartscheer A, Wilde AAM, Balser JR (2000): Two distinct congenital arrhythmias evoked by a multidysfunctional $\mathrm{Na}+$ channel. Circ Res $\underline{86}, 91 \mathrm{e}-97 \mathrm{e}$.

Verkerk AO, Geuzebroek GS, Veldkamp MW, Wilders R (2012): Effects of acetylcholine and noradrenalin on action potentials of isolated rabbit sinoatrial and atrial myocytes. Front Physiol $\underline{3}, 174$

Viatchenko-Karpinski S, Györke S (2001): Modulation of the $\mathrm{Ca}(2+)$-induced $\mathrm{Ca}(2+)$ release cascade by beta-adrenergic stimulation in rat ventricular myocytes. J Physiol $\underline{533}, 837-848$.

Wagner S, Maier LS (2006): Modulation of cardiac $\mathrm{Na}(+)$ and $\mathrm{Ca}(2+)$ currents by CaM and CaMKII. J Cardiovasc Electrophysiol 17 Suppl 1:S26-S33.

Wagner S, Seidler T, Picht E, Maier LS, Kazanski V, Teucher N, Schillinger W, Pieske B, Isenberg G, Hasenfuss G, Kögler H (2003): $\mathrm{Na}(+)-\mathrm{Ca}(2+)$ exchanger overexpression predisposes to reactive oxygen species-induced injury. Cardiovasc Res $\underline{60}, 404-412$.

Wagner S, Dybkova N, Rasenack EC, Jacobshagen C, Fabritz L, Kirchhof P, Maier SK, Zhang T, Hasenfuss G, Brown JH (2006): Ca2+/calmodulin-dependent protein kinase II regulates cardiac $\mathrm{Na}+$ channels. J Clin Invest 116, 3127-3138.

Wagner S, Hacker E, Grandi E, Weber SL, Dybkova N, Sossalla S, Sowa T, Fabritz L, Kirchhof $P$, Bers DM (2009): Ca/calmodulin kinase II differentially modulates potassium currents. Circ Arrhythm Electrophysiol 2, 285-294.

Wagner S, Ruff HM, Weber SL, Bellmann S, Sowa T, Schulte T, Anderson ME, Grandi E, Bers DM, Backs J (2011): Reactive oxygen species-activated Ca/calmodulin kinase IIठ is required for late I(Na) augmentation leading to cellular $\mathrm{Na}$ and $\mathrm{Ca}$ overload. Circ Res $108,555-565$. 
Wagner S, Dantz C, Flebbe H, Azizian A, Sag CM, Engels S, Möllencamp J, Dybkova $\mathrm{N}$, Islam T, Shah AM, Maier LS (2014): NADPH oxidase 2 mediates angiotensin IIdependent cellular arrhythmias via PKA and CaMKII. J Mol Cell Cardiol $\underline{75}$, 206-215.

Wang DW, Makita N, Kitabatake A, Balser JR, George AL Jr (2000): Enhanced Na(+) channel intermediate inactivation in Brugada syndrome. Circ Res $\underline{87}$, 37-43.

Wang H, Grant JE, Doede CM, Sadayappan S, Robbins J, Walker JW (2006): PKC- $\beta_{\|}$ sensitizes cardiac myofilaments to $\mathrm{Ca}^{2+}$ by phosphorylating troponin I on threonin-144. J Mol Cell Cardiol $\underline{41}$, 823-833.

Wang Q, Shen J, Splawski I, Atkinson D, Li Z, Robinson JL, Moss AJ, Towbin JA, Keating MT (1995): SCN5A mutations associated with an inherited cardiac arrhythmia, long QT syndrome. Cell $\underline{80}$, 805-811.

Wang YH, Shi CX, Dong F, Sheng JW, Xu YF (2008): Inhibition of the rapid component of the delayed rectifier potassium current in ventricular myocytes by angiotensin II via the AT1 receptor. Br J Pharmacol 154, 429-439.

Weber KT, Brilla CG (1991): Pathological hypertrophy and cardiac interstitium. Fibrosis and renin-angiotensin-aldosterone system. Circulation $\underline{83}, 1849-1865$.

Weber KT, Brilla CG, Janicki JS (1993): Myocardial fibrosis: functional significance and regulatory factors. Cardiovasc Res 27, 341-348.

Weidmann S (1955): The effect of the cardiac membrane potential on the rapid availability of the sodium-carrying system. J Physiol $\underline{127}$, 213-224.

Weingart R (1977): The actions of ouabain on intercellular coupling and conduction velocity in mammalian ventricular muscle. J Physiol 264, 341-365.

White CN, Figtree GA, Liu CC, Garcia A, Hamilton EJ, Chia KK, Rasmussen HH (2009): Angiotensin II inhibits the Na+-K+ pump via PKC-dependent activation of NADPH oxidase. Am J Physiol Cell Physiol 296, C693-700. 
Williams HC, Griendling KK (2007): NADPH oxidase inhibitors: new antihypertensive agents? J Cardiovasc Pharmacol $\underline{50}$, 9-16.

Wingo TL, Shah VN, Anderson ME, Lybrand TP, Chazin WJ, Basler JR (2004): An EFHand in the sodium channel couples intracellular calcium to cardiac excitability. Nat Struct Mol Biol 11, 2019-225.

Wu X, Zhang T, Bossuyt J, Li X, McKinsey TA, Dedman JR, Olson EN, Chen J, Brown JH, Bers DM (2006): Local InsP3-dependent perinuclear Ca2+ signaling in cardiac myocyte excitation-transcription coupling. J Clin Invest 116, 675-682.

Xiao L, Pimentel DR, Wang J, Singh K, Colucci WS, Sawyer DB (2002): Role of reactive oxygen species and $\mathrm{NAD}(\mathrm{P}) \mathrm{H}$ oxidase in alpha(1)-adrenoceptor signaling in adult rat cardiac myocytes. Am J Physiol Cell Physiol 282, 926-934.

Xiao YF (2011): Cardiac arrhythmia and heart failure: From bench to bedside. J Geriatr Cardiol. 으, 131-132.

Yasuno S, Kuwahara K, Kinoshita H, Yamada C, Nakagawa Y, Usami S, Kuwabara Y, Ueshima K, Harada M, Nishikimi T (2013): Angiotensin II type 1a receptor signaling directly contributes to the increased arrhyhtmogenicity in cardiac hypertrophy. $\mathrm{Br} \mathrm{J}$ Phamacol 170, 1384-1395.

Zafari AM, Ushio-Fukai M, Akers M, Yin Q, Shah A, Harrison DG, Taylor WR, Griendling KK (1998): Role of NADH/NADPH oxidase-derived H2O2 in angiotensin IIinduced vascular hypertrophy. Hypertension $\underline{32}$, 488-495.

Zankov DP, Omatsu-Kanbe M, Isono T, Toyoda F, Ding WG, Matsuura H, Horie M (2006): Angiotensin II potentiates the slow component of delayed rectifier K+ current via the AT1 receptor in guinea pig atrial myocytes. Circulation $\underline{113}, 1278-1286$. 
Zeng Q, Zhou Q, Yao F, O'Rourke ST, Sun C (2008): Endothelin-1 regulates cardiac L-type calcium channels via $\mathrm{NAD}(\mathrm{P}) \mathrm{H}$ oxidase-derived superoxide. J Pharmacol Exp Ther $\underline{326}$, 732-738.

Zeng Q, Han Y, Bao Y, Li W, Li X, Shen X, Wang X, Yao F, O'Rourke ST, Sun C (2010): 20-HETE increases NADPH oxidase-derived ROS production and stimulates the L-type Ca2+ channel via a PKC-dependent mechanism in cardiomyocytes. Am J Physiol Heart Circ Physiol 299, 1109-1117.

Zhang M, Brewer AC, Schröder K, Santos CX, Grieve DJ, Wang M, Anilkumar N, Yu B, Dong X, Walker SJ (2010): NADPH oxidase-4 mediates protection against chronic load-induced stress in mouse hearts by enhancing angiogenesis. Proc Natl Acad Sci U S A $\underline{107}, 18121-18126$.

Zhang T, Johnson EN, Gu Y, Morissette MR, Sah VP, Gigena MS, Belke DD, Dillmann WH, Rogers TB, Schulman H (2002): The cardiac-specific nuclear delta(B) isoform of $\mathrm{Ca}$ 2+/calmodulin-dependent protein kinase II induces hypertrophy and dilated cardiomyopathy associated with increased protein phosphatase 2A activity. J Biol Chem 277, 1261-1267.

Zhang T, Maier LS, Dalton ND, Miyamoto S, Ross J Jr, Bers DM, Brown JH (2003): The deltaC isoform of CaMKII is activated in cardiac hypertrophy and induces dilated cardiomyopathy and heart failure. Circ Res $\underline{92}, 912-919$.

Zhang T, Kohlhaas M, Backs J, Mishra S, Phillips W, Dybkova N, Chang S, Ling H, Bers DM, Maier LS (2007): CaMKIIdelta isoforms differentially affect calcium handling but similarly regulate HDAC/MEF2 transcriptional responses. J Biol Chem $\underline{282}$, 3507835087.

Zhao Z, Fefelova N, Shanmugam M, Bishara P, Babu GJ, Xie LH (2011): Angiotensin II induces afterdepolarizations via reactive oxygen spesies and Calmodulin kinase II signaling. J Mol Cell Cardiol 므, 128-136. 
Zhou J1, Kodirov S, Murata M, Buckett PD, Nerbonne JM, Koren G (2003): Regional upregulation of Kv2.1-encoded current, IK,slow2, in Kv1DN mice is abolished by crossbreeding with Kv2DN mice. Am J Physiol Heart Circ Physiol 284, 491-500.

Zipes DP (2003): Mechanisms of clinical arrhythmias. J Cardiovasc Electrophysiol 14 , 902-912.

Zühlke RD, Reuter H (1998): Ca2+-sensitive inactivation of L-type Ca2+ channels depends on multiple cytoplasmic amino acid sequences of the alpha1C subunit. Proc Natl Acad Sci USA 모, 3287-3294. 


\section{Danksagung}

Ein großer Dank gilt meinem Doktorvater Herrn Prof. Dr. med. Lars S. Maier für die Überlassung des spannenden Dissertationsthemas, für die Unterstützung, die er mir durch die Aufnahme in seine Arbeitsgruppe schenkte, und noch mehr als all das, für das Vermitteln einer Faszination für Forschung.

Von unschätzbarem Wert war die umfangreiche Hilfe und Unterstützung durch meinen Betreuer, Herrn PD Dr. med. Stefan Wagner, der mit seinem umfassenden Fachwissen, viel Geduld und einem unermüdlichen Engagement mir das Durchführen der Experimente und das Erstellen des vorliegenden Manuskriptes ermöglicht hat. Ihm bin ich zu besonders großem Dank verpflichtet, da er trotz seiner vielen anderen Verpflichtungen mir viel von seiner Zeit geschenkt hat, um die vorliegende Arbeit erfolgreich durchzuführen.

Ebenfalls danken möchte ich den Mitgliedern der Arbeitsgruppe von Prof. Dr. med. Maier, die mir stets mit Rat und Tat zur Seite standen. Zu erwähnen sind hier Herr Dr. med. Stefan Neef, Herr PD Dr. med. Samuel Sossalla, Herr Timo Schulte, Herr Thomas Sowa und Frau Felicia Steuer. Ihre immerwährende Unterstützung bei den Fragen und Problemen des Laboralltags waren mir eine unermessliche Hilfe.

Auch soll an dieser Stelle meinem jetzigen Arbeitsgruppenleiter Herrn PD Dr. med. Jochen Gaedcke aus der Klinik für Allgemein-, Viszeral- und Kinderchirurgie gedankt sein, der mir sowohl durch viel Motivation als auch durch die Freistellung von anderen Aufgaben die Fertigstellung dieser Dissertationsarbeit ermöglicht hat.

Ich danke Herrn Hans-Joachim RühImann für die sprachliche Korrektur des vorliegenden Manuskriptes.

Weiterhin möchte ich der Studienstiftung des deutschen Volkes und meinem Vertrauensdozenten Herrn Prof. Arnulf Quadt für das Stipendium danken, das ich auch über die Forschungszeit erhalten habe. 


\section{Lebenslauf}

Am 05.05.1985 wurde ich, Azadeh Azizian, als Tochter von Sedigheh Vafaei, Lehrerin für Oberstufe, und Manochehr Azizian, gelernter Kaufmann, in Karaj/Iran geboren.

Nachdem meine Eltern 1989 nach Deutschland übergesiedelt sind, besuchte ich 1991 zunächst die 1.Klasse der Grundschule in Dortmund, und nach unserem Umzug nach Oldenburg besuchte ich Klasse 2-4 der Grundschule Bloherfelde in Oldenburg (Oldb). Anschließend kam der regelhafte Wechsel in die Orientierungsstufe Eversten, wo ich die 5. und 6. Klasse besuchte. Ab 1999 wechselte ich auf das Gymnasium Eversten Oldenburg, an welchem ich 2005 mein Abitur ablegte (Gesamtnote 1,5).

Zum Wintersemester 2005/2006 begann ich das Studium der Humanmedizin an der Georg-August-Universität Göttingen und beendete es erfolgreich im Frühjahr 2012 mit dem Staatsexamen (Gesamtnote 2).

Über die gesamte Studienzeit wurde ich mit einem Stipendium der Studienstiftung des deutschen Volkes unterstützt.

Im Herbst 2008 begann ich mit der Vorbereitung und Anfertigung meiner Promotion in der Arbeitsgruppe von Herrn Prof. Dr. med. Lars Maier in der Abteilung für Kardiologie und Pulmologie. Oktober 2010 erhielt ich den niedersächsischen Wissenschaftspreis 2010. Die Ergebnisse meiner Promotionsarbeit wurden auf der Jahrestagung der Deutschen Gesellschaft für Kardiologie 2011 in Mannheim vorgestellt

Nach Beendigung meines Studiums habe ich am 15.Oktober 2012 eine Stelle als Assistenzärztin in der Klinik für Allgemein-, Viszeral- und Kinderchirurgie unter der Leitung von Herrn Prof. Dr. med. M. Ghadimi angetreten. Hier habe ich mich der Arbeitsgruppe von Herrn PD Dr. med. J. Gaedcke angeschlossen. Wir untersuchen u.a. neue Ansätze der Diagnostik und Therapie des kolorektalen Karzinoms. 